TESIS DE DOCTORADO EN CIENCIAS NATURALES

FACULTAD DE CIENCIAS NATURALES Y MUSEO UNIVERSIDAD NACIONAL DE LA PLATA

COMPORTAMIENTO ESPACIAL Y MEMORIA EN EL MONO CAÍ (CEBUS APELLA) EN CONTEXTO DE GRUPO: SEMEJANZAS ENTRE PRIMATES NO-HUMANOS Y HUMANOS

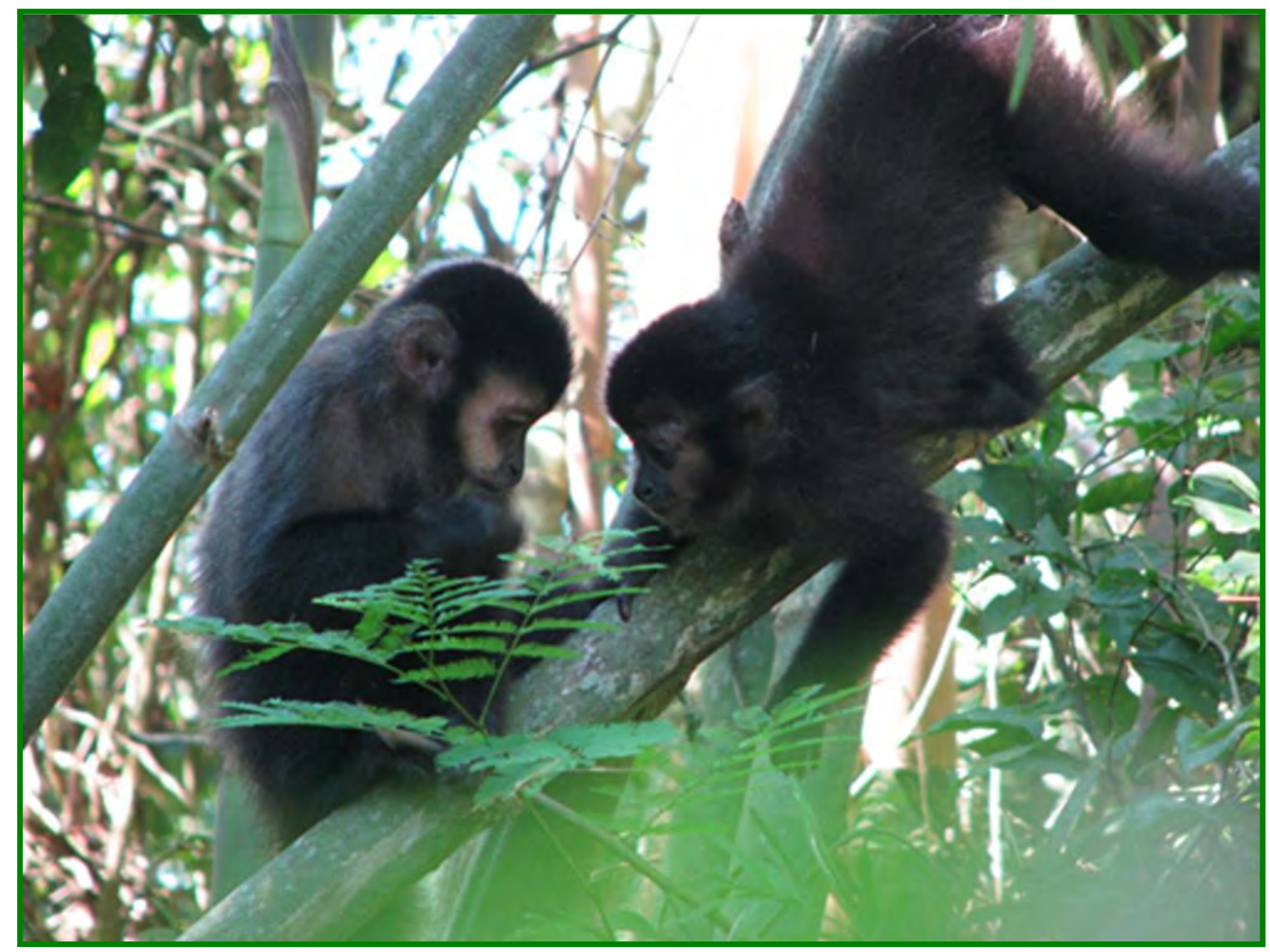

María Paula Tujague

Director: Héctor B. Lahitte

Co-director: Charles H. Janson

La Plata, 2013

TESIS DE DOCTORADO EN CIENCIAS NATURALES 


\title{
COMPORTAMIENTO ESPACIAL Y MEMORIA EN EL MONO CAÍ (CEBUS APELLA)* EN CONTEXTO DE GRUPO: SEMEJANZAS ENTRE PRIMATES NO-HUMANOS Y HUMANOS
}

\author{
María Paula Tujague \\ Director: Héctor B. Lahitte \\ Co-director: Charles H. Janson \\ La Plata, 2013
}

\section{FACULTAD DE CIENCIAS NATURALES Y MUSEO UNIVERSIDAD NACIONAL DE LA PLATA}

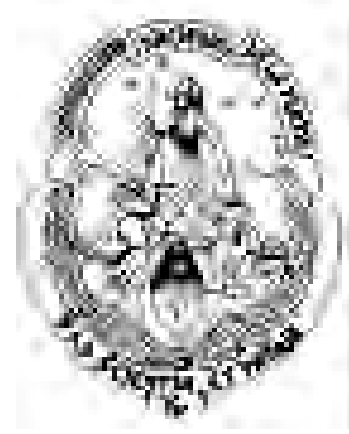

En la actualidad no existe un consenso sistemático acerca de las categorías de subespecies (o especies) de caí dentro de Argentina. Groves (2001) propuso elevar a ambas subespecies de Cebus apella presentes en el país a la categoría de especie. Con nuevas evidencias desde la biogeografía y la genética molecular se ha estimado una divergencia evolutiva entre los caí de la cuenca amazónica (Cebus sp.) y aquellos distribuidos en la mata atlántica (Sapajus sp.) suficiente como para proponer la división del género en dos (Lynch Alfaro et al. 2011, 2012). Dada esta situación, se presenta la siguiente sinonímia: Cebus apella paraguayanus = Cebus libidinosus = Sapajus cay $/$ Cebus apella nigritus = Cebus nigritus = Sapajus nigritus.

Alfaro, J. W., L. Matthews, A. H. Boyette, S. J. Macfarlan, K. A. Phillips, T. Falotico, E. Ottoni, M. Verderane, P. Izar, M. Schulte, A. Melin, L. Fedigan, C. Janson, and M. E. Alfaro. (2011). Anointing variation across wild capuchin populations: a review of material preferences, bout frequency and anointing sociality in Cebus and Sapajus. Am J Primatol 73:1-16.

Groves, C.P. (2001). Primate Taxonomy, USA \& England: Smithsonian Institution Press.

Lynch Alfaro, JW, JP Boubli, LE Olson, A Di Fiore, B Wilson, BA Gutiérrez-Espeleta, M. Schulte, S. Neitzel, V. Ross, D. Schwochow, I. Farias, C. Janson \& ME Alfaro. (2012). Explosive Pleistocene range expansion leads to widespread Amazonian sympatry between robust and gracile capuchin monkeys. Journal of Biogeography 39: 272-288.

Rylands AB, Mittermeier1 RA, Silva Jr JS. (2012). Neotropical primates: taxonomy and recently described species and subspecies. International Zoo Yearbook 46(1):11-24. 


\section{Dedicatoria}

A mis papás, Fernando y Zulma, por haberme dado todo el cariño del mundo.

Y a Ricky, por su amor durante todos estos años. 


\section{Agradecimientos}

Es imposible empezar sin expresarles mi agradecimiento a mi papá Fernando y a mi mamá Zulma, por haberme dado siempre todo su cariño, su apoyo y sus consejos, y por haber aguantado (y en el caso de mi viejo, fomentado) mi amor por los bichos en general. $Y$ es imposible no decirle gracias a mi mamá Concepción (Yetti). La vida nos separó muy temprano pero estoy segura que le hubiera encantado leer esta tesis.

Quiero darle un agradecimiento muy especial a Ricky, por la paciencia a lo largo de estos años en los que me la pasé yendo y viniendo entre los monos de acá y allá, por su apoyo con cada problema y locura que me hacía colapsar (desde salir conmigo al campo hasta arreglar cada cosa que se rompía), pero por sobre todas las cosas, gracias por tu amor y tu compañía. En estos años que pasaron fuiste y sos el mejor regalo que me dio la hermosa tierra misionera.

También a mi hermano, Feny, por haberse bancado tantos viajes a Aeroparque ida y vuelta, por haberme auxiliado cada vez que mi compu colapsaba y por haber sido un sponsor del trabajo de campo aportando ropa y binoculares. ¡Te quiero mucho hermaniten! $Y$ a mi Juli ( $y$ en los últimos años a la pequeña Asaí), por su compañía perruna constante que siempre ayuda a despejar la mente con paseos diarios y ataques de mimos.

Todo el trabajo de esta tesis no hubiera sido posible de ninguna manera sin la ayuda de muchísimas pero muchísimas personas, tanto en el Zoo de La Plata como en Iguazú. A Roberto Alonso (el Zorro), Luis Alonso, Juan Antú Campoamor, Diego Brutti, Ariel González y Verónica Sendra, gracias por su ayuda para llevar adelante el trabajo del Zoo. Y en especial a Verónica Trapani por su amistad, y por su gran amor por los monos. A mi papá, un agradecimiento especial por sus maravillosas ideas sobre elementos de ferretería y sobre "psicología de monos" para la construcción de un diseño experimental de zoológico imposible de romper por los caí.

A todos los moneros de Iguazú: Ana Alvarez (Anita), María Verónica Cifre (Vero), Emanuel Galetto (Ema), Rocío Fernández Quintero (Uruguayana), Elizabeth Gonzáles Valentín (Eli), Daniel Lambruschi (Dani), Luis Molina (Lucho), Juan Pablo Peretti (Juampi), Noelia Rivas (Noe), Taylor Rubin (Tay), Fermino Silva (Beto), por todo el laburo en el campo y por todos los momentos que pasamos juntos. A Vero, Eli, Rocío y Tay, gracias por su apoyo y todo el aguante durante el 2009. El trabajo salió bien gracias a que ustedes estuvieron conmigo. ¡Las quiero mucho chicas! $Y$ a Beto en especial, el trabajo hubiera sido imposible sin tu ayuda constante. 
A las moneras con más copete: Clara Scarry (Claw Ayudanquina) y María Celia Baldovino (Baldoviniiiii), por aguantarme con todas mis locuras, y por ayudarme en el campo y en la vida. $\mathrm{Y}$ a Clara gracias por ayudarme con la estadística, pero especialmente gracias por tu amistad incondicional. ¡No sé qué hubiera hecho todos estos años sin ustedes!

También a Brandon Wheeler y Bárbara Tiddi, por colaborar con el trabajo en equipo para que el Proyecto Caí siga creciendo. A las larvas Lara Colleselli y Natalia Gomez de Olivera, y a Juan Garibaldi, por haberme ayudado con esas cosas que se llaman árboles. Y a Lia Monti por su auxilio con los nombres y partes de las cañas. Gracias chicos: había algo más que monos en la selva. También quiero agradecerle a mis amigos del staff del Centro de Investigaciones Ecológicas Subtropicales (CIES): a Eduardo Lestani (Mosquito) y Romina Dimarco (Romi Mariposas) por la buena onda y la ayuda durante todos los años de convivencia. Tenerlos viviendo en el CIES hizo del lugar un lindo hogar.

A toda la gente del Centro de Investigaciones del Bosque Atlántico (CelBA) y del Instituto de Biología Subtropical (IBS), que de una u otra manera colaboraron con la tesis. A Agustín Paviolo por haberme ayudado durante la primera campaña brindándome los equipos de radio del Proyecto Yagüareté.

A Julio Burgardt de la Unidad de Medios Audiovisuales del Museo de La Plata por su ayuda y su aguante con la edición de los videos para la tesis. A Pablo Campana y Malena Lorente por sus sugerencias matemáticas. $Y$ a Luis Dalprá, que lamentablemente ya no está con nosotros, me hubiera gustado poder darle las gracias por su ayuda con el programa gv_SIG.

También a toda la gente de la División Etnografía del Museo de La Plata, por las charlas e intercambios de ideas. A Susana Tuler por su socorro constante con los programas de dibujo, y en especial a María de los Ángeles Bacigalupe (Marián), por su ayuda con la estadística, sus revisiones de gramática, sus maravillosas ideas y por sobre todo por su hermosa amistad.

A mi director Héctor Lahitte por sus consejos y su guía a lo largo de estos años. Y a mi co-director Charles Janson, por sus ideas y su ayuda con el análisis de los datos, y sobre todo por haberme permitido empezar trabajando con él en el campo y así aprender muchísimo de la ecología y el comportamiento de los monos.

Al Jardín Zoológico y Botánico de La Plata, a sus directivos y a toda la gente que integra la división Biología. 
Al cuerpo de Guardaparques del Parque Nacional Iguazú (PNI), por auxiliarnos cada vez que lo necesitamos, y por brindarnos su apoyo en cada momento.

A la Administración de Parques Nacionales (APN) y al personal de Delegación Regional NEA, Paula Cichero, Dalma Raymundi y Fernanda Fabbio. Y en especial a toda la gente del Centro de Investigaciones Ecológicas Subtropicales (CIES): Justo Herrera, Germán (Colo), Mónica Montero, Eugenia Peralta y Olga Silvero, por su ayuda constante.

A las instituciones que brindaron apoyo académico y/o económico: Universidad Nacional de La Plata (UNLP), Consejo Nacional de Investigaciones Científicas y Técnicas (CONICET), Administración de Parques Nacionales (APN), Jardín Zoológico y Botánico de La Plata, Museo de Ciencias Naturales de La Plata, Idea Wild, American Society of Mammalogists.

Y finalmente, y no por ser menos importantes, a los monos, por sorprenderme una y otra y otra vez... 
TABLA DE CONTENIDOS

Página

CARÁTULA...... 1

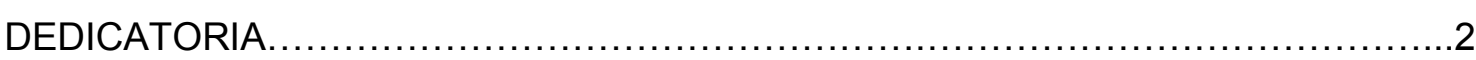

AGRADECIMIENTOS

LISTA DE TABLAS

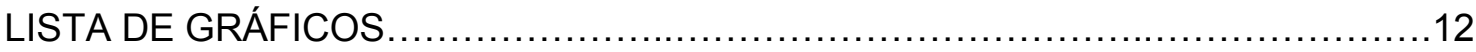

LISTA DE FIGURAS

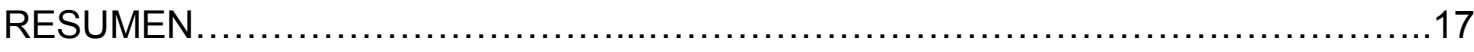

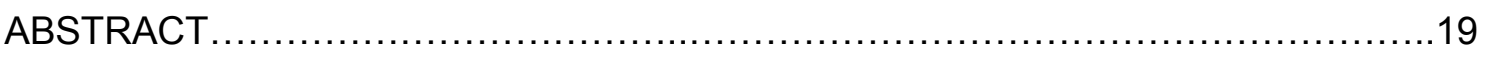

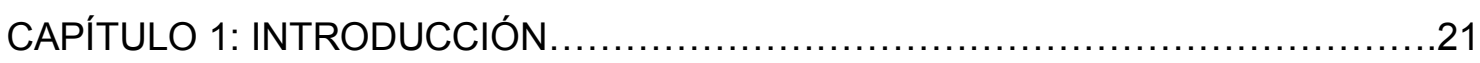

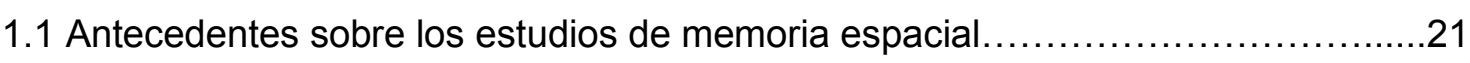



1.1.2 La memoria: clasificación, definiciones y modelos...........................24

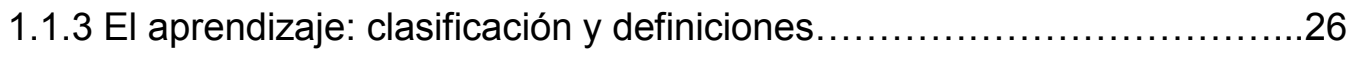

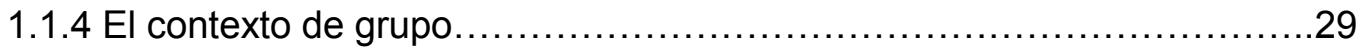

1.2 La ecología sensorial de los primates en relación a la alimentación....................31

1.3 Los estudios de memoria espacial en primates no-humanos...........................32

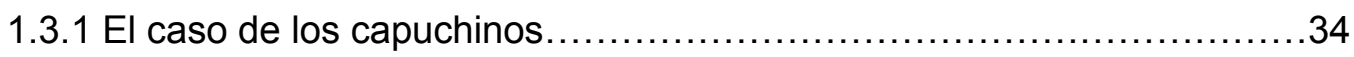

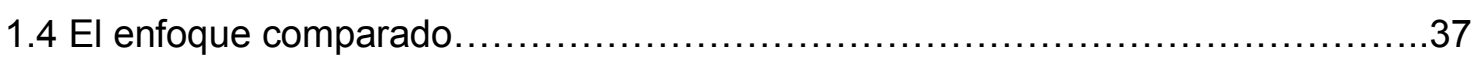

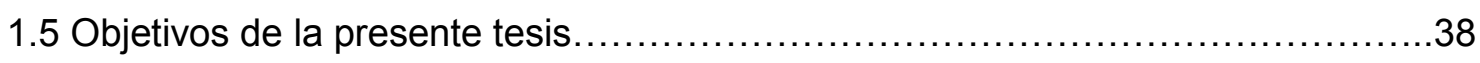



CAPÍTULO 2: ANÁLISIS DESCRIPTIVO DE LA CONDUCTA........................47



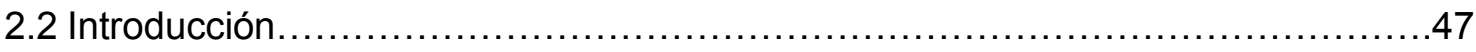



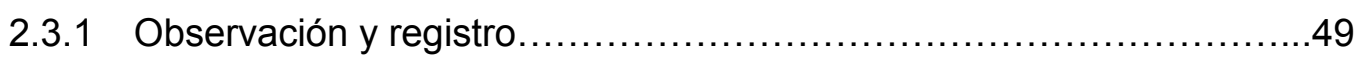

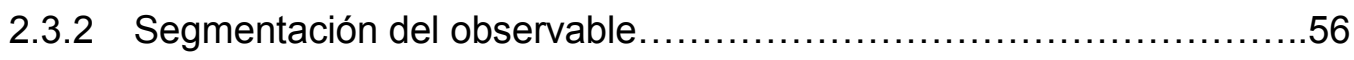

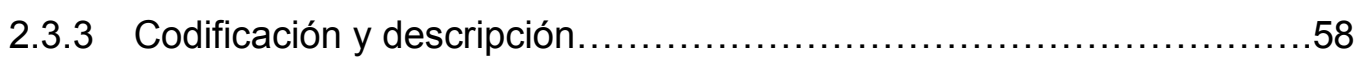

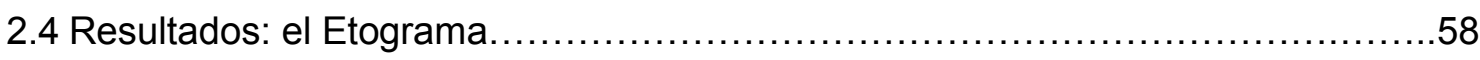

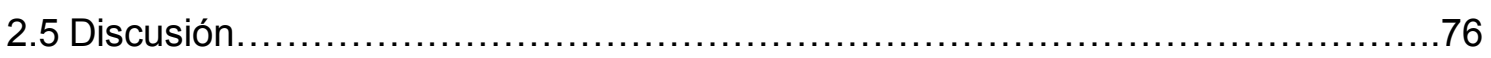

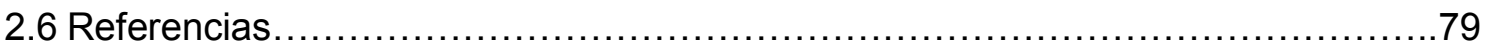

CAPÍTULO 3: CAPACIDAD DE MEMORIA Y DINÁMICA DEL APRENDIZAJE EN CAUTIVERIO EN EL JARDÍN ZOOLÓGICO Y BOTÁNICO DE LA PLATA...............81



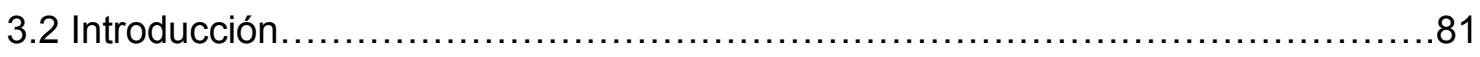

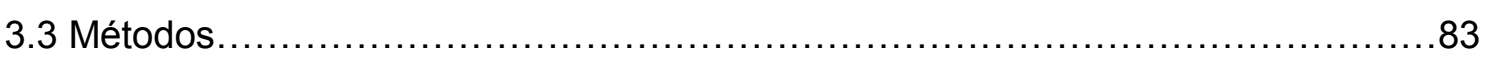






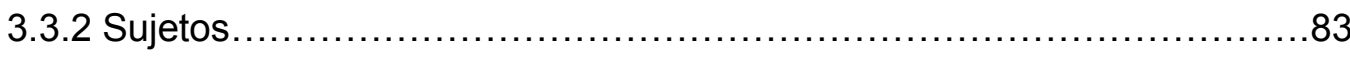

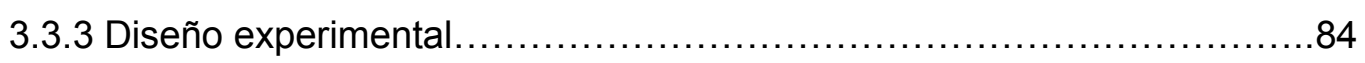

3.3.4 Descripción de las secuencias de forrajeo...........................91

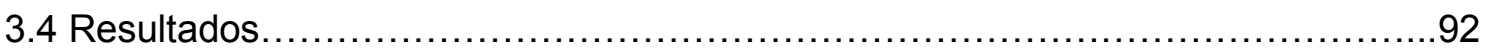

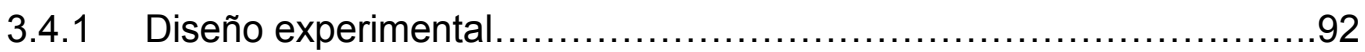

3.4.1.1 Grupo Jaula..............................................

3.4.1.2 Grupo Isla................................................ 103

3.4.2 Descripción y análisis de las secuencias de forrajeo.................113

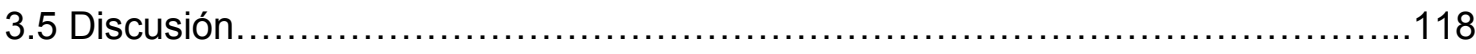

3.5.1 Duración de los ensayos ..........................................118

3.5.2 Aprendizaje y performance de memoria espacial...................... 119

3.5.3 Diferencias entre los grupos estudiados............................121

3.5.4 Análisis de secuencias para el grupo Jaula..........................121

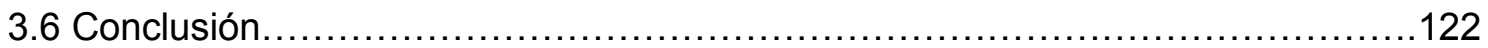

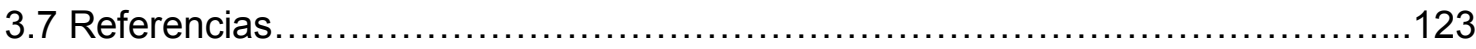

CAPÍTULO 4: CAPACIDA DE MEMORIA SOBRE LA UBICACIÓN DE ÁRBOLES DE FRUTA Y SUS ESTADOS DE FRUCTIFICACIÓN EN EL PARQUE NACIONAL

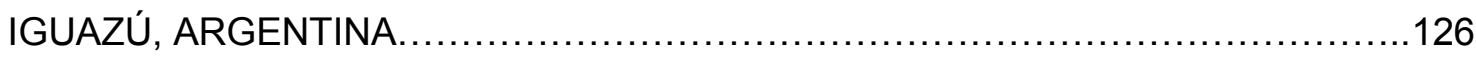

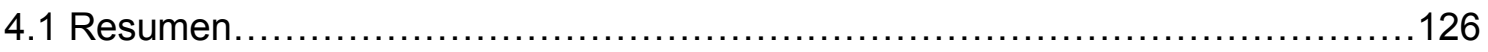

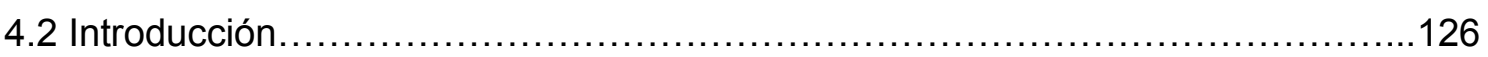

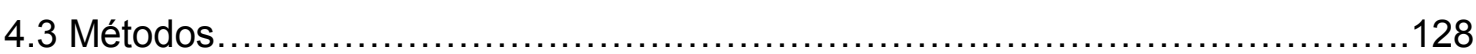

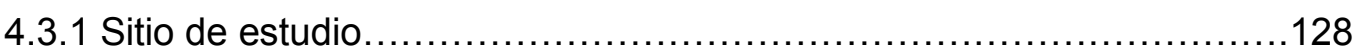

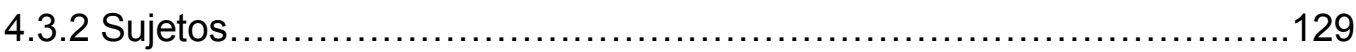



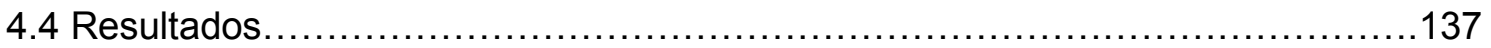

4.4.1 Tamaño de las áreas de acción..................................137

4.4.2 Memoria de los estados de fructificación.............................146

4.4.2.1 Visitas a árboles focales en función de la probabilidad de los mismos de tener o no tener fruta..................................... 146

4.4.2.2 Velocidades Pre RC, Post RC y Medio RC de visita a árboles focales

4.4.2.3 Velocidades de visita a árboles según porcentajes de fruta (madura e inmadura) y madura ........................................154

4.4.2.4 Aceleraciones y medidas de los árboles focales...............158

4.4.2.5 Cantidades de fruta e intervalos de revisita....................161 


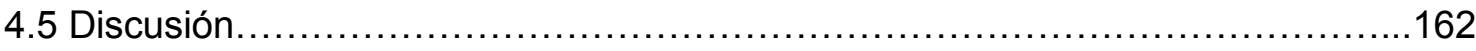

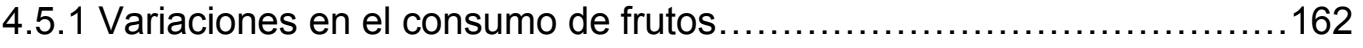

4.5.2 Memoria de los árboles focales y su estado de fructificación.............163

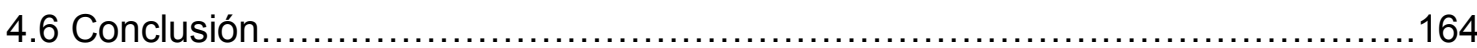

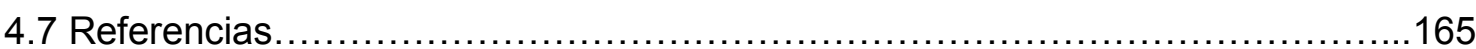

CAPÍTULO 5: SEMEJANZAS Y DIFERENCIAS, CONCLUSIONES FINALES .........169

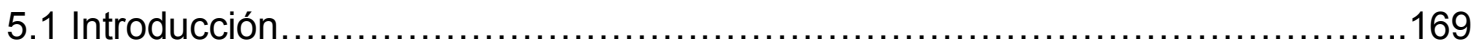

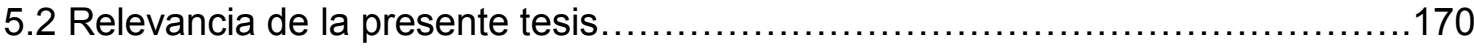

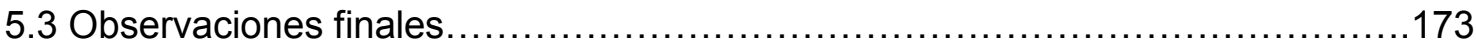

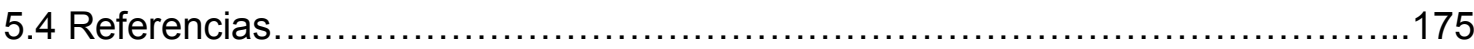

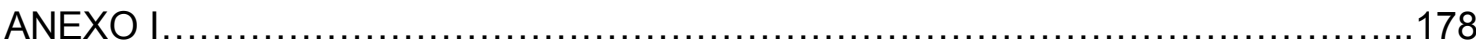

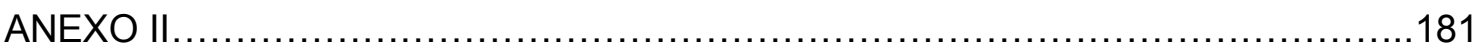

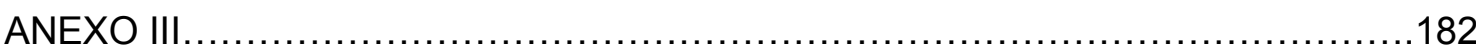

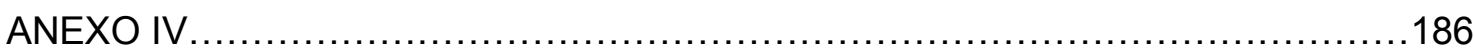

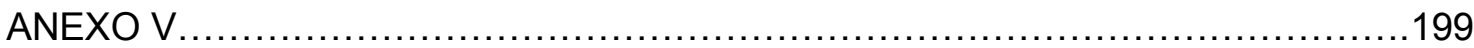

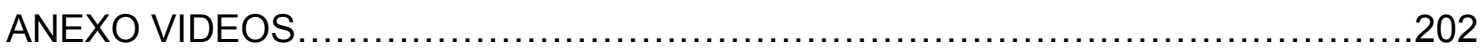


LISTA DE TABLAS

Página

Tabla 1.1: Tipos de aprendizaje según Bateson (1947), ejemplos y su relación con los sistemas de memoria.

Tabla 2.1: Comparación de los comportamientos publicados sobre alimentación y desplazamientos en capuchinos.

Tabla 3.1: composición de los grupos por sexo y sus categorías de edad. Adaptado de Gunst, Boinski \& Fragaszy (2008) y MacKinnon, 2013.

Tabla 3.2: Pautas de comportamiento novedosas dirigidas al diseño experimental....92 Tabla 3.3: Valores promedios, desvíos estándar e intervalos de confianza al $95 \%$ de IPME de los individuos para MCP1 del grupo Jaula. .95

Tabla 3.4: Valores promedios, desvíos estándar e intervalos de confianza al $95 \%$ de IPME de los individuos para MCP2 del grupo Jaula. .98

Tabla 3.5: Valores promedios, desvíos estándar e intervalos de confianza al $95 \%$ de IPME de los individuos para INV del grupo Jaula. 100 Tabla 3.6: IPME promedios \pm desvíos estándar (DS) e intervalos de confianza al 95\% (IC 95\%) por ensayo para cada período experimental del grupo Jaula.

Tabla 3.7: Valores promedios, desvíos estándar e intervalos de confianza al $95 \%$ de IPME de los individuos para MCP1 del Grupo Isla. 106 Tabla 3.8: Valores promedios, desvíos estándar e intervalos de confianza al $95 \%$ de IPME de los individuos para MCP2 del grupo Isla. 108

Tabla 3.9: Valores promedios, desvíos estándar e intervalos de confianza al $95 \%$ de IPME de los individuos para INV del grupo Isla.

Tabla 3.10: IPME promedios \pm desvíos estándar (DS) e intervalos de confianza al 95\% (IC 95\%) por ensayo para cada período experimental del grupo Isla...................112

Tabla 3.11: Descripción de las secuencias de dos contenedores..........................114

Tabla 3.12: Descripción de las secuencias de tres contenedores........................115

Tabla 4.1: Períodos de estudio en meses y años de cada grupo, total de días de seguimiento y tamaños de los grupos con sus composiciones por sexo.

Tabla 4.2: Categorías de comportamientos relacionados a los árboles focales 135

Tabla 4.3: Tamaño del área de acción de cada grupo en hectáreas, cantidad de días completos de seguimiento, promedio y desvío estándar de los puntos georreferenciados colectados por día, y el total de puntos colectados por grupo......137 Tabla 4.4: promedio de árboles / parches de fruta visitados por día, radio crítico, distancia mínima entre árboles focales y número de especies consumidas para cada grupo en cada período de muestreo. 
Tabla 4.5: Listado total de especies frutales (árboles y enredaderas) consumidas por los grupos de estudio. Nombre vulgar, nombre científico y codificación utilizada para gráficos posteriores. $\mathrm{N}$ total de especies $=27$.

Tabla 4.6: Promedios de las velocidades Post RC con y sin visitas de cada grupo a árboles focales, análisis de comparación de medias (test de Student para muestras independientes utilizando la variable log transformada) y cálculo del tamaño del efecto para cada comparación de medias.

Tabla 4.7: test de Student individuales para muestras independientes de las velocidades Pre RC y Post RC log transformadas de Visitas a árboles focales para cada grupo en cada período de muestreo, promedios \pm desvío estándar y tamaño del efecto para cada comparación de medias .......................................153 Tabla 4.8: test de Student individuales para muestras independientes de las velocidades Post RC y Medio RC log transformadas de Visitas a árboles focales para cada grupo en cada período de muestreo, promedios \pm desvío estándar y tamaño del efecto para cada comparación de medias

Tabla 4.9: test de Student para muestras independientes para las velocidades Post RC y Medio RC sin transformar y log transformadas $(\mathrm{m} / \mathrm{min})$ de Visitas árboles focales con más o menos del $50 \%$ de fruta presente, promedios \pm desvíos estándar, y valor de d de Cohen. 155

Tabla 4.10: test de Student para muestras independientes para las velocidades Post RC y Medio RC sin transformar y log transformadas $(\mathrm{m} / \mathrm{min})$ de Visitas árboles focales con más o menos del $25 \%$ de fruta presente, promedios \pm desvíos estándar, y valor de d de Cohen. 156

Tabla 4.11: test de Student para muestras independientes para las velocidades Post $\mathrm{RC}$ y Medio RC sin transformar y log transformadas $(\mathrm{m} / \mathrm{min})$ de Visitas árboles focales con más o menos del $50 \%$ de fruta madura presente, promedios \pm desvíos estándar, y valor de $\mathrm{d}$ de Cohen.

Tabla 4.12: test de Student para muestras independientes para las velocidades Post $\mathrm{RC}$ y Medio RC sin transformar y log transformadas $(\mathrm{m} / \mathrm{min})$ de Visitas árboles focales con más o menos del $25 \%$ de fruta madura presente, promedios \pm desvíos estándar, y valor de de Cohen. 158

Tabla 4.13: Resumen de las correlaciones positivas y negativas significativas para todos los grupos entre las variables aceleración 1 y 2 , total de fruta madura, fruta inmadura, fruta madura, grupo-minuto, volumen de copa (Vol Copa) y diámetro a la

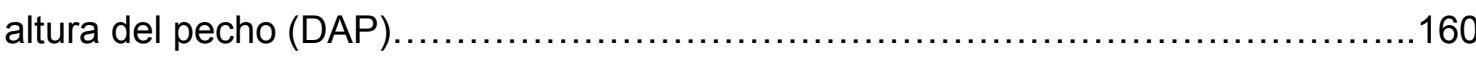

Tabla II: Lista código comportamientos para el registro posterior de datos.............181

Tabla III.1: IPME Período experimental MCP1 Jaula.............................182 
Tabla III.2: IPME Período experimental MCP2 Jaula................................ 182

Tabla III.3: IPME Período experimental INV Jaula................................183

Tabla III.4: IPME Períodos MLP1 y MLP2 Jaula.................................183

Tabla III.5: IPME Período experimental MCP1 Isla ................................. 184

Tabla III.6: IPME Período experimental MCP2 Isla...............................184

Tabla III.7: IPME Período experimental INV Isla...................................... 184

Tabla III.8: IPME Período MLP1 y MLP2 Isla ....................................... 185

Tabla IV.1: IPME por sexo para cada ensayo (Período MCP1 Jaula).................186

Tabla IV.2: IPME por categoría de edad para cada ensayo (Período MCP1

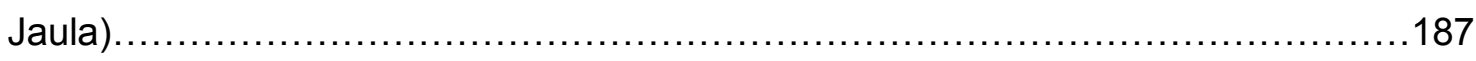

Tabla IV.3: IPME por sexo para cada ensayo (Período MCP2 Jaula)..................188

Tabla IV.4: IPME por categoría de edad por ensayo (Período MCP2 Jaula)...........189

Tabla IV.5: IPME por sexo para cada ensayo (Período INV Jaula)....................191

Tabla IV.6: IPME por categoría de edad (Período INV Jaula)........................192

Tabla IV.7: IPME por sexo para cada ensayo (Período MCP1 Isla)....................194

Tabla IV.8: IPME por categoría de edad para cada ensayo (Período MCP1 Isla).....195

Tabla IV.9: IPME por sexo para cada ensayo (Período MCP2 Isla)..................196

Tabla IV.10: IPME por categoría de edad para cada ensayo (Período MCP2 Isla)...196

Tabla IV.11: IPME por sexo para cada ensayo (Período INV Isla) ....................197

Tabla IV.12: IPME por categoría de edad para cada ensayo (Período INV Isla).......198 
Gráfico 3.1: Visitas a contenedores por ensayo en $\mathrm{PH}(\mathrm{N}$ total $=321)$ 93

Gráfico 3.2: Duración en minutos de los ensayos de memoria de corto plazo 1 y 2 (MCP1 y MCP2), e inversión (INV) para el grupo Jaula. Media MCP1 = $62.46 \pm 15.2$; Media MCP2 $=43.6 \pm 10.7$; Media INV = $43.7 \pm 8.7$ .94

Gráfico 3.3: Visitas correctas (VC) y visitas incorrectas (VI) por ensayo durante MCP1....

Gráfico 3.4: Valores promedio de IPME de cada individuo (IND) para la etapa experimental MCP1. Referencias: $1=\mathrm{GOR}, 2=\mathrm{CE}, 3=\mathrm{EU}, 4=\mathrm{TO}, 5=\mathrm{CH}, 6=\mathrm{PU}, 7$ $=\mathrm{DIE}, 8=\mathrm{NI}, 9=\mathrm{MANU}, 10=\mathrm{RO}$

Gráfico 3.5: IPME promedio por categorías de edad para MCP1. Adultos: 0,46 $\pm 0,52$ DS, IC 95\%: 0,24-0,67, ( $N=25)$; Subadultos: 0,56 \pm 0,6 DS, IC 95\%: 0,3-0,83, ( $N=23)$; Juveniles: 0,47 $\pm 0,38$ DS, IC 95\%: 0,37-0,55, (N=75); Infante: 0,43 $\pm 0,32 \mathrm{DS}$, IC 95\%: $0,25-0,61(N=15)$ 96

Gráfico 3.6: Visitas correctas (VC) y visitas incorrectas (VI) durante MCP2. .97

Gráfico 3.7: Valores promedio de IPME de cada individuo (IND) para la etapa experimental MCP2. Referencias: $1=\mathrm{GOR}, 2=\mathrm{CE}, 3=\mathrm{EU}, 4=\mathrm{TO}, 5=\mathrm{CH}, 6=\mathrm{PU}, 7$ $=$ DIE, $8=\mathrm{NI}, 9=$ MANU, $10=\mathrm{RO}$.

Gráfico 3.8: IPME promedio por categorías de edad para MCP2. Adultos: 0,54 $\pm 0,32$ DS, IC 95\%:0,42-0,66, ( $N=30$ ); Subadultos: 0,67 $\pm 0,29$ DS, IC 95\%: 0,51-0,83 ( $N=15)$; Juveniles: 0,80 \pm 0,22 DS, IC 95\%: 0,75-0,85 (N=75); Infante: 0,78 \pm 0,21 DS, IC 96\%: 0,66-0,9 (N=15). .98

Gráfico 3.9: Visitas correctas (VC) y visitas incorrectas (VI) durante INV. .99 Gráfico 3.10: Valores promedio de IPME de cada individuo (IND) para la etapa experimental INV. Referencias: $1=\mathrm{GOR}, 2=\mathrm{CE}, 3=\mathrm{EU}, 4=\mathrm{TO}, 5=\mathrm{CH}, 6=\mathrm{PU}, 7=$ DIE, $8=\mathrm{NI}, 9=$ MANU, $10=\mathrm{RO}$.

Gráfico 3.11: IPME promedio por categorías de edad para INV. Adultos: $0,37 \pm 0,48$ DS, IC: 0,19-0,56 (N=29); Subadultos: 0,7 $\pm 0,3 \mathrm{DS}, \mathrm{IC}: 0,51-0,89(\mathrm{~N}=12)$; Juveniles: 0,48 \pm 0,31 DS, IC: 0,4-0,55 ( $N=75)$; Infante: 0,52 \pm 0,33 DS, IC: 0,33-0,7 (N=15)...100 Gráfico 3.12: Duración en minutos de los ensayos de memoria de corto plazo 1 y 2 (MCP1 y MCP2), e inversión (INV) para el grupo Isla. Media MCP1 = $43.7 \pm 13.1$; Media MCP2 $=27.9 \pm 9.3 ;$ Media INV $=28.6 \pm 6.7$. 104

Gráfico 3.13: Visitas correctas (VC) y visitas incorrectas (VI) durante MCP1. 105 Gráfico 3.14: Valores promedio de IPME de cada individuo (IND) para la etapa experimental MCP1. Referencias: $1=$ ÑO, $2=$ ALE, $3=$ MAMI, $4=$ MAT, $5=$ FER, $6=$ JU. 105 
Gráfico 3.15: IPME promedio por categorías de edad para MCP1. Adultos: $0,42 \pm 0,37$ DS, IC: 0,30-0,55 ( $\mathrm{N=36}$ ); Juveniles: 0,2 $\pm 0,17 \mathrm{DS}, \mathrm{IC}: 0,09-0,31(\mathrm{~N}=12)$; Infante: 0,25

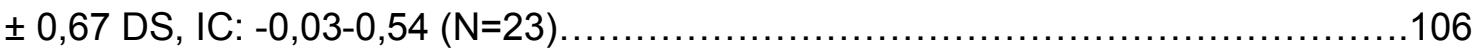

Gráfico 3.16: Visitas correctas (VC) y visitas incorrectas (VI) durante MCP2. 107

Gráfico 3.17: Valores promedio de IPME de cada individuo (IND) para la etapa experimental MCP2. Referencias: $1=$ ÑO, $2=$ ALE, $3=$ MAMI, $4=$ MAT, $5=$ FER, $6=$ JU. 108

Gráfico 3.18: IPME promedio por categorías de edad para MCP2. Adultos $=0,26 \pm$ 0,41 DS, IC 95\%: 0,09-0,42, N=27; infantes = 0,26 $\pm 0,34$ DS, IC 95\%: 0,09-0,43, $\mathrm{N}=18$. 109

Gráfico 3.19: Visitas correctas (VC) y visitas incorrectas (VI) durante INV 109 Gráfico 3.20: Valores promedio de IPME de cada individuo (IND) para la etapa experimental INV. Referencias: $1=\tilde{N} O, 2=$ ALE, $3=$ MAMI, $4=$ MAT, $5=$ FER, $6=$ JU.

Gráfico 3.21: IPME promedio por categorías de edad para INV. Adultos $=0,33 \pm 0,44$ DS, IC 95\%: $0,17-0,5, N=30$; infantes $=0,46 \pm 0,41$ DS, IC 95\%: 0,27 - 0,66, $\mathrm{N}=20$.

Gráfico 3.22: Secuencias de 1 y 2 contenedores durante el período experimental MCP1 para cada individuo.

Gráfico 3.23: Secuencias de 1 y 2 contenedores durante el período experimental MCP2 para cada individuo.

Gráfico 3.24: Secuencias de 3 contenedores durante el período experimental MCP1 para cada individuo.

Gráfico 3.25: Secuencias de 3 contenedores durante el período experimental MCP2 para cada individuo.

Gráfico 4.1: Especies frutales consumidas por el grupo Macuco en 2008. $\mathrm{N}{ }^{\circ}$ total: 52 parches/árboles de fruta. Referencias de las siglas en tabla 4.5. SA: árboles (cedros misioneros - Cedrela fissilis, marmeleros - Ruprechtia laxiflora y cancharanas Cabralea canjerana) infestados con estados larvales de homópteros.

Gráfico 4.2: Especies frutales consumidas por el grupo Macuco en 2009. ${ }^{\circ}$ total: 83 parches/árboles de fruta. Referencias de las siglas en tabla 4.5. 143

Gráfico 4.3: Especies frutales consumidas por el grupo Gundolf en 2009. N ${ }^{\circ}$ total: 48 parches/árboles de fruta. Referencias de las siglas en tabla 4.5. SA: árboles (cedros misioneros, marmeleros y cancharanas) infestados con estados larvales de homópteros.

Gráfico 4.4: Especies frutales consumidas por el grupo Gundolf en 2010. N ${ }^{\circ}$ total: 86 parches/árboles de fruta. Referencias de las siglas en tabla 4.5. 
Gráfico 4.5: Especies frutales consumidas por el grupo Rita en $2010 . N^{\circ}$ total: 59 parches/árboles de fruta. Referencias de las siglas en tabla 4.5. 145

Gráfico 4.6: Especies frutales consumidas por el grupo Rita en 2011. ${ }^{\circ}{ }^{\circ}$ total: 78 parches/árboles de fruta. Referencias de las siglas en tabla 4.5 145

Gráfico 4.7: Entradas a radios críticos del grupo Macuco en 2009. Sin fruta N=24 (N no visitas $=8, N$ visitas $=16)$, Con fruta $N=252(N$ no visitas $=41, N$ visitas $=211) \ldots \ldots 146$ Gráfico 4.8: Entradas a radios críticos del grupo Gundolf en 2009. Sin fruta N=60 (N no visitas $=28, \mathrm{~N}$ visitas $=32) ; \mathrm{y}$ Con fruta $\mathrm{N}=35(\mathrm{~N}$ no visitas $=5, \mathrm{~N}$ visitas $=30) \ldots \ldots 147$ Gráfico 4.9: Entradas a radios críticos de grupo Gundolf en 2010. Sin fruta $N=14$ (N no visitas $=12, \mathrm{~N}$ visitas $=2)$, Con fruta $\mathrm{N}=187(\mathrm{~N}$ no visitas $=38, \mathrm{~N}$ visitas $=149) \ldots \ldots 147$ Gráfico 4.10: Entradas a radios críticos del grupo Rita en 2010. Sin fruta $N=52$ (N no visitas $=45, \mathrm{~N}$ visitas $=7)$, Con fruta $\mathrm{N}=128(\mathrm{~N}$ no visitas $=29, \mathrm{~N}$ visitas $=99) . \ldots .147$ Gráfico 4.11: Entradas a radios críticos del grupo Macuco en 2008. Sin fruta $N=18$ ( $N$ no visitas $=17, \mathrm{~N}$ visitas $=1)$, Con fruta $\mathrm{N}=58(\mathrm{~N}$ no visitas $=10, \mathrm{~N}$ visitas $=48) \ldots .148$ Gráfico 4.12: Entradas a radios críticos del grupo Rita en 2011. Sin fruta $N=3$ (N no visitas $=2, N$ visitas $=1)$, Con fruta $N=201(\mathrm{~N}$ no visitas $=37, \mathrm{~N}$ visitas $=164) \ldots \ldots .148$ Gráfico 4.13: Promedio de las velocidades de visitas Pre-RC (6,7 $\pm 3,4$ DS, IC 95\%: 4,2-9,6, N = 9), Post-RC (7,3 $\pm 2,3$ DS, IC 95\%: 5,5-9,1, N = 9) y Medio-RC (16,47 \pm 18,8 DS, IC 95\%: 2-30,9, $\mathrm{N}=9$ ) del grupo Macuco en 2008.

Gráfico 4.14: Promedio de las velocidades en $\mathrm{m} / \mathrm{min}$ de visitas Pre-RC (4,9 $\pm 2,5 \mathrm{DS}$, IC 95\%: 3,7-6, $N=21)$, Post-RC (7,2 $\pm 5,5$ DS, IC 95\%: 4,7-9,7, $N=21)$ y Medio-RC $(11,2 \pm 9,4$ DS, IC 95\%: 6,8-15,5, N = 21) del grupo Macuco en 2009 .... 150

Gráfico 4.15: Promedio de las velocidades en $\mathrm{m} / \mathrm{min}$ de visitas Pre-RC (4,2 \pm 2 DS, IC 95\%: 3,2-5,3, $N=17)$, Post-RC (5,09 $\pm 2,1 \mathrm{DS}, \mathrm{IC} 95 \%: 4-6,2, \mathrm{~N}=17)$ y Medio-RC (5,05 \pm 2,3 DS, IC 95\%: 3,8-6,2, N = 17) del grupo Gundolf en 2009 152 Gráfico 4.16: Promedio de las velocidades en $\mathrm{m} / \mathrm{min}$ de visitas Pre-RC (3,8 \pm 1,9 DS, IC 95\%: 3,2-4,5, N = 35), Post-RC (4,8 $\pm 1,8$ DS, IC 95\%: 4,1-5,4, $N=35)$ y Medio-RC (6,3 \pm 4 DS, IC 95\%: 5-7,7, N = 35) del grupo Gundolf en 2010 .

Gráfico 4.17: Promedio de las velocidades en $\mathrm{m} / \mathrm{min}$ de visitas Pre-RC (4,6 $\pm 2,5 \mathrm{DS}$, IC 95\%: 3,5-5,7, N = 24), Post-RC (5,8 $\pm 3,7$ DS, IC 95\%: 4,2-7,3, $N=24)$ y Medio-RC (7,5 \pm 4,7 DS, IC 95\%: 5,5-9,5, N = 24) del grupo Rita en 2010 152

Gráfico 4.18: Promedio de las velocidades en $\mathrm{m} / \mathrm{min}$ de visitas Pre-RC (4,8 $\pm 2,4 \mathrm{DS}$, IC 95\%: 3,9-5,6, $N=37)$, Post-RC (7,8 \pm 6 DS, IC 95\%: 5,8-9,8, $N=37$ ) y Medio-RC (12,3 \pm 11,1 DS, IC 95\%: 8,6-16, N = 37) del grupo Rita en 2011

Gráfico 4.19: Intervalos de revisita (en horas) a los árboles según sus categorías de fruta madura e inmadura ( 0 a 4 ). 162 
LISTA DE FIGURAS

Página

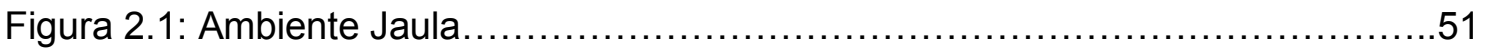

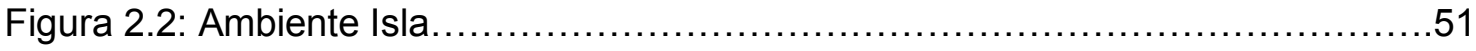

Figura 2.3: Selva Paranaense, Parque Nacional Iguazú........................... 52

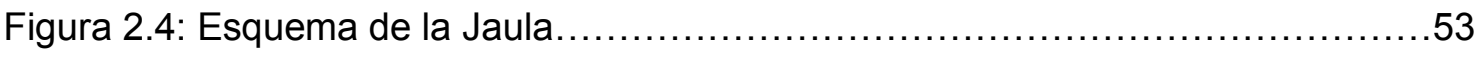

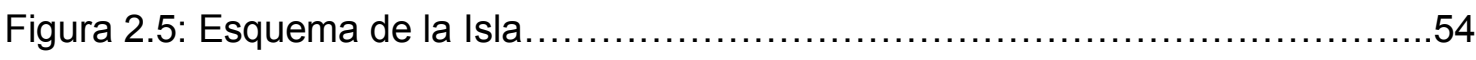

Figura 2.6: Mapa de sendas elaborado a partir de puntos georreferenciados.........55

Figura 2.7: Categorías principales de segmentación del observable. 1 = cabeza, $2=$ cuello, $3=$ cuerpo, 4 = región posterior, $5=$ miembro anterior, $6=$ miembro posterior, 7 $=$ cola $(\mathrm{B}$. Wheeler $)$.

Fig. 2.8: Estados del descriptor cola sin apoyo. a - Vertical, b - Horizontal, c -

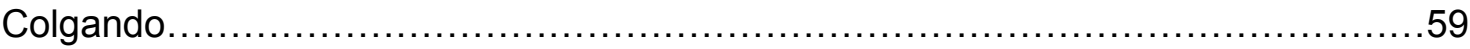

Figura 2.9: Estados del descriptor cola con apoyo. a - Horizontal, b - Colgando......59

Figura 2.10: Estados del descriptor cabeza. a - En línea con el cuerpo, b - Hacia arriba,

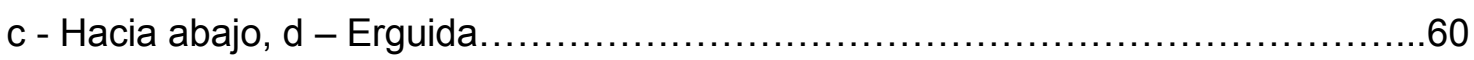

Figura 2.11: Estados del descriptor miembro anterior estirado. a - Vertical, b Paralelo.

Figura 2.12: Descriptor miembro anterior flexionado 61

Figura 2.13: Estados del descriptor miembro posterior estirado. a - Vertical, b Paralelo 61

Figura 2.14: Descriptor miembro posterior flexionado $\ldots \ldots \ldots \ldots \ldots \ldots \ldots \ldots \ldots \ldots \ldots \ldots \ldots \ldots \ldots \ldots \ldots \ldots \ldots \ldots$

Figura 2.15: Descriptor miembro posterior Semiflexionado...........................62

Figura 2.16: Estado contactar. a - Con cola, b - Con mano............................63

Figura 2.17: Posición parado en 4 patas.........................................66

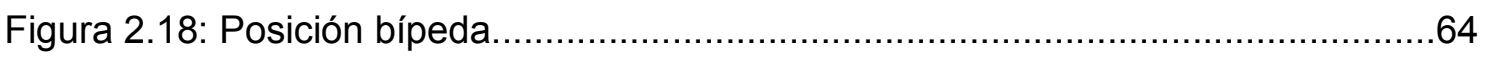

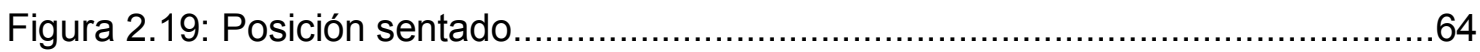

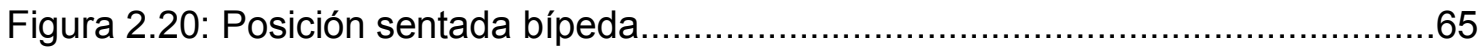

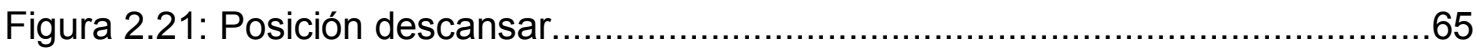

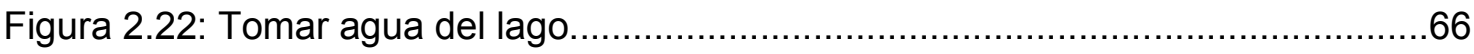

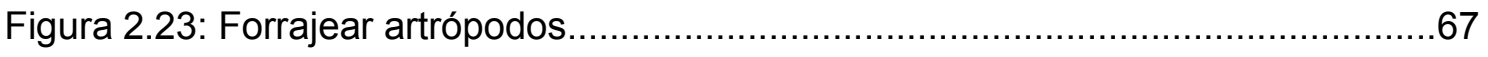

Figura 2.24: Hembra consumiendo fruto de Ambay (Cecropia pachystachya).............68

Figura 2.25: Hembra consumiendo frutos de palmera Pindó.........................................69

Figura 2.26: Secuencia de consumo de brote de caña chasquea...............................70

Figura 2.27: Juvenil sosteniendo un anfibio........................................................... 71

Figura 2.28: Patas en el suelo y en el aire, según el método propuesto por CocatreZilgien (1993)... 
Figura 2.29: Grafos de las caminatas (W - walking) descriptas, W1 a W5, según el método de Cocatre-Zilgien (1993).................................................................... 73

Figura 2.30: Grafos de otros desplazamientos, CL, DR, J, según el método de Cocatre-Zilgien (1993). 74

Figura 2.31: Grafos de las formas de viajar ( $\mathrm{T}$ - Travelling), T1 a T4, según el método

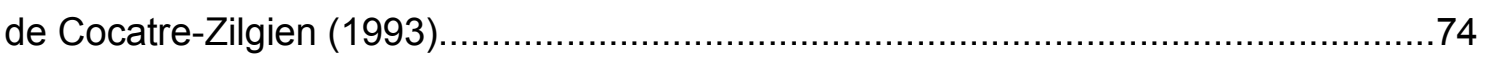

Figura 2.32: Grafos de los tipos de desplazamientos involucrados en los CLE (comportamientos locomotores estereotipados), según el método de Cocatre-Zilgien (1993). .75

Figura 3.1: Ubicación de los contenedores de alimento durante el período de

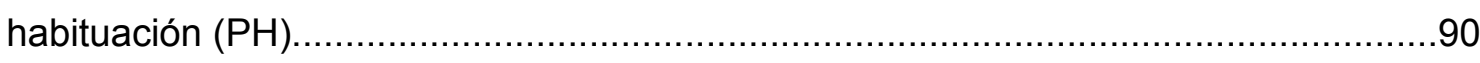

Figura 3.2: Ubicación de los contenedores en el período de memoria de corto y largo



Figura 3.3: Contenedores accesibles (izquierda) e inaccesibles (derecha)................91

Figura 3.4: Código gráfico para representar las secuencias de desplazamiento de los

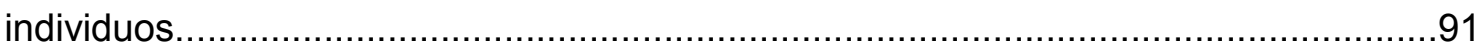

Figura 3.5: individuo PU retirando alimento de un contenedor accesible (CCA).........93

Figura 3.6: Individuo ÑO retirando alimento de CCA ..............................................104

Figura 3.7: Ejemplo de mapa de secuencias (ensayo 1, Memoria de Corto Plazo

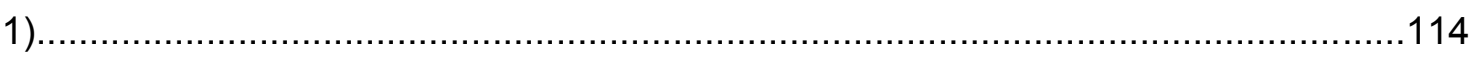

Figura 4.1: Macho adulto del grupo Macuco consumiendo frutos de Maclura

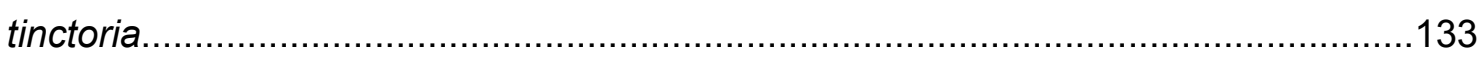

Figura 4.2: Mapa del área de acción del grupo Macuco en 2008 y 2009 ....................138

Figura 4.3: Mapa del área de acción del grupo Gundolf en 2009 y $2010 \ldots \ldots \ldots \ldots . . . . . . . . .139$

Figura 4.4: Mapa del área de acción del Grupo Rita en 2010 y 2011 .......................140

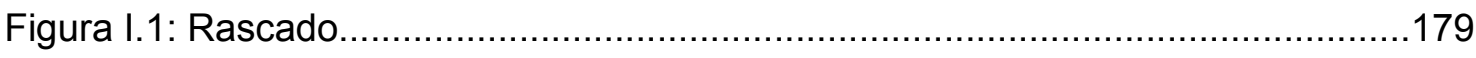

Figura V.1: Mapa del Ensayo 3, período MCP1 ....................................................199

Figura V.2: Mapa del Ensayo 8, período MCP1 ....................................................199

Figura V.3: Mapa del Ensayo 10, período MCP1 ................................................200

Figura V.4: Mapa del Ensayo 2, período MCP2 ...............................................200

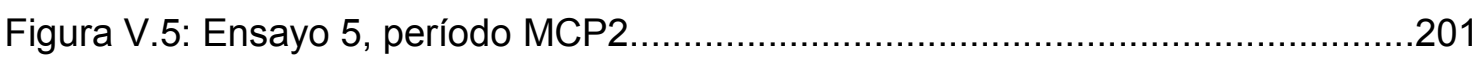

Figura V.6: Mapa del Ensayo 9, período MCP2 ..................................................201 


\section{Resumen}

La memoria espacial se considera un factor selectivo en la evolución de la inteligencia. Los estudios en animales permiten pensar que los procesos cognitivos descriptos en los seres humanos tienen mucho en común con los de otras especies. En el caso de los primates sudamericanos, la diversidad de plantas que son fuente de alimento, y la forma en que éstas se distribuyen en tiempo y espacio, han sido señaladas como la mayor fuerza selectiva en el desarrollo de las complejidades cerebrales avanzadas. Es así que la conducta de búsqueda del alimento es uno de los ámbitos más accesibles a un enfoque cognitivo comparado. Se estudió el comportamiento espacial vinculado a la búsqueda del alimento de los monos caí o capuchinos, y su capacidad de retener información sobre la ubicación y estado del mismo. Si bien la memoria espacial había sido probada con anterioridad en esta especie, estos estudios evaluaban a los individuos de forma individual, excluidos de su grupo (contexto opuesto a la situación en la cual este comportamiento ha evolucionado en ambiente natural), o utilizaban diseños experimentales insertados por el investigador en el ambiente, evaluando la capacidad de memoria de lugar y de cantidades de retribución de alimento esperada, sin cambios estacionales ni de maduración del recurso. Durante el desarrollo de la presente tesis se estudió este comportamiento en contexto de grupo, analizando si los individuos eran capaces de integrar la información memorizada acerca de los sitios de alimento, y si esta memoria implicaba o no el registro de los cambios de estado del recurso. El capítulo 1 incluye una revisión bibliográfica introductoria sobre el tema. A lo largo del capítulo 2 se construyó un etograma parcial de las conductas vinculadas a la búsqueda, localización y consumo del alimento de los grupos de monos estudiados tanto en cautiverio como en vida silvestre. Se realizó una comparación de los resultados obtenidos en el marco de las publicaciones sobre comportamiento alimentario en capuchinos. En el capítulo 3 se presentan los experimentos realizados para evaluar la capacidad de memoria de corto y de largo plazo en dos grupos de Cebus apella paraguayanus $=$ Cebus libidinosus $=$ sapajus cay $(\mathrm{N}=10 ; \mathrm{N}=6)$ en cautiverio y semi-cautiverio en el Jardín Zoológico y Botánico de La Plata, Buenos Aires, Argentina. Los individuos estudiados fueron capaces de recordar las posiciones de los sitios de alimento accesible e inaccesible por períodos de 48 horas, 76 días y hasta 4 meses, utilizando el aprendizaje de conjuntos (o sets de aprendizaje) para minimizar los tiempos de re-aprendizaje frente a un cambio en la estructura espacial aprendida, utilizando la memoria espacial y aumentando su eficiencia de forrajeo. En el capítulo 4 se presentan los resultados de un diseño observacional cualitativo utilizado durante los seguimientos de tres grupos de Cebus apella nigritus = Cebus 
nigritus $=$ Sapajus nigritus $($ Rita $\mathrm{N}=12-19$, Gundolf $\mathrm{N}=20-23$, Macuco $\mathrm{N}=27-32)$ en sus desplazamientos diarios dentro del Parque Nacional Iguazú, Misiones, Argentina. Se evaluaron las cantidades de fruta madura e inmadura presentes en los árboles de fruta que consumen los monos, y se registraron las visitas a los mismos. Las visitas resultaron dependientes de la presencia de fruta y de la cantidad de fruta madurainmadura, indicando que los monos retienen información particular de la ubicación y condición de cada árbol. Por último, el capítulo 5 incluye una comparación teórica de los procesos de memoria espacial de primates humanos y no-humanos, y una conclusión sobre el tema estudiado y los resultados obtenidos en los capítulos 2, 3 y 4. Estos conocimientos son fundamentales para la comprensión del funcionamiento de los mecanismos cognitivos no mediados por el lenguaje, permitiendo un mejor análisis de la base biológica del comportamiento espacial humano y a la vez enfatizando las características de nuestra especie en particular.

\section{Palabras clave:}

Comportamiento Espacial, Memoria, Aprendizaje, Primates No-humanos, Monos Caí, Humanos 


\section{Abstract}

Spatial memory is considered a selective factor in the evolution of intelligence. Animal studies lead us to believe that cognitive processes described in humans have much in common with those of other species. In the case of South American primates, the diversity of fruiting trees and their spatial and temporal distribution have been identified as the major selective force in the development of advanced brain complexities. Foraging behavior is one of the most accessible areas to compared cognitive studies. We studied the foraging spatial behaviour of capuchin monkeys, and its ability to retain information about food location and quality. While spatial memory had been tested previously in this species, these studies evaluated individuals excluded from their social group (as opposed to the context in which this behavior occurs in the wild), or experimental designs inserted by the researcher in the environment, assessing the memory of place and food amounts expected, with no seasonal changes and maturation of resources. During this thesis we studied this behavior of capuchin monkeys in group context, analyzing whether individuals were able to integrate stored information about food sites and changes in the ripening of the resource. Chapter 1 includes a revision of literature on the subject. Throughout chapter 2 we built a partial ethogram of foraging behaviors of monkeys in captivity and in the wild. We compared the results in the course of feeding behavior publications. Chapter 3 presents the experiments performed to evaluate short and long term memory in two groups of Cebus apella paraguayanus $=$ Cebus libidinosus $=$ Sapajus cay $(N=10, N=6)$ in captivity and semi-captivity at the Jardín Zoológico y Botánico de La Plata, Buenos Aires, Argentina. Monkeys were able to remember the positions of accessible and inaccessible food sites for periods of 48 hours, 76 days and up to 4 months using learning sets to minimize re-learning new positions of food after a change in the spatial structure, using spatial memory and increasing their foraging efficiency. Chapter 4 presents the results of a qualitative observational design used for the monitoring of three groups of Cebus apella nigritus $=$ Cebus nigritus $=$ Sapajus nigritus ( Rita N $=12-$ $19, N=20-23$ Gundolf, Macuco $N=27-32$ ) in their daily movements in Iguazú National Park, Misiones, Argentina. We evaluated the amounts of ripe and unripe fruit present in fruiting trees consumed by monkeys. Visits to fruiting trees were dependent on the presence of fruit and the amount of ripe-unripe fruit, indicating that monkeys remember specific information on the location and condition of each tree. Finally, Chapter 5 includes a theoretical comparison of the processes of spatial memory in human and non-human primates, and a conclusion of the results obtained in Chapters 2, 3 and 4. These findings are essential to understand cognitive mechanisms not mediated by 
language, allowing a better analysis of the biological basis of human spatial behavior while emphasizing the characteristics of our species in particular.

\section{Key word}

Spatial Behaviour, Memory, Learning, Non-human Primates, Capuchin Monkeys, Humans 


\section{Capítulo 1: Introducción}

La presente tesis analiza la existencia de habilidades cognitivas vinculadas al espacio de los primates no-humanos alejados de la línea homínida para responder interrogantes acerca del aprendizaje y la memoria en contexto de grupo. En función de esto, se realiza una revisión bibliográfica sobre el tema.

\subsection{Antecedentes sobre los estudios de memoria espacial}

Todos los organismos viven en un mundo en constante cambio, a veces predecible, a veces no. La disponibilidad de pareja, alimento y otros estímulos biológicamente significativos varían en tiempo y espacio. Si estas variaciones ocurrieran de forma predecible, sería beneficioso aprender esa variabilidad espacio-temporal (y recordarla) para poder maximizar la explotación de esos recursos (Thorpe \& Wilkie, 2006). Para cualquier individuo es importante tener la capacidad para almacenar experiencias y beneficiarse de las mismas en el futuro (Ballesteros, 1999).

El interés de los investigadores por estudiar la cognición de los primates deriva de lo que estos estudios pueden revelar sobre la evolución de la cognición de una especie en particular: la especie humana. Es claro que algunos rasgos humanos importantes son más antiguos que el pleistoceno, donde trata de situarse al ancestro modelo de los humanos actuales. Los primates no humanos son una fuente adicional de evidencia disponible y esta evidencia comparativa es de particular importancia para estudios cognitivos, dado que el comportamiento puede ser estudiado de igual forma que la morfología (Byrne, 2000).

El estudio de los procesos de memoria relacionados con la alimentación ocupa gran parte de los esfuerzos de los investigadores en cognición animal (Garber, 2004). Todo individuo debe enfrentar el problema de encontrar cantidades y calidades adecuadas de alimento. Es en este contexto en el cual las formas de búsqueda, localización y obtención del mismo (a lo que llamaremos "comportamiento de forrajeo") ponen en evidencia el nexo entre el organismo y su entorno (incluyendo al resto de los miembros de su grupo), generando la dimensión de comportamiento que caracteriza a cada individuo en particular (Lahitte et al., 2003). Desde los inicios, los estudios de los procesos de memoria han centrado su atención en características vinculadas al lenguaje, requiriendo del uso del mismo para evaluar las capacidades de retención y recuperación posterior (Ballesteros, 1999). En este ámbito, la cognición comparada ha adoptado el marco teórico general que guía el estudio de la memoria humana, distinguiendo entre un sistema de memoria de largo plazo y otros sistemas de 
mantenimiento temporal de la información, como la memoria de corto plazo o la memoria operativa (Aguado Aguilar, 1990).

Cada organismo posee un conjunto de caracteres que son producto de la evolución. Para muchos animales, las habilidades cognitivas son parte de este "arsenal adaptativo". Así la cognición animal puede ser vista como una parte de la biología evolutiva (Lahitte et al., 2003). Se entenderá al término cognición como el conjunto de capacidades que le permiten al individuo la coordinación entre la heterogeneidad ambiental y sus acciones (Godfrey-Smith, 2001), implicando algún tipo de representación interna de la información sensorial externa (Lahitte et al., 2003). El objeto de estudio de las ciencias cognitivas son los mecanismos puestos en juego en la generación de conocimiento (Lahitte \& Ortiz Oria, 2005). En este marco teórico, un animal debe poseer información sobre la estructura espacial y temporal de su entorno (Godfrey-Smith, 2001), la cual será procesada, manipulada y utilizada para su supervivencia (Riba I Campos, 1997; Rehbein et al., 2002; Lahitte et al., 2003). Las modificaciones del comportamiento en respuesta a cambios en el espacio reflejan que el animal posee alguna representación interna o "mapa cognitivo" de la situación espacial que le resulta familiar, que será comparada con la nueva situación desconocida (Gouteux et al., 1999). Ese mapa le permitirá almacenar información relativa de diversos puntos en el espacio durante un tiempo prolongado en la memoria de largo plazo (Chamizo, 1990; Aguado Aguilar, 1990; Godfrey-Smith, 2001) y desarrollar a partir de ésta recorridos novedosos al desplazarse (Bennett, 1996; ver Mackintosh, 2002 para una revisión detallada de las distintas definiciones de mapa cognitivo).

\subsubsection{Un poco de historia}

El estudio de la memoria se ocupa de descifrar cómo la información adquirida en determinado momento influye en el comportamiento futuro. Una vez establecido que los animales son capaces de retener información sobre eventos pasados, surgen una serie de cuestiones interesantes: qué tipo de información pueden retener, cuánta y durante cuánto tiempo. Para poder responder a estas preguntas se distingue entre dos tipos de memoria: una que perdura poco tiempo, influyendo en el aprendizaje asociativo y en la actividad presente del animal, y otra que persiste por períodos largos de tiempo y se adquiere durante el curso de un condicionamiento o la representación de un evento determinado. Los estudios de memoria de largo plazo en humanos han puesto de manifiesto sus dos características más elementales: su capacidad y su duración (Pearce, 1998). La memoria da al ser humano la posibilidad de acumular información y contar con los indicios de la experiencia anterior tras desaparecer los 
fenómenos que la motivaron (Luria, 1979). Estas características también pueden encontrarse en otros animales (Pearce, 1998).

Las primeras etapas de los estudios de la memoria limitaron su atención a la investigación en humanos, centrándose en la actividad mnémica y consciente (Luria, 1979). En los años ochenta del siglo ante-pasado, H. Ebbinghaus (mediante procedimientos de memorización de sílabas sin sentido) dedujo las curvas de memorización del material aprendido, describió las leyes básicas del proceso y estudió la duración de las huellas de la memoria y su extinción gradual. A posteriori, el conocido psiquiatra alemán Krepelin, aplicó los métodos de Ebbinghaus al análisis del proceso de memorización en pacientes con alteraciones psíquicas, mientras que Müller, de manera simultánea, dedicó su investigación a las leyes del afianzamiento y reproducción de las huellas de la memoria en humanos.

Recién a finales del siglo XIX y principios del XX, aparecieron las investigaciones de Thorndike (psicólogo norteamericano), quien estudió el proceso formativo de los hábitos en los animales: cómo el animal aprendía a encontrar su camino en un laberinto y cómo iba afianzando los hábitos adquiridos. Con Pávlov y sus estudios de los reflejos condicionados se lograron observar los principales mecanismos fisiológicos de la formación de nuevas conexiones y las condiciones según las cuales éstas se mantenían. Esta teoría fue la fuente esencial del conocimiento sobre los mecanismos fisiológicos de la memoria. Así, durante el siglo XX se buscó de manera incansable la localización de la memoria o "huella mnémica" en el cerebro. Recién en 1931, el psicólogo soviético L. S. Vygotski demostró que las formas voluntarias y conscientes de memoria, que le permitían al ser humano retornar a voluntad a cualquier etapa del pasado, eran un aspecto complejo de la actividad psíquica, de índole social por su origen (Luria, 1979). Finalmente en 1949 Donald Hebb propuso que no habría una localización específica sino que la memoria estaría formada por un conjunto de neuronas activadas y mantenidas por fortalecimiento de las conexiones celulares. Las memorias se almacenarían de esta forma en distintas cortezas de asociación.

Los resultados de los estudios de la base neurológica de la memoria indican que la excitación neural específica inicial crea cambios temporales en la sinapsis (memoria de corto plazo), mientras que los procesos de memoria de largo plazo resultan de la creación de nuevas proteínas que modifican la capacidad de respuesta permanente de la neurona (Lindsay \& Norman, 1983). Además ha sido posible identificar estructuras cerebrales específicas sin las cuales no podrían formarse algunas memorias: el hipocampo, importante para la codificación, formación y consolidación de la memoria declarativa, la memoria de reconocimiento y la memoria espacial; el diencéfalo con su participación en la instancia intermedia de formación de memoria entre el hipocampo y 
la neocorteza; la neocorteza, donde se almacenarían las memorias formadas en el hipocampo y finalmente la corteza prefrontal que tendría un rol preponderante en la memoria de trabajo.

En la actualidad se considera que en los primates la memoria de experiencias pasadas es mayormente almacenada en la neocorteza cerebral (la parte filogenéticamente más nueva de la corteza del cerebro). El pensamiento sobre la organización cortical de la memoria ha cambiado desde una visión neuropsicológica que localiza distintas memorias en diferentes partes del sistema nervioso hacia una visión de la memoria como una propiedad de los mismos sistemas corticales, esto es redes de neuronas interconectadas, formadas por asociaciones (network memory: Fuster, 1997, Van Strien et al., 2009).

\subsubsection{La memoria: clasificación, definiciones y modelos}

El aprendizaje es un proceso de cambio relativamente permanente en el comportamiento de un individuo como resultado de la experiencia. La memoria será entonces el registro permanente de esa experiencia que subyace al aprendizaje: la impronta neuronal o huella dejada por esa experiencia, un sistema de almacenamiento de información que registra las experiencias para su uso posterior (Bacigalupe, 2012). En este sistema los efectos de una entrada ("input") persisten después de que esa entrada haya terminado, y son recuperables en condiciones aproximadamente iguales o iguales a las condiciones en las que el aprendizaje original ocurrió (Rumbaugh et al., 2007).

Existen varias formas de clasificar a la memoria, las cuales se superponen y entrelazan (Bacigalupe, 2012):

A. Basada en la forma de codificación del "input" y en la duración de la retención (memoria sensorial, de corto plazo y de largo plazo).

B. Basada en el tipo de información (memoria declarativa o explicita que incluye la memoria episódica y la semántica, y por otro lado la memoria de procedimientos, procesal implícita, o no-declarativa).

C. Basada en la dirección temporal (retrospectiva - la capacidad de recordar algo que se planeó en el pasado, y prospectiva - la capacidad de recordar algo que se planeó a futuro). La memoria retrospectiva está incluida en la memoria declarativa, y ambos tipos pertenecen a una clasificación vinculada a la capacidad humana de expresar lo recordado (Tiparu-Ustárroz \& MuñozCéspedes, 2005). 
A.

Pueden describirse 4 modelos de memoria basados en la forma de codificación:

1 - El modelo de Atkinson y Shiffrin (1968), donde un "input" es mantenido en la memoria de corto plazo mediante el ensayo, lo que constituye el proceso para la formación de la memoria de largo plazo. Incluye 3 tipos de memoria: sensorial (icónica / ecóica); de corto plazo o memoria de trabajo; de largo plazo o memoria permanente. 2 - El modelo de Craik \& Lockhart (1972) donde existiría un solo tipo de memoria con diferentes niveles de procesamiento de la información.

3 - El modelo de la memoria de trabajo (Baddeley \& Hitch, 1974) donde existiría un tipo activo de memoria transitoria o de corto plazo que utiliza memorias remotas y estrategias almacenadas en función de un problema específico en determinado momento. Sería un tipo de registro temporario que activa memorias permanentes en un momento específico.

4 - El modelo de la resonancia mórfica (Sheldrake, 2006), donde se interpreta a la memoria en términos de resonancia mórfica (efecto actual de rasgos acumulados en el pasado, medio por el cual la información se transfiere de un sistema anterior a uno posterior del mismo tipo, por ejemplo, dos individuos de la misma especie), constituyendo una alternativa para el conflicto de la localización de la memoria en el cerebro. Si los recuerdos dependen de campos mórficos, no es necesario que se almacenen en un lugar específico, sino que pueden obtenerse por resonancia mórfica del pasado del propio organismo.

B.

La memoria declarativa (explícita o representacional) es la memoria de hechos y acontecimientos y requiere rememoración consciente. Desde la neuropsicología clínica se han distinguido 3 etapas de la memoria declarativa (Lezak, 1995):

1 - Registro o memoria sensorial: proceso de selección y registro en un almacén sensorial, con una duración estimada de 200 a 2.000 milisegundos. La información registrada puede pasar al estado de memoria de corto plazo, o decaer.

2 - Memoria de corto plazo (o memoria primaria): dentro de esta categoría encontramos a la memoria de corto plazo inmediata (30 segundos a varios minutos); sería el primer estado de memoria de corto plazo que mantiene la información en el proceso de registro.

3 - Memoria de largo plazo (o memoria secundaria): involucra un conjunto de procesos que ocurren a nivel celular, incluyendo alteraciones neuroquímicas de las neuronas y de la sinapsis que pueden conducir a diferencias en la cantidad de neurotransmisores liberada y cambios morfológicos de las dendritas para ampliar las 
zonas de contacto. La memoria de largo plazo reciente almacena la información durante horas, días, semanas e incluso meses. La memoria de largo plazo remota, es aquella almacenada de tiempos remotos, como por ejemplo la niñez.

Existe una discordancia desconcertante entre el tiempo asociado a la memoria de corto plazo en los animales no-humanos y seres humanos. Mientras que la memoria de corto plazo, determinada para humanos, generalmente, hace referencia a un tiempo medido en segundos a minutos (aunque no existe un acuerdo universal para estos tiempos), en algunos estudios con animales se plantea que cualquier evento retenido durante las primeras 24 horas hasta 1 o 2 días después de un acontecimiento proviene de la memoria de corto plazo (Lindsay \& Norman, 1983). Algunos autores clasifican esto dentro de la memoria de largo plazo reciente, mientras que cualquier evento retenido más allá del mes de desaparecido el "input" se adjudicará a la memoria de largo plazo remota (Lezack, 1995).

En la memoria declarativa suelen distinguirse a su vez dos grupos diferentes de contenidos: la memoria episódica (eventos o incidentes del pasado de la persona, que implican rememoración consciente) y la memoria semántica (referida al sistema que procesa, almacena y recupera información acerca del significado de las palabras, conceptos y hechos). La memoria no-declarativa incluye a las memorias o vías de adquisición de información cuya recuperación no requiere de un esfuerzo consciente (Bacigalupe, 2012).

\subsubsection{El aprendizaje: clasificación y definiciones}

El aprendizaje tiene un rol fundamental en el desarrollo y la emergencia del comportamiento en diferentes especies y en diferentes situaciones (Papini, 2008). Existen dos amplias categorías de aprendizaje (que no son mutuamente excluyentes, y a veces son muy difíciles de separar):

- el aprendizaje no asociativo, que involucra la experiencia con un evento simple (habituación, sensibilización, impronta).

- el aprendizaje asociativo, entendido como la adquisición, almacenamiento y recuperación de información sobre eventos que ocurrieron en un espacio o tiempo cercanos (condicionamiento clásico, condicionamiento instrumental).

La información aprendida en el aprendizaje asociativo puede influir sobre el comportamiento, aunque no de manera inmediata (por ejemplo animales pre expuestos a un laberinto experimental tienen un mejor rendimiento que animales inexpertos o naive, que no han sido pre expuestos al mismo). 
A su vez se pueden distinguir varias categorías de aprendizaje asociativo (Grier \& Burk, 1992):

- Aprendizaje exploratorio: involucra el uso de la experiencia adquirida previamente para la modificación de una conducta mucho tiempo después. Es particularmente útil para la información espacial.

- Aprendizaje espacial o de lugares: implica la habilidad de orientarse y reorientarse en el espacio. Algunos autores lo consideran un aprendizaje de ensayo y error (habilidad instrumental).

- Aprendizaje observacional o cultural: el animal aprende observando lo que otro hace (facilitación social). Es un tipo de transmisión no genética de la información que, en el caso de primates, es modulado además por la estructura social del grupo (Coussi-Korbel \& Fragaszy, 1995). La dinámica social influencia la probabilidad de aprendizaje social.

- Aprendizaje por formación de conjuntos o sets de aprendizaje: los animales generalizan desde aprendizajes previos y resuelven tareas similares muy rápidamente. Aprenden a aprender una serie de principios o estrategias.

De manera general, pueden describirse tres etapas en el proceso de aprendizaje (Papini, 2008):

1. Adquisición: adquirir información a través de la experiencia.

2. Almacenamiento: trasladar la información adquirida a un registro neuronal más o menos permanente.

3. Recuperación: reactivación de la información previamente almacenada.

Estas etapas se llevan a cabo en un contexto que funciona como sistema de referencia. En el caso del aprendizaje espacial, Potì (2000) explica que hay dos sistemas de referencia que determinan la habilidad de un organismo para localizar objetos: el sistema auto-referenciado (o egocéntrico) y el sistema de referencia externa (o exocéntrica). En el primero la localización de un objeto se especifica en relación al propio cuerpo del individuo. Consta de una forma simple, el aprendizaje de respuesta, basado en la memoria de la posición de objetos con respecto a ejes propios del cuerpo (memoria de las propias acciones), y una forma compleja, el cómputo perfectamente calibrado (dead reckoning), cuando el animal actualiza constantemente la información sobre distancias y direcciones en relación a sus propios movimientos. En el sistema de 
referencia externa, encontramos también una forma simple, el aprendizaje de señales, que implica ubicar un objeto en relación a una marca cercana o distante, y una forma compleja, el aprendizaje de lugar, en donde 2 o más relaciones entre objetos y marcas deben ser computadas. El aprendizaje de lugar ha sido considerado como una forma de mapeo cognitivo.

A continuación se presenta una tabla clasificatoria (Tabla 1.1) de los tipos de aprendizaje según Bateson (1974) y se plantea su relación con los sistemas de memoria:

\begin{tabular}{|c|c|}
\hline 4) & Sistema de Memoria \\
\hline $\begin{array}{l}\text { Aprendizaje } 0 \\
\text { Simple recepción de información que procede de un acontecimiento } \\
\text { externo. Base de todos los actos que no estén sujetos a corrección } \\
\text { por ensayo y error. } \\
\text { Ej.: Exploración inicial de un lugar }\end{array}$ & $\begin{array}{l}\text { Sistema de } \\
\text { almacenamiento de } \\
\text { información sensorial } \\
\text { Imagen detallada de la } \\
\text { información sensorial que } \\
\text { ingresa por algún órgano } \\
\text { de los sentidos al cerebro. } \\
\text { Es retenida por unas } \\
\text { décimas de segundo. }\end{array}$ \\
\hline $\begin{array}{l}\text { Aprendizaje I (Protoaprendizaje) } \\
\text { Cambio en el aprendizaje 0. Casos en que un organismo produce en } \\
\text { un tiempo } 2 \text { una respuesta diferente a la que dio en un tiempo } 1 . \\
\text { Supuesto de mismidad del contexto: el contexto debe ser el mismo en } \\
\text { el tiempo } 1 \text { que en el } 2 \text { (por ejemplo la campana de Pavlov en el } \\
\text { condicionamiento). Sino, todo aprendizaje sería un aprendizaje tipo } 0 . \\
\text { Ej.: } \\
\text { Condicionamiento (pavloviano / instrumental) } \\
\text { Habituación } \\
\text { Aprendizaje espacial o de lugares } \\
\text { Aprendizaje memorístico, en el cual } 1 \text { ítem de conducta del } \\
\text { organismo se convierte en estímulo para otro ítem de conducta. }\end{array}$ & $\begin{array}{l}\text { Sistema de memoria de } \\
\text { corto plazo } \\
\text { La información ya } \\
\text { "codificada" se retiene por } \\
\text { unos segundos, minutos, } \\
\text { tal vez horas. }\end{array}$ \\
\hline 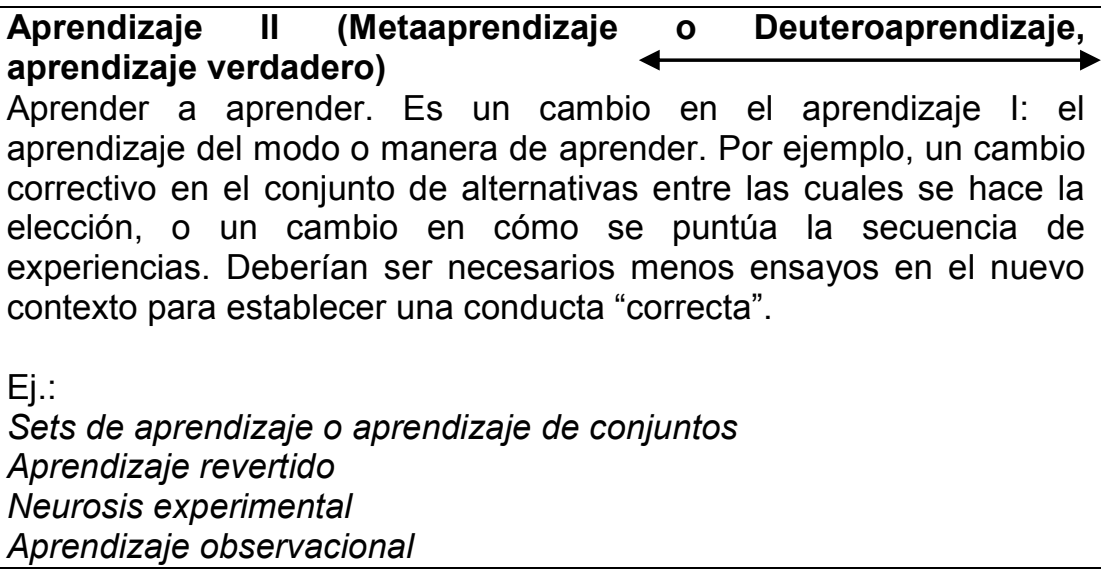 & $\begin{array}{l}\text { Sistema te memoria de } \\
\text { largo plazo } \\
\text { Registros permanentes de } \\
\text { las experiencias. Implica } \\
\text { almacenamiento } \\
\text { recuperación posterior de } \\
\text { la información. }\end{array}$ \\
\hline
\end{tabular}

Tabla 1.1: Tipos de aprendizaje según Bateson (1947), ejemplos y su relación con los sistemas de memoria. 


\subsubsection{El contexto de grupo}

Los primates, comparados con otros mamíferos, poseen cerebros grandes en relación con su tamaño corporal. Pero, ¿Por qué necesitan cerebros tanto más grandes que otros mamíferos que se enfrentan a decisiones de forrajeo semejantes? La hipótesis del cerebro social (basada en la hipótesis de la inteligencia maquiavélica de Byrne \& Whiten, 1988 en Dunbar \& Shultz, 2007) plantea que el punto central de este dilema es el complejo ambiente social en el que los primates viven: los individuos en grupos sociales estables deben enfrentar demandas cognitivas diferentes a aquellos que viven en agregados inestables. A su vez esto tiene un correlato ecológico: las implicancias del aprendizaje social en la adquisición de recursos alimentarios (Dunbar \& Shultz, 2007). Los demás miembros dentro del grupo influencian las decisiones de forrajeo de otros por medio del refuerzo sobre la importancia de determinados objetos o de localizaciones de objetos (o alimento) en el ambiente (Nicol, 1995 en Dunbar \& Shultz, 2007). Un conespecífico que observa a otro puede adquirir información general acerca del momento temporal (a través de la coordinación del comportamiento en el tiempo), de la localización espacial (a través de la coordinación del comportamiento en el espacio) y, a veces, de ambas cosas a la vez. Por medio del monitoreo de la actividad de otros, el individuo observador puede "ponerse al día", distinguiendo y sincronizando sus actividades con las de los demás. Esto ayuda a la cohesión del grupo lo que contribuye, entre otras cosas, a explotar de forma eficiente los recursos. La coordinación del comportamiento en tiempo y espacio implica una proximidad espacial entre individuos. En este tipo de coordinación un individuo se acerca al lugar en que otro se encuentra y se involucra en la misma actividad del demostrador, utilizando el mismo patrón de acciones, o inspeccionando, por ejemplo, lo que el demostrador está consumiendo (Coussi-Korbel \& Fragaszy, 1995).

Podemos distinguir entre dos tipos de aprendizaje social: el aprendizaje social dirigido (ASD) y aprendizaje social inespecífico (ASI). Esta distinción es importante desde el punto de vista biológico porque, mientras el ASI permite la sincronización y homogeneidad del comportamiento, el ASD puede generar diferencias de comportamiento dentro de un mismo grupo pero a la vez aumentar la eficiencia de transmisión de información específica entre determinados individuos. Para demostrar que ha ocurrido ASD debe probarse que la identidad del demostrador influencia la transmisión de información (Coussi-Korbel \& Fragaszy, 1995).

En la teoría de la organización del aprendizaje (Gallistell, 1990 en Thorpe \& Wilkie, 2006), se plantea que cada vez que un evento biológicamente significativo ocurre, se forma un código de memoria que incluye la naturaleza del evento, como también el tiempo y lugar donde este ocurrió. Frente a una nueva necesidad, el animal podrá usar 
esa información almacenada para guiar su comportamiento actual. Podemos explicitar tres modelos que ofrecen explicaciones alternativas (y por qué no complementarias) al aprendizaje en contexto de grupo. El modelo de reforzamiento indirecto (vicarious reinforcement model) sugiere que la recompensa obtenida por el actor de un comportamiento funciona para el que observa como un cebador "motivador". Según este modelo, la observación de un conespecífico que adquiere exitosamente una recompensa refuerza la atención dada al comportamiento observado (Palometo \& Lefebvre, 1985 en Bonnie \& de Waal, 2007). En cambio, el modelo del aprendizaje observacional reforzado (reinforced observational learning model) trata al aprendizaje en contexto social como un caso de aprendizaje individual donde los compañeros sociales pueden afectar la adquisición inicial de un comportamiento novedoso pero, en ausencia de un reforzador positivo para el observador, el comportamiento recientemente adquirido se extinguirá o se reemplazará por otra alternativa (Heyes et.al, 1993 en Bonnie \& de Waal, 2007). Por último, el modelo de aprendizaje observacional basado en la identificación y el vínculo con compañeros sociales (bonding-and-identification-based observational learning) pone su énfasis en la recompensa intrínseca de actuar de la misma forma que otros, especialmente si esos otros son individuos afiliativamente cercanos al actor, con los cuales el actor se identifica (Matsuzawa et al., 2001 en Bonnie \& de Waal, 2007). El hecho de estudiar a un individuo en contexto de grupo puede revelar qué aspectos (si los hay) del comportamiento de forrajeo de los demás miembros del grupo están siendo tomados en cuenta para el comportamiento individual (Janson \& Byrne, 2007).

Según el tipo de dinámica social presente dentro de un grupo, se ha clasificado a los grupos sociales en despóticos (con una marcada jerarquía entre miembros y proximidades espaciales diferenciales) e igualitarios (tolerantes, con proximidad espacial semejantes entre todos los miembros del grupo). Existen grupos con características intermedias, como es el caso de Cebus apella, en donde las relaciones de dominancia existen pero se presentan a la vez subgrupos con tolerancia espacial marcada. En estos subgrupos la coordinación en tiempo y espacio ocurre de forma más frecuente mientras que las coordinaciones solo en tiempo o solo en espacio ocurren de forma igualitaria entre todos los miembros del grupo. En estos grupos sociales deberemos esperar una transmisión de información acerca de comportamientos entre determinados miembros en función de las relaciones sociales pre-existentes (presencia de ASD más que de ASI). La variable "proximidad espacial" puede ser utilizada entonces como una buena medida de las dinámicas sociales entre individuos o entre subgrupos dentro de un grupo (Coussi-Korbel \& Fragaszy, 1995). 


\subsection{La ecología sensorial de los primates en relación a la alimentación}

La eficiencia de forrajeo se relaciona con la capacidad de los individuos de discernir señales precisas del alimento, y de su ubicación en tiempo y espacio (Dominy, 2004). Las modalidades perceptivas varían en función del aparato sensorial de cada especie. Estudios experimentales han revelado diferencias entre las modalidades de estímulos que cada especie percibe, en los rangos dentro de cada modalidad y en la discriminación dentro de esos rangos. Podemos llamar a estas limitaciones sensoriales y comportamentales, la "clausura operacional del objeto de estudio" (Lahitte, 1996; Lahitte et al., 2003). En este sentido es importante no forzar los límites de una especie frente a una tarea arbitraria, sino desvelar la actuación de los procesos cognitivos en situaciones ecológicamente relevantes (Aguado Aguilar, 1990).

Como es sabido, la precisión de los sentidos declina con la distancia. Esta parece ser una excelente razón para que los primates hayan desarrollado la memoria espaciotemporal como un medio adicional para agilizar la localización del alimento. En una detallada revisión sobre el tema, Dominy y colaboradores (2001) analizan cada uno de los sentidos disponibles para la localización y selección del alimento por parte de los primates, y las variaciones a nivel especie en cada caso. Basándose en trabajos sobre Cebus apella, los autores sugieren hablar de "esferas de desarrollo" de los sentidos, definiéndolos como campos que se extienden a diferentes distancias del individuo, según el modo sensorial del que se trate: el sentido del tacto se limita al radio de acción al que lleguen los miembros anteriores, la vista hasta 20 o 30 metros en un contexto de vegetación selvática, 200 metros para el olfato y 2 kilómetros para la audición (utilizada en este caso para escuchar las vocalizaciones referidas a la localización de alimento por parte de congéneres).

La vista ha sido considerada convencionalmente la modalidad sensorial preponderante para el orden Primates, mientras que el olfato ha recibido poca atención en los estudios referentes a las estrategias de localización y selección de alimento. Un estudio reciente con capuchinos silvestres (Cebus nigritus) ha revelado que los mismos no utilizan las señales olfativas de manera eficiente para localizar el alimento ubicado en plataformas experimentales, pero si la información visual (Fichtner Gomes \& Bicca-Marques, 2012). La visión en los primates posee la característica de ser estereoscópica, lo que permite que los movimientos y la profundidad sean detectados de forma precisa. El color es muy importante para la percepción del estado de maduración del alimento, e involucra aspectos como el brillo, la saturación y el matiz. En base a estudios genéticos y morfo-fisiológicos se sabe hoy que los Catarrhinos (primates del Viejo Mundo) poseen una visión tricromática, mientras que entre Platirrinos (primates del Nuevo Mundo) los espectros sensitivos son variables, 
identificándose seis polimorfismos de visión en color: tres formas de visión tricromática (incluyendo la visión normal de humanos) y tres formas de visión dicromática, las seis asociadas con seis combinaciones de fotopigmentos (Pessoa et al., 2000; Thompson, 2000; Dominy, 2004; Jacobs, 2007). En el caso de Cebus, los machos poseen una forma de visión en color en la cual ven como amarillo puro lo que un humano con visión normal vería como verde o rojo, lo cual implica que poseen una forma de dicromatismo. A su vez, las hembras pueden poseer visión dicromática o tricromática (Jacobs, 1996; Jacobs, 1998 en Fragazsy et al., 2004).

Estudios actuales han demostrado que numerosas especies nocturnas utilizan el sentido del olfato para alimentarse, concluyendo que el olfato, el gusto y el tacto parecen superar en importancia a la vista en situaciones en que los individuos se enfrentan a alimentos desconocidos (Krause \& Laska, 2003). Pero en líneas generales, la vista es considerada la llave del éxito a la hora de tomar decisiones alimenticias para los primates diurnos (Drapier et al., 2003). En un estudio a campo, Bicca-Marques y Garber (2004), pusieron a prueba el uso de la información espacial, visual y olfativa en la búsqueda de alimento en 4 especies de primates del Nuevo Mundo: 3 diurnas (dos especies del género Saguinus: $S$. fuscicollis weddelli y $S$. imperator imperator y una de Callicebus: C. cupreus) y una nocturna (Aotus nigriceps). Los autores encontraron que las 4 especies fueron capaces de usar solamente la vista para distinguir entre frutos maduros e inmaduros, pero además Aotus nigriceps y un grupo de Saguinus imperator, fueron capaces de utilizar el olfato en la detección del alimento. Un dato relevante de esta investigación es que para las cuatro especies la información espacial resultó ser igualmente importante. Los autores postularon que la habilidad de representar internamente la localización de los sitios de alimentación (plataformas de experimentación) aumentaba la eficiencia alimenticia a la vez que minimizaba el tiempo y la energía utilizados en la búsqueda al azar. Los resultados de este trabajo indican que, cuando la localización de las plataformas era predecible en el tiempo, tanto las especies diurnas como la nocturna encontraban con éxito los sitios basándose sólo en información espacial.

\subsection{Los estudios de memoria espacial en primates no-humanos}

Las primeras investigaciones sobre memoria espacial en vertebrados se centraron en estudios de roedores en laberintos (Tolman \& Honzik, 1930) y en aves acaparadoras de alimento (para una revisión ver Balda \& Kamil, 2002; Shettleworth, 2001). A diferencia de los experimentos con roedores, los primates han sido testados en situaciones experimentales de laberintos virtuales (Merchant et al., 2004: Macaca mulatta, Pan et al., 2011: Cebus apella). Algunas innovaciones en este ámbito intentan 
reconciliar las diferencias existentes entre los estudios en tres dimensiones con roedores y aquellos en dos dimensiones con primates (para una revisión sobre el tema ver Kelly \& Gibson, 2007). Washburn y Astur (2003) plantean la utilización de laberintos virtuales en tres dimensiones para el estudio del comportamiento espacial de monos rhesus (Macaca mulatta), donde 4 individuos fueron entrenados para utilizar un joystick y mover un cursor en la pantalla hasta llegar a un objetivo al final del laberinto, logrando aprender y resolver la tarea con éxito.

La importancia de que el individuo pueda interactuar con las localizaciones espaciales es evidente. Acorde a este enfoque se han desarrollado trabajos en ambiente natural y en laboratorios (o en cautiverio), encontrando resultados interesantes. Para estudiar la memoria espacial en tamarines (Leontopithecus rosalia), Tarou y Maple (2000) utilizaron una modificación del laberinto radial para roedores, colocando 8 fuentes de alimento con una disposición circular en los árboles del recinto de alimentación. Frente a la presencia constante de alimento en las fuentes, los investigadores encontraron que la precisión en la localización del alimento aumentaba progresivamente. Cuando se invirtió la posición de las fuentes llenas y vacías, esta precisión disminuyó abruptamente. Dado que el experimento controlaba las variables visual y olfativa, los investigadores concluyeron que los tamarines utilizaban la memoria espacial para aumentar la eficacia alimentaria. Se han encontrado resultados similares para monos ardilla (Saimiri sp.) en situación experimental (Sutton, Olthof \& Roberts, 2000; Ludvig et al., 2003) y en gorilas y monos tití del género Callithrix sp. (MacDonald, 1994). El trabajo de Ludvig et al. (2003) es particularmente interesante: los autores evaluaron a 3 individuos de mono ardilla (Saimiri sciureus) en una tarea de memoria espacial de corto y largo plazo en la cual los monos debían recolectar pellets de alimento escondidos en 8 a 20 sitios en la pared de un aparato experimental. Los sitios con pellets estaban intercalados con sitios vacíos, por lo cual los individuos debían utilizar la memoria para recordar los sitios con comida. Los resultados indicaron que la memoria de las posiciones con comida se incrementaba con el paso de los días que los sujetos llevaban interactuando con el diseño.

Numerosos estudios de campo afirman que los primates realizan movimientos directos hacia parches de alimento, de una forma que sugiere la existencia de un propósito en la dirección de los desplazamientos y de mapas mentales del ambiente en el que viven (Oates, 1987; Janson, 1998). Es importante tener presente que, en el uso que cada individuo hace del espacio, el observador realiza un mapeo e infiere a partir de ello la estructura espacial interna del organismo en cuestión (Lahitte et. al, 2005). Como se explicó con anterioridad, los primates se caracterizan por poseer cerebros de gran 
tamaño, importantes habilidades manipulativas y complejas habilidades cognitivas. Esto influye en la manera en que los individuos codifican y usan la información percibida y almacenada. Estudios experimentales han demostrado que los primates son excelentes resolviendo problemas y poseen una gran capacidad para aprender a reconocer patrones de relación entre objetos e individuos (Garber et al., 2012; Völter \& Call, 2012). La habilidad para tomar decisiones o formular estrategias basadas en reconocer estas pautas puede ser usada por los individuos para disminuir la incertidumbre y resolver problemas en ambientes impredecibles (Auersperg et al., 2012). Los estudios en ecología cognitiva se centran en los diferentes desafíos con los que prosimios, primates de Nuevo Mundo, primates del Viejos Mundo, incluyendo grandes simios y humanos se enfrentan ( $y$ se han enfrentado) a ambientes caracterizados por marcados cambios espaciales y temporales en diversos aspectos: disponibilidad de alimento, riesgo de depredación, ambientes sociales cambiantes (Garber, 2004).

La Antropología tradicional ha tendido a pasar por alto a los primates sudamericanos como posibles objetos de estudio, por el hecho de no encontrarse en la rama principal de la evolución homínida, estudiando en cambio, de forma exhaustiva y desde hace décadas, a los primates del Viejo Mundo (Kinzey, 1986, Schmitt et al., 2012). En cuanto al estudio de la memoria espacial, modelos, observación y experimentación en primates del Nuevo Mundo sugieren que la misma explica la detección de comida más que otras señales, como el olfato o la vista (en las introducciones de los capítulos 3 y 4 de esta tesis podrá encontrarse información específica para las especies aquí estudiadas). La memoria espacial se plantea como una de las mayores fuerzas selectivas en la evolución de la inteligencia humana (Milton, 1981, 1988). Un primate (pertenezca o no a la línea homínida) debe integrar conocimiento espacial obtenido del movimiento repetitivo a través de su territorio, como también información sobre la cantidad, calidad y condición del alimento (Cunningham \& Janson, 2007). De esto se deduce que la memoria espacial será necesaria y beneficiosa en períodos en que el alimento sea escaso o se encuentre distribuido de manera heterogénea (Janson, 1996).

\subsubsection{El caso de los capuchinos}

El mono caí o capuchino es una especie de primate diurna con una dieta basada predominantemente de frutos y artrópodos. La distribución y disponibilidad de recursos es el factor que más afecta el tamaño del área de acción de los individuos (Di Bitetti, 2001). En Iguazú, los capuchinos consumen pulpas de frutos de al menos 81 especies diferentes de árboles, enredaderas, arbustos y epífitas. Viven en grupos polígamos 
multimacho-multihembra, generalmente de 7-45 individuos independientes (Janson et al., 2012), con hembras filopátricas. Es una especie que presenta habilidades cognitivas llamativas desde el punto de vista adaptativo en relación a la localización y adquisición de recursos (Visalberghi \& Fragazsy, 1995; Janson, 1998; Visalberghi et al., 2003, Potì et al., 2005), incluyendo el uso de herramientas (Moura \& Lee, 2004, Garber et al., 2012). En estudios de capacidades cognitivas, aprendizaje y memoria, diferentes autores han encontrado que Cebus apella es capaz de un aprendizaje cognitivo (Tavares \& Tomaz, 2000, Rosengart \& Fragaszy, 2003), de abstraer categorías representativas de ubicación espacial (Spinozzi et al., 2002a) y de capacidades perceptivas que priorizan los detalles locales por sobre los globales frente a estímulos homeomorfos (Spinozzi et al., 2002b). Presentan un conjunto de convergencias morfológicas y comportamentales con hominoideos, incluyendo un cerebro alométrico en relación a su peso corporal (semejante al que existe en el género Pan sp.), un incremento en el desarrollo de la neocorteza y un pulgar altamente móvil (Costello \& Fragaszy, 1988 en Clevelan, Rocca, Wendt \& Westergaard, 2003; Fragaszy \& Mitchell, 1990 en Clevelan, Rocca, Wendt \& Westergaard, 2003; Westergaard \& Kuhn, 2001 en Clevelan, Rocca, Wendt \& Westergaard, 2003).

Dadas sus conocidas capacidades cognitivas y manipulativas como también su distancia filogenética con simios y humanos, los capuchinos representan una oportunidad única para analizar las presiones grupales y ecológicas que llevan a las convergencias existentes entre Cebus sp., Pan sp. y Homo sp. (Westergaard, 1998 en Clevelan, Rocca, Wendt \& Westergaard, 2003). D’Amato y Buckiewicz (D’Amato \& Buckiewicz, 1980 en Fragazsy et al., 2004) estudiaron la memoria de los capuchinos (Cebus apella) para recordar dónde habían encontrado previamente alimento, utilizando un ambiente que simulaba un laberinto en $\mathrm{T}$. Luego del entrenamiento los autores encontraron que los monos mostraban una preferencia por el lado del ambiente en el que habían estado los 30 minutos previos a encontrar alimento. Más aun, 4 meses después de la experiencia ( $y$ sin haber vuelto a estar en contacto con el laberinto), todavía seguían demostrando una clara preferencia por ese lado, pasando cerca del 80 \% de su tiempo en esa zona. Rosengart y Fragaszy (2003), investigando el rol de la memoria en la permanencia de objetos, encontraron que los individuos de Cebus apella con los que experimentaron eran capaces de localizar un objeto en una determinada localización (A), pero continuaban buscando en $(A)$ cuando el objeto había sido corrido a un lugar (B). Estos resultados concuerdan con el desarrollo de permanencia de objetos que Piaget adjudica a los niños de 2 años de edad. McGonigle y colaboradores (2003) evaluaron a 7 capuchinos en tareas secuenciales 
de clasificación de estímulos y objetos en un monitor táctil de computadora, concluyendo que Cebus apella demuestra capacidades de organización jerárquica para clasificar objetos acorde a un niño de 6 años de edad, siendo capaces de seleccionar sus propias estrategias cognitivas frente a tareas que demanden utilizar la memoria.

En un artículo publicado en el año 2000, Patrizia Potì realiza un detallado análisis de la capacidad de aprendizaje de esta especie en situación experimental. Encuentra que, a diferencia de los humanos, los capuchinos sólo son capaces de un aprendizaje asociativo simple entre objetos y marcas locales, pero no entre dos o más objetos y marcas. En vida libre, sin embrago, los capuchinos parecen usar información sobre la localización de al menos dos recursos, uno en relación al otro, para decidir una ruta de forrajeo, recordando en qué sitios las retribuciones (en cuanto a cantidad de alimento) son mayores (Garber \& Paciulli, 1997; Janson, 2007). La evidencia experimental de que los capuchinos recuerdan la localización de los recursos alimentarios dentro de su área de acción proviene de una serie de estudios llevados a cabo por Janson y colaboradores dentro del Parque Nacional Iguazú, Argentina (Janson, 1998; Janson \& Di Bitetti, 1997). Utilizando plataformas experimentales con comida los autores demostraron que los monos eran capaces de aprender la ubicación de los sitios de las plataformas y viajar en rutas directas entre ellos. Los experimentos en cautiverio pueden subestimar las habilidades que los individuos poseen en su ambiente natural. Lo ideal es utilizar la combinación de ambos enfoques para el estudio del comportamiento (Janson \& Byrne, 2007).

Resumiendo, los primates sudamericanos son elegidos con mayor frecuencia para el estudio de capacidades cognitivas dada su habilidad para el forrajeo extractivo de comida oculta y para mapear recursos alimenticios en tiempo y espacio (King, 1986 en Fragazsy et al., 2004).

Como observa Urbani (2009), podría resumirse que existe evidencia en cautiverio acerca de que la memoria espacial de los capuchinos se caracteriza por: un uso de información egocéntrica y exocéntrica para localizar la comida, el uso de marcas simples para generar relaciones espaciales entre sitios de comida en el espacio a pequeña escala, patrones de visita a parches de comida que reduce el backtracking (regresar por el mismo camino por el cuál se llegó) y la revisita a sitios agotados, y evidencia de que pueden planear rutas al navegar en espacios de pequeña escala. En vida libre en cambio, existe evidencia de que pueden usar 2 o 3 marcas para localizar sitios de comida y que registran información sobre la presencia o ausencia de una recompensa de alimento en primer lugar y también información sobre cantidades de recompensa baja o alta. A su vez, se ha encontrado que seleccionan el sitio más 
cercano para alimentarse antes de uno lejano con una mayor recompensa (Janson, 2007).

\subsection{El enfoque comparado}

La comparación es una herramienta muy útil para elaborar explicaciones (Lahitte et al., 2012). En palabras de Matt Ridley (2004, p. 17): la semejanza es la sombra de la diferencia. Dos cosas son semejantes en virtud de que difieren de otras; o diferentes en virtud de la semejanza de una con una tercera. A mediados del siglo XX, hablar de mentes animales era una herejía al igual que hablar de instintos humanos. Lo más importante era la diferencia, no la semejanza. Hoy, en cambio, los trabajos de cognición en primates no-humanos nos llegan de la mano de los estudios comparados con humanos, que buscan las similitudes y explicitan las diferencias, dado que las dos son importantes por igual (Maestripieri, 2003).

Pero esta comparación no puede ni debe ser una simple enumeración de connotados caracteres compartidos, como pueden encontrase aún hoy en textos de divulgación (Sapolsky, 2006). El eje para toda comparación es la descripción que nos permita definir estructuras formales, que permitan a su vez establecer grados de similitud/diferencia de manera clara y replicable (Lahitte et al., 2012, Lahitte \& Tujague, 2007).

Con la aparición del libro de David Premack en 1977 "Intelligence in apes and man", se inician en el campo de la Etología una serie de investigaciones referidas a la comparación de las capacidades cognoscitivas entre especies. El texto de Premack profundiza particularmente la investigación de dichas capacidades en chimpancés con el objetivo de obtener - por vía indirecta - una descripción de nuestras propias competencias como otra especie las percibe. Premack instituye la hipótesis según la cual el lenguaje es condición necesaria pero no suficiente para concebir y comparar modos de comunicación social (juego, combate, descubrimiento, sexualidad, etc.). El autor, conjuntamente con Liberman (1996) y Menzel (1973), esboza los primeros protocolos para relevar gramáticas de juego en chimpancés y niños, proponiendo la necesidad de profundizar los relevamientos a campo y cautiverio para dar consistencia a eventuales comparaciones. En este sentido fueron destacables los aportes de Davenport y Rogers (1971), como los de Coway y Weiskrantz (1975), que han demostrado la existencia de asociaciones visuales y táctiles con la asociación visual auditiva para el juego y el combate. Los trabajos de Yeni-Komshian y Benson informan desde el año 1976 sobre las diferencias hemisféricas en los primates superiores análogos a las del ser humano pero menos acentuadas. De todos modos, desconocemos aun si estas diferencias están asociadas o no a una diferencia 
funcional o, en el caso en que lo estuviera, si es comparable a la que encontramos en humanos. Una extrapolación del comportamiento de primates no-humanos al de humanos ( $y$ viceversa) debe llevarse a cabo considerando que todas las especies de primates no-humanos serán interesantes para esto en uno u otro aspecto (Maestripieri, 2003).

\subsection{Objetivos de la presente tesis}

\section{Objetivo general}

Estudiar el comportamiento espacial vinculado a la búsqueda del alimento de los monos caí, Cebus apella paraguayanus = Cebus libidinosus = Sapajus cay y Cebus apella nigritus $=$ Cebus nigritus $=$ Sapajus nigritus (Orden Primate - Familia Cebidae) en contexto de grupo, y su capacidad de retener información sobre la localización y el estado o condición del mismo (memoria espacial), desde la perspectiva de los procesos de memoria descriptos en humanos. Se evaluará a los grupos de manera experimental (cautiverio, Jardín Zoológico y Botánico de La Plata, Buenos Aires, Argentina) y observacional (vida silvestre, Parque Nacional Iguazú, Misiones, Argentina).

\section{Objetivos específicos}

Se presentan a continuación los objetivos específicos que se desarrollaron a lo largo de la tesis tanto en un nivel conceptual y bibliográfico como a partir del trabajo de campo:

1. Elaborar una descripción detallada de los comportamientos de búsqueda y consumo de alimento del mono caí o capuchino en situación de grupo.

2. Comprobar la capacidad del mono caí o capuchino de retener la ubicación de sitios de alimento constantes en el espacio y renovables en el tiempo (diferentes estados de maduración).

3. Evaluar si ese aprendizaje se mantiene a lo largo de diferentes lapsos temporales, determinando si los individuos son capaces de realizar una asociación espacio-temporal de la presencia de alimento apto para ser consumido en los sitios.

4. Estudiar los cambios en la conducta de la especie frente a modificaciones en la ubicación del alimento, por medio del análisis de los patrones de desplazamiento. 
5. Analizar las relaciones espaciales y la dinámica de subgrupos de los individuos durante la búsqueda de alimento para evaluar el rol del contexto grupal en el aprendizaje espacial y la memoria.

6. Determinar qué características del aprendizaje y la memoria descriptas en seres humanos se encontraron al analizar los resultados obtenidos a lo largo de la tesis.

\section{Las hipótesis planteadas fueron las siguientes:}

\section{Capacidad de memoria espacial}

$\mathrm{H} 1$ : los capuchinos retienen la información espacial aprendida en contexto de grupo acerca de la presencia del alimento en localizaciones fijas (o árboles que periódicamente fructifiquen dentro del territorio del grupo) en sus memorias de corto y largo plazo.

Premisa de base: Los cambios de disponibilidad del alimento generarán cambios en el uso del espacio y los movimientos del grupo.

- P1: La performance de memoria individual y grupal se incrementará con el transcurso del tiempo interactuando con los sitios de alimento.

- P2: Los individuos focales aumentarán sus visitas correctas y disminuirán sus visitas incorrectas a medida que aumente el tiempo interactuando con el diseño experimental.

- P3: Luego de transcurridos distintos lapsos de tiempo sin interactuar con los sitios de alimento, la eficiencia adquirida en la utilización de los mismos no cambiará.

H2: Los acercamientos a árboles frutales están determinados por la presencia de fruta en distintas cantidades y estados de maduración.

Premisas de base: los árboles focales difieren en cantidad y estado de maduración de la fruta en el tiempo / la velocidad es una buena medida de la expectativa de los monos en relación a un recurso.

- P1: los intervalos de revisita serán menores a árboles con mayor cantidad de fruta madura.

- P2: el grupo focal aumentará su velocidad a medida que se aproxima a un árbol visitado con anterioridad y que aun presenta fruta.

- P3: el grupo focal visitará con mayor frecuencia y a mayor velocidad árboles con mayor cantidad de fruta en estado maduro. 
H3: La ausencia de cambios inmediatos en la conducta de la especie frente a una situación espacial novedosa demuestra que existe un registro de la situación espacial anterior.

- P1: frente al cambio de posición de los sitios con comida accesible e inaccesible, la performance de memoria inmediata disminuirá.

- P2: frente al agotamiento progresivo de frutos en determinados árboles, las revisitas a los mismos se espaciarán temporalmente para luego dejar de visitar los mismos.

H4: Los individuos tienen la capacidad de memorizar la disposición espacial de más de dos sitios con y sin alimento disponible, integrando esa información en conjunto.

- P1: al invertirse las posiciones espaciales de los sitios accesibles e inaccesibles, re-aprenderán en menor tiempo la nueva situación espacial.

Dinámica espacial del aprendizaje en contexto de grupo

$\mathrm{H} 1$ : El aprendizaje social dirigido influye en la capacidad de memoria individual.

- P1: la performance de memoria individual dentro de un mismo grupo es diferente según las categorías de edad, sexo e individuo.

- P2: existirán patrones de desplazamiento compartidos entre subgrupos dentro de un mismo grupo.

El capítulo 2 incluye la elaboración de un etograma parcial de los comportamientos registrados en los individuos estudiados, mientras que en los capítulos 3 y 4 se analizan las cuestiones puntuales sobre memoria. Finalmente, en el capítulo 5 se reevalúan los resultados obtenidos, integrando los mismos a las cuestiones planteadas en este capítulo introductorio. 


\subsection{Referencias}

Aguado Aguilar, L. 1990. Problemas y métodos de la cognición comparada. En: Aguado Aguilar, L. Cognición comparada. Alianza Editorial, Madrid (Pp.: 17-66).

Atkinson, R. C. \& R. M. Shiffrin. 1968. Human memory: a proposed system and its control processes. Stanford University, USA.

Auersperg, A. M. I., Gajdon, G. K. \& A. M.P. von Bayern. 2012. A new approach to comparing problem solving, flexibility and innovation. Commun Integr Biol., 5(2): 140-145.

Baddeley, A. D. \& G. Hitch. 1974. Working memory. University of Striling, Scotland.

Bacigalupe, M. de los A. 2012. Neurobiología del aprendizaje: enfoque transdisciplinario de la relación sujeto-medio. Editorial Polemos, Buenos Aires.

Balda, R. P \& A. C. Kamil. 2002. Spatial and social cognition in corvids: an evolutionary approach. En: The cognitive animal: empirical and theoretical perspectives on animal cognition. Marc Bekoff, Colin Allen \& Gordon M. Burhgardt (eds). MIT Press: USA (Pp.: 129-134).

Ballesteros, S. 1999. Memoria humana: investigación y teoría. Psicothema, 11 (4): 705-723.

Bateson, G. 1974. Observations of a cetacean community (Pp. 146-167). En: J. McIntyre, ed. Mind in the waters. Charles Scribner's Sons, New York, NY.Bennett, Andrew T. D. 1996. Do animals have cognitive maps? The Journal of Experimental Biology. 199: 219224.

Bicca-Marques, J. C. \& P. Garber. 2004. Use of spatial, visual, and olfactory information during foraging in wild nocturnal and diurnal anthropoids: a field experimental comparing Aotus, Callicebus and Saguinus. Am. J. Primatol. 62: 171-187.

Bonnie, K. E. \& F. B. M. de Waal. 2007. Coping without rewards: socially influenced foraging decisions among brown capuchin monkeys. Animal Cognition. 10: 283-292.

Byrne, R. W. 2000. Evolution of primate cognition. Cognitive Science, 24 (3): 543-570.

Chamizo, Victoria D. 1990. Ratas en el laberinto: memoria espacial y mapas cognitivos. En: Aguado Aguilar, L. Cognición comparada. Alianza Editorial: Madrid (Pp: 177-197).

Cleveland, A., Rocca, A. R., Wendt, E. L. \& G. C. Westergaard. 2003. Throwing behavior and mass distribution of stone selection in tufted capuchin monkeys (Cebus apella). Am. J. Primatol. 61: 159-172.

Coussi-Korbel, S. \& D. M. Fragaszy. 1995. On the relation between social dynamics and social learning. Animal Behaviour. 50: 1441-1453.

Cowey, A. \& L. Weiskrantz. 1975. Demonstration of cross-modal matching in rhesus monkeys, Macaca mulatta. Nueropsychologia. 13:117-120.

Craik, F. I. M. \& R. S. Lockhart. 1972. Levels of processing: A framework for memory research. Journal of Verbal Learning and Verbal Behavior, 11 (6): 671-684.

Cunningham, E. \& C. H. Janson. 2007. Integrating information about location and value of resources in white-faced saki monkeys (Phitecia phitecia). Animal Cognition, 10: 293304. 
Davenport, R. K. \& C. M. Rogers. 1971. Perception of photographs by apes. Behavior, 39 (2-4): 318-320(3).

Di Bitetti, M. 2001. Home-range use by tufted capuchin monkeys (Cebus apella nigritus) in a subtropical rainforest of Argentina. J. Zool. 253: 33-45.

Dominy, J. N., Lucas, P. W., Osorio, D \& N. Yamashita. 2001. The sensory ecology of primate food perception. Evolutionary Anthropology. 10: 171-186.

Dominy, N. 2004. Fruits, fingers and fermentation: the sensory cues available to foraging primates. Integr.Comp.Biol. 44: 295-303.

Drapier, M., Addessi, E. \& E. Visalberghi. 2003. Response of Cebus apella to foods flavored with familiar or novel odor. Int. J. Primatol., 24: 295-315.

Dunbar, R.I.M. \& S. Shultz. 2007. Evolution in the social brain. Science, 317: 1344-1347.

Fichtner Gomes, D. \& J. C. Bicca-Marques. 2012. Capuchin monkeys (Cebus nigritus) use spatial and visual information during within-patch foraging. Am. J. Primatol., 74:58-67

Fortes, A. F. \& H. Merchant. 2004. Comparative and categorical spatial judgments in the monkeys: « high » and «low ». Animal Cognition, 7: 101-108.

Fragaszy, D.M; Visalberghi, E. \& L.M. Fedigan. 2004. The complete capuchin: the biology of the genus Cebus. Cambridge University Press. United Kingdom.

Fuster, J. M. 1997. Network memory. Trends Neurosci., 20: 451-459.

Garber, P. \& L. M. Pacuilli. 1997. Experimental field study of spatial memory and learning in wild capuchin monkeys (Cebus capuchinus). Folia Primatológica. 68: 236-253.

Garber, P. A. 2004. New perspectives in primate cognitive ecology. Am. J. Primatol. 62:133137.

Garber, P. A., Gomes, D. F. \& J. C. Bicca-Marques. 2012. Experimental field study of problemsolving using tools in free-ranging capuchins (Sapajus nigritus, formerly Cebus nigritus). Am. J. Primatol., 74:344-358.

Godfrey-Smith, P. 2001. Environmental complexity and the evolution of cognition. Pp.: 18-21. En: The evolution of intelligence. R. Sternberg and J. Kaufman (eds). Lawrence Erlbaum Associates: USA.

Gouteux, S., Vauclar, J. \& C. Thinus-Blanc. 1999. Reaction to spatial novelty and exploratory strategies in baboons. Animal Learning \& Behaviour. 27 (3): 323-332.

Grier, J. W. \& T. Burk. 1992. Biology of animal behavior ( $2^{\text {da }}$ edición). St. Louis, Missouri. MO: Mosby year book.

Hebb, D. O. 1949. Organization of behavior. New York: Wiley.

Jacobs, Gerald H. 2007. New world monkeys and color. Int. J. Primatol. 28: 729-759.

Janson, C. H. 1996. Toward an experimental socioecology of primates: examples of argentine brown capuchin monkeys (Cebus apella nigritus). Pp.: 309-325. En: Adaptive radiations of neotropical primates. Ed. By Norconk et al. Plenum Press. New York.

Janson, C.H. \& M. Di Bitetti. 1997. Experimental analysis of food detection in capuchin monkeys : effects of distance, travle speed and resource size. Behav. Ecol. Sociobiol. 41:17-24. 
Janson, Charles H. 1998. Experimental evidence for spatial memory in foraging wild capuchin monkeys, Cebus apella. Animal Behaviour. 55: 1229-1243.

Janson, C.H. 2007. Experimental evidence for route integration and strategic planning in wild capuchin monkeys. Animal Cognition, 10: 341-356.

Janson, C.H. \& R. Byrne. 2007. Review: What wild primates know about resources: opening up the black box. Animal Cognition, 10: 357-367.

Janson C. H., Baldovino M. C. \& M. S. Di Bitetti. 2012. The group life cycle and demography of brown capuchin monkeys (Cebus [apella] nigritus) in Iguazú National Park, Argentina. Pp.: 185-212. En: Kappeler PM, Watts DP, editors. Long-Term Field Studies of Primates. Heidelberg: Springer.

Kelly, D. B. \& B. M. Gibson. 2007. Spatial navigation: spatial learning in real and virtual environments. Comparative Cognition and Behavior Reviews, 2: 111-124.

Kinzey, W. G. 1986. New world primate field studies: What's in it for anthropology? Ann. Rev. Anthropol. 15:121-148.

Krause, S. \& M. Laska. 2003. Which senses play a role in squirrel monkeys food choice? Folia Primatol. 74: 179-230.

Lahitte, H.B; Ferrari, H. R.; Ortiz Oria, V. \& L. C. Lázaro. 2003. Sobre la conducta como articulación individuo-entorno ( $2^{\circ}$ edición). Vol. III. Kliczkowsky Ediciones. Buenos Aires.

Lahitte, H. B \& V. Ortiz Oria. 2005. El Otro: Antropología del Sujeto. Editorial Nobuko. Buenos Aires.

Lahitte, H.B; Ferrari, R.H \& L.C. Lázaro. 2012. Etogramática: teoría y práctica de la descripción en ciencias del comportamiento. $2^{\mathrm{a}}$ edición. Buenos Aires. Editorial Nobuko. Buenos Aires.

Lahitte, H. B. \& M. P. Tujague. 2007. El conocimiento etológico como fantasma de la biología y su importancia para los estudios comparados. Revista Antípoda, 5: 317-332.

Lezak, M. 1995. Neuropsycological Assessment. (3rd edition). USA: Oxford.

Liberman, A. M. 1996. Speech. Cambridge. M. A: The MIT Press.

Lindsay,P.H. \& D.A.Norman. 1983. Introducción a la Psicología Cognitiva. Editorial Tecnos: Madrid.

Ludvig, N., Tang, H. M., Eichenbaum, H. \& B. C. Gohil. 2003. Spatial memory performance of freely-moving squirrel monkeys. Behavioural Brain Research. 140: 175-183.

Luria, A. R. 1979. Breviarios de conducta humana $N^{\circ}$ 12: atención y memoria. Ed. Fontanella, Barcelona.

MacDonald, S. E. 1994. Gorillas'(Gorilla gorilla gorilla) spatial memory in a foraging task. J. Comp. Psychol. 108 (2): 107-113.

Mackintosh, N. J. 2002. Do not ask whether they have a cognitive map, but how they find their way about. Psicológica, 23: 165-185.

McGonigle, B., Chlamers, M. \& A. Dickinson. 2003. Concurrent disjoint and reciprocal classification by Cebus apella in seriation tasks: evidence for hierarchical organization. Animal Cognition. 6: 185-197. 
Maestripieri, D. 2003. Primate Psychology. Harvard University Press, Cambridge.

Menzel, E. W. 1973. Chimpanzee spatial memory organization. Science. 182: 943-945.

Merchant, H., Fortes, A. F. \& A. P. Georgopoulos. 2004. Short-term memory effects on the representation of two-dimensional space in the rhesus monkeys. Animal Cognition. 7: 133-143.

Milton, K. 1981. Distribution patterns of tropical plant foods as an evolutionary stimulus to primate mental development. American Anthropologist, 83: 534-548.

Milton, K. 1988. Foraging behaviour and the evolution of primate intelligence. En R. Byrne \& A. Whiten (Eds.), Machiavellian intelligence (pp. 285-305). Oxford, Uk: Oxford University Press.

Moura, A. C. de A. \& P.C. Lee. 2004. Capuchin stone tool use in Caatinga dry forest. Science, 306: 1909.

Oates, John F. 1987. Food distribution and foraging behaviour. En: Primates Societies. B. B. Smuts, D. L. Cheney, R. M. Seyfarth, R. W. Wrangham \& T.T. Struhsaker (eds). The University of Chicago Press (pp. 197-209).

Pan, J., Kennedy, E. H., Pickering, T., Menzel, C.R., Stone, B. W. \& D. M. Fragaszy. 2011. Development of maze navigation by tufted capuchins (Cebus apella). Behav Processes. 86 (2): 206-215.

Papini, M. (2008). Comparative Psychology: evolution and development of behavior $\left(2^{\text {nd }}\right.$ Edition). Psychology Press: New York.

Pearce, J. M. 1998. Aprendizaje y cognición. Ed. Ariel Psicología, Buenos Aires.

Pessoa, V. F., Gomes, U., Tavares, M. C. H. \& C. Tomaz. 2000. Colour perception in the South American Monkey Cebus apella: behavioural evidence of trichromaticity. Folia Primatol. 71: 189-248.

Potì, P. 2000. Aspects of spatial cognition in capuchins (Cebus apella): frames of reference and scale of space. Animal Cognition. 3: 69-77.

Potì, P.; Bartolommei, P. \& M. Saparoti. 2005. Landmark use by Cebus apella. Int. J. Primatol., 26 (4): 921-945.

Premack, David. 1977. Intelligence in Ape and Man. Lawrence Erlbaum Assoc Inc.: New Jersey.

Rehbein, L. \& Mark B. Moss. 2002. Explorations of three modes of spatial cognition in the monkeys. Psichologica. 23: 139-163.

Riba I Campos, Carles. 1997. El pensamiento animal a la luz de la comunicación. Pp: 113-155. En: Pelaéz del Hierro F. \& J. Vea Baró. Etología: bases biológicas de la conducta animal y humana. Ediciones Pirámide. Colección "Psicología", Madrid.

Ridley, Matt. 2004. Qué nos hace humanos. Editorial Taurus: Madrid.

Rosengart, C. R. and D. M. Fragaszy. 2003. The role of memory in an object performance task in capuchin monkeys, Cebus apella. Am. Journal of Primatology. 60: 33-148. 
Rumbaugh, D. M., King, J. E., Beran, M. J., Washburn, D. A. \& K. L. Gould. 2007. A salience theory of learning and behavior: with perspectives on neurobiology and cognition. Int $J$ Primatol, 28: 973-996.

Sapolsky, R. M. 2006. The naked ape. Foreign Affairs, New York. Vol.85, pg 104.

Schmitt V., Pankau, B. \& J. Fischer. 2012. Old world monkeys compare to apes in the primate cognition test battery. PLoS ONE 7(4): e32024. doi:10.1371/journal.pone.0032024

Shettleworth, S. J. 2002. Spatial behaviour, food storing and the modular mind. Pp.: 123-128. En: The cognitive animal: empirical and theoretical perspectives on animal cognition. Marc Bekoff, Colin Allen \& Gordon M. Burhgardt (eds). MIT Press: USA.

Sheldrake, R. 2006. La presencia del pasado: resonancia mórfica y hábitos de la naturaleza ( $3^{a}$ edición). Editorial Kairós. Barcelona.

Spinozzi, G., Lubrano, G. and V. Truppa. 2002a. The categorical representation of spatial relations by tufted capuchin monkeys. Folia Primatologica. 73: 297-337.

Spinozzi, G., Truppa, V. and C. de Lillo. 2002b. Perceptual processing of hierarchical visual stimuli in tufted capuchin monkeys, Cebus apella. Folia Primatologica. 73: 297-337.

Sutton, Olthof \& Roberts. 2000. Landmark use by squirrel monkeys (Saimiri sciureus). Animal Learning and Behavior. 28: 28-42.

Tarou, L. R \& T. L. Maple. 2000. The use of spatial memory in foraging by a group of captive golden lion tamarins (Leontopithecus rosalia). Am. Journal of Primatology. 51 (1): 1-20.

Tavares, M.C.H and C. Tomaz. 2000. Cognitive learning and declarative memory in capuchin monkeys (Cebus apella). Folia Pirmatologica, 71: 189-248.

Thompson, Evan. 2000. Comparative Color Vision: Quality Space and Visual Ecology. In: Steven Davis (Eds). Color Perception: Philosophical, Psychological, Artistic and Computational Perspectives. Pp. 163-186. Vancouver Studies in Cognitive Sciences. Oxford University Press.

Thorpe, C.M. \& D.M. Wilkie. 2006. Chapter 12: Properties of time-place learning. En: Comparative Cognition: Experimental Explorations of Animal Intelligence. Edward A. Wasserman \& Thomas R. Zentall (Eds). Oxford University Press: USA (Pp.: 229-245).

Tirapu-Ustárroz, j. \& J. M. Muñoz-Céspedes. 2005. Memoria y funciones ejecutivas. Rev. Neurol., 41 (8): 475-484.

Tolman, E. C \& Honzik. 1930. Introduction and removal of reward, and maze performance in rats. University of California Publications in Psychology. 4: 257-275.

Urbani, B. 2009. Spatial mapping in wild White-faced capuchin monkeys (Cebus capucinus). PhD Dissertation. University of Illinois at Urbana-Champaign.

Van Strien, N. M., Cappaert N. L. M. \& M. P. Witter. 2009. The anatomy of memory: an interactive overview of the parahippocampal-hippocampal network. Nature, 10: 272282.

Visalberghi, E. \& D. Fragaszy. 1995. The Behaviour of capuchin monkeys, Cebus apella, with novel food: the role of social context. Animal Behaviour. 49: 1089-1095. 
Visalberghi, E. \& D. Fragaszy. 1996. Pedagogy and imitation in monkeys: yes, no or maybe? En D. Olsen (Ed.), Handbook of psychology in education: new models of learning, teaching, and schooling (pp. 277-301). New York: Black-well.

Visalberghi, E.; C.H. Janson \& I. Agostini. 2003. Response toward novel food and novel objects in wild Cebus apella. Int. J. Primatol., 24 (3): 653-675.

Völter, C. J. \& J. Call. 2012. Problem solving in great apes (Pan paniscus, Pan troglodytes, Gorilla gorilla, and Pongo abelii): the effect of visual feedback. Animal Cognition, 15 (5): 923-936.

Vygotzki, L. S. 1931. Historia del desarrollo de las funciones psíquicas superiores (Obras escogidas No. III). Visor Distribuciones S.A., Madrid.

Washburn, D. A. \& R. S. Astur. 2003. Exploration of virtual mazes by rhesus monkeys (Macaca mulatta). Animal Cognition, 6: 161-168.

Yeni-Komshian, G. H. \& D. A. Benson. 1976. Anatomical study of cerebral asymmetry in the temporal lobe of humans, chimpanzees and rhesus monkeys. Science. 192: 387-389. 


\section{Capítulo 2: Análisis descriptivo de la conducta}

\subsection{Resumen}

La conducta es el nexo entre el organismo y el ambiente, donde un observador recorta esquemas de acción que, por repetición y redundancia, le permitirán extraer actos de conducta. La descripción de las conductas observadas es un proceso complejo formado por tres fases: la observación, el registro y la descripción a partir del registro. Se observaron, registraron y describieron las conductas de 2 grupos de monos caí en cautiverio y 3 grupos en vida libre, y se construyó un etograma parcial constituido por 74 pautas de conducta vinculadas a la búsqueda, localización y consumo del alimento. Se realizó una comparación de los resultados obtenidos en el marco de las publicaciones de etogramas parciales sobre comportamiento alimentario en capuchinos, concluyendo el registro de 12 pautas que ya han sido reportadas para capuchinos y el aporte de pautas novedosas no publicadas hasta la actualidad.

\subsection{Introducción}

Toda investigación debe iniciarse con la descripción y el ordenamiento de los fenómenos a estudiar (Eibl-Eibesfeldt, 1979). La descripción de las conductas observadas no es un proceso sencillo ya que se trata de una problemática en la cual se distinguen al menos tres fases: la observación, el registro y la descripción a partir del registro (Lahitte et al., 2012). Lo que un individuo hace es percibido por el observador como una serie de cambios de la disposición del cuerpo del animal en el espacio (Lahitte et al., 1998), y es de ese flujo ininterrumpido de acción que el observador recorta series de movimientos o esquemas de acción (EA) a los que identifica como movimientos, cambios posturales o de otro tipo, del organismo con respecto al entorno. Cuando ese mismo observador, por repetición y redundancia, extrae de ese EA conjuntos de rasgos constitutivos (o patrones, Manning \& Dawkins, 1992) se hablará de un acto de conducta (AC) que expresará una determinada calidad de relación o acople organismo/entorno. En la descripción de la conducta se apela a la regularidad (redundancia) y a las distinciones para llamar Acto $A$ a determinado conjunto de cambios de posiciones, siendo siempre éste el punto de vista humano del quehacer animal. Así, se hace ciencia desde las descripciones y es de esa descripción de base desde la que se construirá el tipo de ciencia que se hará (Lahitte et al., 2012). Partiendo del propio marco conceptual (conjunto de informaciones y creencias del observador) se decide qué cosa es un acto y se interpreta a través de un esquema de acción. Debe hacerse explícito en detalle qué cosa hace el observador de la conducta, cómo lo hace (por ejemplo, las técnicas de observación y registro) y desde qué 
conceptos. Esto será el recorte a utilizar, que debe ser explícito para que las conclusiones puedan ser entendidas por quien las lea.

Finalmente, valiéndose de esas pautas de conducta el observador construye un etograma o listado parcial de pautas para determinada especie en determinado momento y lugar (Eibl-Eibesfeldt, 1979). En el etograma el lenguaje científico es el código, donde pueden aislarse 3 elementos (Lahitte et al., 1993):

1. los descriptores: términos desprovistos de contenido simbólico que surgen de la reducción del observable a sus componentes.

2. los rasgos: elementos diferenciados que cualifican al descriptor.

3. Ios atributos: elementos que cualifican al rasgo.

Estos descriptores, rasgos y atributos son componentes del análisis descriptivo que se utilizan para dar cuenta de los cambios que se observan en el individuo estudiado. Se aislarán a partir de 3 reglas que orientan la descripción, a saber:

- Orientación: explicitación de la posición del observador con respecto al observable.

- Segmentación: reducción del observable a sus componentes.

- Diferenciación: consideración de cada segmento como un ítem que puede ser evaluado en sus posibles valores.

El etograma es así la elaboración de una entidad semiótica, la construcción de un lenguaje que supone un código explícito donde cada acto es un signo que sustituye a lo observado, y como tal puede ser situado en 3 dimensiones: sintáctica, semántica y pragmática. Estos signos podrán ser ubicados en la categoría de símbolos cuando otro observador, repitiendo los procedimientos del primero, llegara a distinciones semejantes (Bateson, 1985; Lahitte et al., 2012).

Las palabras conducta y comportamiento suelen usarse de manera equivalente. Para esta tesis se entenderá a la conducta como las secuencias de actos que el observador ha de especificar en su observación, mientras que el comportamiento será considerado una categoría más abarcativa que tipificará a una serie de secuencias de actos de conducta (Lahitte et al., 1993). Maturana (1982) define a la conducta como los cambios de posición o de forma del organismo con respecto al medio, una relación entre el organismo y el medio en el cual un observador lo distingue y contempla. Así es como la entenderemos a lo largo de esta tesis. 


\subsection{Métodos}

\subsubsection{Observación y registro}

Para la Etología, la conducta es el nexo entre el organismo y el ambiente, sea este la copa de un árbol o una jaula. En cautiverio existe una ausencia de determinados estímulos (presencia de depredadores, determinados alimentos disponibles, áreas de acción de tamaños mayores en las cuales desplazarse, etc.). Esto ocasionará la ausencia o el redireccionamiento de determinadas conductas como también la aparición de pautas novedosas, dado el ambiente simplificado (o con estímulos diferentes a aquellos encontrados en vida silvestre, lejos de la interacción directa con humanos). La observación de la conducta de los sujetos en vida libre permite comprender muchos comportamientos que en cautiverio carecen de una función aparente (Lahitte et al., 2012).

Los referentes sobre los que se realizaron las observaciones fueron dos grupos de monos caí (Cebus apella paraguayanus = Cebus libidinosus = Sapajus cay) alojados en el Jardín Zoológico y Botánico de La Plata (ver capítulo 3) y tres grupos de monos caí silvestres (Cebus apella nigritus = Cebus nigritus = Sapajus nigritus) dentro del Parque Nacional Iguazú (ver capítulo 4). La inclusión de dos subespecies (o especies) diferentes se debió a cuestiones meramente operativas: el sitio de estudio de capuchinos en Iguazú ofrecía todas las posibilidades (grupos de monos ya habituados a los investigadores, sistemas de sendas para hacer posibles los seguimientos continuos, etc.) y la trajectoria de trabajo con la especie necesario para llevar a cabo la investigación. A su vez, los caí alojados en zoológicos son en la mayoría de los casos provenientes de la región de Salta y Jujuy, por lo cual encontrar individuos de C. apella nigritus en cautiverio es extremadamente raro. En la sección de discusión de este capítulo podrá apreciarse que aun entre especies diferentes, el comportamiento de los capuchinos tiene numerosos puntos en común, aunque no por esto debemos dejar de resaltar que se ha trabajado con dos subespecies (o especies) diferentes.

Se elaboró el etograma parcial de las conductas de búsqueda, localización y consumo del alimento en los individuos de estudio (Lahitte et. al, 2003; Lahitte et. al, 2005). Otras conductas fueron observadas, registradas y definidas pero las mismas se adjuntaron en el Anexo I para ser consultadas en caso de necesidad, dado que excedían los fines de comprensión de la temática de la tesis. La observación en vida libre fue de gran utilidad para poder interpretar determinadas observaciones en cautiverio, permitiéndo encontra el sentido a pautas que parecían no tenerlo (por ejemplo frotarse con cebolla o lavandina podría considerarse un redireccionamiento del ya descripto comportamiento de fricción de pelos o fur rubbing). 
Se identificó a cada individuo por los siguientes indicadores: sexo, edad, patrón de coloración y facciones del rostro. Para realizar las observaciones se utilizaron las técnicas de observación Ad Libitum y animal focal (Altmann, 1974), realizando éstas con binoculares y a ojo descubierto. Los registros se llevaron a cabo por medio de notas y planillas, de forma continua y por períodos (Martin \& Bateson, 1986), complementando el registro con un soporte fotográfico (Cámara Digital Canon PowerShot S5IS) y fílmico (Filmadora Panasonic VHS AM 9000 / Cámara Digital Canon PowerShot S5IS), para acompañar la descripción de manifestaciones no verbales a través de un código digital (Lahitte et al., 1998).

En primer lugar se realizó la descripción de los dos ambientes correspondientes a las observaciones en cautiverio y semi-cautiverio: el ambiente Jaula (Figuras 2.1 y 2.4 ) y el ambiente Isla (Figuras 2.2 y 2.5). El ambiente jaula mide 14,8 metros de largo por 4 de ancho, y 2 metros de altura. El mismo se encuentra dividido en dos zonas A y $B$, cada una de $6 \mathrm{~m} \times 4 \mathrm{~m}$ separadas por una puerta guillotina, y dos lugares de dormidero techados de 2,80 m x $4 \mathrm{~m}$ cada uno, a ambos lados de A y $\mathrm{B}$. La isla donde se ubicaban los individuos es una isla artificial distribuida, junto con otras islas pequeñas, en el lago del Zoológico de La Plata. La misma mide 40 metros de ancho por 110 metros de largo, y se encuentra a una distancia de entre 5 a 10 metros de la costa. Dentro del ambiente se ubican dos dormideros de madera a 1,5 metros sobre el nivel del suelo, una plataforma de alimentación a la misma altura, restos de un puente viejo y árboles de diferentes especies: un eucalipto de más de 10 metros de altura, 3 palmeras, y varios ejemplares de Ácer, Acer negundo L., Familia Aceráceas, ligustro, Ligustrum lucidum W.T. Aiton, Familia Oleáceas, y tipas, Tipuana tipu (Benth) Kuntze, Familia Leguminosae o Fabaceae. Las posibles ubicaciones del observador para colectar los datos en ambos ambientes fueron dos, que se marcan en ambos gráficos como Lado $A$ y Lado $B$ (ver Figuras 2.4 y 2.5). En la isla, se realizaron también observaciones desde el bote a remo que se utilizaba para acceder a la misma a instalar el diseño. 


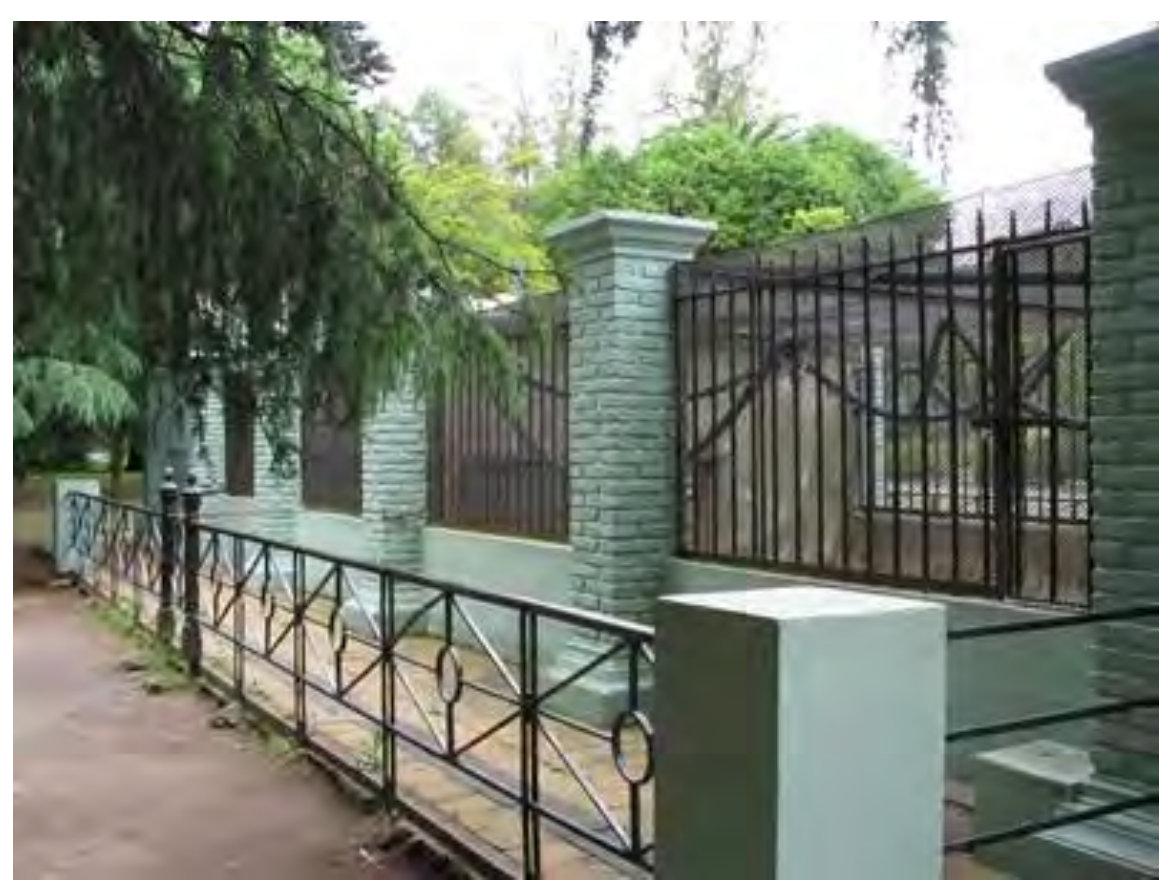

Figura 2.1: Ambiente Jaula (M. P. Tujague)

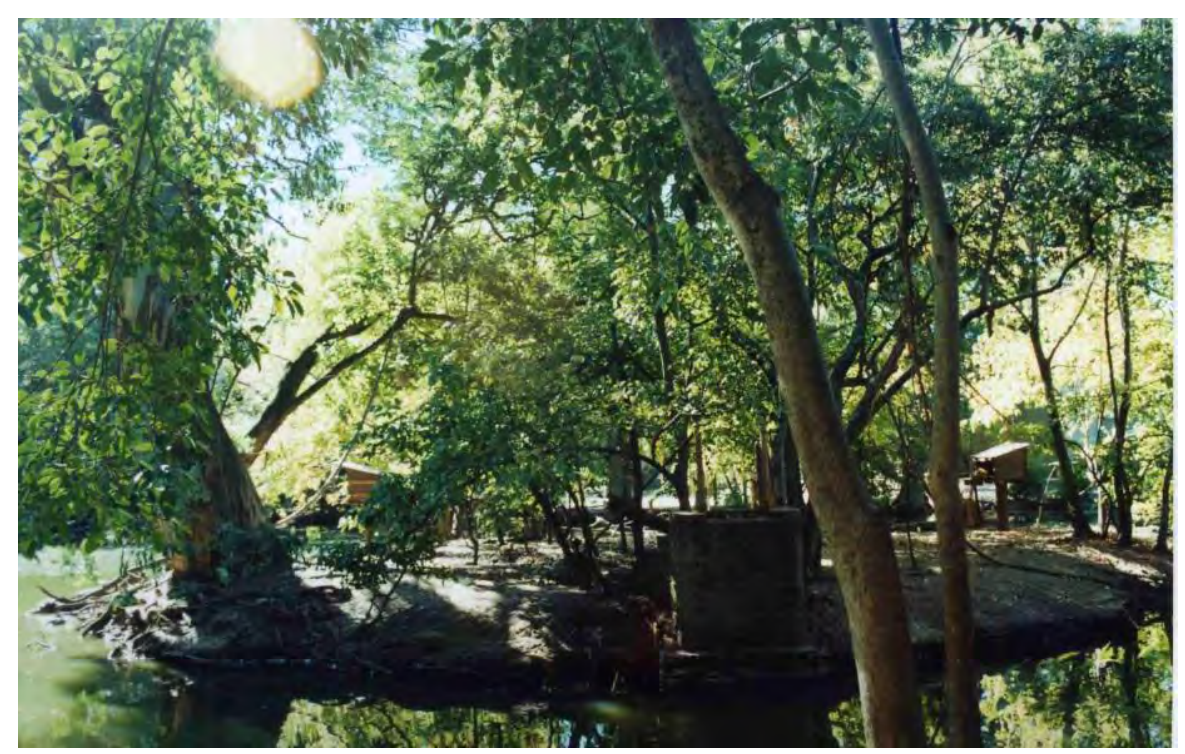

Figura 2.2: Ambiente Isla (M. P. Tujague)

Las observaciones en vida libre se llevaron a cabo dentro del Parque Nacional Iguazú ubicado en la provincia de Misiones, Argentina ( $25^{\circ} 40^{\prime \prime} \mathrm{S}, 54^{\circ} 30^{\prime \prime} \mathrm{O}$ ), mediante el seguimiento de grupos de caí a través de un sistema de sendas abiertas a machete (Figuras 2.3 y 2.6). El Parque Nacional Iguazú comprende una porción de selva subtropical semidecidua o selva Paranaense caracterizada por un clima subtropical húmedo, carente de estación seca (Brown \& Zunino, 1990). 


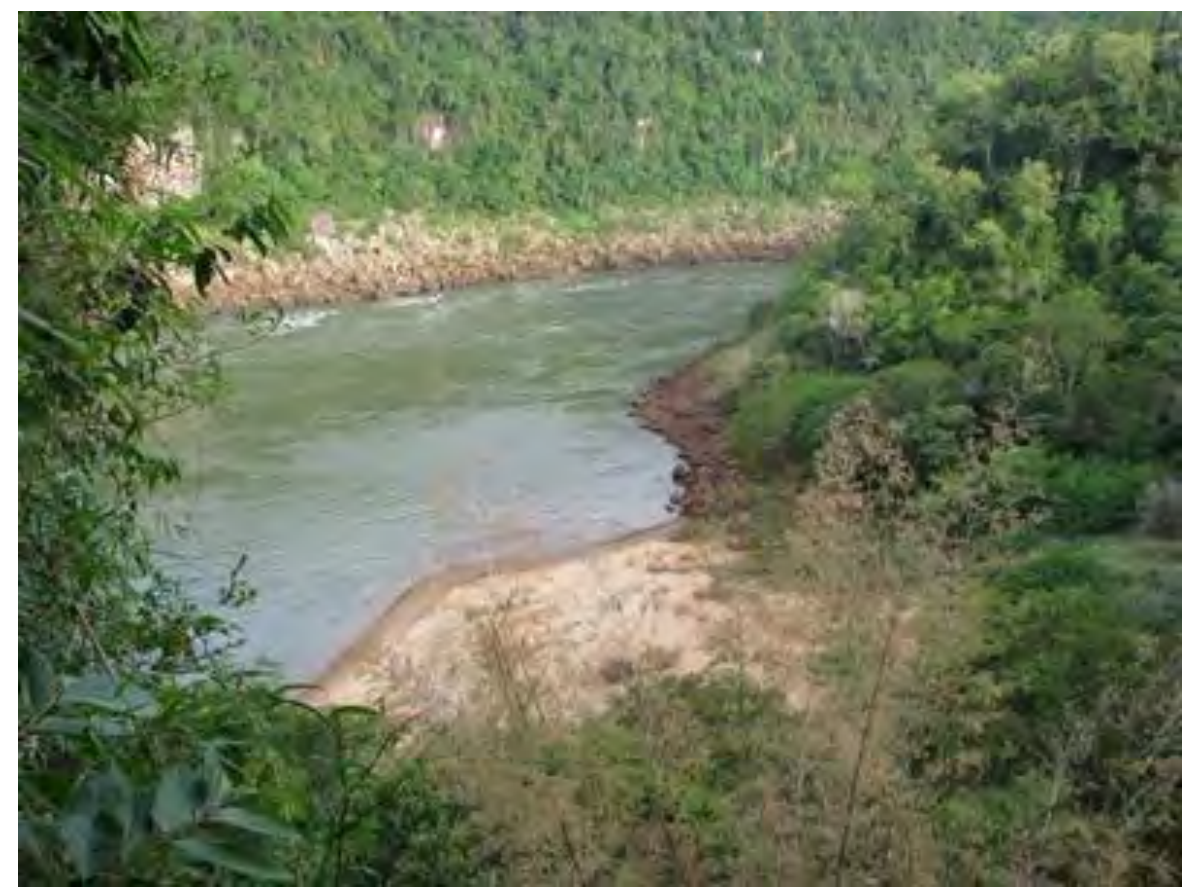

Figura 2.3: Selva Paranaense, Parque Nacional Iguazú (M. P. Tujague)

Se realizaron un total de 80 horas de observación Ad Libitum y 60 horas de observación de animal focal en los dos ambientes del zoológico entre 2007 y 2010, y 2080 horas de observación de campo entre 2008 y 2011 (un total de 204 días de seguimiento de los grupos) dentro del Parque Nacional Iguazú.

Las observaciones en ambos sitios cubrieron todos los horarios del día. En el zoológico se realizaron por bloques durante la mañana, mediodía, tarde y atardecer, balanceando las horas para obtener la misma cantidad en cada momento. Dado que el alimento era introducido por el personal del zoológico durante la mañana, se procedió a priorizar este horario en el caso del grupo Jaula que no poseía acceso a ningún otro recurso, mientras que en el grupo Isla los individuos también se alimentaban de insectos y brotes disponibles en el ambiente, por lo cual las pautas de alimentación eran también frecuentes por la tarde.

En vida silvestre los seguimientos fueron continuos, desde el amanecer (los observadores arribaban antes de la salida del sol al sitio dormidero donde el grupo de monos había finalizado su recorrido la noche anterior) hasta el anochecer (cuando el segundo grupo de observadores que habían seguido a los monos desde el mediodía arribaba junto con ellos al nuevo sitio dormidero). 


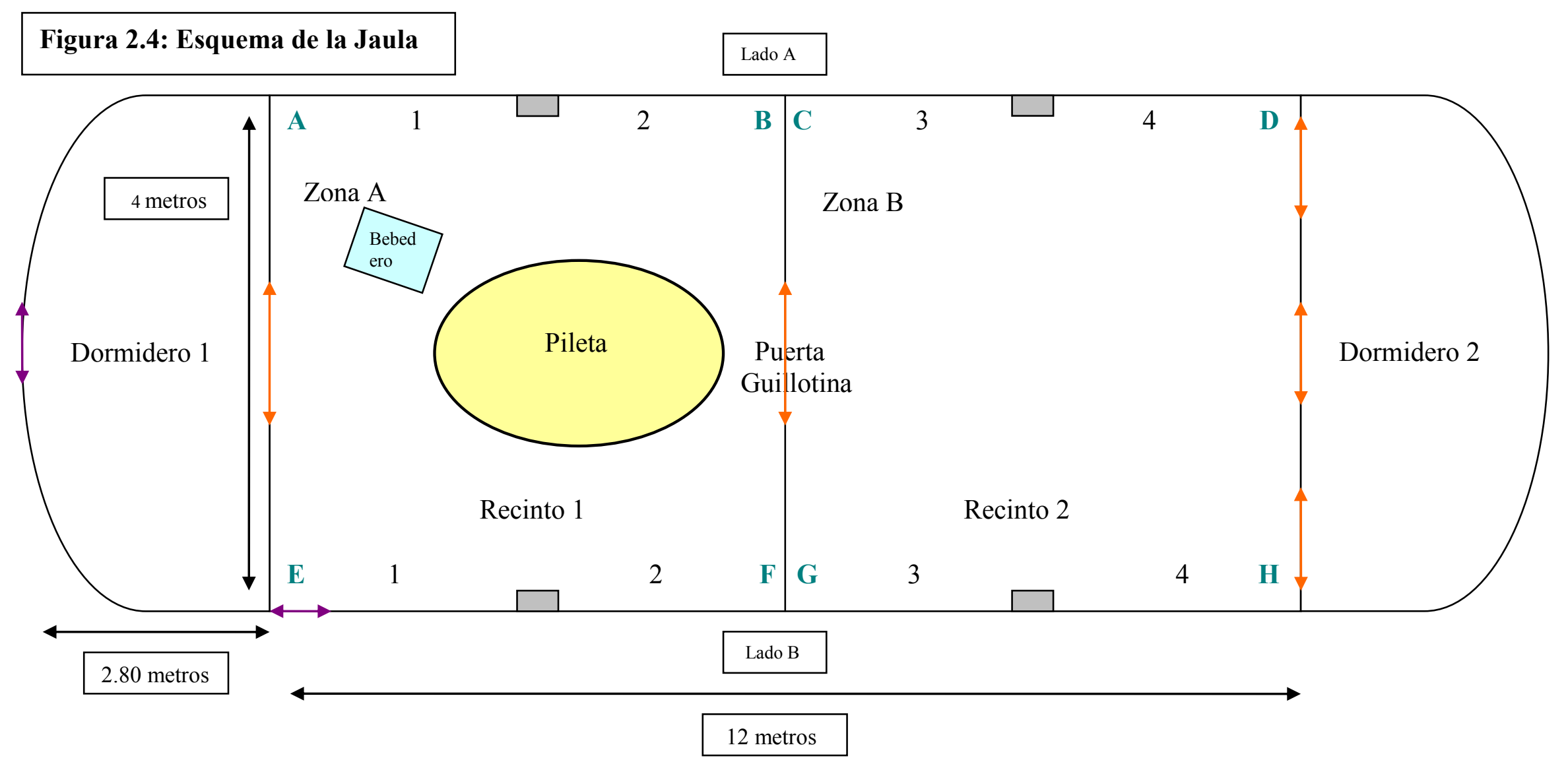

Referencias

Puertas de acceso para cuidadores.

1 a 4: división de rejas laterales.

Puertas acceso a dormideros y puerta divisoria Recinto 1 - Recinto 2.

Columnas laterales.

Altura del recinto: 2 metros.

Incluye troncos laterales y diagonales a 1 metro de altura, y sogas cruzando entre los lados. 
Figura 2.5: Esquema de la Isla

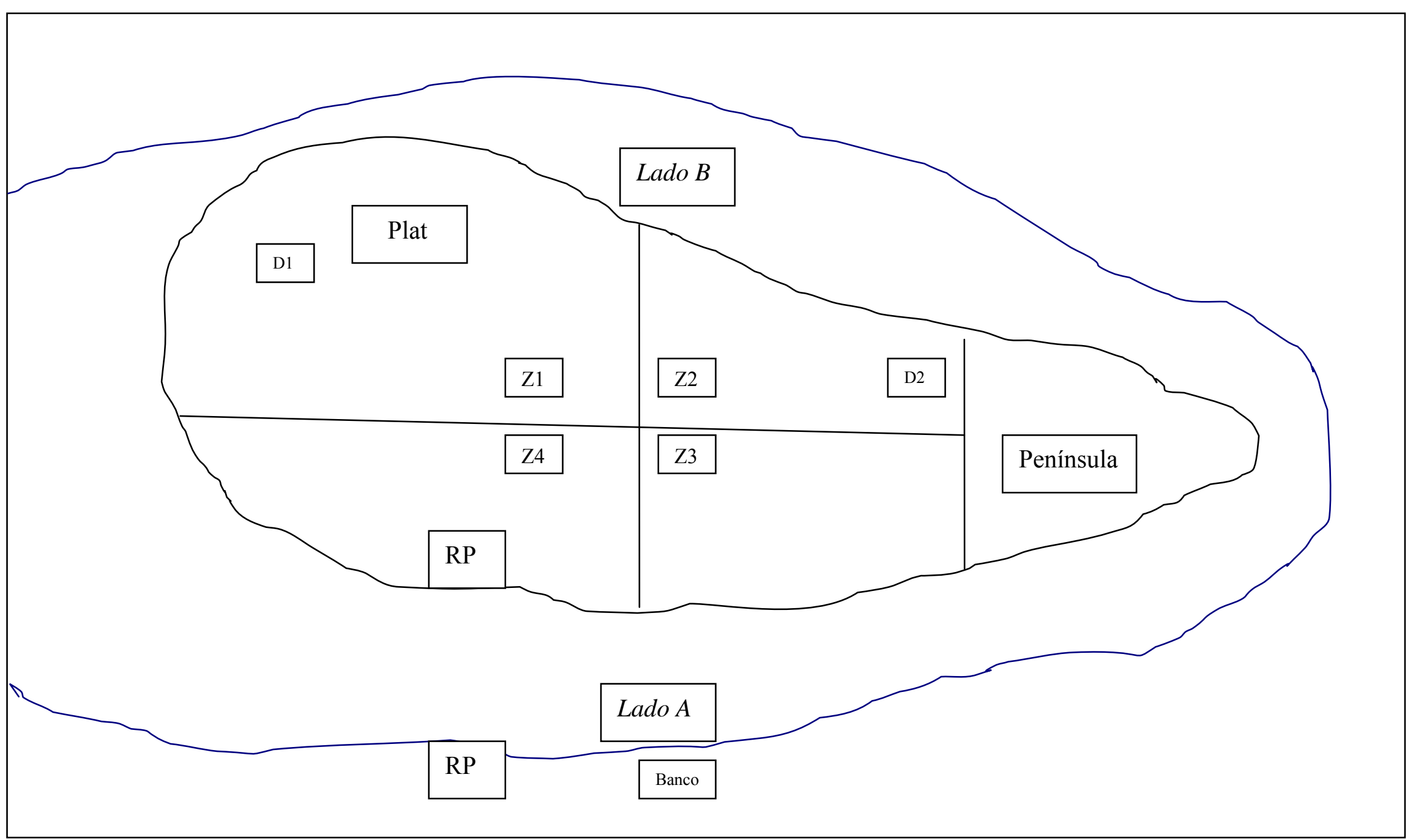

\section{Referencias:}

Plat: Plataforma

D1 y D2: Dormideros

Lados A y B: lados de desplazamiento del observador

Z 1, 2, 3 y 4: Zonas divisorias de la isla

Banco: Punto de observación

RP: Restos de puente viejo 


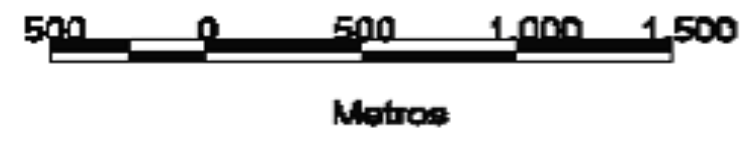

Metros


Figura 2.6: Mapa de sendas elaborado a partir de

puntos georreferenciados -

Parque Nacional Iguazú

Sendas abiertas a machete para seguir a los grupos de estudio

\section{Senderos turísticos}

Caminos de uso exclusivo para personal del Parque Nacional 
Se definieron los siguientes parámetros para la observación y posterior descripción de las pautas de comportamiento:

Sustrato: utilizado como sinónimo de superficie (rama, troncos, suelo, plataforma, dormideros, cañas) por donde camine, trepe o esté sentado el animal.

Alimento: se consideró alimento a todo aquello que los individuos obtengan del ambiente ( $y$ en el caso del cautiverio, a lo suministrado por los cuidadores) y que lo ingresen a la boca y traguen.

Entre el alimento suministrado por cuidadores en cautiverio se encontraron: verduras trozadas y en rodajas, frutas enteras y en gajos, nueces enteras sin pelar, arroz, huevos cocidos, trozos de pollo cocido y cereales sin azúcar. Ocasionalmente se les suministraban ratas de laboratorio muertas.

Fuera de vista de observación (FVO): término utilizado en el registro para indicar el espacio de tiempo en el que el o los individuos no pueden ser observados por el observador, ya que se encuentran dentro de los dormideros, en copas altas de los árboles o detrás de algún objeto que impide la visualización.

Entrar/ Salir: aplicados para el ingreso y egreso de los individuos a dormideros, sitios de alimentación, o dentro de la vegetación tupida. Dentro de los mismos los individuos se encuentran FVO.

Subir/Bajar o ascender/descender: indica el desplazamiento vertical de los individuos hacia arriba (desde un estrato de menor altura hacia estratos de mayor altura) o hacia abajo (desde estratos de mayor altura a estratos de menor altura).

Dentro del etograma se distinguió entre estado y evento. Un evento es un cambio discreto, una conducta instantánea con un principio y un fin delimitados (por ejemplo, "sentarse"). En cambio, un estado es una situación de duración apreciable, por ejemplo "estar sentado" o "dormir" (Altmann, 1974).

\subsubsection{Segmentación del observable}

Para poder describir los cambios de las posiciones del sujeto en su relación con el entorno, se requiere elaborar una descripción del referente que permita reconocer en él las partes que cambian su posición con respecto de otras y del entorno mismo. Se utiliza para esto el lenguaje descriptivo, el cual está compuesto de un conjunto de términos bien definidos a los que se llama descriptores cuya función principal es codificar la descripción. Estos descriptores se obtienen mediante un proceso llamado segmentación del observable o sujeto. La segmentación que se utilizó siguió el esquema descriptor/ rasgo/ atributo (Figura 2.7). Descriptores, rasgos y atributos guardan entre si relaciones de tipificación lógica (miembro/clase) y son tipos de 
variables (Lahitte \& Hurrell, 1995). Por segmentación se obtuvieron los descriptores (cabeza, tronco, etc.). Dentro del descriptor cabeza se pueden diferenciar rasgos (de frente, girada a un lado, etc.) y dentro de ellos atributos (para el rasgo "de frente": elevada, inclinada, etc.) (Lahitte et al, 1993). A partir de la segmentación del observable, se definieron 30 descriptores con sus rasgos y atributos.

La segmentación del observable que utilizada fue la siguiente:

1. Cabeza: frente, ojos, trompa (frontal-nariz, lateral izquierdo, lateral derecho, mandíbula, dientes, boca, lengua), orejas (izquierda y derecha), occipital.

2. cuello: dorsal, lateral (izquierdo y derecho), ventral.

3. Cuerpo: pecho, panza, espalda (anterior-pecho- y posterior -panza-), flanco o lateral (derecho e izquierdo), axila derecha e izquierda.

4. Región posterior: región anal-glandular, región genital.

5. Miembros anteriores: manos (dedos, palma, dorso), antebrazo (dorsal, lateral y palmar), brazo (dorsal, lateral, palmar), hombro, codo.

6. Miembros posteriores: pie (planta, dorso, talón, dedos), rodilla, pierna (anterior y posterior), ante-pierna (anterior y posterior)

7. Cola: basal, medio y punta.

8. Pelaje.

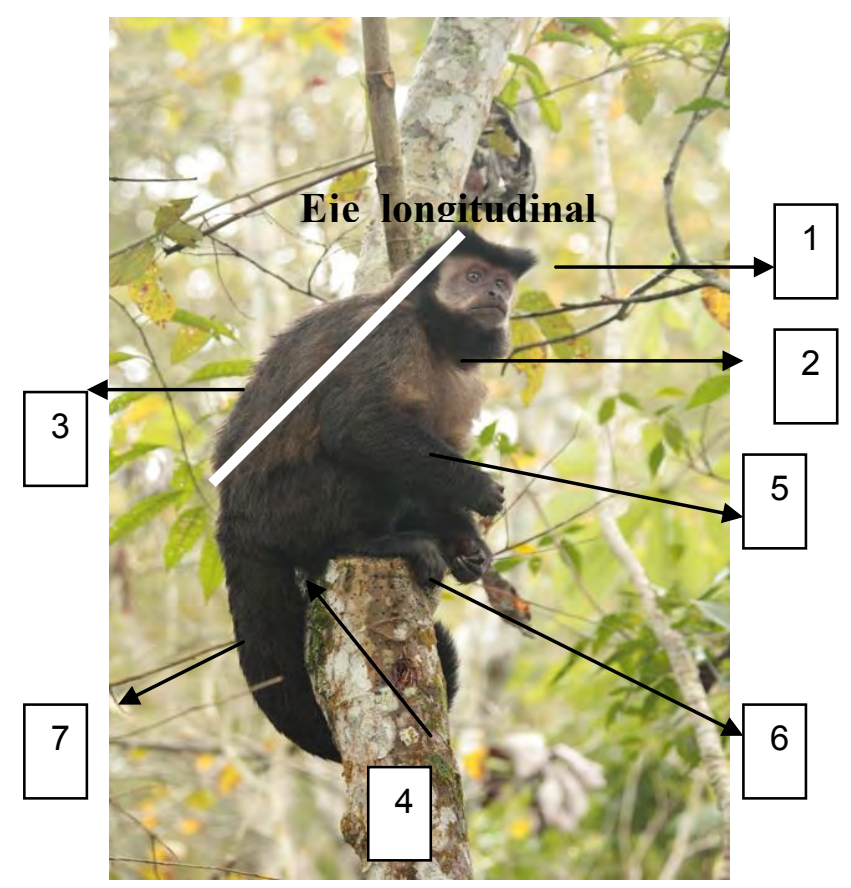

Figura 2.7: Categorías principales de segmentación del observable. 1 = cabeza, 2 = cuello, $3=$ cuerpo, $4=$ región posterior, $5=$ miembro anterior, $6=$ miembro posterior, $7=$ cola $(B$.

Wheeler) 


\subsubsection{Codificación y descripción}

Se entenderá al código como un conjunto de unidades constitutivas (analógicas o digitales) cuyo valor operativo está dado por la organización que surge de las reglas de orientación. La función de un código es hacer explícitas las condiciones de una descripción, esto es hacer identificable el referente al que el autor se remite. Es un medio para optimizar el registro (Lahitte et al., 2012). En el Anexo II se detalla el código utilizado para el registro de los comportamientos durante la toma de datos de los capítulos 3 y 4 de la presente tesis.

Ya sea que se realice un etograma parcial (referido a un aspecto) o total, se emplea algún tipo de equilibrio entre el esfuerzo invertido y lo que se va definiendo para decidir cuán completo es el listado de comportamientos que se obtuvo. Existen parámetros de completitud del etograma (Lahitte et al., 1998) que miden el esfuerzo en relación a las horas de observación una vez que fueron observados ambos sexos y todas las edades en todas las épocas del año. Entre ellos se encuentran:

1 - pautas acumuladas versus tiempo (Hutt \& Hutt, 1970): si al graficar los comportamientos registrados en función del tiempo de muestreo se obtiene una asíntota, significa que ya no aparecen pautas nuevas. No es que ya no hay nuevas pautas sino que el esfuerzo de muestreo ya no es rentable.

2 - Índice de cobertura de la muestra (IC): 1 - (I/N), donde I son las pautas que se observaron una sola vez y $\mathrm{N}$ el número total de pautas. El índice va de 0 a 1 , cuantas más pautas vistas una sola vez el índice se aproximará más a 1 (modificado de Fagen \& Goldman, 1977).

\subsection{Resultados: El etograma}

Se elaboró un etograma parcial integrado por 74 pautas de conducta (35 estados y 39 eventos).

El índice de cobertura de la muestra para el presente etograma parcial fue de 0,92. Se puede concluir que el etograma presentó una elevada cobertura.

El Anexo Videos incluye filmaciones de algunos de los comportamientos (tanto del etograma parcial como del Anexo I) descriptos. Puede accederse al mismo desde el DVD anexo a la tesis (Anexo Videos).

Estados de los descriptores:

\section{De la cola}

Sin apoyo: la cola no contacta con superficie alguna y describe siempre un espiral hacia abajo, con la punta enroscándose en forma centrífuga hacia el cuerpo. 
- Vertical: perpendicular al sustrato (Figura 2.8a).

- Horizontal: paralela al sustrato y en línea con el cuerpo, sin apoyar ninguna de sus partes sobre sustrato (Figura 2.8b).

- Colgando: perpendicular al suelo, con la punta por debajo del cuerpo (Figura 2.8c).
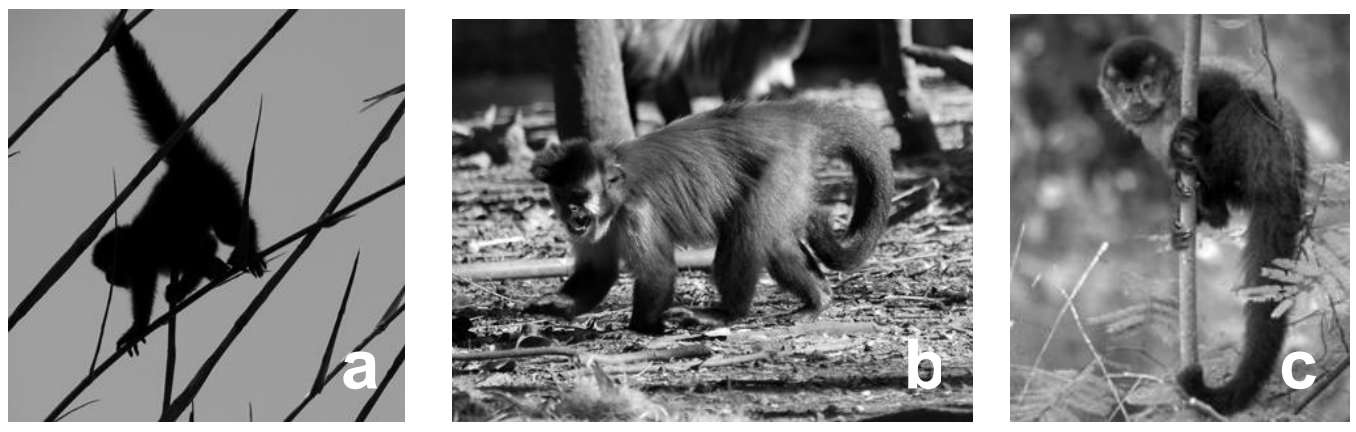

Fig. 2.8: Estados del descriptor cola sin apoyo. a - Vertical, b - Horizontal (M. P. Tujague), c -

$$
\text { Colgando (C. Scarry) }
$$

Con apoyo: al contactar con una superficie ya no describe el rulo centrífugo definido anteriormente.

- Horizontal: paralela al sustrato y apoyada sobre éste, en línea con el cuerpo quedando la punta orientada hacia atrás o hacia un costado formando un ángulo con el eje longitudinal del cuerpo (Figura 2.9a).

- Colgando: perpendicular al sustrato y con la punta orientada hacia el mismo sustrato (Figura 2.9b). El individuo está ubicado en un sitio elevado del suelo. Puede ubicarse hacia un lado (con la base orientada hacia la derecha o la izquierda) o en línea con el cuerpo (con el eje longitudinal de la cola en línea con el eje longitudinal del cuerpo).

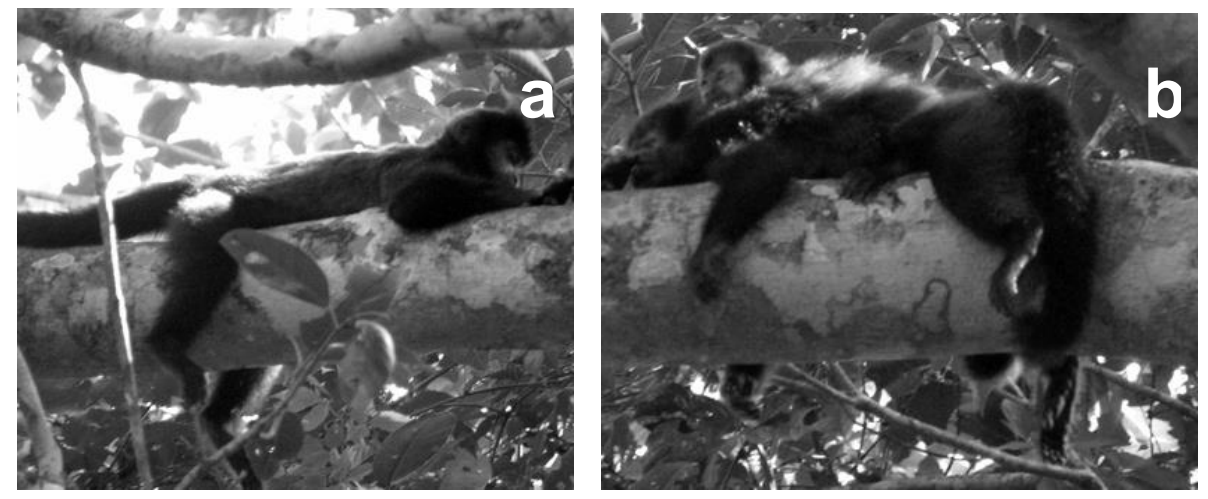

Figura 2.9: Estados del descriptor cola con apoyo. a - Horizontal, b - Colgando (M. P.

Tujague)

\section{De la cabeza}

- En línea con el cuerpo: eje longitudinal de la cabeza en la misma dirección que el eje longitudinal del cuerpo (Figura 2.10a). 
- Hacia arriba: eje longitudinal de la cabeza forma un ángulo con el eje longitudinal del cuerpo, quedando la trompa orientada en sentido opuesto al sustrato (Figura 2.10b).

- Hacia abajo: eje longitudinal de la cabeza en ángulo con el eje longitudinal del cuerpo, quedando la trompa orientada hacia el sustrato (Figura 2.10c).

- Erguida: el occipital forma un ángulo obtuso con la espalda anterior. La trompa se orienta hacia delante (Figura 2.10d).

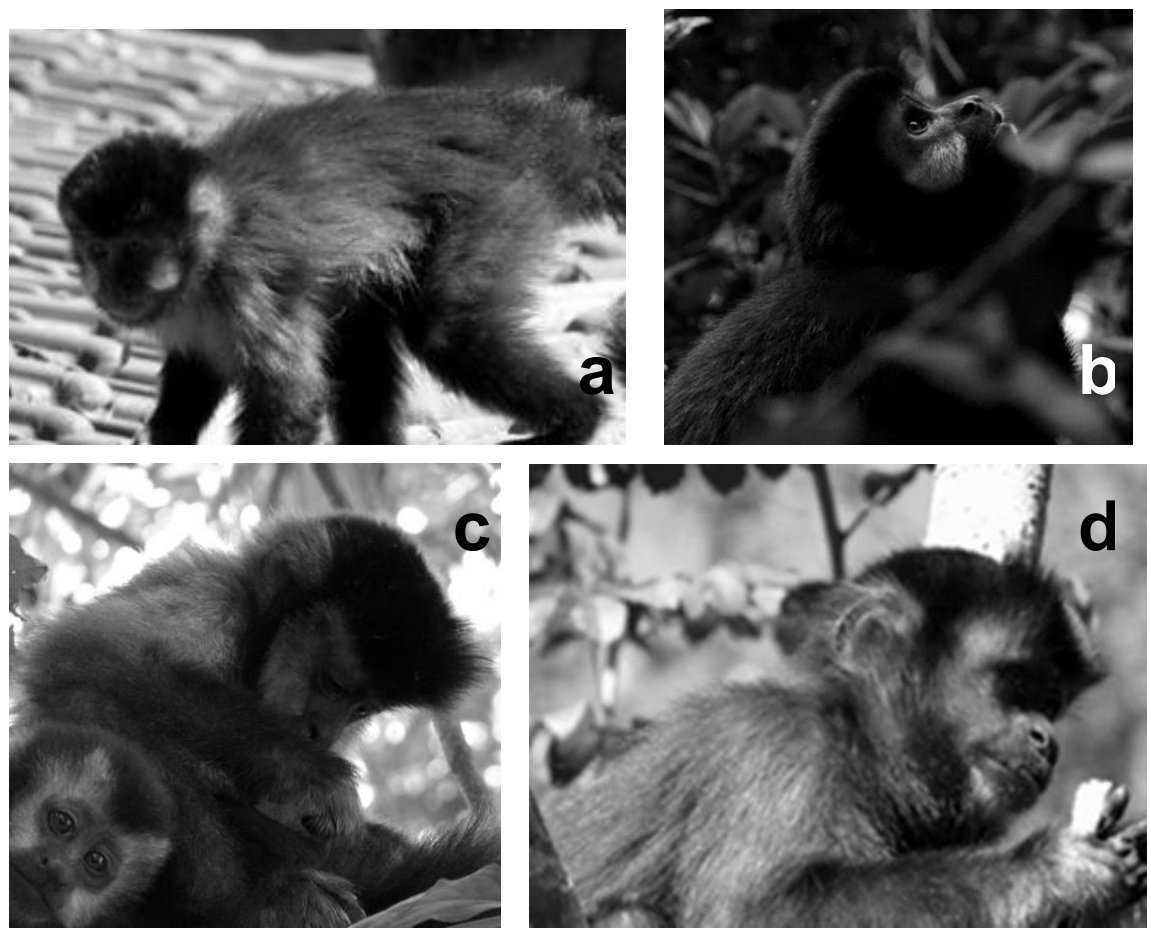

Figura 2.10: Estados del descriptor cabeza. a - En línea con el cuerpo, b - Hacia arriba, c Hacia abajo, d - Erguida (M. P. Tujague)

\section{De las patas}

\section{A. Miembro anterior}

- Estirado: brazo y antebrazo forman entre sí un ángulo mayor a $90^{\circ}$.

a) Vertical: estirado y perpendicular al sustrato. Palmas apoyadas sobre el sustrato (Figura 2.11a).

b) Paralelo: estirado y paralelo al sustrato (Figura 2.11b). 

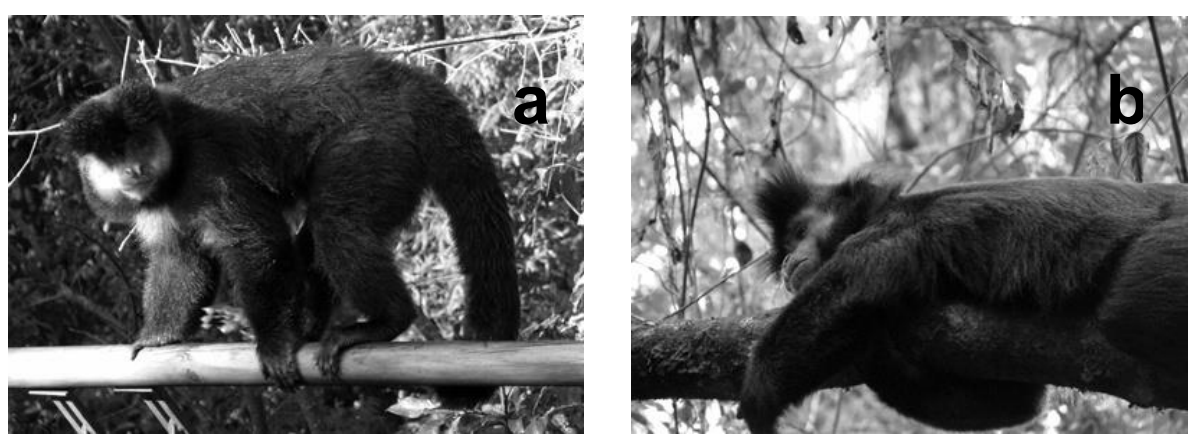

Figura 2.11: Estados del descriptor miembro anterior estirado. a - Vertical, b - Paralelo (M. P.

Tujague)

- Flexionado: brazo y antebrazo forman entre sí un ángulo menor a $90^{\circ}$. Codo dirigido hacia atrás (Figura 2.12).

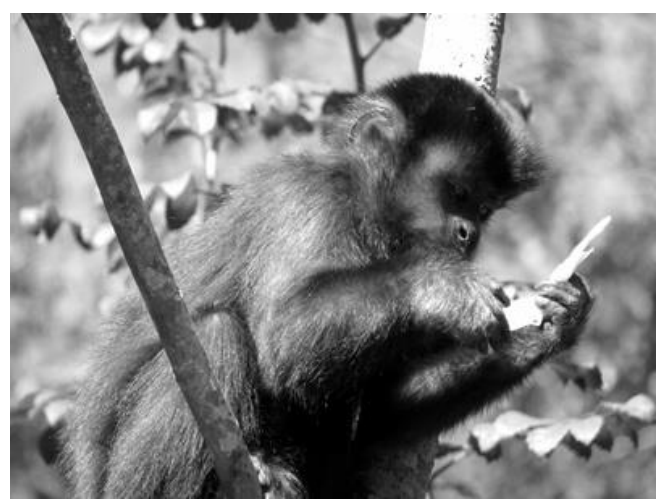

Figura 2.12: Descriptor miembro anterior flexionado (M. P. Tujague)

\section{B. Miembro posterior}

- Estirado: pierna y ante-pierna en una misma línea.

a) Vertical: estirado y perpendicular al sustrato. Planta apoyada sobre el sustrato.

b) Paralelo: estirado y paralelo al sustrato.

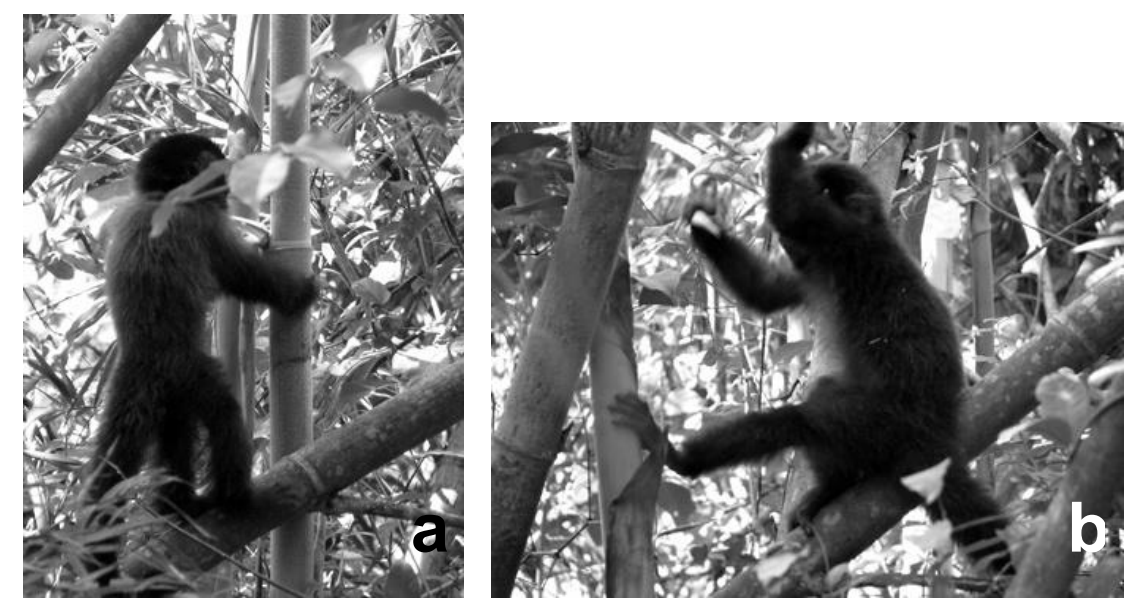

Figura 2.13: Estados del descriptor miembro posterior estirado. a - Vertical, b - Paralelo (M. P.

Tujague)

- Flexionado: pierna y ante-pierna forman un ángulo entre sí. Rodilla contacta con el flanco. Pie dirigido hacia delante y plantas sobre el sustrato (Figura 2.14). 


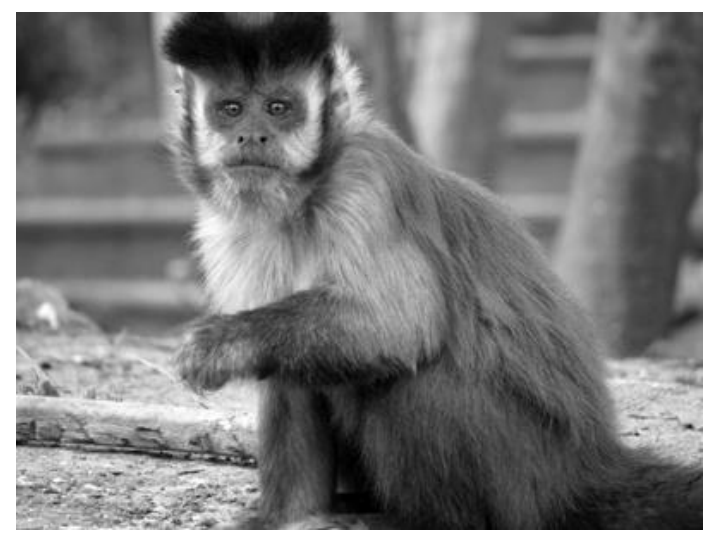

Figura 2.14: Descriptor miembro posterior flexionado (M. P. Tujague)

- Semiflexionado: pierna y ante-pierna forman un ángulo entre sí. La rodilla no contacta con el flanco (Figura 2.15).

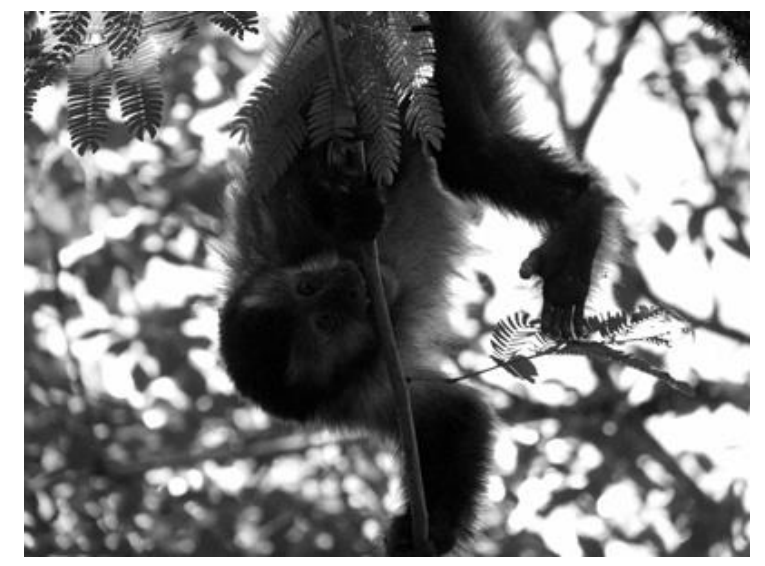

Figura 2.15: Descriptor miembro posterior semiflexionado (M. P. Tujague)

\section{Actos de conducta}

\section{Categoría 1 - Contacto de la mano/cola con objetos}

\section{Estados}

1. Sujetar: rodear un objeto con la cola, o palma y dedos de una o ambas manos o pies, y modificar la posición corporal del individuo en relación a ese objeto o viceversa. Nota: para una detallada revisión de los diferentes tipos de agarres con las manos descriptos para capuchinos ver Spinozzi, Trupa \& Laganà (2004).

2. Manipular (MN - Manipulate): sujetar un objeto, modificando la posición espacial del mismo de manera repetitiva, y sin soltarlo. Los objetos manipulados comprenden palos, ramas de árboles, plumas, nueces, piedras, plantas, bolsas de nylon, botellas plásticas, sogas, semillas (ver Anexo Videos).

3. Explorar: manipular dos o más objetos simultáneos de forma continuada. 
4. Contactar/Apoyar: cuando la cola (Figura 2.16a) o la palma (Figura 2.16b), planta y/o dedos de alguno o todos los miembros se ubican en contacto con alguna superficie u objeto, sin que se modifiquen la posición del individuo, del objeto o de la superficie.
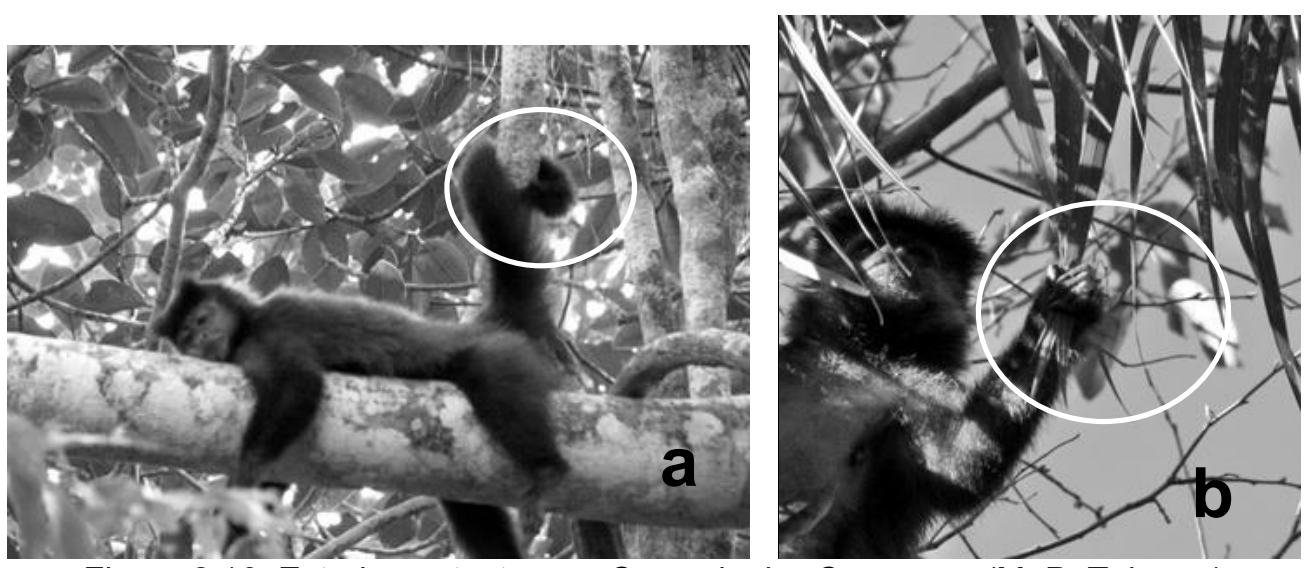

Figura 2.16: Estado contactar. a - Con cola, b - Con mano (M. P. Tujague)

5. Apretar: ejercer presión de un objeto o alimento sobre otro objeto o superficie utilizando los miembros o la cola.

6. Golpear: apretar un objeto sobre otro utilizando los miembros, elevando uno de los mismos en el aire y dejándolo caer sin soltarlo contra la superficie (ver Anexo Videos - cortesía de Ricardo Tiddi).

7. Frotar: apretar un objeto o alimento contra una superficie y realizar movimientos ascendentes y descendentes, o hacia delante y atrás.

\section{Categoría 2 - Posiciones}

\section{Estados}

1. Parado en 4 patas (S4 - Stand in 4 members): los 4 miembros en posición vertical, apoyadas sobre el suelo o sobre un tronco, con el eje longitudinal del cuerpo paralelo al sustrato. La cabeza y la cola en cualquiera de las posiciones descriptas (Figura 2.17).

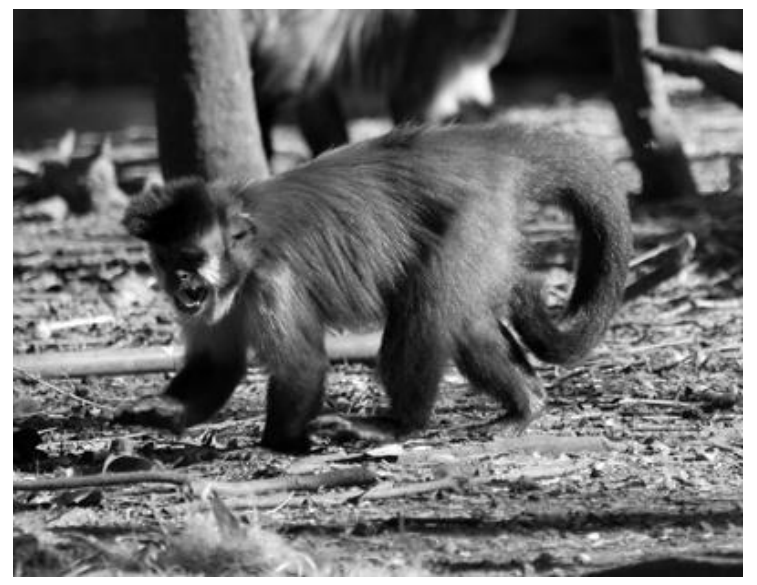

Figura 2.17: Posición parado en 4 patas (M. P. Tujague) 
2. Parado en dos patas o bípeda (SB - Stand in biped position): los miembros posteriores en posición vertical, y apoyados sobre el suelo o un tronco, con el eje longitudinal del cuerpo perpendicular al sustrato. La cabeza y la cola en cualquiera de las posiciones descriptas. Los miembros anteriores no contactan con el sustrato (Figura 2.18).

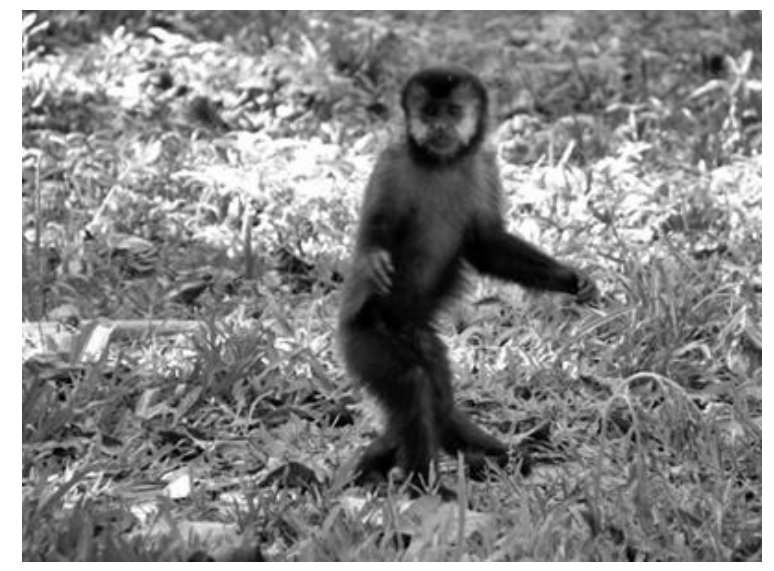

Figura 2.18: Posición bípeda (M. P. Tujague)

3. Sentado (S - Sit): cuatro patas y región anal apoyadas en el piso. Espalda arqueada. Cabeza erguida. Miembros anteriores verticales. Miembros posteriores flexionados. Cola en posición horizontal (Figura 2.19).

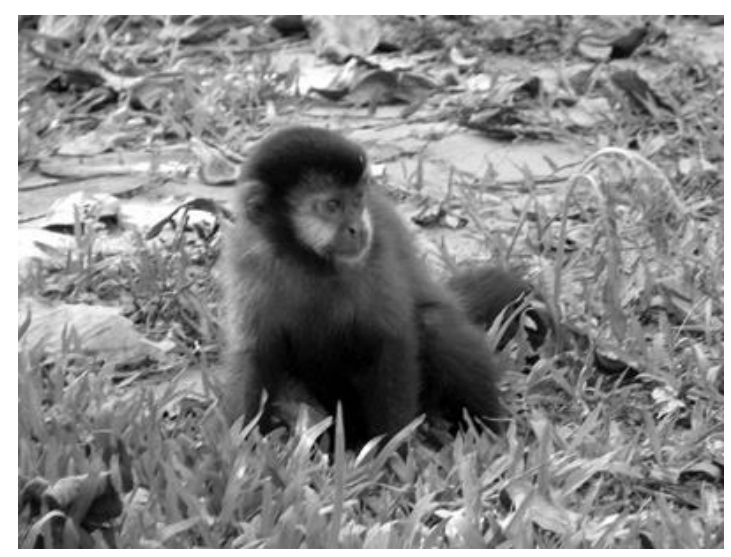

Figura 2.19: Posición sentado (M. P. Tujague)

4. Sentada bípeda: eje longitudinal del cuerpo perpendicular al sustrato en donde apoyan plantas de los pies y región anal. Miembros posteriores flexionados y anteriores semiflexionados, sin apoyar sobre el sustrato. Cola en posición horizontal o colgando. Cabeza erguida (Figura 2.20). 


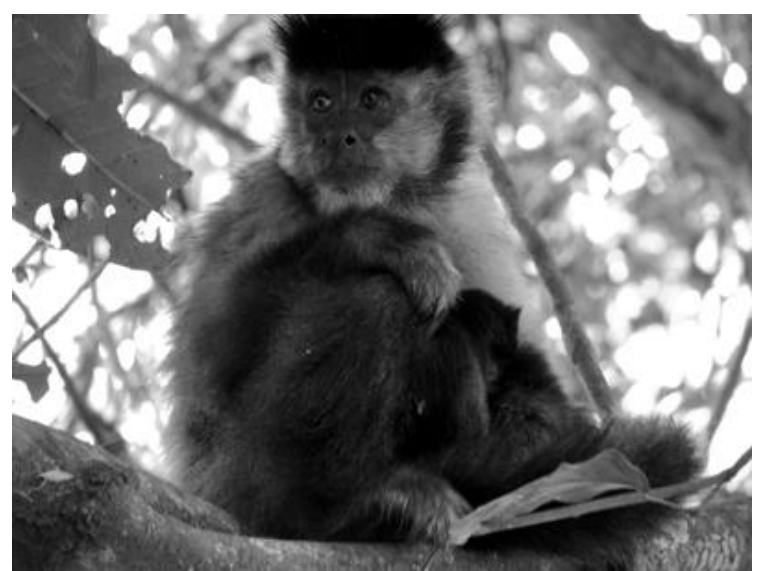

Figura 2.20: Posición sentada bípeda (M. P. Tujague)

5. Descansar (R - resting): el cuerpo apoyado sobre una superficie (vientre, dorso o algún lateral), sin moverse del lugar (Figura 2.21). Ojos abiertos o cerrados (ver Anexo Videos).

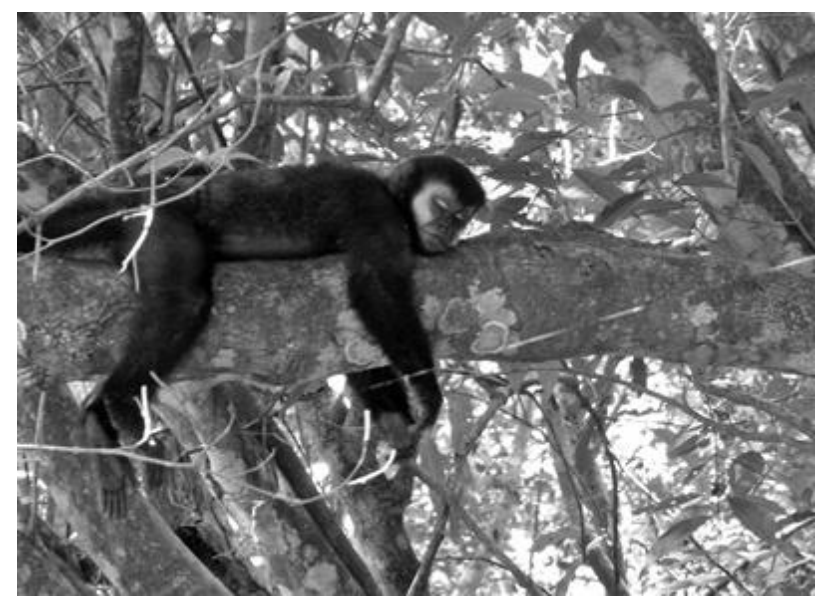

Figura 2.21: Posición descansar (M. P. Tujague)

\section{Categoría 3 - Alimentación}

\section{Estados}

1. Masticar: abrir y cerrar la boca de manera continuada más de dos veces, quedando la cabeza hacia arriba o en línea con el cuerpo. Mueve la mandíbula hacia arriba y hacia abajo.

2. Morder: el alimento, mientras es tomado con una de las manos, queda en la región anterior o en algún lateral de la trompa y entre los dientes.

3. Tragar: llevarse un alimento o líquido a la boca y que el mismo no salga de la misma a posteriori de su ingreso.

4. Comer (ET - Eating): morder, masticar y tragar alimento.

5. Olfatear: contactar la nariz con alguna superficie. 
6. Pescar: atrapar un objeto o alimento del agua y llevárselo a la boca (ver Anexo Videos).

7. Escanear: dirigir la mirada hacia un sustrato (Escanear sustrato - SCS) o en una dirección definida (Escaneo social - SCSO, que incluye el escaneo controlando por la presencia de posibles depredadores), manteniendo la atención en lo observado por más de 5 segundos.

\section{Eventos}

8. Tomar agua (DW - Drinking water): tragar agua en diferentes contextos.

Del lago: en el borde de la isla, los miembros posteriores apoyan sobre la tierra o sobre raíces de los árboles. Los miembros anteriores apoyan en ramas que se ubican sobre el agua (Figura 2.22). Cuerpo oblicuo hacia abajo y boca en contacto con el agua. Cola en espiral (ver Anexo Videos).

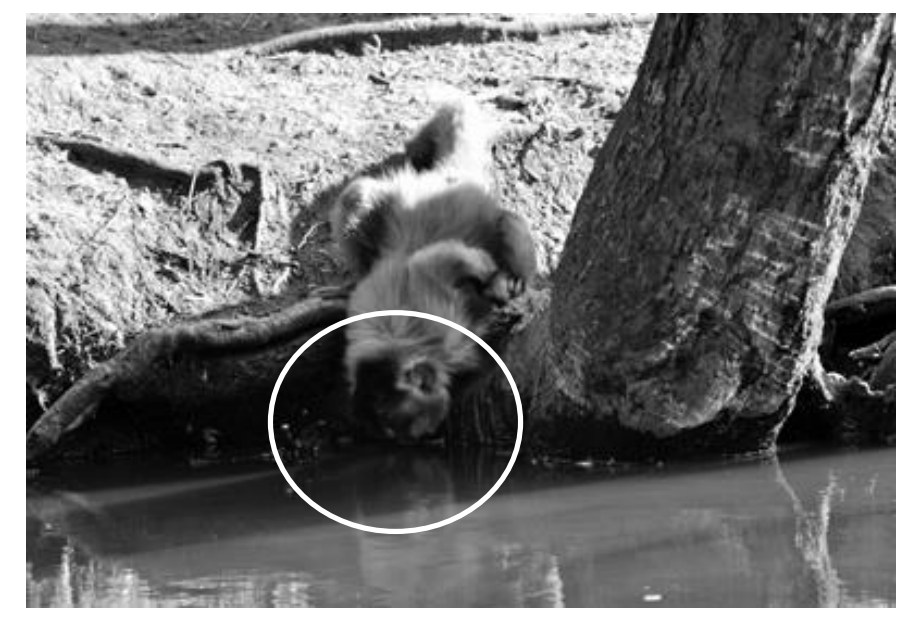

Figura 2.22: Tomar agua del lago (M. Schinca)

De hoyos de árboles: introducir la mano en el hueco de un árbol, retirar la mano mojada y llevársela a la boca. Pasar la lengua sobre la misma.

Del suelo o de un bebedero: con las 4 patas en el suelo o anteriores en suelo y posteriores en tronco, el individuo apoya la boca contra en cuerpo de agua.

De caña: sujetando la caña con patas y boca, el individuo golpea la caña con la base de mano, luego realiza un corte con la boca en la parte superior de los nudos de la caña, apoya la boca en la incisión hecha y succiona (se escucha el ruido de la succión y se observa agua gotear por la caña - ver Anexo Videos).

9. Revolver el alimento: de posición sentado o parado, toma alimento ubicado en las entradas de los dormideros o sobre la plataforma de alimentación con una mano hasta llevarse algo a la boca. 
10. Buscar en hojarasca: de posición sentado o parado, manipula con una o ambas manos las hojas sobre el suelo hasta sujetar algún artrópodo y llevarse algo a la boca.

11. Romper nueces con piedras: solo observada en el ambiente isla (semicautiverio). El individuo sujeta con una o ambas manos una piedra y golpea una nuez ubicada sobre una superficie dura (por ejemplo, los escalones viejos de cemento que quedan de un antiguo puente). Realiza golpes sucesivos ubicando la nuez en posiciones diferentes entre golpe y golpe, hasta que la cáscara de la nuez se rompe (ver Anexo Videos).

12. Forrajear (F - Forage): en posición de parado, sentado o en movimiento, cualquier comportamiento de búsqueda, localización y consumo del alimento (ver Anexo Videos). Según el tipo de alimento que se forrajea:

a) Forrajear invertebrados (ETI - Eating invertebrates):

i) Artrópodos en hojas verdes, hojas secas, troncos y cortezas: tomar las hojas, troncos o cortezas con las manos, separarlas y estirarlas (si están secas las deshacen en pequeños trozos). Si encuentran un artrópodo lo toman con los dedos y se lo llevan a la boca (Figura 2.23).

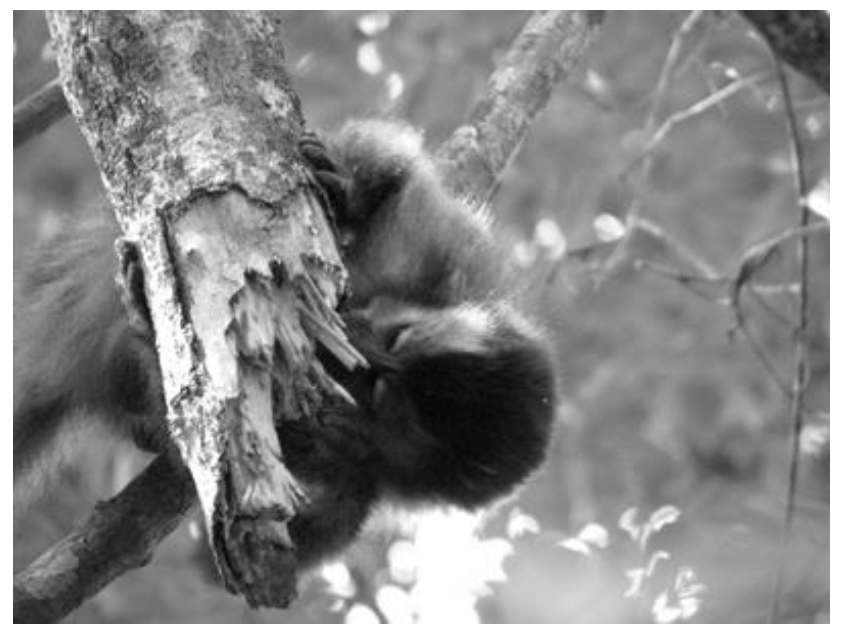

Figura 2.23: Forrajear artrópodos (M. P. Tujague)

ii) Larvas en cañas (Merostachys clausenii - yatevó o tacuara mansa, Guadua chacoensis - tacuruzú, Guadua trini - tacuara brava): el individuo sujeta la caña con una mano, y con la base de palma de la otra mano (y los dedos flexionados, arqueando la palma), apoya de forma repetitiva y constante la base de la misma o los extremos de los dedos, sobre la caña (comportamiento conocido como tap scanning - Phillips et al., 2003), a la vez que acerca la oreja a la zona del golpe, intercalando con olfateo de la 
misma. Esta pauta es seguida de la ruptura de la caña con la boca (sostiene con ambas manos y tiran con la boca en sentido contrario, hacia atrás) y la obtención de larvas del interior de la caña, que luego son consumidas. Es con extremidades de los dedos (pulpa) y arqueando la palma.

iii) Larvas en Cedrela fissilis = Cedrela tubiflora (Cedro misionero): abren la fruta por zonas de dehiscencia con manos y boca, y con la lengua sacan larvas de adentro. No comen las semillas (las mismas se caen).

iv) Atrapar insectos: en posición bípeda, extiende los miembros anteriores hasta juntar ambas palmas entre sí en el aire o contra una superficie, donde queda inmovilizado un insecto que luego es ingerido (ver Anexo Videos).

v) Larvas de panales: exponiéndose a ser picados por abejas o avispas, retiran el panal con una o ambas manos hasta alejarse del sitio donde lo encontraron. Luego lo abren con las manos y retiran del interior de las celdas las larvas, se las llevan a la boca y tragan.

b) Consumir frutos (ETF - Eating fruit): manipular, morder, masticar y tragar los mismos. Si son de tamaño mayor a 1 o $2 \mathrm{~cm}$ los aprietan con la mano mientras consumen. Sino, los sujetan y los llevan directamente a la boca y los muerden con la boca directamente (Figura 2.24).

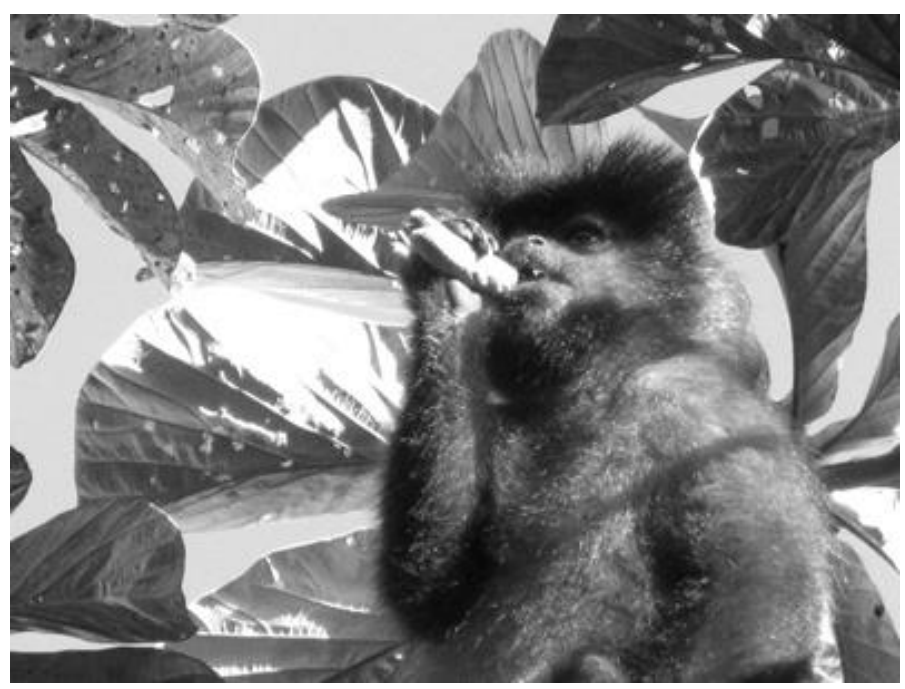

Figura 2.24: Hembra consumiendo fruto de Ambay (Cecropia pachystachya) (M. P. Tujague)

Algunos frutos presentan variaciones en su consumo:

i) Palmera Pindó (Arecastrum romanzoffianum): Con una mano retiran frutos de la panoja y se los llevan a la boca, muerden los mismos para retirar lo comestible y los dejan caer (Figura 2.25). 


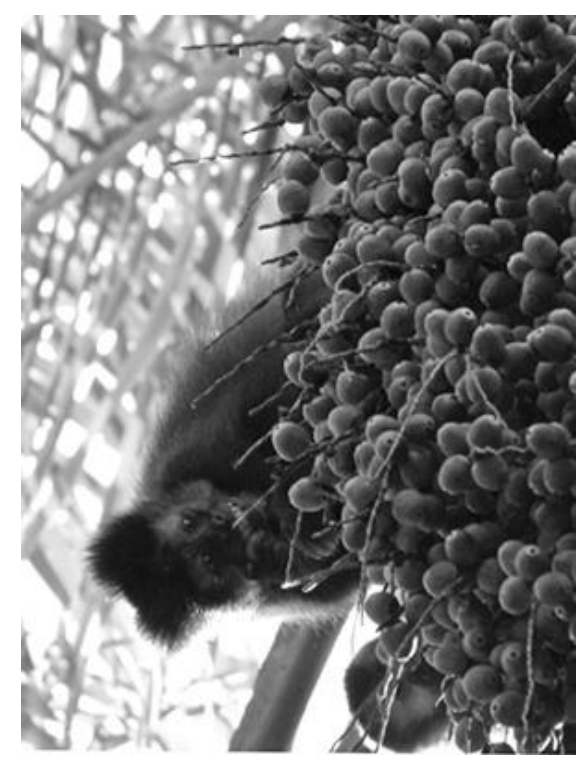

Figura 2.25: Hembra consumiendo frutos de palmera Pindó (M. P. Tujague)

ii) Tala (Celtis tala): abren con la boca, de costado, sacan la semilla dentro de la boca y dejan caer la cobertura.

iii) Caragüatá (Bromelia balansae): separan los frutos con las manos y (trasportándolos en manos y/o boca) suben a comer a mayor altura (las plantas de caragüatá no superan el metro, y los monos deben bajar para conseguirlos). Al fruto le retiran la cáscara con la boca, mordiendo y tirando hacia el costado, mientras los sujetan con las manos. Luego, con las manos, retiran la pulpa y se la llevan a la boca, o llevan el fruto a la boca directamente.

iv) Frutos en ramillete (Obenia - Hovenia dulcis, Camboatá - Matayba eleagnoides, Miconia - Miconia sp.): toman un ramillete con la mano, ya sea separándolo del tronco o no, y lo acercan a la boca. Con la boca separan el fruto y lo mastican (ver Anexo Videos).

v) Naranjas y mandarinas (Citrus $s p$.): pueden retirar la cáscara con manos y boca, o solamente hacer un agujero con los dedos y boca, y retirar la pulpa y el jugo con los dedos, que luego es llevada a la boca. Es común que las sostengan con los pies sobre un tronco, mientras retiran la cáscara y comen.

c) Consumir brotes de cañas (Chusquea ramosissima - tacuarembó o crisiuma, Merostachys clausenii - yatevó o tacuara mansa, Guadua chacoensis - tacuruzú, Guadua trini - tacuara brava) y bromelias (Bromeliaceae): retiran primero las vainas del culmo o tallo de la caña con la mano o la boca, y luego las hojas hasta dejar el brote descubierto. Lo cortan 
con las manos y/o boca y se llevan a boca. Muerden, mastican y tragan (Figura 2. 26 , ver Anexo Videos).

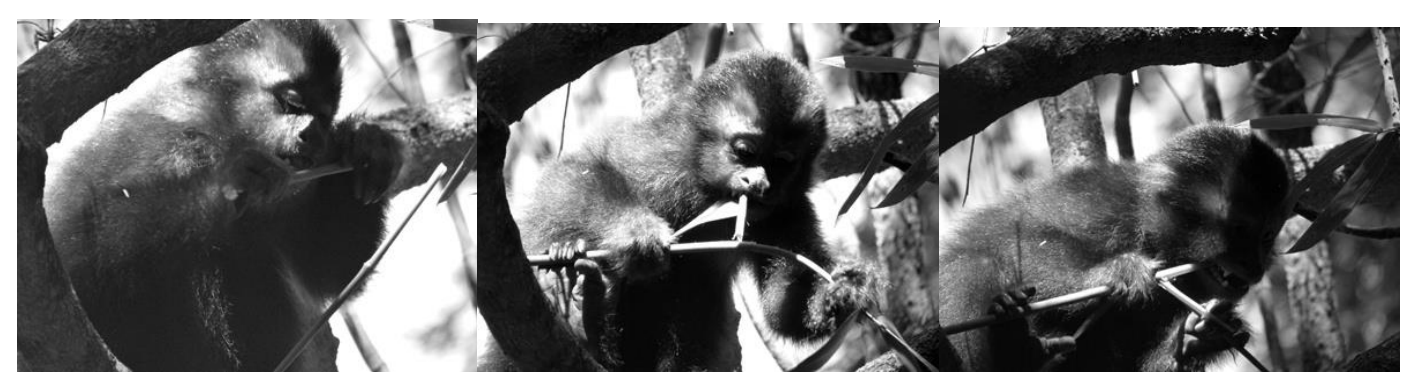

Figura 2.26: Secuencia de consumo de brote de caña chasquea (M. P. Tujague)

d) Consumir vertebrados (ETV- Eating vertebrates): anfibios, aves y micromamíferos (ver Anexo Videos):

Aves: desde posición parado o sentado, toma el ave con una o ambas manos, cola en posición horizontal o colgando. Se lleva el ave a la boca o la apoya contra el sustrato al mismo tiempo que coloca la cabeza hacia abajo. Muerde la piel del ave en la zona del cuello y el vientre, con la cabeza girada hacia un lado del eje longitudinal del cuerpo, retirando pedazos de piel y plumas con las manos y la boca. Muerde, mastica y traga. Separa las plumas hacia los lados usando las manos. Contacta sus manos contra el sustrato realizando movimientos ascendentes y descendentes para retirar la sangre que tiene sobre las mismas. Con las manos y la boca toma las vísceras, muerde, mastica y traga. Separa la cabeza de los restos del cuerpo del ave, y tomando con una mano el pico del ave y con la otra la zona occipital de la cabeza muerde, mastica y traga.

Nota: en cautiverio generalmente el vertebrado ya está sin vida al momento de ser consumido, pero en libertad la secuencia iniciaría con golpes repetitivos del animal contra un tronco o alguna superficie dura. En el caso de los anfibios (Figura 2.27), los mismos emiten sonidos durante el tiempo que permanecen con vida mientras el individuo los golpea, e incluso pueden llegar a morder partes del anfibio cuando éste aún continúa emitiendo vocalizaciones. Estos sonidos pueden apreciarse en el video del Anexo. 


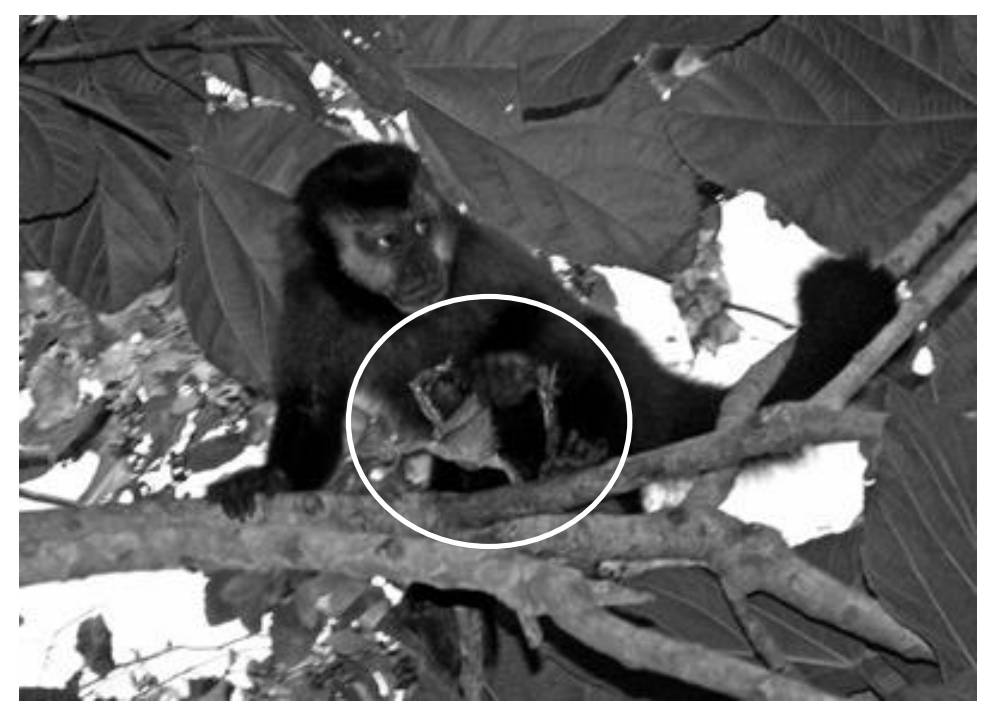

Figura 2.27: Juvenil sosteniendo un anfibio (G. Alvariza)

\section{Categoría 4- Desplazamientos}

Los desplazamientos son pautas de comportamiento cuyas descripciones son difíciles de evaluar y comparar, dado que es muy común el uso de terminología confusa para delimitar los distintos tipos de marchas (por ejemplo, más rápido que, más lento que). Para el registro y la descripción de las pautas de desplazamiento se utilizó el método propuesto por Cocatre-Zilgien (1993), en el que cada postura se enuncia en términos de qué patas están en contacto con el suelo y el paso entre posturas completa la descripción al dejar indicado el tipo y sentido de la marcha. En esta propuesta, a cada pata (comenzando de adelante hacia atrás y de izquierda a derecha) se le asigna una potencia de dos: la pata delantera izquierda será $2^{\circ}$, la izquierda trasera $2^{1}$, derecha delantera $2^{2}$ y la derecha trasera $2^{3}$. Así las patas serán codificadas como $1,2,4$ y 8 respectivamente en el gráfico. Finalmente, para cada configuración de patas apoyadas en el suelo que se da durante la marcha se suman los valores de las patas involucradas: si el animal tiene todas en el aire el valor es 0 , si tiene todas apoyadas el valor es 15 . Si tiene la delantera izquierda y la trasera derecha apoyadas el valor será de 9 .

El esquema utilizado para un tetrápodo generalizado puede observarse en la figura 2.28. En función del mismo se dibujan grafos para cada tipo de marcha, uniendo cada configuración de patas con la siguiente en el orden determinado del desplazamiento. La descripción de estos grafos resulta de anotar de manera numérica esas configuraciones (Lahitte et al., 2012). 


\section{Eventos}

Desplazamiento (MV - Moving): cambio de la posición del cuerpo en el espacio recorriendo una distancia de centímetros a 1 metro cómo límite fijado de manera arbitraria para realizar un recorte: el animal parte de un lugar y llega a otro. Vertical y horizontal. Incluye Caminatas (Figura 2.29) y Otros desplazamientos (Figura 2.30).

Viajar (T - Travel): desplazamiento a distancias de más de un metro y de forma continuada. Implica a todo el grupo (Figura 2.31).

Comportamientos Locomotores Estereotipados (CLE): movimientos repetitivos de desplazamiento, observados solo en cautiverio.

- Giro de cabeza (G. de C.): durante el desplazamiento el individuo realiza un movimiento de izquierda a derecha con la cabeza, llevando ésta primero hacia atrás y a la izquierda, luego hacia adelante y hacia la derecha.

- Giro de cabeza en ocho: en posición colgando en 4 patas del alambre del techo del recinto-jaula, la cabeza se mueve hacia los laterales dibujando un 8 acostado. Al mismo tiempo el cuerpo se balancea acompañando el movimiento de la cabeza. Cola colgando o sujeta al techo.

- Giro en $360^{\circ}$ en posición cuadrúpeda (G. $360^{\circ} \mathrm{c}$ ): durante el desplazamiento ocurre una rotación total del cuerpo de izquierda a derecha en el lugar, quedando en la misma posición que antes de girar. El único miembro que se despega del suelo al rotar es el anterior izquierdo.

- Giro $360^{\circ}$ en posición bípeda (G. $360^{\circ}$ b): ídem anterior pero apoyando las palmas de manos en rejas o paredes laterales del recinto (exclusiva del recintojaula).

- Giro $360^{\circ}$ sobre un objeto: por ejemplo, un caño horizontal, tomado de manos y pies al caño, el cuerpo gira hacia delante y hacia el suelo hasta volver a su posición inicial.

- Recorridos circulares (RCi): desplazamiento circular por el contorno de la isla (exceptuando P), por bordes de jaula o sobre contorno de pileta, generalmente en el sentido de las agujas del reloj, que se repite 4 o más veces seguidas.

- Desplazamientos: sobre troncos, suelo o paredes laterales de los ambientes, que se repite 4 o más veces seguidas en una dirección y otra alternadamente. CLE1, CLE2, CLE3 (Figura 2.32). 


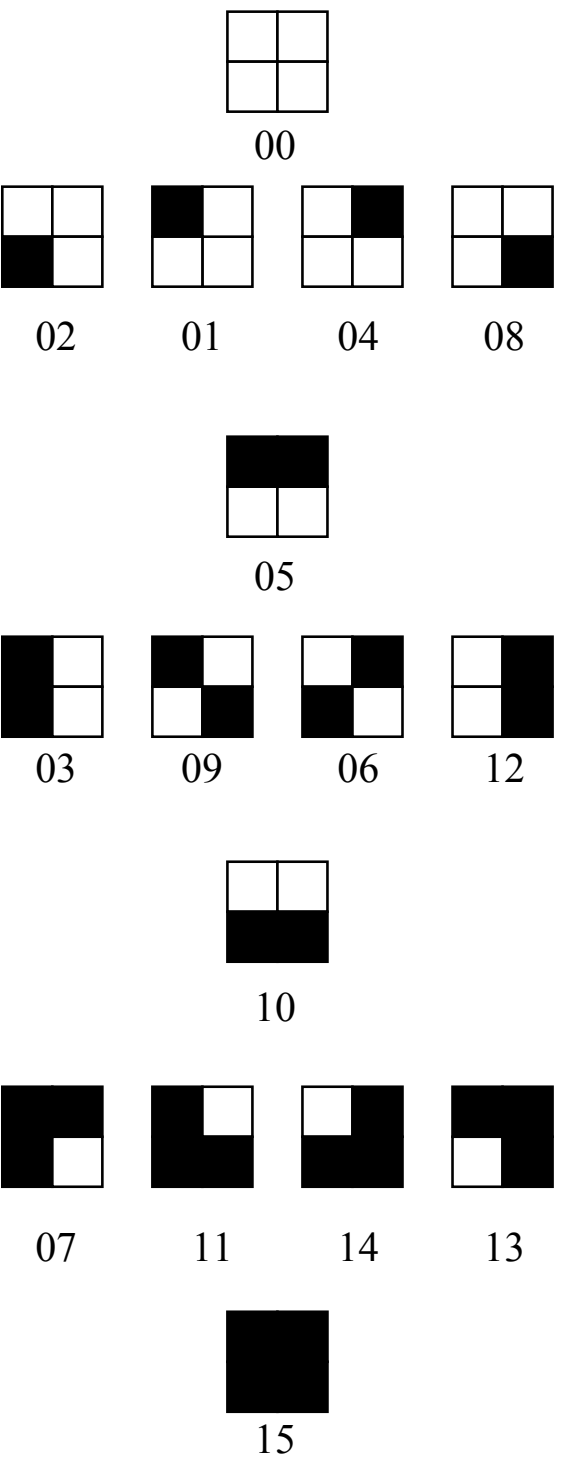

Figura 2.28: $\square$ Patas en el suelo $\square$ Patas en el aire Método propuesto por Cocatre-Zilgien (1993)

Figura 2.29: Grafos de las caminatas (W - walking) descriptas, W1 a W5, según el método de Cocatre-Zilgien (1993).

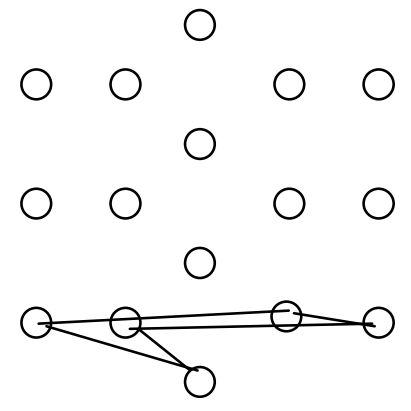

W1: 15-11-13-14-07-15 $\bigcirc$

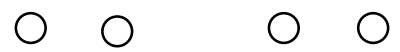<smiles>O</smiles>



W2: 03-11-15-12-13-15

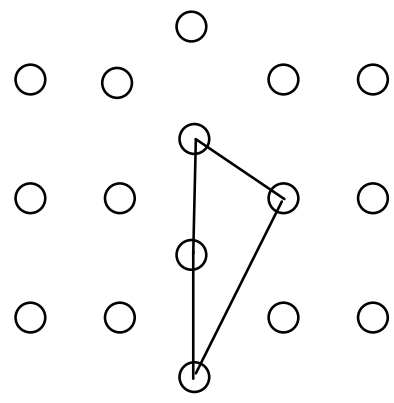

W3: 15-06-05-10-15 


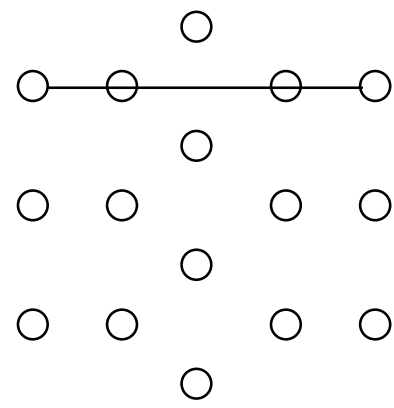

W4: 02-08-02 (bípeda)

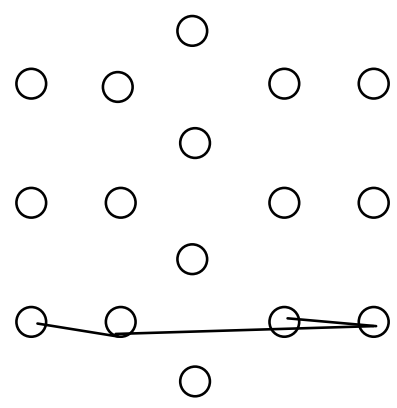

W5: 14-13-11-07 (por el techo)

\section{Otros desplazamientos:}

Descenso 0 ascenso (CL - climbing): 15-03-12-15

Desplazamiento lateral por la reja (DR): 15-03-14-13-15

Saltar (J - Jump): 15-10-05-15

Figura 2.30: Grafos de otros desplazamientos, CL, DR, J, según el método de Cocatre-Zilgien (1993).

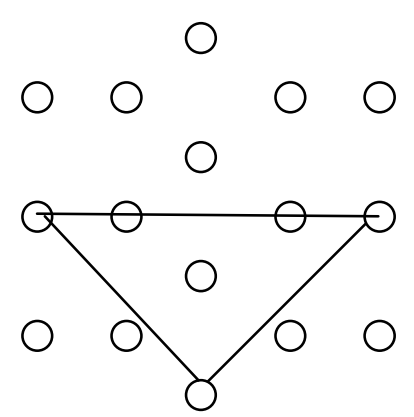

CL: 15-03-12-15

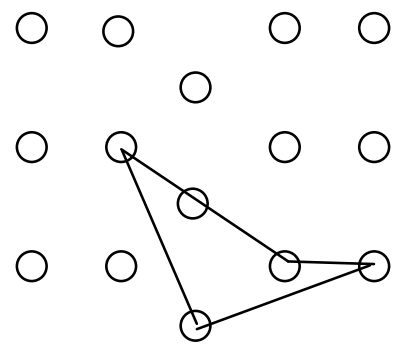

DR: 15-03-14-13-15
00<smiles></smiles>

J: 15-10-05-15

Figura 2.31: Grafos de las formas de viajar ( $\mathrm{T}$ - Travelling), T1 a T4, según el método de Cocatre-Zilgien (1993).

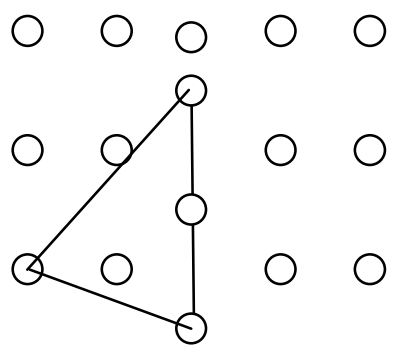

T1: 15-05-07-15

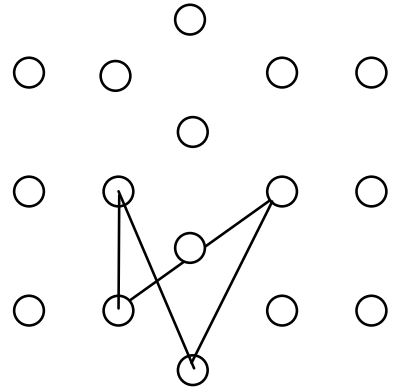

T2: 15-06-11-09-15

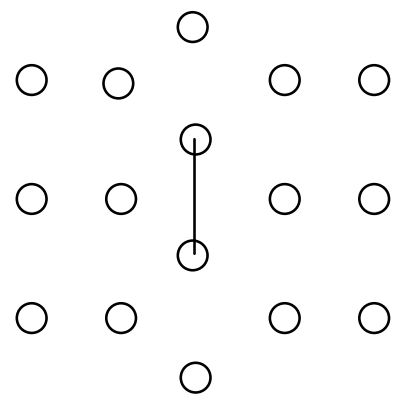

T3: $10-05-10$ 




T4: $15-14-10-13-05-13-15$

Figura 2.32: Grafos de los tipos de desplazamientos involucrados en los CLE (comportamientos locomotores estereotipados), según el método de Cocatre-Zilgien (1993).

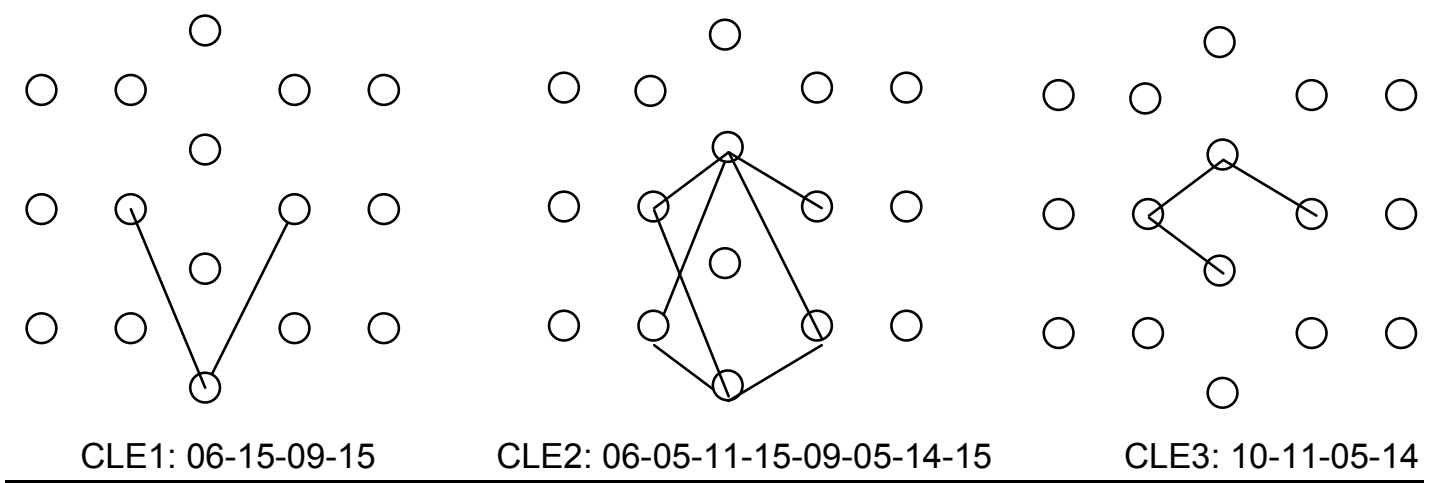




\subsection{Discusión}

Una vez realizado el etograma, una de las formas de llevar adelante el proceso de síntesis y reinterpretación es comparándolo con otros etogramas. La necesidad de sistematizar la técnica de observación/registro se basa en la importancia de hacer comunicables y comparables nuestros resultados (Lahitte et al., 2012).

Los trabajos cuyo objetivo principal fuera la descripción de comportamientos son escasos para la gran mayoría de las especies animales. Lo más frecuente es encontrar descripciones aisladas de ciertos comportamientos en función del tema abordado en la investigación y, en general, referidos a diferentes especies. Pero la publicación de descripciones de comportamientos específicos, etogramas parciales (y menos aún completos, si es que esto puede lograrse en alguna instancia) es prácticamente inexistente. Serbena \& Leite de Araujo Monteiro-Filho (2002) presentan una descripción del comportamiento de Cebus apella en cautiverio, aunque los individuos observados eran solo juveniles. En total describen 21 comportamientos incluidos en las categorías de alimentación, juego, contacto y alerta.

Giudice \& Pavé (2007) describen e identifican una serie de comportamientos especieespecíficos en Cebus paraguayanus en cautiverio. Identifican nuevos comportamientos y reconocen comportamientos ya descriptos con anterioridad para esta $u$ otras especies de capuchinos en cautiverio y en vida silvestre.

Fragaszy, Visalberghi \& Fedigan (2004) describen a lo largo de su libro "The complete capuchin" una descripción de comportamientos de varias especies de capuchinos separados en cada capítulo según la temática del mismo. Así el libro ofrece un etograma parcial al colectar e incluir numerosas descripciones aisladas en trabajos específicos.

A su vez, los trabajos de Gunst et al. (2010), Izawa \& Mizuno (1977), Izawa (1978), Ottoni \& Mannu (2001) y Phillips et al. (2003), son descripciones detalladas de comportamientos específicos vinculados a la alimentación.

A continuación se presenta una tabla comparativa de los comportamientos que se presentan en los diferentes trabajos antes citados y en la presente tesis, ordenados de manera cronológica desde el más antiguo al más reciente: 


\begin{tabular}{|c|c|c|c|c|c|c|c|c|c|c|}
\hline \multirow{2}{*}{\multicolumn{2}{|c|}{$\begin{array}{l}\text { Caracterísiticas } \\
\text { Del estudio }\end{array}$}} & \multicolumn{9}{|c|}{ Publicación } \\
\hline & & $\begin{array}{l}\text { Izawa \& } \\
\text { Mizuno } \\
(1977)\end{array}$ & $\begin{array}{l}\text { Izawa } \\
\text { (1978) }\end{array}$ & $\begin{array}{l}\text { Ottoni \& } \\
\text { Mannu } \\
(2001)\end{array}$ & $\begin{array}{l}\text { Serbena \& } \\
\text { Leite de } \\
\text { Araujo } \\
\text { Monteiro- } \\
\text { Filho (2002) }\end{array}$ & $\begin{array}{l}\text { Phillips et } \\
\text { al. (2003) }\end{array}$ & $\begin{array}{l}\text { Fragaszy, } \\
\text { Visalberghi \& } \\
\text { Fedigan } \\
(2004)\end{array}$ & $\begin{array}{l}\text { Giudice \& Pavé } \\
(2007)\end{array}$ & $\begin{array}{l}\text { Gunst et al. } \\
(2010)\end{array}$ & Tesis actual \\
\hline \multicolumn{2}{|c|}{ Especie } & $\begin{array}{l}\text { Cebus } \\
\text { apella }\end{array}$ & $\begin{array}{l}\text { Cebus } \\
\text { apella }\end{array}$ & Cebus apella & $\begin{array}{l}\text { Cebus } \\
\text { apella }\end{array}$ & Cebus apella & $\begin{array}{l}\text { Cebus apella / } \\
\text { Cebus } \\
\text { olivaceus / } \\
\text { Cebus } \\
\text { capucinus }\end{array}$ & $\begin{array}{l}\text { Cebus } \\
\text { paraguayanus }\end{array}$ & $\begin{array}{l}\text { Cebus apella } \\
\text { apella }\end{array}$ & $\begin{array}{l}\text { Cebus apella } \\
\text { paraguayanus } \\
\text { / Cebus } \\
\text { apella nigritus }\end{array}$ \\
\hline \multicolumn{2}{|c|}{$\begin{array}{l}N^{\circ} \text { de grupos } \\
\text { y/o individuos }\end{array}$} & $\begin{array}{l}\text { No } \\
\text { especificado }\end{array}$ & $\begin{array}{l}\text { No } \\
\text { especificado }\end{array}$ & $\begin{array}{l}1 \text { grupo (18 } \\
\text { individuos) }\end{array}$ & $\begin{array}{l}\text { No } \\
\text { especificado }\end{array}$ & $\begin{array}{l}1 \text { grupo }\left(\mathrm{N}^{\circ}\right. \\
\text { individuos no } \\
\text { especificado) }\end{array}$ & $\begin{array}{l}\text { No } \\
\text { especificado }\end{array}$ & $\begin{array}{l}4 \text { grupos }(19,8, \\
12 \text { y } 12 \\
\text { individuos) }\end{array}$ & $\begin{array}{l}1 \text { grupo (31 } \\
\text { individuos) }\end{array}$ & $\begin{array}{l}5 \text { grupos }(6, \\
10,12-19,20- \\
23,27-32)\end{array}$ \\
\hline \multicolumn{2}{|c|}{ Sitio de estudio } & $\begin{array}{l}\text { Parque } \\
\text { Nacional La } \\
\text { Macarena, } \\
\text { Colombia }\end{array}$ & $\begin{array}{l}\text { Parque } \\
\text { Nacional La } \\
\text { Macarena, } \\
\text { Colombia }\end{array}$ & $\begin{array}{l}\text { Parque } \\
\text { Ecológico } \\
\text { del río Tiete } \\
\text { (Sao Paulo, } \\
\text { Brasil) }\end{array}$ & $\begin{array}{l}\text { Parque } \\
\text { Zoológico } \\
\text { Municipal de } \\
\text { Iguazú, } \\
\text { Brasil }\end{array}$ & $\begin{array}{l}\text { Centro de } \\
\text { Investigación } \\
\text { Tambopata, } \\
\text { Madre de } \\
\text { Dios, Perú }\end{array}$ & $\begin{array}{l}\text { Parque } \\
\text { Nacional } \\
\text { Santa Rosa } \\
\text { en Costa Rica, } \\
\text { Hato } \\
\text { Masaguaral } \\
\text { en Venezuela, } \\
\text { Cautiverio }\end{array}$ & $\begin{array}{l}\text { Zoo Buenos } \\
\text { Aires, Zoo La } \\
\text { Plata, Estación } \\
\text { ECAS } \\
\text { Berazategui, } \\
\text { Estación } \\
\text { Zoológica } \\
\text { Experimental de } \\
\text { Santa Fé }\end{array}$ & $\begin{array}{l}\text { Reserva } \\
\text { Natural } \\
\text { Raleighvallen, } \\
\text { Suriname }\end{array}$ & $\begin{array}{l}\text { Zoológico de } \\
\text { La Plata / } \\
\text { Parque } \\
\text { Nacional } \\
\text { Iguazú, } \\
\text { Misiones }\end{array}$ \\
\hline \multicolumn{2}{|c|}{ Tipo de estudio } & $\begin{array}{l}\text { Observación } \\
\text { directa en } \\
\text { libertad }\end{array}$ & $\begin{array}{l}\text { Observación } \\
\text { directa en } \\
\text { libertad }\end{array}$ & $\begin{array}{l}\text { Observación } \\
\text { directa e } \\
\text { indirecta en } \\
\text { semi-libertad }\end{array}$ & $\begin{array}{l}\text { Observación } \\
\text { directa }\end{array}$ & $\begin{array}{l}\text { Observación } \\
\text { directa }\end{array}$ & $\begin{array}{l}\text { Observación } \\
\text { directa }\end{array}$ & $\begin{array}{l}\text { Observación } \\
\text { directa }\end{array}$ & $\begin{array}{l}\text { Observación } \\
\text { directa en } \\
\text { libertad }\end{array}$ & $\begin{array}{l}\text { Observación } \\
\text { directa }\end{array}$ \\
\hline \multirow{3}{*}{ 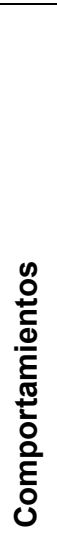 } & C1 & $\begin{array}{l}\text { abrir nueces } \\
\text { o frutos } \\
\text { duros en } \\
\text { vida libre }\end{array}$ & & & $\begin{array}{l}\text { Pegar con } \\
\text { las manos }\end{array}$ & & $\begin{array}{l}\text { Golpear } \\
\text { objetos que } \\
\text { contienen } \\
\text { alimento } \\
\text { integrando } 1 \\
\text { objeto y un } \\
\text { sustrato } \\
\text { (actividades } \\
\text { combinatorias) }\end{array}$ & & & Golpear \\
\hline & $\mathrm{C2}$ & & & & & $\begin{array}{l}\text { Golpe de } \\
\text { exploración }\end{array}$ & Golpeteo & & & $\begin{array}{l}\text { Golpear con } \\
\text { base de } \\
\text { palma y } \\
\text { dedos }\end{array}$ \\
\hline & C3 & & & & $\begin{array}{l}\text { Atrapar } \\
\text { hormigas }\end{array}$ & & $\begin{array}{l}\text { Revolver } \\
\text { hojas y pastos }\end{array}$ & & & $\begin{array}{l}\text { Revolver en } \\
\text { hojarasca }\end{array}$ \\
\hline
\end{tabular}


Memoria espacial monos caí - María Paula Tujague 2013

\begin{tabular}{|c|c|c|c|c|c|c|c|}
\hline & & & en pasto & & & & \\
\hline C4 & & & $\begin{array}{l}\text { Alimentarse } \\
\text { de pasto }\end{array}$ & & & & \\
\hline C5 & & & $\begin{array}{l}\text { Atrapar } \\
\text { moscas }\end{array}$ & & & & \begin{tabular}{|l} 
Atrapar \\
insecto
\end{tabular} \\
\hline C6 & & $\begin{array}{l}\text { Uso de } \\
\text { herramientas } \\
\text { para romper } \\
\text { nueces }\end{array}$ & $\begin{array}{l}\text { Yunque y } \\
\text { martillo }\end{array}$ & $\begin{array}{l}\text { Uso de } \\
\text { objetos como } \\
\text { herramientas }\end{array}$ & $\begin{array}{l}\text { Uso de } \\
\text { herramientas } \\
\text { (Visalberghi, } \\
1990 \text { en Guidice } \\
\text { \& Pavé, 2007) }\end{array}$ & & $\begin{array}{l}\text { Romper } \\
\text { nueces con } \\
\text { piedras }\end{array}$ \\
\hline C7 & & & $\begin{array}{l}\text { Sondear } \\
\text { con un palo } \\
\text { o ramita }\end{array}$ & & & & \\
\hline C8 & $\begin{array}{l}\text { Consumo } \\
\text { de ranas }\end{array}$ & & & $\begin{array}{l}\text { Captura de } \\
\text { vertebrados }\end{array}$ & $\begin{array}{l}\text { Comportamiento } \\
\text { de caza }\end{array}$ & & $\begin{array}{l}\text { Consumo de } \\
\text { vertebrados }\end{array}$ \\
\hline C9 & & & & & forrajear & & forrajear \\
\hline C10 & & & & & $\begin{array}{l}\text { Comportamientos } \\
\text { manipulativos } \\
\text { (pero incluye la } \\
\text { boca) }\end{array}$ & & Manipular \\
\hline C11 & & & & & Beber agua & & $\begin{array}{l}\text { Tomar agua } \\
\text { de hoyos }\end{array}$ \\
\hline C12 & & & & $\begin{array}{l}\text { Tomar agua } \\
\text { de bebederos }\end{array}$ & & & $\begin{array}{l}\text { Tomar agua } \\
\text { de bebederos }\end{array}$ \\
\hline C13 & & & & $\begin{array}{l}\text { Aplicar fuerza } \\
\text { a un objeto }\end{array}$ & & & Apretar \\
\hline C14 & & & & & & $\begin{array}{l}\text { Extracción de } \\
\text { larvas de } \\
\text { bambú }\end{array}$ & $\begin{array}{l}\text { Consumo de } \\
\text { larvas de } \\
\text { cañas }\end{array}$ \\
\hline
\end{tabular}

Tabla 2.1: Comparación de los comportamientos publicados sobre alimentación y desplazamientos en capuchinos. 
Se observa que, en la bibliografía analizada, se encuentran un total de 12 de los comportamientos descriptos en esta tesis. El resto de las pautas descriptas en este capítulo pueden considerarse novedosas en cuanto a descripciones de comportamientos para Cebus.

Es importante destacar que el comportamiento de compartir comida (food sharing) ha sido descripto para C. apella por Ferreira et al. (2002) (en Giudice \& Pavé, 2007) en condiciones de semi-cautiverio y para C. capucinus por Perry \& Rose (1994) y Rose (1997) en libertad. Este comportamiento implica la transferencia de comida de un individuo a otro, o el hecho de permitir que otro individuo colecte los restos de una presa (micromamíferos, anfibio o ave) que otro individuo ha capturado. A lo largo de las observaciones en libertad solo pudieron registrarse dos eventos de tipo anecdótico. En el primero, el macho alfa de uno de los grupos de estudio (Macuco) capturó un anfibio y, durante el proceso de consumo del mismo, partes de éste cayeron al suelo. Un juvenil colectó restos del sapo y los consumió, pero la distancia entre el macho alfa (aproximadamente 10 metros, sobre un árbol), y la posición del juvenil que colectó los restos del suelo, impidieron homologar el evento con las pautas ya descriptas en otros sitios de investigación de capuchinos. El segundo evento respondió a la descripción de este comportamiento pero el alimento involucrado fueron larvas dentro de un panal de avispas.

\subsection{Referencias}

Altmann, J. 1974. Observational study of behaviour: sampling methods. Behaviour. 49: 227265.

Bateson, G. 1985. Pasos hacia una ecología de mente. Ed. Lohlé. Buenos Aires.

Brown, A. D. \& Zunino, G. E. 1990. Dietary variability in Cebus apella in extreme habitats: evidence of adaptability. Folia Primatol. 54: 187-195

Cocatre-Zilgien, J.H. \& F. Delcomyn. 1993. A new method for depicting step patterns. Animal Behav., 45: 820-824.

Eibl-Eibesfeldt, I. 1979. Etología, introducción al estudio comparado del comportamiento (2 ed.). Ediciones Omega, Barcelona.

Fagen, R. \& R. N. Goldman. 1977. Behavioural catalogue analysis methods. Animal Behaviour 25: 261-274.

Fragaszy, D.M; Visalberghi, E. \& L.M. Fedigan. 2004. The complete capuchin: The Biology of the Genus Cebus. Cambridge University Press. United Kingdom.

Giudice, A. M. \& R. Pavé. 2007. Cebus paraguayanus in Zoos: the spontaneous expression of species-specific behaviors. Neotropical Primates, 14 (2): 65-71. 
Gunst, N., Boinski, S. \& D. M. Fragaszy. 2010. Development of skilled detection and extraction of embedded prey by wild Brown capuchin monkeys (Cebus apella apella). Journal of Comparative Psychology, 124 (2): 194-204.

Hutt S. J. \& C. Hutt. 1970. Direct observation and measurement of behavior. C. C. Thomas, Springfield.

Izawa, K. \& A. Mizuno. 1977. Palm-fruit cracking behavior of wild Black-capped capuchins (Cebus apella). Primates, 19: 633-642.

Lahitte, H. B., Hurell, J. \& A. Malpartida. 1993. Ecología de la Conducta. De la Información a la Acción. Ediciones Nuevo Siglo. La Plata.

Lahitte, H. B; Ferrari, H. R. \& P. Celis Banegas. 1998. Manual de Etología. Vol. II: Sobre las técnicas de observación, registro y análisis. Ediciones Científicas Americanas, Buenos Aires.

Lahitte, H. B. \& Hurrell, J. 1995. Ecología de las ideas: epistemología de la relación. Editorial Cause. Colección Ciencias Cognitivas. Salamanca.

Lahitte, H. B; Ferrari, H. R.; Ortiz Oria, V. \& L. C. Lázaro. 2003. Manual de Etología: Sobre la conducta como articulación individuo-entorno. Vol. III. ( $2^{\mathrm{a}}$ edición). Kliczkowsky Ediciones. Buenos Aires.

Lahitte, H. B, Ferrari, H. R \& L. C. Lázaro. 2012. Etogramática: teoría y práctica de la descripción en ciencias del comportamiento ( $2^{\mathrm{a}}$ edición). Editorial Nobuko. La Plata.

Manning, A. \& M. Stamp Dawkins. An introduction to animal behavior ( $4^{\circ}$ ed.). Cambridge University press. United Kingdom.

Martin, P. \& P. Bateson. 1986. Measuring behaviour: an introductory guide ( $1^{\circ}$ ed.). Cambridge University Press. United Kingdom.

Maturana, H. 1982. Reflexiones: ¿Aprendizaje o deriva ontogenética? Arch. Biol. Med. Exp. 15: 261-271.

Ottoni, E. B. \& M. Mannu. 2001. Semifree-ranging Tufted Capuchins (Cebus apella) spontaneously use tools to crack open nuts. Int. J. Primatol., 22 (3): 347-358.

Perry, S. \& L. M. Rose. 1994. Begging and transfer of coati meat by white-faced capuchin monkeys, Cebus capucinus. Primates 35: 409-415.

Phillips, K. A., Grafton, B. W. \& M. E. Haas. 2003. Tap-scanning for invertebrates by capuchins (Cebus apella). Folia Primatologica 74 (3): 162-164.

Rose, L. M. 1997. Vertebrate predation and food-sharing in Cebus and Pan. Int. J. Primatol., 18: 727-765.

Serbena, A. L. \& Leite de Araujo Monteiro-Filho, E. 2002. A behavioral description of cautive young capuchin monkey (Cebus apella). Revista de Etologia, 4 (2): 109-116.

Spinozzi, G., Truppa, V. \& T. Laganà. 2004. Grasping behavior in tufted capuchin monkeys (Cebus apella): grip types and manual laterality for picking up a small food item. Am. Journal of Physical Anthropology, 125: 30-41.

Visalberghi, E. 1990. Tool use in Cebus. Folia Pirmatologica 54: 146-154. 


\section{Capítulo 3: Capacidad de memoria y dinámica del aprendizaje en cautiverio en el Jardín Zoológico y Botánico de La Plata.}

\subsection{Resumen}

El comportamiento de forrajeo implica la búsqueda, localización y consumo de alimento. La capacidad de recordar la ubicación de los sitios donde alimentarse (memoria espacial) permite a los individuos mejorar su eficiencia, minimizando las visitas a sitios sin comida disponible, o a sitios agotados. Se utilizó una modificación del laberinto radial para evaluar la capacidad de memoria de corto y de largo plazo en dos grupos de Cebus apella paraguayanus = Cebus libidinosus = Sapajus cay $(\mathrm{N}=10 ; \mathrm{N}=6)$ en cautiverio y semi-cautiverio en el Jardín Zoológico y Botánico de La Plata, Argentina, entre 2007 y 2010. El diseño experimental constó de 6 contenedores ( 3 con comida accesible y 3 con comida inaccesible). Se realizó un período de habituación al diseño, dos períodos de memoria de corto plazo, 2 períodos de memoria de largo plazo y 1 período de inversión de los contenedores. Se analizó la capacidad de los individuos para el aprendizaje de conjuntos. Los individuos estudiados fueron capaces de recordar las posiciones de los sitios de alimento accesible e inaccesible por períodos de 48 horas, 76 días y hasta 4 meses, utilizando el aprendizaje de conjuntos para minimizar los tiempos de re-aprendizaje frente a un cambio en la estructura espacial aprendida. Los capuchinos estudiados utilizaron la memoria espacial para aumentar su eficiencia de forrajeo.

\subsection{Introducción}

El comportamiento de forrajeo es entendido como toda pauta de comportamiento que implique la búsqueda, localización y consumo de alimento (Boyer et al., 2003). La búsqueda puede ser definida como el problema de qué hacer en situaciones que requieren la exploración de múltiples alternativas. La naturaleza serial de la misma está implícita en su definición: la exploración serial de más de dos alternativas requiere la habilidad para mantener el registro de los movimientos realizados para evitar perder tiempo y energía en considerar alternativas que ya han sido exploradas por el mismo individuo o por miembros de su grupo (De Lillo, Visalberghi \& Aversano, 1997), o bien alternativas que no presentan alimento disponible para ser consumido. Cuando el desplazamiento de los individuos en el espacio no es regular puede sugerirse que los mismos estarán utilizando la memoria espacial para evitar los sitios ya agotados o inaccesibles. La memoria de sitios de comida agotados y sin agotar (Olton, 1982 en Cabrera, 2009) es una de las clásicas alternativas para los experimentos que deben ser resueltos mediante el desarrollo de estrategias de aprendizaje y memoria (Olton \& Samuelson, 1976 en Yoerg \& Kamil, 1982). Una alternativa será utilizar un diseño 
experimental que evalúe la capacidad de los individuos de recordar sitios accesibles e inaccesibles de alimento que siempre presenten comida para eliminar el componente de recuerdo de sitios agotados.

La mayoría de los estudios sobre memoria en cautiverio o laboratorio evalúan a los individuos de manera aislada, separados de su contexto grupal (ver Capítulo 1). Sin embargo, los resultados obtenidos de los mismos presentan un problema al momento de generalizar conclusiones, dado que no es la situación en la que los primates forrajean en vida libre. A lo largo de este capítulo se considerará al cautiverio o semicautiverio como la situación de confinamiento en zoológicos y afines cuyo objetivo sea el mantenimiento de especies con fines educativos, de exhibición y recría, mientras que el laboratorio será toda situación en la cual un animal se encuentre confinado al encierro para fines netamente experimentales.

Los trabajos en los que los individuos son testeados en grupo son escasos. Gibeault \& MacDonald (2000) realizaron un experimento en cautiverio utilizando una modificación del laberinto radial para evaluar la memoria espacial de tres pares madre-cría de gorilas (Gorilla gorilla gorilla) de un mismo grupo. Ubicaron 16 contenedores de metal pintados de verde y aprovisionados con comida en lugares no visibles del ambiente. Los individuos fueron capaces de recordar las ubicaciones de los contenedores que ellos habían agotado, y también los sitios que habían sido visitados por sus compañeros. Scheumann \& Call (2006) realizaron una serie de experimentos con orangutanes de Sumatra (Pongo abelii) y 1 gibón crestado de mejillas amarillas (Nomascus gabriellae), testeados todos juntos en grupo. El objetivo del trabajo era evaluar la capacidad de los individuos de recordar dónde y qué comida estaba en cada lugar del ambiente. Para esto se escondieron diferentes alimentos (bananas, uvas y naranjas) siempre asociados a algún rasgo determinado del ambiente (por ejemplo, las bananas siempre eran escondidas en una misma especie de árbol). Los autores concluyeron que los individuos recordaban la ubicación y el tipo de alimento pero no las cantidades del mismo en cada sitio.

En el presente capítulo se evaluó a los individuos en contexto grupal, analizando la capacidad de memoria espacial ya conocida de Cebus en diferentes lapsos temporales, con el objetivo final de analizar si los caí presentaron la formación de sets de aprendizaje espacial.

Es interesante recalcar que los zoológicos son una alternativa única para el estudio de los primates dado que ofrecen un ambiente que se aproxima a la situación de vida libre si se compara con la que ofrece un laboratorio experimental, aunque con la posibilidad de un menor control de las variables ambientales (Melfi, 2007). En una revisión sobre este tema, Melfi (2005) analiza la situación de los estudios de primates 
en zoológicos de Gran Bretaña e Irlanda, concluyendo que si bien ha existido un progresivo crecimiento de los estudios en zoológicos en los últimos 40 años, los proyectos de investigación experimental son los menos frecuentes debido a las dificultades para el manejo y control de los individuos y de las variables a medir.

Para el experimento que se planteó en este capítulo, la memoria será entendida como la capacidad de los individuos para recordar la ubicación de los sitios con comida accesible e inaccesible, utilizando esta información retenida para optimizar la localización de la misma, en contexto grupal. Se utilizara la definición de memoria de corto plazo como aquella retenida hasta dos días de haber desaparecido el input, y de largo plazo aquella retenida superados los dos días de desaparecido el input.

\subsection{Métodos}

Con la finalidad de cumplir con los objetivos específicos 1 a 4 detallados en el capítulo 1 se realizaron experimentos en cautiverio que permitieron evaluar la capacidad de memoria de los individuos en diferentes períodos de tiempo, como también las variaciones en el aprendizaje grupal. En términos generales, los experimentos de cualquier tipo se realizan sobre el conteo de las frecuencias o apariciones de actos de conducta o los cambios que en ellos se producen (Lahitte et al. 2005).

\subsubsection{Sitio de estudio}

Los estudios fueron desarrollados con los individuos de Cebus apella paraguayanus (= Cebus libidinosus = Sapajus cay)) que residen en el jardín Zoológico y Botánico de La Plata (Paseo del Bosque $\mathrm{S} / \mathrm{N}^{\circ}$, La Plata, Buenos Aires, Argentina). Éste cuenta con dos grupos de monos caí: un grupo de 10 individuos alojados en un recinto-jaula, y un grupo de 6 individuos en semi-cautiverio ubicados en una isla artificial (ambos ambientes fueron descriptos en el capítulo 2).

\subsubsection{Sujetos}

Esta especie de caí se distribuye en Bolivia, centro y noreste de Brasil, este de Paraguay y noroeste de Argentina (Rylands et al., 2000; Groves 2001), donde se extiende en la zona de las selvas de las Yungas de las provincias de Salta y Jujuy.

Los sujetos con los que se trabajó durante los experimentos habían participado en programas de enriquecimiento ambiental con los cuidadores y personal del zoológico, pero nunca habían participado de un experimento de memoria con anterioridad a éste. Cada grupo (tabla 3.1) era alimentado una vez al día con vegetales, frutas, huevos, pollo cocido y cereales. El alimento utilizado para el experimento fue integrado en la dieta diaria de los individuos para evitar que ganaran peso. 


\begin{tabular}{|c|c|c|c|c|c|}
\hline & & Grupo & AULA & Grup & SLA \\
\hline Categoría de edad & Sexo & $\lambda^{\lambda}$ & q & đ & q \\
\hline $\begin{array}{l}\text { Adultos (7 años en adel } \\
\text { activos y reproductores. }\end{array}$ & xualemente & GOR & CE & ÑO & $\begin{array}{l}\text { ALE } \\
\text { MAMI }\end{array}$ \\
\hline $\begin{array}{l}\text { Subadultos ( } 5 \text { a } 7 \text { años } \\
\text { comportamientos explor }\end{array}$ & $\begin{array}{l}\text { os } \\
\text { de juego. }\end{array}$ & $\mathrm{CH}$ & EU & & \\
\hline $\begin{array}{l}\text { Juveniles (1 a } 5 \text { años), } \\
\text { madre. Elevada frecuend } \\
\text { exploratorios y de juego. }\end{array}$ & $\begin{array}{l}\text { dientes de su } \\
\text { mportamientos }\end{array}$ & $\begin{array}{l}\text { PU } \\
\text { NI } \\
\text { MANU }\end{array}$ & $\begin{array}{l}\text { RO } \\
\text { DIE }\end{array}$ & MAT & \\
\hline $\begin{array}{l}\text { Infantes (nacimiento a } 1 \\
\text { de sus madres u otros } \mathrm{m} \\
\text { los desplazamientos a la } \\
\text { lactantes aunque a parti } \\
\text { consumen alimento por }\end{array}$ & $\begin{array}{l}\text { ), dependientes } \\
\text { del grupo para } \\
\text { ancia, aun } \\
5 \text { meses } \\
\text { a. }\end{array}$ & TO & & FER & JU \\
\hline
\end{tabular}

Tabla 3.1: composición de los grupos por sexo y sus categorías de edad. Adaptado de Gunst, Boinski \& Fragaszy (2008) y MacKinnon, 2013.

\subsubsection{Diseño experimental}

Previo al inicio de los experimentos, se realizaron pruebas con diferentes modelos de contenedores de comida, aptos de ser usados durante los diferentes ensayos. Estos contendores debían cumplir varios requisitos: soportar las diferentes actividades sin romperse ni abrirse durante la interacción de los monos con el diseño, no ser peligrosos para el bienestar de los individuos (no poseer clavos ni objetos punzantes o cortantes en su estructura) y contar con un sistema de amarre que imposibilitara a los monos mover los contenedores de lugar. Luego de sucesivas pruebas, que incluyeron contenedores de diferentes materiales y con diferentes estructuras, se llegó al diseño que se explicará más adelante.

Los individuos de cada grupo fueron expuestos al diseño del experimento de manera grupal, replicando la situación en la que los mismos forrajean en vida libre. Si bien el contexto grupal influye en las elecciones individuales (por ejemplo, individuos subordinados pueden evitar determinados sitios de alimentación por la presencia de un individuo de mayor jerarquía en el mismo), se considera que esto no es una limitante para evaluar la performance de manera grupal tomando algunos recaudos: que el número de contenedores de comida ofrecidos no sea bajo, que la cantidad y el tipo de alimento ofrecido permita su duración en el tiempo evitando un consumo rápido por parte de los monos, que la colecta de datos controle que cada uno sea independiente de otro y que el análisis de los mismos controle la variación a nivel individual. Para algunos autores el diseño utilizado a lo largo de este capítulo se considera "cuasiexperimental" dado que, por cuestiones de imposibilidad operativa, no existe un verdadero "grupo control", sino que el mismo grupo estudiado funciona como 
control de sí mismo, lo que se conoce como "diseño con grupo autocontrol" (Salkind, 1999; Basualdo, Grenóvero \& Minvielle, 2005).

Los experimentos con el grupo Jaula se realizaron entre septiembre de 2007 y octubre de 2008, mientras que los del grupo Isla tuvieron lugar desde junio de 2009 a junio de 2010. El diseño experimental que se replicó para ambos grupos de monos se desarrolló en 4 períodos sucesivos, a saber:

1 - Período de habituación a los contenedores de alimento $(\mathrm{PH})$ : se ubicaron 2 contenedores novedosos de alimento en sitios constantes del ambiente (Figura 3.1), utilizando a lo largo de todas las etapas experimentales el lado A del ambiente Jaula (ver Gráfico 2.4 del ambiente en Capítulo 2), dado que era la zona habitual de alimentación de los individuos, mientras que en el ambiente Isla fueron colgados de dos árboles elegidos al azar. Cada contenedor consistió de un tubo de PVC (polyvinyl chloride) blanco opaco de $11 \mathrm{~cm}$. de diámetro y $14 \mathrm{~cm}$. de altura, con una tapa superior y otra inferior (Figura 3.3). La superior era fija y poseía una abertura circular de $5.5 \mathrm{~cm}$. de diámetro para posibilitar la extracción del alimento del interior. La tapa inferior era móvil permitiendo el llenado de los mismos. Se ataron a la reja en el ambiente Jaula y a árboles en el ambiente Isla, con un sistema de sogas que impedía a los monos moverlos de lugar. Para cada ensayo fueron llenados fuera de la vista de los individuos con 150 gramos de copos de maíz sin azúcar. La elección de este alimento se basó en que el mismo formaba parte de la dieta habitual de los monos, y además ofrecía el suficiente tiempo de manipuleo necesario por parte de los individuos para consumirlo, permitiendo el registro de los comportamientos necesarios a lo largo de cada ensayo.

Los contenedores eran oscuros para evitar que puedan guiarse por la identificación visual a distancia del alimento en los períodos de experimentación posterior. Los mismos fueron instalados en cada ensayo experimental, y retirados al finalizar los mismos. Se realizaron registros continuos de las visitas de los individuos a los contenedores. Se consideró como finalizado el período de habituación una vez que todos los individuos habían aprendido a buscar el alimento dentro de los contenedores (esto es, habían utilizado al menos por una vez alguno de los contenedores).

2 - Período 1 de aprendizaje de localizaciones y memoria a corto plazo (MCP1): se utilizó una modificación del laberinto radial (Tarou \& Maple, 2000) para ubicar 6 contenedores idénticos a los utilizados en $\mathrm{PH}$, atados con sogas a sitios determinados y constantes de las rejas laterales del ambiente, y a la misma altura. Tres de ellos llevaron una malla plástica interna que impedía retirar alimento (Contenedores con Comida Inaccesible o $\mathrm{CCl}$ ). Para esto se utilizaron barreras plásticas para insectos 
marca Fhik's Tou, de $12.5 \times 12.5 \mathrm{~cm}$. (Figura 3.3). Externamente eran idénticos al resto de los Contenedores con Comida Accesible (CCA), pero en ellos los individuos jamás pudieron retirar alimento del interior. La ubicación espacial fue intercalada CCA$\mathrm{CCl}$ (Figura 3.2). Así pudo asegurarse que los individuos se estarían guiando por el recuerdo de la ubicación del alimento disponible (y no disponible) y no por una señal olfativa ni visual inmediata. A su vez, la ubicación de los contenedores en las rejas laterales del ambiente implicaban que los individuos debían llegar a los mismos de manera activa (trepando o saltando), sin que existiera la posibilidad de estar desplazándose por el ambiente y encontrar un contenedor al azar.

Los contenedores fueron llenados fuera de la vista de los individuos, y colocados en el ambiente a posteriori de aislar a los individuos en R2 (recinto 2) utilizando la puerta guillotina (ver esquema 1 del ambiente en capítulo 2). Se realizaron un total de 9 a 15 ensayos (dependiendo del grupo estudiado) cada 48 horas, siempre en los mismos horarios durante la mañana. Los individuos se encontraron siempre con 24 horas de ayuno. Se utilizó la técnica de grupo focal (Altmann, 1974) para registrar el orden de visita de cada individuo a los contenedores de manera simultánea, observando cada cambio en el espacio ocurrido (Gouteux et al., 1999), el número de visitas a CCA (Visitas Correctas o VC) y a $\mathrm{CCl}$ (Visitas Incorrectas o $\mathrm{VI}$ ). Se registró también la duración temporal de cada ensayo. Las observaciones se realizaron de manera directa por un mismo observador (M. P. Tujague) entrenado para identificar a los individuos con la rapidez suficiente para no confundir ni perder eventos de visita.

El criterio de finalización de cada ensayo fue que 1 de los 3 contenedores CCA estuviera vacío para poder evaluar de esta manera la situación de oferta completa de alimento (en todos los sitios accesibles). En la práctica ocurrió que se vaciaban 2 de los 3 contenedores de manera simultánea.

3 - Período único de memoria a largo plazo 1 (MLP1): posterior a un primer período de 76 días de no exponer a los individuos al experimento, se procedió a colocar (por única vez) los contenedores nuevamente en el ambiente, en igual condición que para el período MCP1. Se registró el comportamiento inmediato de los individuos y la reacción de los mismos al cambio en su eficiencia de visita a los contenedores accesibles e inaccesibles, tomando los mismos datos que para el período MCP1. La elección de la cantidad de días fue en base a dejar transcurrir por lo menos un período de tiempo igual o superior al utilizado para realizar el período experimental de memoria de corto plazo.

4 - Período 2 de aprendizaje de localizaciones y memoria a corto plazo (MCP2): luego del ensayo único de memoria de largo plazo 1 (MLP1), se replicó el período de 9 a 15 ensayos (según el grupo estudiado) de memoria de corto plazo descriptos para MCP1. 
5 - Período único de memoria a largo plazo 2 (MLP2): posterior a un período de 4 meses de finalizados los ensayos de MCP2 y de no exponer a los individuos al experimento, se procedió a colocar (por única vez) los contenedores nuevamente en el ambiente, en igual condición que para los períodos MCP1 y MCP2. Se registró el comportamiento inmediato de los individuos y la reacción de los mismos al cambio en su eficiencia de visita a los contenedores accesibles e inaccesibles. La elección de la distancia temporal en relación al último ensayo de memoria de corto plazo 2 tuvo como objeto duplicar por lo menos la distancia temporal utilizada para el período de memoria de corto plazo 2.

6 - Período de inversión de la ubicación de los contenedores: luego del ensayo único de memoria de largo plazo 2 (MLP2), se invirtieron las posiciones de los contenedores con alimento accesible y los que contenían alimento inaccesible, y se registró el tiempo que les tomó volver a aprender la localización de los mismos, colectando iguales datos que para los períodos MCP1 y MCP2. El objetivo de este período fue analizar la capacidad de los individuos de integrar en conjunto la información aprendida y memorizada (sets de aprendizaje). Dada la ausencia de un grupo control en el diseño utilizado, y dado que todos los contenedores contenían siempre alimento, esta situación invertida cumplió la función de "ensayo control" al controlar sobre la variable de ubicación espacial de los contenedores. La posibilidad de utilizar como control experimental la introducción de los contenedores sin alimento en el ambiente hubiera interferido en el proceso de registro de las posiciones que se debía ir formando a lo largo de las sucesivas etapas del diseño.

Se consideró como evento de visita a cada instancia en la que un individuo se dirigiera un contenedor y se detuviera en el mismo para mirar en su interior, dirigir comportamientos exploratorios o de juego, o retirar alimento del mismo en el caso que el contenedor fuera accesible (CCA). Un ensayo fue definido como cada instancia en que se expuso a los individuos de estudio a los contenedores de alimento, aprovisionados con comida.

Análisis de datos

Para cada ensayo dentro de cada etapa experimental se obtuvieron los siguientes datos:

1. Total de VC por individuo y por ensayo.

2. Total de $\mathrm{VI}$ por individuo y por ensayo.

3. Duración de cada ensayo. 
4. Índice de Performance de Memoria Espacial para evaluar la capacidad individual de memoria en cada etapa experimental, (por individuo por ensayo) (modificado de Ludvig et al., 2003):

$$
I P M E=\frac{(V C-V I)}{(V C+V I)}
$$

Donde $\mathrm{VC}=$ visitas correctas y $\mathrm{VI}=$ visitas incorrectas

Este índice varía entre 1 y -1 , indicando con un valor de 1 una performance perfecta (VI igual a 0), -1 una performance baja (VC igual a 0 ) y 0 cuando la cantidad de visitas correctas e incorrectas fue igual. Si no se registraron visitas para un individuo se consideró como sin datos (0 visitas correctas y 0 incorrectas). Un valor por encima de 0 indicaría que existió una formación de memoria (Ludvig et al., 2003).

Dadas las características del diseño (un mismo grupo experimental al cual se le aplican los sucesivos tratamientos y de manera simultánea a todos los individuos juntos, en contexto grupal), se utilizó un Modelo Lineal Generalizado de Efectos Mixtos en R (MGLM - R Development Core Team 2010) para poder evaluar la performance (IPME) de los grupos en cada ensayo y período experimental controlando la variación individual. Los MGLM permiten el análisis de los datos cuando existe un efecto al azar en ellos (Bolker et al., 2009) ofreciendo una mejor evaluación de los efectos de las variables no controladas (Janson, 2012) como es en este caso la identidad de los individuos. Se utilizó como efectos al azar (random effect) la identidad del animal focal, y como efectos fijos (fixed effects) a los ensayos, los períodos experimentales (MCP1, MCP2 e INV), categoría de edad y sexo de los individuos. Se evaluaron todos los modelos posibles controlando para cada efecto fijo, y se los comparó con el modelo global general (que incluye todos los efectos fijos a la vez). Se escogió como modelo con mejor fit al de menor valor de CIA (criterio de información de Akaike) que estima la distancia relativa esperada entre el modelo estimado y cada modelo generado con los datos observados (Bolker et al., 2009). Se utilizó también el test de Student para muestras pareadas con el objetivo de analizar diferencias de IPME promedio entre ensayos puntuales. Todos los test de Student se realizaron a una cola dado que se asume que los monos aprendían a medida que el tiempo transcurría. En cada caso en el que se realizó una comparación de medias de este tipo, se calculó el tamaño del efecto (effect size) mediante el método de Cohen ( $d$ de Cohen: Morales Vallejo, 2012; Nakawaga \& Cuthill, 2007) como análisis complementario al análisis de diferencias 
entre promedios. El tamaño del efecto es una medida estandarizada de la magnitud del efecto observado que nos permite detectar, en el caso de muestras de tamaño pequeño, aquellas diferencias importantes que pueden pasarse por alto con los tests estadísticos clásicos al obtener un p-valor no significativo o, en su defecto, analizar si una diferencia que se evaluó como significativa a partir de su p-valor lo es realmente. Dado que un valor de t y su p-valor no son informativos por sí solos (Amstrong, 2007; Anderson et al., 2000) ni un p-valor es indicador por sí solo del tamaño de la diferencia encontrada, el cálculo de estas magnitudes es de suma importancia para no aceptar una hipótesis nula cuando no es verdadera (Greenwald, 1975), teniendo en cuenta que ésta nunca lo es de manera estricta (Likken, 1968).

Cohen (1988 en Nakawaga \& Cuthiil, 2007) ha propuesto valores convencionales como puntos de referencia para interpretar el valor de $d$ : bajos ( $d=0,2$ o menores) medios o moderados $(d=0,5)$ y altos $(d=0,8$ o mayores). Si bien estos valores son un tanto arbitrarios, pueden considerarse orientadores al momento de evaluar el tamaño del efecto encontrado (Coe \& Merino, 2003, Morales Vallejo, 2012).

Para el caso de los MGLM las estimaciones de tamaño del efecto se encuentran en una etapa de discusión y ajuste de métodos, por lo cual se considera que en un futuro los análisis realizados en la presente tesis podrán complementarse al respecto, dando a la interpretación de los resultados una mayor solidez. 
Figura 3.1: Ubicación de los contenedores de alimento durante el Período de Habituación (PH)

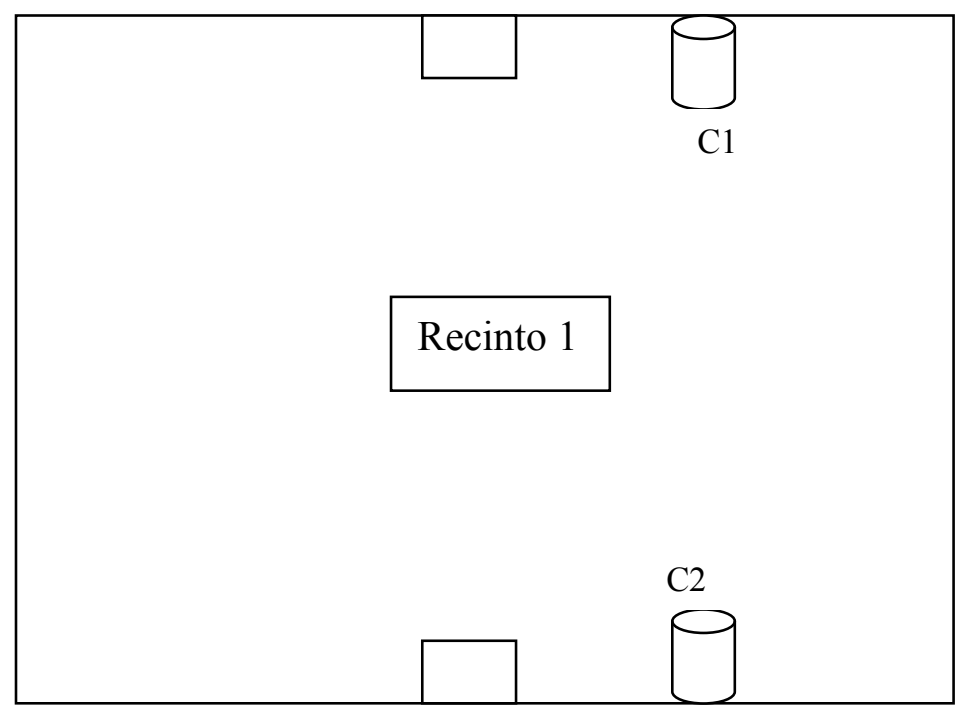

Figura 3.2: Ubicación de los contenedores en el Período de Memoria de Corto y Largo Plazo (MCP y MLP)

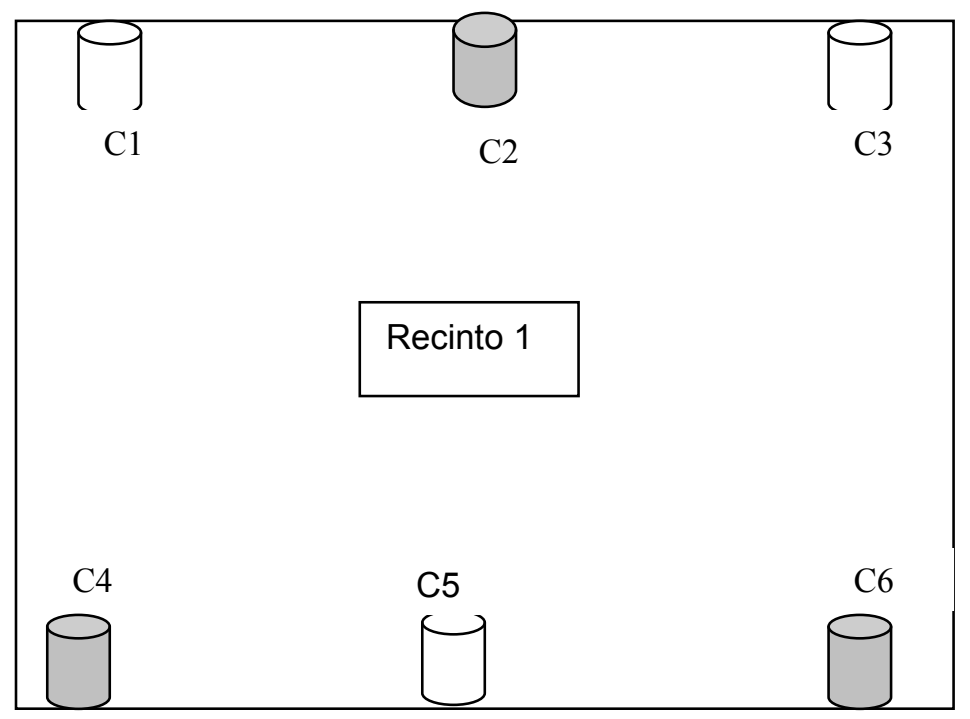

CCA: Contenedores con Comida Accesible

$\mathrm{CCl}$ : Contenedores con

Comida Inaccesible 


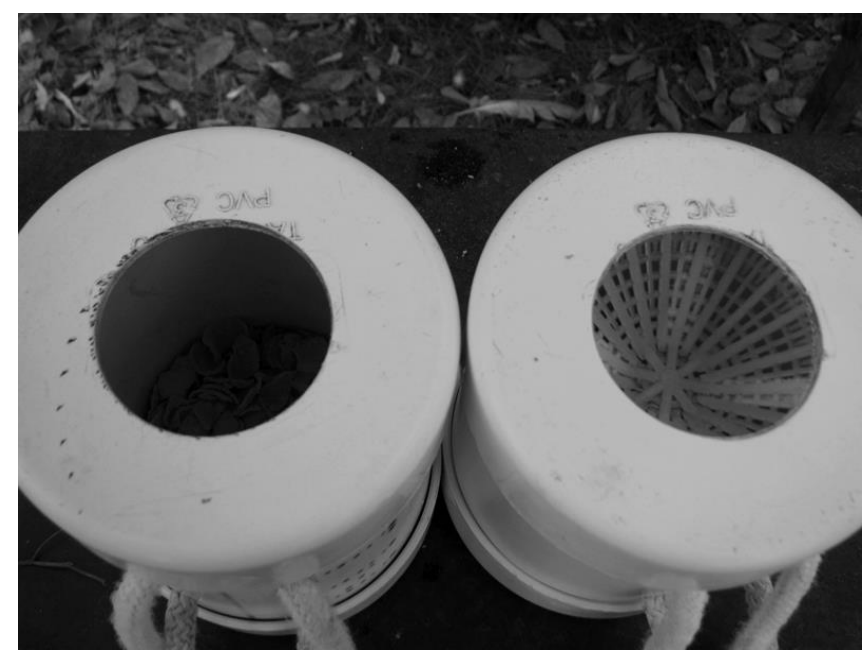

Figura 3.3: Contenedores accesibles (izquierda) e inaccesibles (derecha) (M. P. Tujague)

\subsubsection{Descripción de las secuencias de forrajeo}

Se analizaron los patrones de forrajeo (secuencias repetitivas de visitas que cada individuo ejecutó a lo largo de los experimentos) con el objetivo de evaluar las estrategias utilizadas a nivel individual. Este análisis sólo se realizó para el grupo Jaula, dado que el ambiente permitía instalar los contenedores a la misma altura y distancia entre sí, mientras que en semi-cautiverio (grupo Isla), existió una diferencia en las alturas de instalación, a la vez que el acceso a los contenedores era posible desde el suelo o desde las copas de los árboles donde estaban instaladas. Estas variaciones impidieron un registro de secuencias inmediatas entre los mismos.

Se elaboró un código gráfico para representar a los sujetos y las visitas (Figura 3.4). Se representaron las secuencias de movimiento usando el programa Photo Scape 3.5 (software libre) para analizar la repetición y redundancia y así obtener un mapa de secuencias para cada ensayo experimental, incluyendo a todos los individuos.

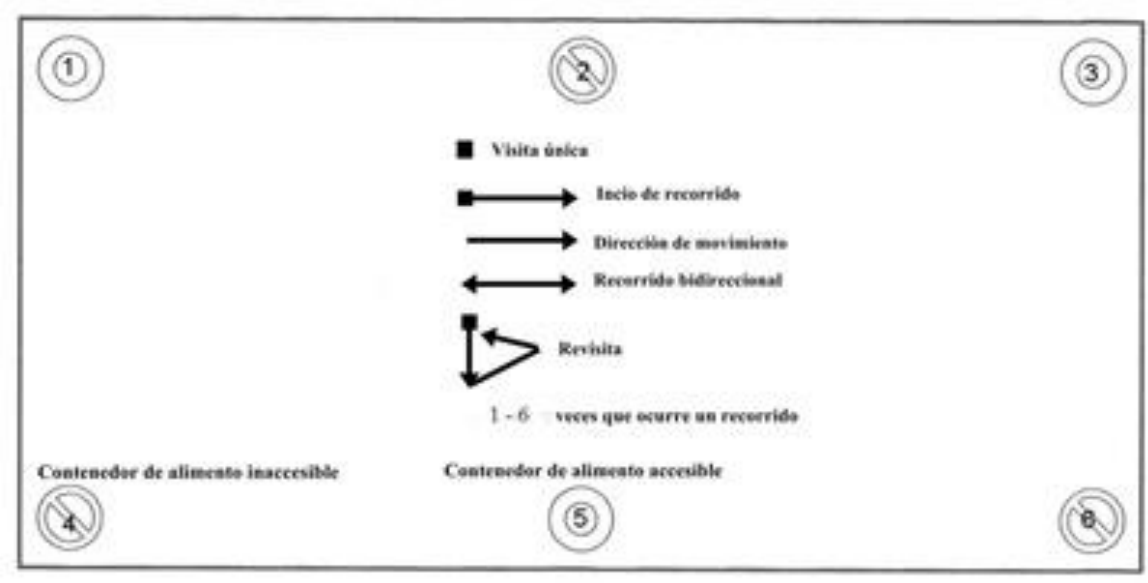

Figura 3.4: Código gráfico para representar las secuencias de desplazamiento de los individuos 
Se construyó un código de secuencias a partir del análisis gráfico de los movimientos de los monos entre los contenedores 1 a 6 . Una vez que la codificación estuvo concluida, se procedió a evaluar la repetición y la redundancia de secuencias, y a identificar los cambios entre ensayos a nivel individual.

Lo que se obtuvo en este caso fueron mapas conductuales entendidos como una representación del registro de la conducta espacial, muestreada temporalmente (a diferencia de un mapa cognitivo, que es la simulación de la imagen mental del entorno: Rifa Burrull, 1999).

\subsection{Resultados}

\subsubsection{Diseño experimental}

A lo largo de todas las etapas experimentales se describieron 10 pautas de comportamiento novedosas dirigidas al diseño en ambos grupos de estudio (Tabla 3.2):

\begin{tabular}{|c|c|}
\hline $\begin{array}{l}\text { Ingresar } \\
\text { objeto }\end{array}$ & $\begin{array}{l}\text { Ingresar la mano y antebrazo en CCA o cono plástico } \mathrm{CCl} \text { para dejar alimento u } \\
\text { objetos (piedras, palos) dentro de los mismos. }\end{array}$ \\
\hline $\begin{array}{l}\text { Retirar } \\
\text { alimento }\end{array}$ & $\begin{array}{l}\text { Introducir la mano y antebrazo en CCA y retirarlo extrayendo alimento del mismo } \\
\text { con la mano cerrada. }\end{array}$ \\
\hline $\begin{array}{l}\text { Mirar en } \\
\text { cono }\end{array}$ & $\begin{array}{l}\text { De posición parado o colgando, ubicar la cabeza sobre abertura superior dirigiendo } \\
\text { la vista hacia el interior de } \mathrm{CCA} \text { o } \mathrm{CCl} \text {. }\end{array}$ \\
\hline ver & $\begin{array}{l}\text { Introducir la mano y antebrazo en CCA para mover el alimento dentro del mismo sin } \\
\text { retirarlo. }\end{array}$ \\
\hline $\begin{array}{l}\text { Tirar en } \\
\text { cono }\end{array}$ & $\mathrm{CCl}$. \\
\hline $\begin{array}{l}\text { Comer } \\
\text { de cono }\end{array}$ & Intrc \\
\hline Girar & $\begin{array}{l}\text { Con las manos u objetos realizar movimientos descendentes repetitivos hacia el } \\
\text { exterior de CCA y/o CCl. }\end{array}$ \\
\hline Empujar & $\begin{array}{l}\text { Con una o ambas manos apoyadas sobre CCA y/o CCI realizar presión hacia arriba } \\
\text { o los costados para moverlos de lugar. }\end{array}$ \\
\hline $\begin{array}{l}\text { Morder } \\
\text { soga }\end{array}$ & $\begin{array}{l}\text { Con la boca cerrada sobre las sogas que atan los Contenedores, presionar y tirar } \\
\text { hacia los lados. }\end{array}$ \\
\hline Palanca & $\begin{array}{l}\text { Introducir objeto de largo superior a la altura de CCA y realizar movimiento } \\
\text { descendente sujetando con las manos el extremo exterior del objeto. }\end{array}$ \\
\hline
\end{tabular}

Tabla 3.2: Pautas de comportamiento novedosas dirigidas al diseño experimental 
Se describieron los resultados de cada período experimental para cada grupo por separado, en el orden cronológico en el cual se realizaron.

\subsubsection{Grupo Jaula}

\section{Período de habituación a los contenedores de alimento (PH):}

Fueron necesarios 5 ensayos de $\mathrm{PH}$ para alcanzar el punto de corte (que todos los individuos hubieran retirado al menos una vez alimento de un contenedor). Se registraron 321 eventos de visita (Gráfico 3.1). La mayor cantidad de eventos de visita se registraron en los juveniles $\mathrm{PU}(\mathrm{N}=58)$, MANU $(\mathrm{N}=52)$ y $\mathrm{NI}(\mathrm{N}=49)$, y en el infante TO $(\mathrm{N}=43)$, mientras que los individuos que presentaron menor cantidad de visitas fueron las hembras adulta CE $(\mathrm{N}=13)$ y subadulta EU $(\mathrm{N}=7)$. En la figura 3.5 se observa al individuo PU retirando alimento de un contenedor accesible (CCA).

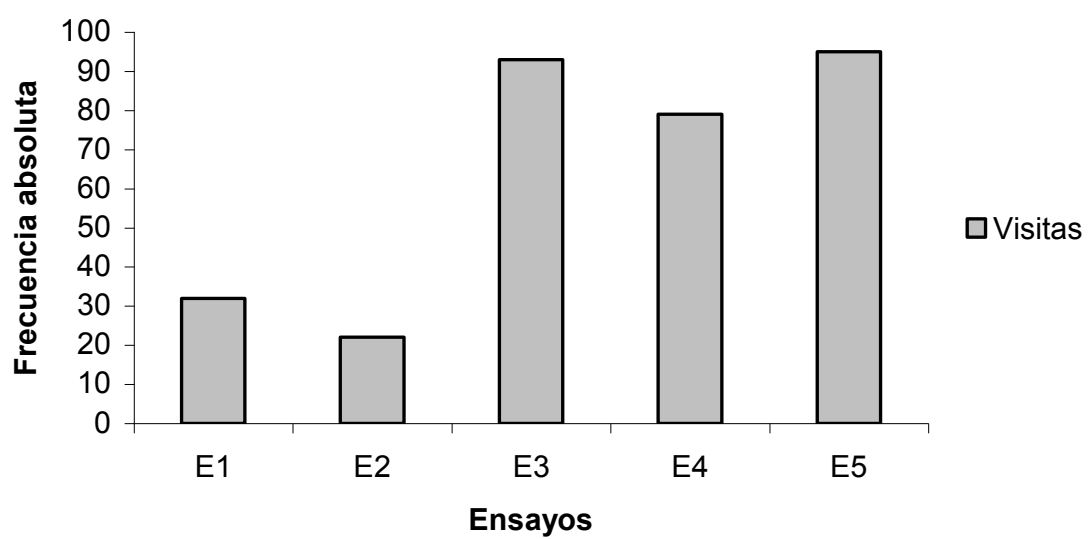

Gráfico 3.1: Visitas a contenedores por ensayo en $\mathrm{PH}(\mathrm{N}$ total $=321)$.

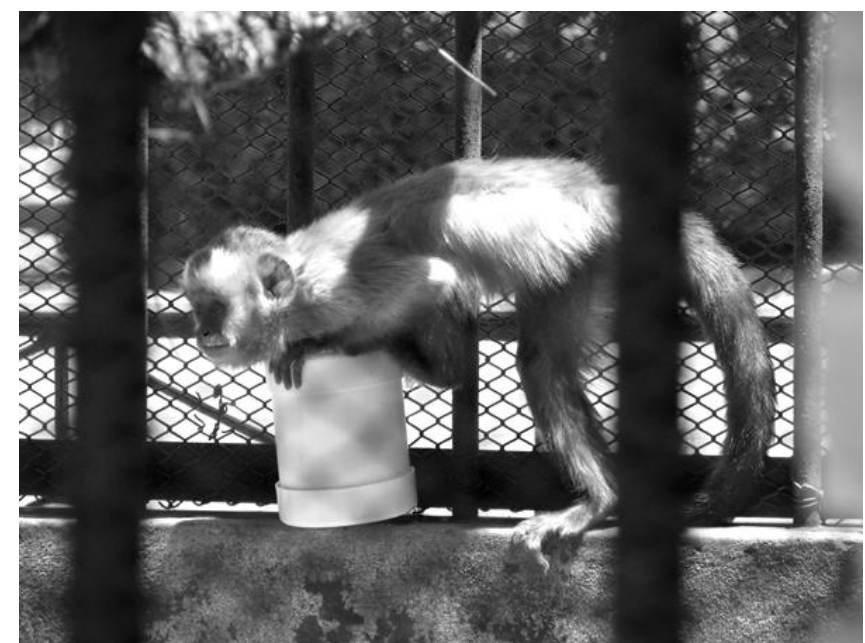

Figura 3.5: Individuo PU retirando alimento de un contenedor accesible (CCA) (M. P. Tujague) 


\section{Períodos de memoria de corto plazo 1 y 2 , e inversión de los contenedores:}

La duración de los ensayos de los períodos de memoria de corto plazo 1 y 2 , y los ensayos del período de inversión pueden verse en el gráfico 3.2.

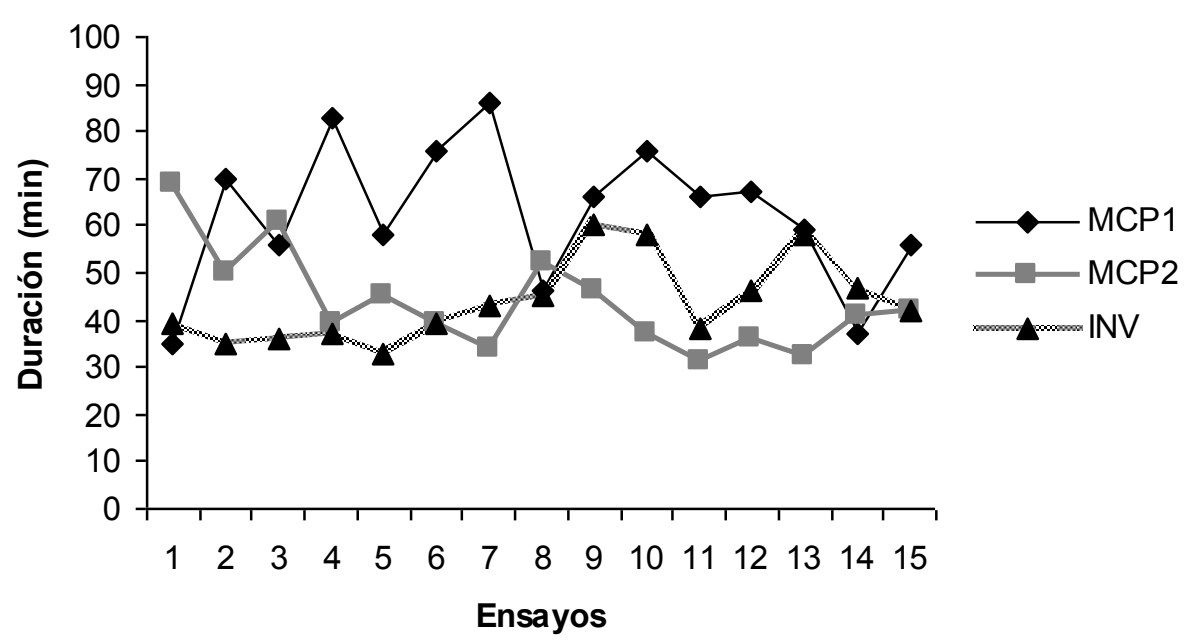

Gráfico 3.2: Duración en minutos de los ensayos de memoria de corto plazo 1 y 2 (MCP1 y MCP2), e inversión (INV) para el grupo Jaula. Media MCP1 = 62.46 \pm 15.2 DS; Media MCP2 = $43.6 \pm 10.7$ DS; Media INV $=43.7 \pm 8.7$ DS.

Memoria de corto plazo 1 (MCP1): Se realizaron 15 ensayos registrándose 931 eventos de visita ${ }^{1}$ de los cuales el $68.3 \%$ correspondió a VC $(n=645)$ y el $30.7 \%$ a VI $(n=286)$. Se presentan las cantidades totales de VC y VI en cada ensayo (Gráfico 3.3).

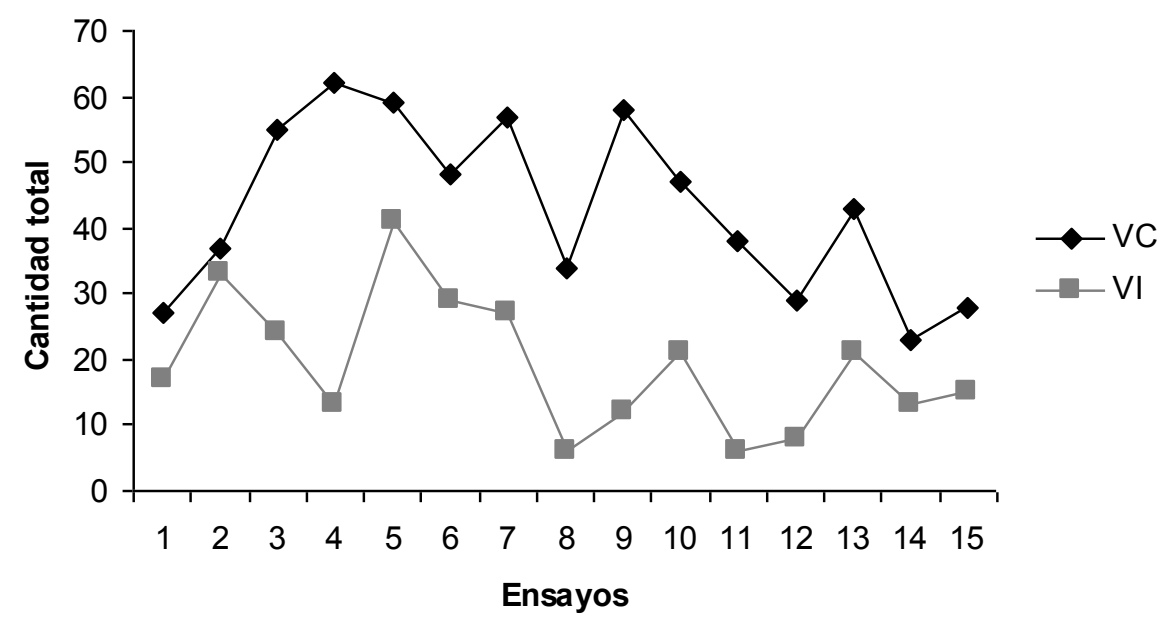

Gráfico 3.3: Visitas correctas (VC) y visitas incorrectas (VI) totales por ensayo durante MCP1.

\footnotetext{
${ }^{1}$ Para el análisis de las visitas se excluyeron aquellas en las que el individuo focal se dirigía al contenedor en el cual se encontraba otro individuo dado que no se podría saber en estos casos si la elección no se debía al hecho de observar a otro en el sitio.
} 
Todos los individuos tuvieron una performance promedio por encima de cero con elevados desvíos estándar, observándose sólo 3 valores átipicos (Gráfico 3.4, tabla 3.3). La mayor cantidad de eventos de visita (correctas e incorrectas) fueron observados en los juveniles PU ( $N=194), N I(N=146)$ y el infante TO y la hembra juvenil $R O(N=130)$, mientras que los individuos que presentaron menor cantidad de visitas fueron las hembras adulta $C E(N=30)$ y subadulta $E U(N=22)$, siendo las VC mayores que las $\mathrm{VI}$ en todos los casos. La hembra adulta CE registró valores del índice de IPME cercanos a -1 , siendo el único individuo que presentó valores tan bajos. En la tabla III.1 del Anexo III pueden observarse los IPME de cada individuo en cada ensayo.

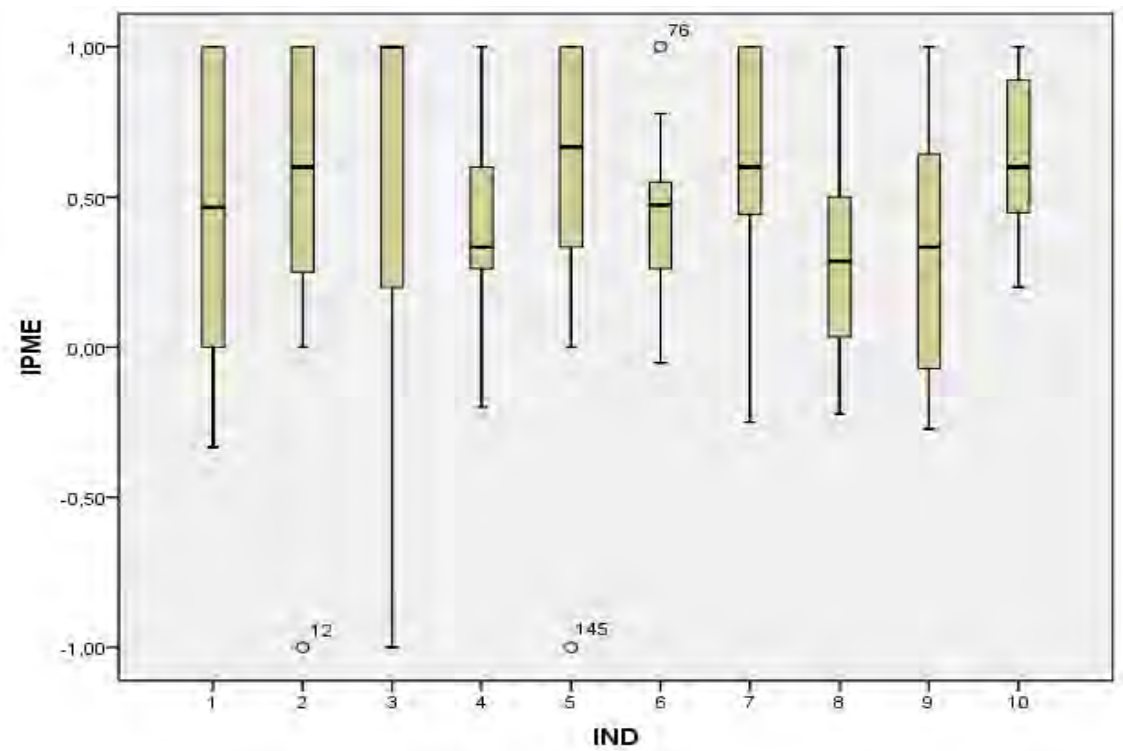

Gráfico 3.4: Valores promedio de IPME de cada individuo (IND) para la etapa experimental MCP1. Referencias: $1=\mathrm{GOR}, 2=\mathrm{CE}, 3=\mathrm{EU}, 4=\mathrm{TO}, 5=\mathrm{CH}, 6=\mathrm{PU}, 7=\mathrm{DIE}, 8=\mathrm{NI}, 9=$ MANU, $10=$ RO.

\begin{tabular}{|l|l|l|l|l|l|l|l|l|l|l|}
\hline Individuos & GOR & CE & EU & TO & CH & PU & DIE & $\begin{array}{l}\text { NI } \\
(4)\end{array}$ & $\begin{array}{l}\text { MANU } \\
(9)\end{array}$ & $\begin{array}{l}\text { RO } \\
(1)\end{array}$ \\
\hline Promedio \pm & $0,44 \pm$ & $0,48 \pm$ & $0,56 \pm$ & $0,43 \pm$ & $0,57 \pm$ & $0,43 \pm$ & $0,62 \pm$ & $0,29 \pm$ & $0,34 \pm$ & $0,63 \pm$ \\
desví & 0,46 & 0,61 & 0,67 & 0,32 & 0,58 & 0,26 & 0,39 & 0,39 & 0,45 & 0,27 \\
\hline IC $95 \%$ & $0,17-$ & $0,07-$ & $0,08-$ & $0,25-$ & $0,21-$ & $0,29-$ & $0,4-$ & $0,07-$ & $0,08-$ & $0,48-$ \\
& 0,7 & 0,9 & 1,04 & 0,61 & 0,92 & 0,58 & 0,8 & 0,51 & 0,58 & 0,78 \\
\hline $\mathrm{N}$ & 14 & 11 & 10 & 15 & 13 & 15 & 15 & 15 & 15 & 15 \\
\hline
\end{tabular}

Tabla 3.3: Valores promedios, desvíos estándar e intervalos de confianza al 95\% de IPME de los individuos para MCP1 del grupo Jaula. 
Considerando que dentro del grupo estudiado se encontraban representados individuos de todas las categorías de edad y de ambos sexos, se procedió a analizar si existían diversos desempeños en estos grupos.

Los machos presentaron una performance promedio menor que las hembras, registrando en ambos grupos elevados desvíos estándar (IPME promedio machos = $0,41 \pm 0,41 \mathrm{DS}$, IC 95\%: 0,32 - 0,50, N=87); IPME promedio hembras $=0,58 \pm 0,47$ DS, IC 95\%: 0,45 - 0,71, N=51). En la tabla IV.1 del Anexo IV puede consultarse la tabla con los promedios, desvíos estándar e intervalos de confianza de cada sexo separado por ensayo para este período experimental.

En cuanto a las categorías de edad (Gráfico 3.5) puede observarse que entre los adultos existe un elevado desvío estándar con valores en el límite inferior cercanos a 1, aunque el promedio del grupo se encontró por encima de cero. Subadultos, juveniles e infante lograron una performance promedio también por encima de cero con desvíos estándar menores, siendo los subadultos los únicos que no registraron valores por debajo de cero para el IPME. Los valores promedio y estadísticos asociados de cada categoría de edad por ensayo pueden consultarse en la tabla IV.2 del Anexo IV.

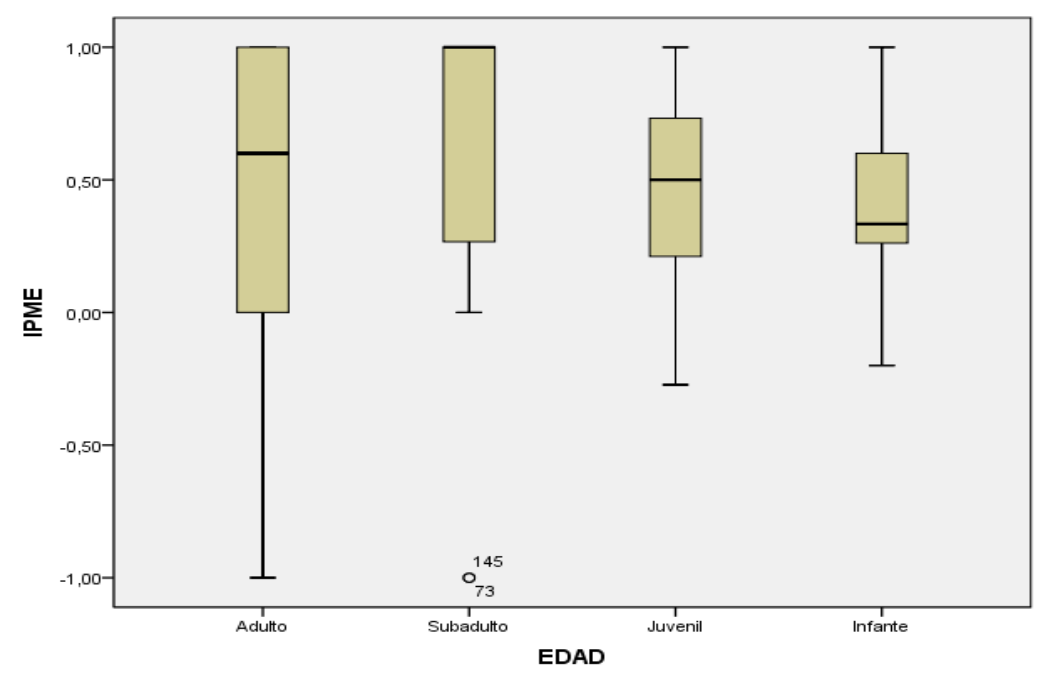

Gráfico 3.5: IPME promedio por categorías de edad para MCP1. Adultos: 0,46 $\pm 0,52 \mathrm{DS}$, IC 95\%: 0,24-0,67, ( $N=25)$; Subadultos: 0,56 \pm 0,6 DS, IC 95\%: 0,3-0,83, ( $N=23)$; Juveniles: 0,47 \pm 0,38 DS, IC 95\%: 0,37-0,55, (N=75); Infante: 0,43 \pm 0,32 DS, IC 95\%: 0,25-0,61 ( $N=15)$.

Memoria de corto plazo 2 (MCP2): Se realizaron 15 ensayos registrándose 1287 eventos de visita de los cuales el $85.86 \%$ correspondió a VC $(n=1105)$ y el $14.14 \%$ a VI $(n=182)$. Se presentan las cantidades totales de VC y VI en cada ensayo (Gráfico 3.6), donde puede observarse que los valores de VI fueron inferiores a los de VC a lo largo de los ensayos, y ambas curvas son estables con fluctuaciones escasas a 
diferencia de lo observado en el gráfico 3.3.

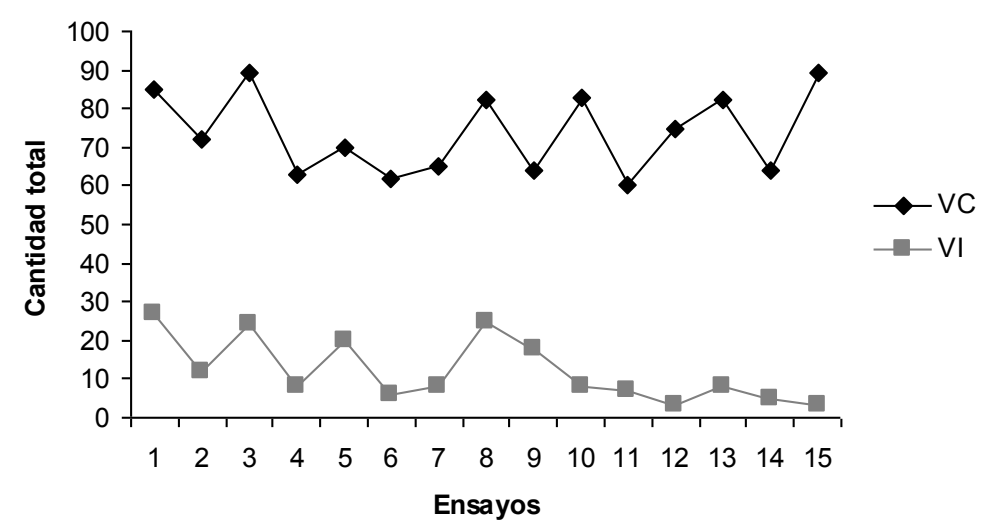

Gráfico 3.6: Visitas correctas (VC) y visitas incorrectas (VI) durante MCP2.

Durante este período experimental todos los individuos tuvieron una performance promedio por encima de 0 con desvíos estándar menores al período experimental precedente (Gráfico 3.7, tabla 3.4). Es importante resaltar que ninguno de los individuos registró valores de IPME por debajo de cero. La mayor cantidad de eventos de visita fueron observados en el subadulto $\mathrm{CH}(\mathrm{N}=209)$, los juveniles $\mathrm{RO}(\mathrm{N}=166)$ y MANU ( $N=168)$ y el infante TO $(\mathrm{N}=191)$, mientras que los individuos que presentaron menor cantidad de visitas (y menor IPME promedio) fueron el macho adulto GOR $(\mathrm{N}=101)$ y la hembra adulta $\mathrm{CE}(\mathrm{N}=59)$, siendo las $\mathrm{VC}$ mayores que las $\mathrm{VI}$ en todos los casos. En la tabla III.2 del Anexo III pueden observarse los IPME de cada individuo en cada ensayo.

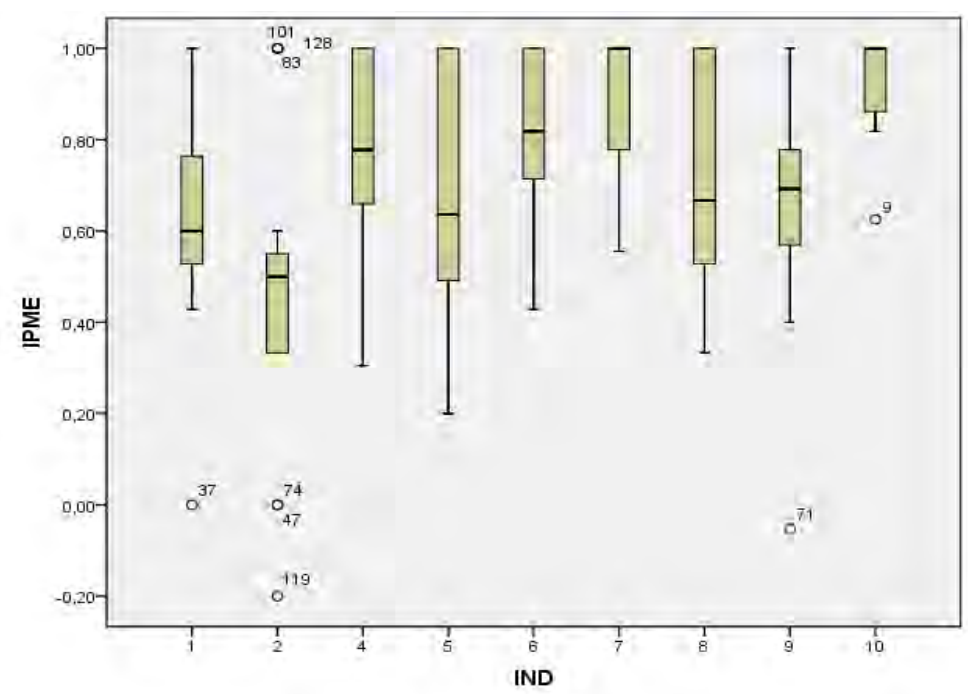

Gráfico 3.7: Valores promedio de IPME de cada individuo (IND) para la etapa experimental MCP2. Referencias: $1=\mathrm{GOR}, 2=\mathrm{CE}, 3=\mathrm{EU}, 4=\mathrm{TO}, 5=\mathrm{CH}, 6=\mathrm{PU}, 7=\mathrm{DIE}, 8=\mathrm{NI}, 9=$ MANU, $10=$ RO. 


\begin{tabular}{|l|l|l|l|l|l|l|l|l|l|}
\hline Individuos & GOR & CE & TO & CH & PU & DIE & NI & MANU & RO \\
$(1)$ & $(2)$ & $(4)$ & $(5)$ & $(6)$ & $(7)$ & $(8)$ & $(9)$ & $(10)$ \\
\hline Promedio \pm & $0,64 \pm$ & $0,44 \pm$ & $0,78 \pm$ & $0,67 \pm$ & $0,81 \pm$ & $0,89 \pm$ & $0,73 \pm$ & $0,65 \pm$ & $0,93 \pm$ \\
desvío & 0,26 & 0,36 & 0,21 & 0,29 & 0,2 & 0,15 & 0,24 & 0,26 & 0,1 \\
\hline IC $95 \%$ & $0,49-$ & $0,24-$ & $0,66-$ & $0,51-$ & $0,7-$ & $0,81-$ & $0,59-$ & $0,5-$ & $0,87-$ \\
& 0,78 & 0,64 & 0,9 & 0,83 & 0,93 & 0,98 & 0,86 & 0,79 & 0,99 \\
\hline $\mathrm{N}$ & 15 & 15 & 15 & 15 & 15 & 15 & 15 & 15 & 15 \\
\hline
\end{tabular}

Tabla 3.4: Valores promedios, desvíos estándar e intervalos de confianza al 95\% de IPME de los individuos para MCP2 del grupo Jaula.

Ambos sexos presentaron una performance promedio elevada y desvíos estándar bajos (IPME promedio machos = 0,71 $\pm 0,25 \mathrm{DS}, \mathrm{IC} 95 \%$ : 0,66 - 0,77, N=90; IPME promedio hembras $=0,76 \pm 0,32 \mathrm{DS}, \mathrm{IC} 95 \%$ : 0,66 -0,85, N=45). En la tabla IV.3 del Anexo IV pueden consultarse los promedios, desvíos estándar e intervalos de confianza de cada sexo por ensayo.

En cuanto a las categorías de edad (Gráfico 3.8) puede observarse que entre los adultos se alcanzaron valores negativos, aunque el promedio del grupo se encontró por encima de cero, mientras que subadultos, juveniles e infante lograron una performance promedio por encima de cero, y superior a la de los adultos, con desvíos estándar menores, siendo juveniles e infante los grupos que presentaron IPME promedio más altos. Los valores promedio y estadísticos asociados de cada categoría de edad por ensayo pueden verse en la tabla IV.4 del Anexo IV.

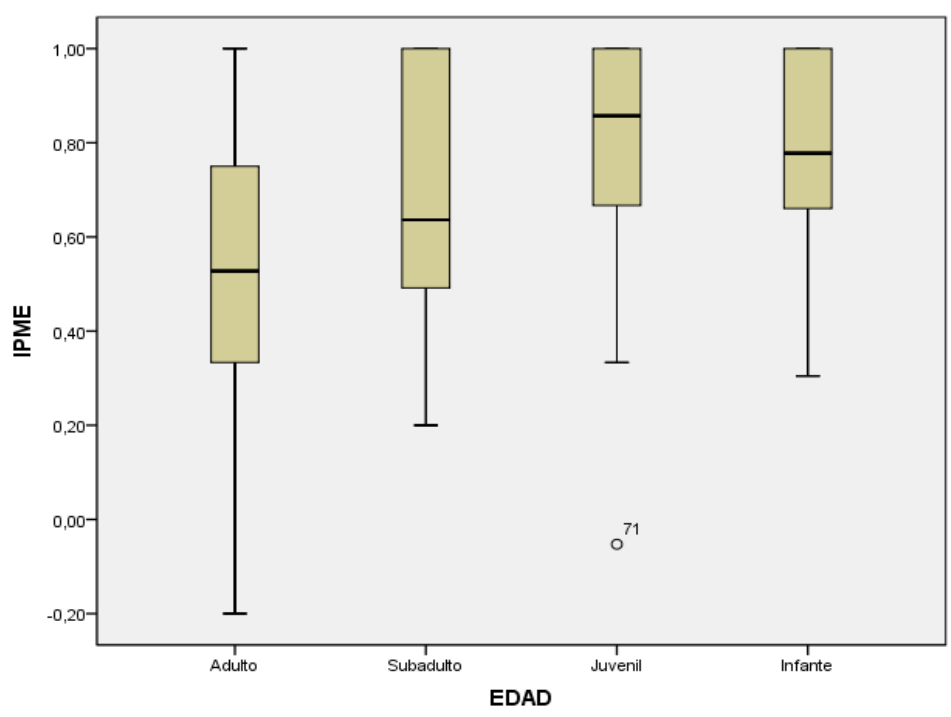

Gráfico 3.8: IPME promedio por categorías de edad para MCP2. Adultos: $0,54 \pm 0,32 \mathrm{DS}$, IC 95\%:0,42-0,66, ( $N=30)$; Subadultos: 0,67 $\pm 0,29 \mathrm{DS}$, IC 95\%: 0,51-0,83 ( $\mathrm{N}=15)$; Juveniles: 0,80 $\pm 0,22$ DS, IC 95\%: 0,75-0,85 ( $N=75$ ); Infante: 0,78 $\pm 0,21$ DS, IC 96\%: 0,66-0,9 ( $N=15)$.

Período de inversión de los contenedores (INV): Se realizaron 15 ensayos durante el período de inversión registrándose 1279 eventos de visita de los cuales el $71.5 \%$ 
corresponde a VC $(n=914)$ y el $28.5 \%$ a VI $(n=365)$. Se presentan las cantidades totales de VC y VI en cada ensayo (Gráfico 3.9), donde puede observarse que en el primer ensayo los valores de visitas incorrectas fueron elevados.

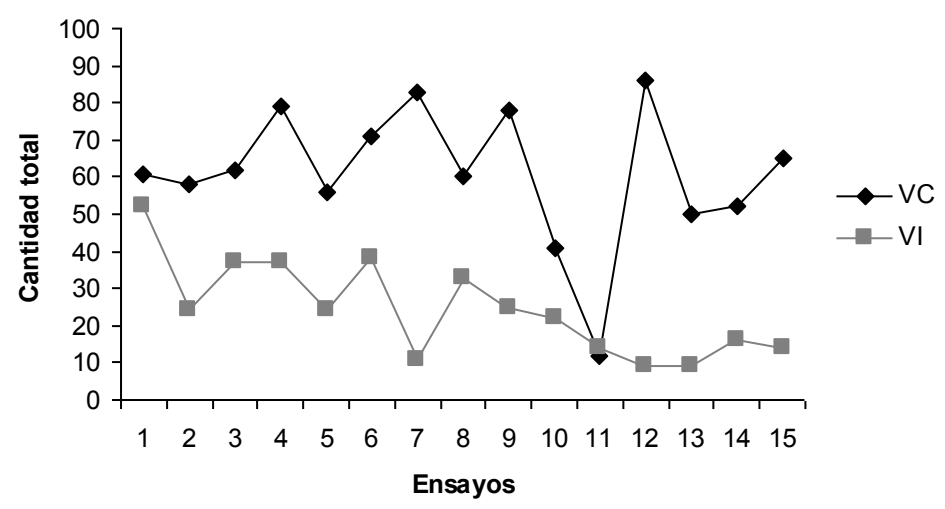

Gráfico 3.9: Visitas correctas (VC) y visitas incorrectas (VI) durante INV.

Todos los individuos tuvieron una performance promedio por encima de cero pero 4 de ellos tuvieron desvíos estándar que indicaron una performance por debajo de cero (Gráfico 3.10, tabla 3.5), alcanzando valores negativos de IPME. La mayor cantidad de eventos de visita fueron observados en los juveniles PU (N=263), $\mathrm{NI}(\mathrm{N}=178)$, MANU $(\mathrm{N}=171)$, RO $(\mathrm{N}=158)$ y el infante TO $(\mathrm{N}=163)$, mientras que los individuos que presentaron menor cantidad de visitas fueron el macho adulto $\mathrm{GOR}(\mathrm{N}=75)$ y la hembra adulta $\mathrm{CE}(\mathrm{N}=88)$, quien registró el valor promedio de IPME más bajo. En la tabla III.3 del Anexo III pueden observarse los IPME de cada individuo en cada ensayo.

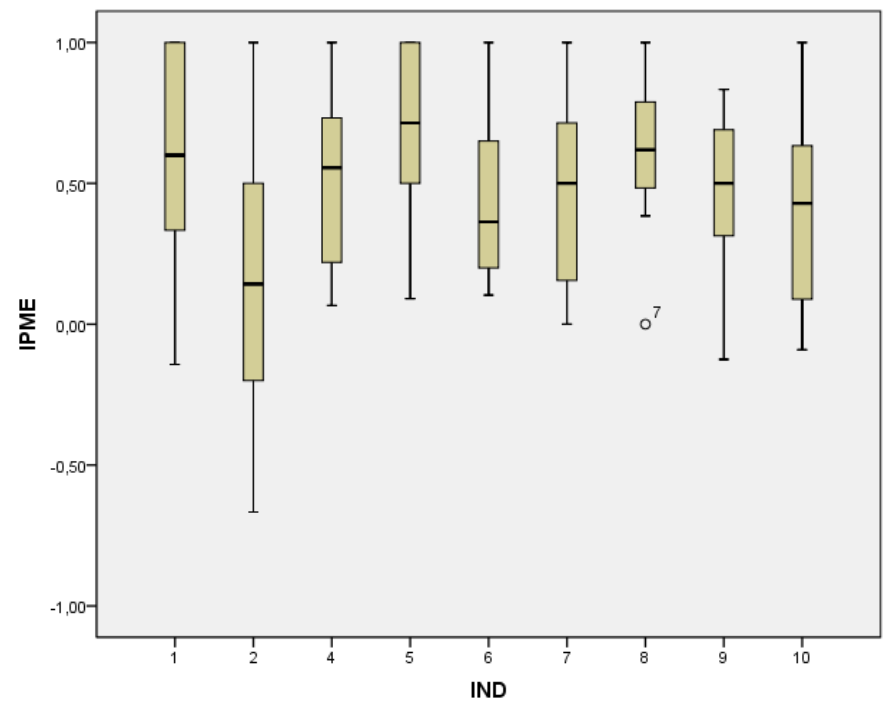

Gráfico 3.10: Valores promedio de IPME de cada individuo (IND) para la etapa experimental INV. Referencias: $1=\mathrm{GOR}, 2=\mathrm{CE}, 3=\mathrm{EU}, 4=\mathrm{TO}, 5=\mathrm{CH}, 6=\mathrm{PU}, 7=\mathrm{DIE}, 8=\mathrm{NI}, 9=$ MANU, $10=$ RO. 


\begin{tabular}{|l|l|l|l|l|l|l|l|l|l|}
\hline Individuos & GOR & CE & TO & CH & PU & DIE & NI & MANU & RO \\
& $(1)$ & $(2)$ & $(4)$ & $(5)$ & $(6)$ & $(7)$ & $(8)$ & $(9)$ & $(10)$ \\
\hline Promedio & $0,6 \pm$ & $0,13 \pm$ & $0,52 \pm$ & $0,7 \pm$ & $0,45 \pm$ & $0,47 \pm$ & $0,6 \pm$ & $0,47 \pm$ & $0,4 \pm$ \\
\pm desvío & 0,41 & 0,44 & 0,33 & 0,3 & 0,31 & 0,36 & 0,24 & 0,29 & 0,32 \\
\hline IC $95 \%$ & $0,37-$ & $-0,12-$ & $0,33-$ & $0,51-$ & $0,27-$ & $0,27-$ & $0,46-$ & $0,31-$ & $0,22-$ \\
& 0,83 & 0,38 & 0,7 & 0,89 & 0,62 & 0,67 & 0,73 & 0,63 & 0,58 \\
\hline $\mathrm{N}$ & 15 & 14 & 15 & 12 & 15 & 15 & 15 & 15 & 15 \\
\hline
\end{tabular}

Tabla 3.5: Valores promedios, desvíos estándar e intervalos de confianza al 95\% de IPME de los individuos para INV del grupo Jaula.

Ambos sexos presentaron una performance promedio por encima de cero pero intermedia a baja y desvíos estándar bajos, siendo las hembras las que tuvieron un promedio menor (IPME promedio machos $=0,55 \pm 0,35$ DS, IC 95\%: 0,48 - 0,62; IPME promedio hembras $=0,34 \pm 0,39 \mathrm{DS}$, IC 95\%: 0,22 - 0,46). En la tabla IV.5 del Anexo IV pueden consultarse los promedios, desvíos estándar e intervalos de confianza de cada sexo por ensayo.

Con respecto a las categorías de edad (Gráfico 3.1) puede observarse que entre los adultos existió un elevado desvío estándar, aunque el promedio del grupo se encontró por encima de cero, mientras que subadultos, juveniles e infante lograron una performance promedio superior a la de los adultos, con desvíos estándar menores, siendo los subadultos los que presentaron IPME promedio más altos. Los valores promedio y estadísticos asociados de cada categoría de edad por ensayo pueden verse en la tabla IV.6 del Anexo IV.

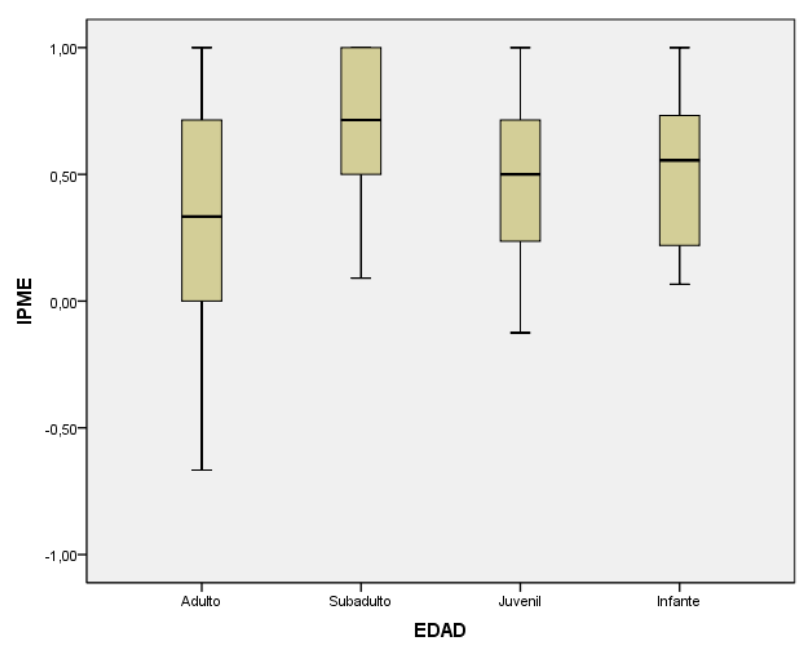

Gráfico 3.11: IPME promedio por categorías de edad para INV. Adultos: $0,37 \pm 0,48 \mathrm{DS}$, IC: 0,19-0,56 ( $N=29)$; Subadultos: 0,7 $\pm 0,3 \mathrm{DS}, \mathrm{IC}: 0,51-0,89(\mathrm{~N}=12)$; Juveniles: 0,48 $\pm 0,31 \mathrm{DS}$, IC: 0,4-0,55 (N=75); Infante: 0,52 $\pm 0,33 \mathrm{DS}$, IC: 0,33-0,7 (N=15). 


\section{Modelo generalizado lineal de efectos mixtos (MGLM) para el grupo Jaula:}

El modelo con mejor fit fue el modelo original que es aquel que incluyó todos los efectos fijos a la vez (ensayos, períodos experimentales, categoría de edad y sexo de los individuos). Se encontraron diferencias en la performance entre los ensayos dentro de cada período del experimento (MLGM, Chiq $=29.316, \mathrm{p}=6.148 \mathrm{e}-08, \mathrm{gl}=1)$, y también diferencias entre los diferentes períodos de memoria de corto plazo 1 y 2 (MCP1, MCP2) e inversión espacial (INV) de los contenedores (MLGM, Chiq = 44.659, $p=2.006 \mathrm{e}-10, \mathrm{gl}=2)$. No se encontraron diferencias entre los sexos (MLGM, Chiq = $0.0056, \mathrm{p}=0.9403, \mathrm{gl}=1)$ ni entre categorías de edad $(\mathrm{MLGM}$, Chiq $=5.7283, \mathrm{p}=$ $0.1276, \mathrm{gl}=3$ ).

La varianza asociada al efecto aleatorio "individuos" fue de 0.005 , representando el $4,1 \%$ de la varianza total del modelo. Dado que la varianza del efecto aleatorio fue baja, puede concluirse que otros efectos no considerados en el modelo en relación a las diferencias entre individuos no fueron importantes.

En cuanto a los valores de IPME por ensayo en cada período experimental (promedio de los valores individuales), la performance aumentó con los ensayos dentro de cada período (Tabla 3.6). Tanto MCP2 como INV presentaron mayores valores que MCP1, pero la etapa MCP2 fue la que presentó valores más altos. En el período experimental INV se observó un aumento del promedio en los últimos 5 ensayos. 


\begin{tabular}{|c|c|c|c|}
\hline $\begin{array}{l}\text { Período } \\
\text { experim. } \\
\text { Ensayos }\end{array}$ & MCP1 & MCP2 & INV \\
\hline 1 & $0,43 \pm 0,48$ IC: $0,06-0,8$ & $0,57 \pm 0,17$ IC: $0,43-0,7$ & $0,1 \pm 0,17$ IC: $-0,02-0,24$ \\
\hline 2 & $0,12 \pm 0,56$ IC: $-0,3-0,5$ & $0,65 \pm 0,2$ IC: $0,48-0,82$ & $0,45 \pm 0,25$ IC: $0,24-0,65$ \\
\hline 3 & $0,4 \pm 0,3$ IC: $0,18-0,52$ & $0,58 \pm 0,19$ IC: $0,43-0,73$ & $0,23 \pm 0,28$ IC: $0,02-0,45$ \\
\hline 4 & $0,68 \pm 0,2$ IC: $0,52-0,84$ & $0,7 \pm 0,21$ IC: $0,61-0,94$ & $0,37 \pm 0,34$ IC: $0,1-0,63$ \\
\hline 5 & $0,34 \pm 0,43$ IC: $0,007-0,67$ & $0,56 \pm 0,3$ IC: $0,3-0,82$ & $0,41 \pm 0,21$ IC: $0,24-0,57$ \\
\hline 6 & $0,45 \pm 0,46$ IC: $0,09-0,8$ & $0,79 \pm 0,3$ IC: $0,53-1,04$ & $0,38 \pm 0,3$ IC: $0,15-0,62$ \\
\hline 7 & $0,33 \pm 0,06$ IC: $0,61-0,35$ & $0,75 \pm 0,26$ IC: $0,55-0,95$ & $0,76 \pm 0,36$ IC: $0,48-1,04$ \\
\hline 8 & $0,57 \pm 0,64$ IC: 1,00 - 0, & $0,57 \pm 0,29$ IC: $0,34-0,79$ & $0,2 \pm 0,42$ IC: $-0,09-0,5$ \\
\hline 9 & $0,68 \pm 0,2$ IC: $0,54-0,83$ & $0,57 \pm 0,32$ IC: $0,32-0,82$ & $0,59 \pm 0,34$ IC: $0,32-0,86$ \\
\hline 10 & $0,49 \pm 0,35$ IC: $0,24-0,74$ & $0,85 \pm 0,18$ IC: $0,71-0,99$ & $0,3 \pm 0,41$ IC: $-0,01-0,62$ \\
\hline 11 & $0,72 \pm 0,35$ IC: $0,47-0,97$ & $0,76 \pm 0,24$ IC: $0,58-0,95$ & $0,63 \pm 0,3$ IC: $0,37-0,89$ \\
\hline 12 & $0,67 \pm 0,39$ IC: $0,37-0,97$ & $0,92 \pm 0,15$ IC: $0,8-1,00$ & $0,79 \pm 0,15$ IC: $0,67-0,92$ \\
\hline 13 & $0,5 \pm 0,37$ IC: $0,25-0,84$ & $0,81 \pm 0,19$ IC: $0,6-0,96$ & $0,65 \pm 0,35$ IC: $0,35-0,95$ \\
\hline 14 & $0,41 \pm 0,53$ IC: $-0,03-0,85$ & $0,81 \pm 0,41$ IC: $0,49-1,12$ & $0,61 \pm 0,32$ IC: $0,34-0,89$ \\
\hline 15 & $0,21 \pm 0,6$ IC: $-0,29-0,71$ & $0,95 \pm 0,08$ IC: $0,89-1,00$ & $0,73 \pm 0,26$ IC: $0,5-0,95$ \\
\hline
\end{tabular}

Tabla 3.6: IPME promedios \pm desvíos estándar (DS) e intervalos de confianza al 95\% (IC 95\%) por ensayo para cada período experimental del grupo Jaula.

A pesar de las diferencias encontradas entre los ensayos dentro de cada período experimental, no se encontraron diferencias significativas entre los valores promedio del IPME para el primero y último ensayos de MCP1 (t E1-E15 $=0.63, p=0,544, \mathrm{IC}$ 95\% para la diferencia de medias: $-0,4-0,7$; media $\mathrm{E} 1=0,36 \pm 0,46$, media $\mathrm{E} 15=$ $0,21 \pm 0,60)$. Se estimó el tamaño del efecto para esta comparación de medias, encontrándose que la magnitud de las diferencias entre ambos ensayos fue baja ( $d$ de Cohen $=-0,25 ; N=17$ ). El signo negativo del valor del $d$ de Cohen indicó que la puntuación del ensayo 15 fue menor que el del ensayo 1, algo que puede observarse analizando los valores de las medias. Para el período experimental MCP2 se encontraron diferencias significativas entre los promedios del IPME de los individuos de los ensayos E1 y E15 ( $t=-7.707, p=0.000$, IC 95\% para la diferencia de medias: $0,5--0,27$, media $\mathrm{E} 1=0,57 \pm 0,17 \mathrm{DS}$; media $\mathrm{E} 15=0,95 \pm 0,08 \mathrm{DS})$, lo que indicó un aumento de la consolidación de la memoria. El tamaño del efecto de esta comparación de medias fue elevado ( $d$ de Cohen $=4,75 ; \mathrm{N}=20$ ). En cuanto a los 
ensayos 1 y 15 de INV, también se encontraron diferencias significativas entre los promedios ( $\mathrm{E} 1-\mathrm{E} 15=-6.135, \mathrm{p}=0,000$, IC 95\% para la diferencia de medias: $-0,85$ - 0,38; media $\mathrm{E} 1=0,1 \pm 0,18 \mathrm{DS}$; media E15 = 0,73 $\pm 0,26 \mathrm{DS})$, indicando que al inicio los individuos disminuyeron su performance de manera abrupta pero al final la misma se había recuperado. El tamaño del efecto de esta comparación de medias fue elevado ( $d$ de Cohen = 2,43; $N=20$ ).

Períodos de memoria de largo plazo 1 y 2: se realizaron dos ensayos únicos de memoria de largo plazo, uno a los 76 días del último ensayo MCP1 y previo al inicio de los ensayos del período MCP2 (llamado ensayo de memoria de largo plazo 1 o MLP1), y un ensayo de memoria de largo plazo 2 (MLP2) al haber transcurrido 4 meses del último ensayo MCP2, previo al inicio del período experimental INV.

Memoria de largo plazo 1 (MLP1): todos los individuos presentaron valores de IPME por encima de cero, registrándose un total de 87 visitas correctas y 27 incorrectas totales (en la tabla III.4 del Anexo III pueden consultarse los valores de IPME por individuo). A pesar del valor superior a cero y el bajo desvío estándar del promedio de IPME de este ensayo, no se encontraron diferencias significativas entre los IPME promedio del último ensayo de MCP1 y el ensayo de MLP1 (t E15 MCP1 - E MLP1 = 1.828, $p=0,110$; IC 95\% para la diferencia de medias: $-0,83-0,1$; media $E 15$ MCP1 = $0,21 \pm 0,60$; media MLP1 $=0,57 \pm 0,17$ ). Sin embrago se estimó el tamaño del efecto para esta comparación de medias, encontrándose que existió una diferencia en la performance promedio entre ambos ensayos (tamaño del efecto elevado) no explicada por el resultado no significativo del test ( $d$ de Cohen $=2,11 ; \mathrm{N}=18$ ).

Memoria de largo plazo 2 (MLP2): los valores de IPME de cada individuo durante el ensayo MLP2 fueron superiores a cero, registrándose un total de 55 visitas correctas y 11 incorrectas totales (en la tabla III.4 del Anexo III pueden consultarse los valores de IPME por individuo). No se encontraron diferencias significativas en los valores promedio de IPME del último ensayo MCP2 y el ensayo único MLP2 (t E15 MCP2- E MLP2 $=1.983, p=0,083$; IC 95\% para la diferencia de medias: $-0,03-0,45$; media $E 15$ $=0,95 \pm 0,08 \mathrm{DS} ;$ media $\mathrm{E} \mathrm{MLP2}=0,75 \pm 0,35 \mathrm{DS}$ ). Se estimó el tamaño del efecto para esta comparación de medias, encontrándose que el mismo fue bajo y negativo ( $d$ de Cohen = - 0,57; $N=20$ ).

\subsubsection{Grupo Isla}

\section{Período de habituación a los contenedores de alimento (PH):}

Se necesitó solo 1 ensayo para alcanzar el punto de corte para esta etapa. Se registraron un total de 17 visitas, con la mayor cantidad para los adultos ÑO (Figura 
3.6) y ALE ( $N=4$ cada uno), seguidos por MAT (juvenil, $N=2$ ), y por último la adulta MAMI y los infantes FER y JU con 2 visitas cada uno.

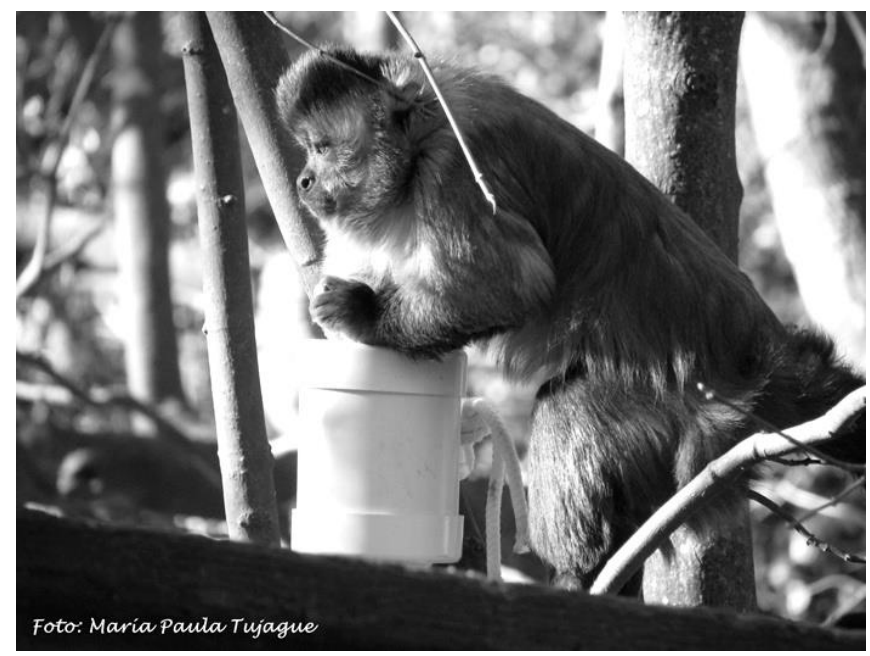

Figura 3.6: Individuo ÑO retirando alimento de CCA (M. P. Tujague)

\section{Períodos de memoria de corto 1 y 2 , e inversión de los contenedores:}

La duración de los ensayos de los períodos 1 y 2 de memoria de corto plazo, y los ensayos del período de inversión pueden observarse en el gráfico 3.12.

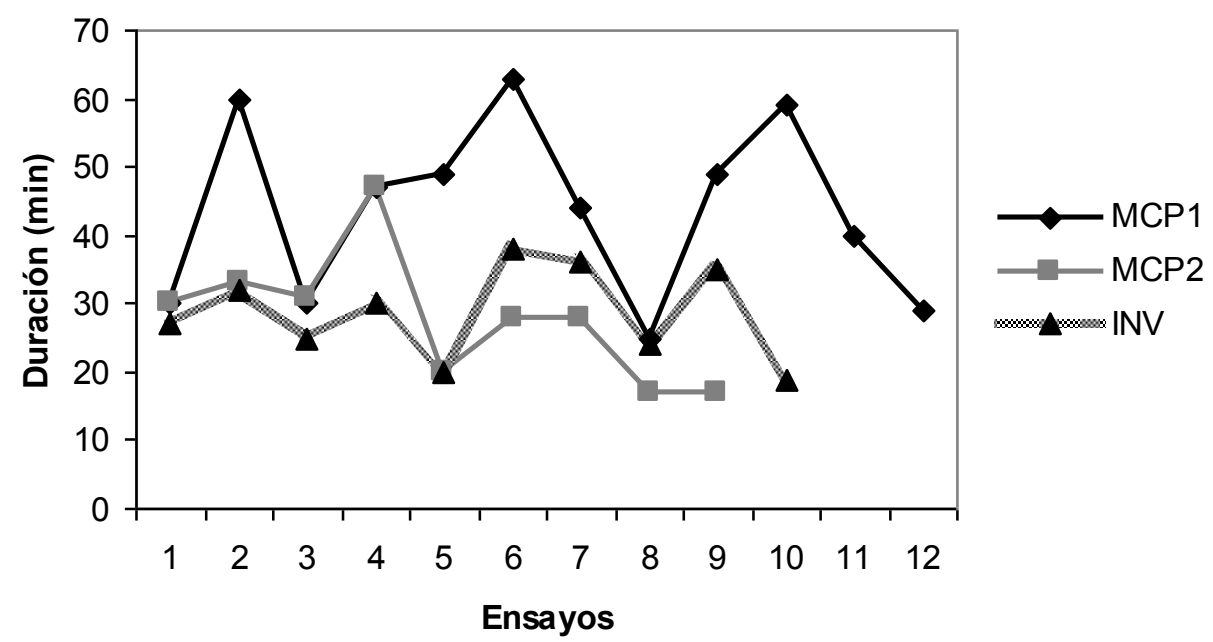

Gráfico 3.12: Duración en minutos de los ensayos de memoria de corto plazo 1 y 2 (MCP1 y MCP2), e inversión (INV) para el grupo Isla. Media MCP1 = $43.7 \pm 13.1$ DS; Media MCP2 = $27.9 \pm 9.3$ DS; Media INV $=28.6 \pm 6.7$ DS.

Memoria de corto plazo 1 (MCP1): Se realizaron 12 ensayos registrándose 570 eventos de visita de los cuales el $64 \%$ correspondió a VC $(\mathrm{N}=635)$ y el $36 \%$ a VI $(\mathrm{N}=205)$. Se presentan las cantidades totales de VC y VI en cada ensayo, siendo las 
VC mayores que las VI en todos los casos, excepto en ensayo 9 donde se registraron 24 visitas correctas y 26 incorrectas (Gráfico 3.13).

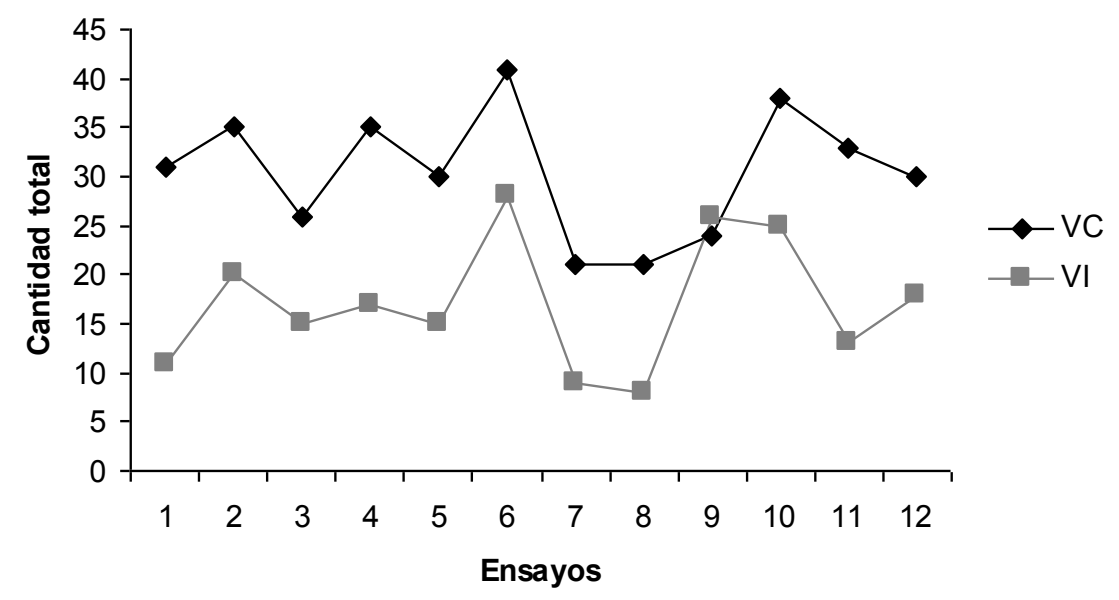

Gráfico 3.13: Visitas correctas (VC) y visitas incorrectas (VI) durante MCP1.

Aunque todos los individuos tuvieron una performance promedio por encima de cero, se registró una variación importante entre ellos, observándose en los dos infantes y el único macho adulto ÑO valores negativos de IPME (Gráfico 3.14, tabla 3.7). La mayor cantidad de eventos de visita fueron observados en los adultos $\tilde{N} O(N=112)$ y MAMl $(\mathrm{N}=121)$ y en el juvenil MAT $(\mathrm{N}=173)$, mientras que los individuos que presentaron menor cantidad de visitas fueron la hembra adulta restante ALE $(N=60)$ y los infantes JU ( $\mathrm{N}=33)$ y FER $(\mathrm{N}=71)$ En la tabla III.5 del Anexo III pueden observarse los IPME de cada individuo en cada ensayo.

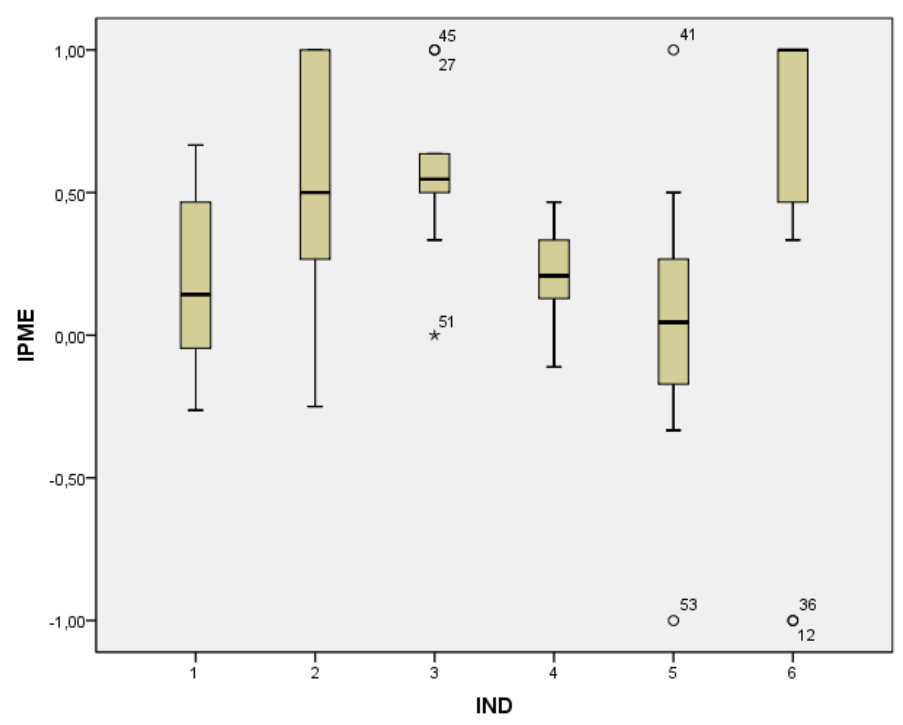

Gráfico 3.14: Valores promedio de IPME de cada individuo (IND) para la etapa experimental MCP1. Referencias: $1=$ ÑO, $2=$ ALE, $3=$ MAMI, $4=$ MAT, $5=$ FER, $6=\mathrm{JU}$. 


\begin{tabular}{|l|l|l|l|l|l|l|}
\hline Individuo & $\begin{array}{l}\mathrm{NO} \\
(1)\end{array}$ & $\begin{array}{l}\text { ALE } \\
(2)\end{array}$ & $\begin{array}{l}\text { MAMI } \\
(3)\end{array}$ & $\begin{array}{l}\text { MAT } \\
(4)\end{array}$ & $\begin{array}{l}\text { FER } \\
(5)\end{array}$ & $\begin{array}{l}\text { JU } \\
(6)\end{array}$ \\
\hline $\begin{array}{l}\text { Promedio } \pm \\
\text { desví }\end{array}$ & $0,18 \pm 0,31$ & $0,52 \pm 0,42$ & $0,56 \pm 0,26$ & $0,2 \pm 0,17$ & $0,03 \pm 0,48$ & $0,5 \pm 0,7$ \\
\hline IC $95 \%$ & $-0,009-0,38$ & $0,25-0,79$ & $0,4-0,73$ & $0,09-0,31$ & $-0,27-0,34$ & $-0,01-1$ \\
\hline $\mathrm{N}$ & 12 & 12 & 12 & 12 & 12 & 11 \\
\hline
\end{tabular}

Tabla 3.7: Valores promedios, desvíos estándar e intervalos de confianza al 95\% de IPME de los individuos para MCP1 del Grupo Isla.

Los machos presentaron una performance promedio cercana a cero mientras que las hembras tuvieron una mejor performance promedio aunque con elevado desvío estándar (IPME promedio machos $=0,14 \pm 0,34$ DS, IC 95\%: 0,02 - 0,26; IPME promedio hembras $=0,53 \pm 0,50$ DS, IC 95\%: 0,35 - 0,7). En el Anexo IV puede consultarse la tabla IV.7 con los promedios, desvíos estándar e intervalos de confianza de cada sexo por ensayo.

En cuanto al análisis de las categorías de edad, es importante destacar que en este grupo no había individuos subadultos y existía un solo individuo juvenil. Los adultos presentaron el valor promedio de IPME más altos, mientras que el juvenil tuvo una performance constante, con el promedio y desvío estándar más bajos, mientras que los infantes tuvieron una performance promedio también por encima de cero pero con desvíos estándar muy elevados, llegando incluso a índices cercanos a -1 (Gráfico 3.15). Los valores promedio y estadísticos asociados de cada categoría de edad por ensayo pueden verse en la tabla IV.8 del Anexo IV.

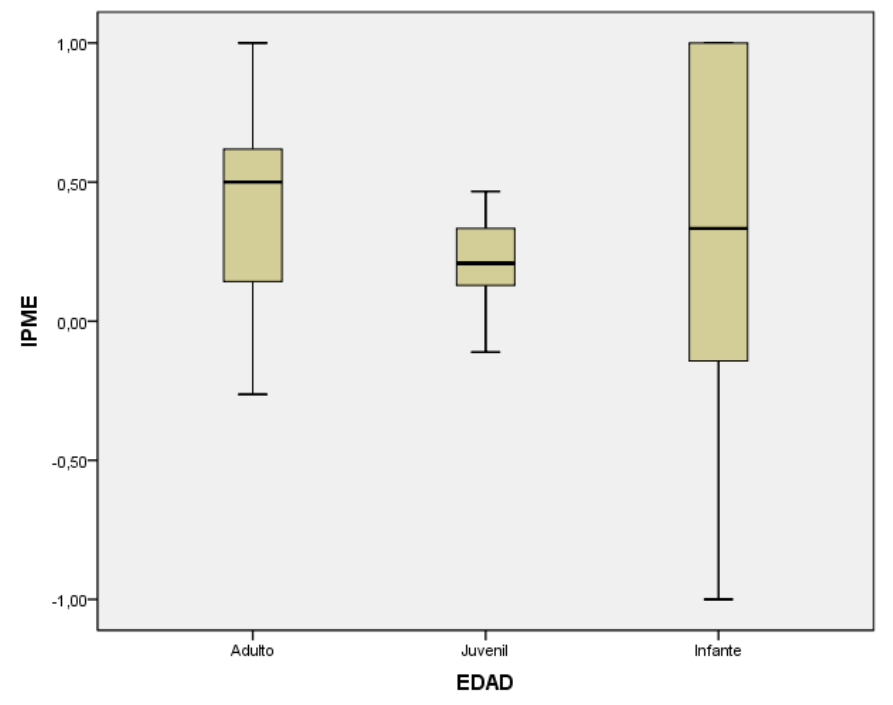

Gráfico 3.15: IPME promedio por categorías de edad para MCP1. Adultos: $0,42 \pm 0,37$ DS, IC: 0,30-0,55 ( $N=36)$; Juveniles: 0,2 $\pm 0,17 \mathrm{DS}, \mathrm{IC}: 0,09-0,31$ ( $N=12)$; Infante: 0,25 $\pm 0,67 \mathrm{DS}$, IC: $0,03-0,54(\mathrm{~N}=23)$. 
Memoria de corto plazo 2 (MCP2): antes de iniciar este período experimental, el único juvenil del grupo murió, quedando solo 5 individuos.

Se realizaron 9 ensayos registrándose 423 eventos de visita de los cuales el $60 \%$ corresponde a VC $(\mathrm{N}=254)$ y el $40 \%$ a $\mathrm{VI}(\mathrm{N}=169)$. Se presentan las cantidades totales de VC y VI en cada ensayo (Gráfico 3.16), donde puede verse al igual que para el grupo Jaula que en el segundo período experimental de memoria de corto plazo ocurre una estabilización de las curvas, que no se observa en el período de memoria de corto plazo 1 en ninguno de los dos grupos. Los valores de VI fueron siempre inferiores a los de VC.

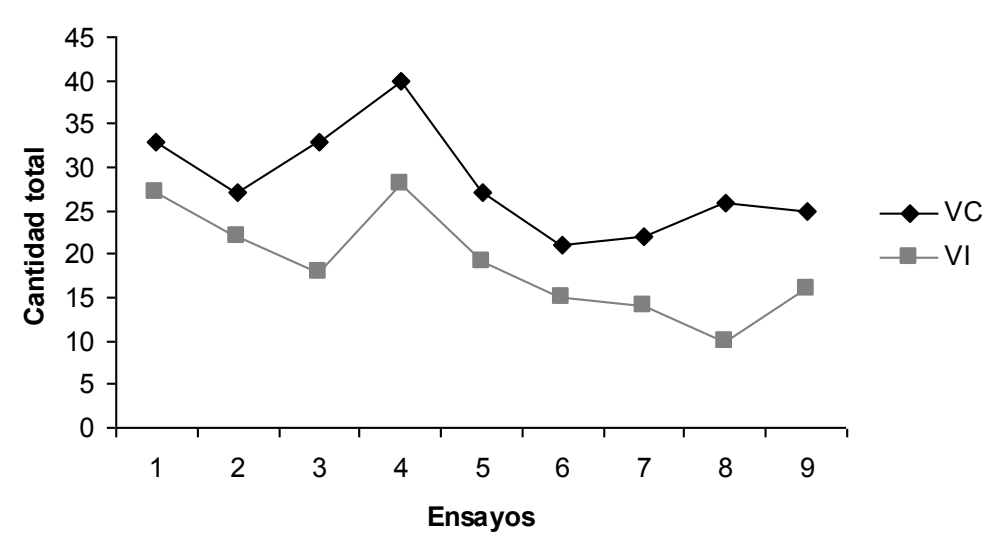

Gráfico 3.16: Visitas correctas (VC) y visitas incorrectas (VI) durante MCP2.

Aunque todos los individuos tuvieron una performance promedio por encima de cero, se registró una variación importante entre ellos, con valores negativos de IPME para los individuos ÑO, ALE y FER (Gráfico 3.17, tabla 3.8). La mayor cantidad de eventos de visita fueron observados en los adultos $\tilde{N} O(N=116)$ y en los dos infantes $\mathrm{JU}(\mathrm{N}=93)$ y FER ( $\mathrm{N}=97$ ), mientras que los individuos que presentaron menor cantidad de visitas fueron las dos hembras adultas MAMI $(\mathrm{N}=61)$ y ALE $(\mathrm{N}=56)$. Para el caso de $\tilde{N} O$, la cantidad de visitas incorrectas superó al de correctas en total, registrando un promedio por debajo de cero. En la tabla III.6 del Anexo III pueden observarse los IPME de cada individuo en cada ensayo. 




Gráfico 3.17: Valores promedio de IPME de cada individuo (IND) para la etapa experimental MCP2. Referencias: $1=$ NO, $2=\mathrm{ALE}, 3=\mathrm{MAMI}, 4=\mathrm{MAT}, 5=\mathrm{FER}, 6=\mathrm{JU}$.

\begin{tabular}{|l|l|l|l|l|l|}
\hline Individuo & $\begin{array}{l}\text { NO } \\
(1)\end{array}$ & $\begin{array}{l}\text { ALE } \\
(2)\end{array}$ & $\begin{array}{l}\text { MAMI } \\
(3)\end{array}$ & $\begin{array}{l}\text { FER } \\
(5)\end{array}$ & $\begin{array}{l}\text { JU } \\
(6)\end{array}$ \\
\hline $\begin{array}{l}\text { Promedio } \pm \\
\text { Desvío }\end{array}$ & $-0,12 \pm 0,23$ & $0,5 \pm 0,42$ & $0,4 \pm 0,23$ & $0,03 \pm 0,29$ & $0,48 \pm 0,21$ \\
\hline IC 95\% & $-0,3-0,05$ & $0,17-0,83$ & $0,23-0,58$ & $-0,19-0,26$ & $0,31-0,65$ \\
\hline $\mathrm{N}$ & 9 & 9 & 9 & 9 & 9 \\
\hline
\end{tabular}

Tabla 3.8: Valores promedios, desvíos estándar e intervalos de confianza al 95\% de IPME de los individuos para MCP2 del grupo Isla.

Los machos presentaron una performance promedio menor a cero mientras que las hembras tuvieron performance promedio positivas e intermedias (IPME promedio machos $=-0,04 \pm 0,27$ DS, IC 95\%: $-0,18-0,09$; IPME promedio hembras $=0,46 \pm 0,3$ DS, IC 95\%: 0,34 - 0,58). En el Anexo IV puede consultarse la tabla IV.9 con los promedios, desvíos estándar e intervalos de confianza de cada sexo por ensayo.

En cuanto al análisis de las categorías de edad, adultos e infantes presentaron promedios iguales y positivos aunque bajos (Gráfico 3.18). Los valores promedio y estadísticos asociados de cada categoría de edad por ensayo pueden verse en la tabla IV.10 del Anexo IV. 


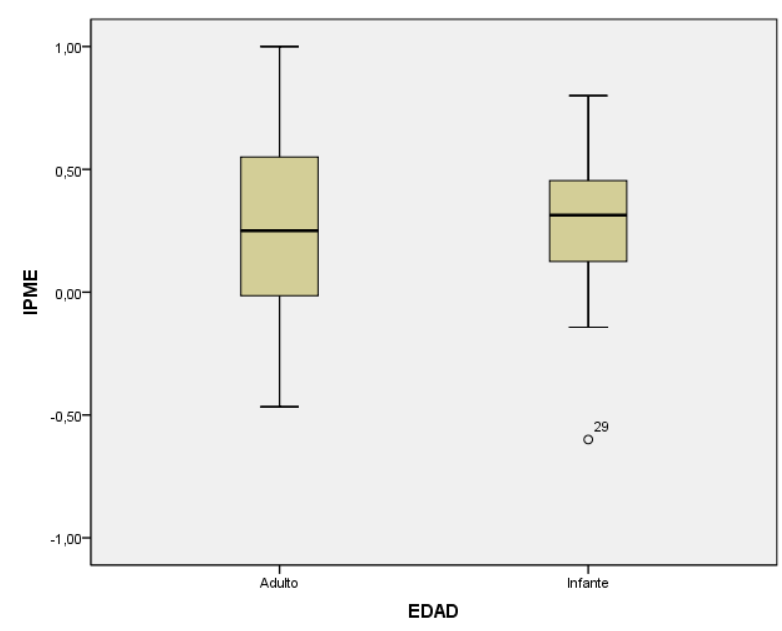

Gráfico 3.18: IPME promedio por categorías de edad para MCP2. Adultos $=0,26 \pm 0,41 \mathrm{DS}$, IC $95 \%: 0,09-0,42, N=27$; infantes $=0,26 \pm 0,34 \mathrm{DS}, \mathrm{IC} 95 \%: 0,09-0,43, \mathrm{~N}=18$.

Período de inversión de los contenedores (INV): se realizaron 10 ensayos registrándose 382 eventos de visita de los cuales el $63 \%$ correspondió a VC $(n=241)$ y el $37 \%$ a VI $(n=141)$. Se presentan las cantidades totales de VC y VI en cada ensayo, donde los valores de VC fueron siempre superiores a los de VI exceptuando el ensayo 1 donde se registraron 30 visitas correctas y 33 incorrectas (Gráfico 3.19).



Gráfico 3.19: Visitas correctas (VC) y visitas incorrectas (VI) durante INV.

Aunque todos los individuos tuvieron una performance promedio por encima de 0 , se registró una variación importante entre ellos, registrándose en todos los casos valores de IPME negativos (Gráfico 3.20, tabla 3.9). La mayor cantidad de eventos de visita fueron observados en los adultos $\tilde{N} O(N=86)$ y los infantes FER $(N=128)$ y JU $(N=87)$, mientras que los individuos que presentaron menor cantidad de visitas fueron las dos hembras adultas MAMI ( $\mathrm{N}=38)$ y ALE $(\mathrm{N}=43)$. En la tabla III.7 del Anexo III pueden observarse los IPME de cada individuo en cada ensayo. 


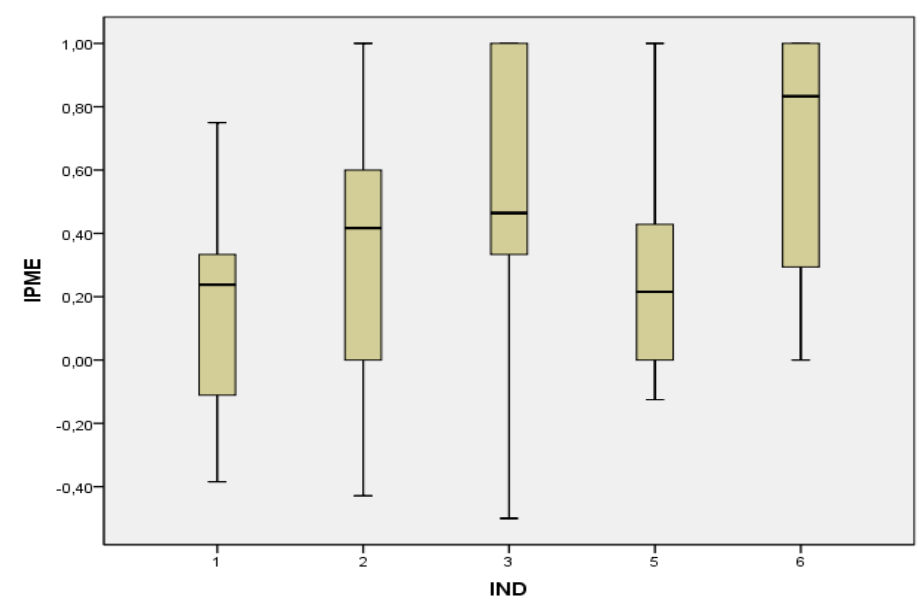

Gráfico 3.20: Valores promedio de IPME de cada individuo (IND) para la etapa experimental INV. Referencias: $1=$ ÑO, $2=\mathrm{ALE}, 3=\mathrm{MAMI}, 4=\mathrm{MAT}, 5=\mathrm{FER}, 6=\mathrm{JU}$.

\begin{tabular}{|l|l|l|l|l|l|}
\hline Individuo & $\begin{array}{l}\text { NO } \\
(1)\end{array}$ & $\begin{array}{l}\text { ALE } \\
(2)\end{array}$ & $\begin{array}{l}\text { MAMI } \\
(3)\end{array}$ & $\begin{array}{l}\text { FER } \\
(5)\end{array}$ & $\begin{array}{l}\text { JU } \\
(6)\end{array}$ \\
\hline $\begin{array}{l}\text { Promedio } \pm \\
\text { Desvío }\end{array}$ & $0,16 \pm 0,34$ & $0,36 \pm 0,49$ & $0,48 \pm 0,46$ & $0,26 \pm 0,33$ & $0,67 \pm 0,39$ \\
\hline IC 95\% & $-0,07-0,41$ & $0,007-0,41$ & $0,16-0,81$ & $0,02-0,5$ & $0,39-0,95$ \\
\hline $\mathrm{N}$ & 10 & 10 & 10 & 10 & 10 \\
\hline
\end{tabular}

Tabla 3.9: Valores promedios, desvíos estándar e intervalos de confianza al 95\% de IPME de los individuos para INV del grupo Isla.

Los machos presentaron una performance promedio menor que las hembras pero ambos valores fueron positivos (IPME promedio machos $=0,21 \pm 0,33 \mathrm{DS}$, IC $95 \%$ : $0,05-0,37, \mathrm{~N}=20$; IPME promedio hembras $=0,5 \pm 0,45 \mathrm{DS}$, IC 95\%: 0,33-0,67, N = 30). En el Anexo IV puede consultarse la tabla IV.11 con los promedios, desvíos estándar e intervalos de confianza de cada sexo por ensayo.

Los adultos e infantes presentaron valores promedio semejantes y con desvíos estándar muy elevados, registrándose en ambos grupos valores de IPME negativos llegando incluso a índices cercanos a -1 para los adultos (Gráfico 3.21). Los valores promedio y estadísticos asociados de cada categoría de edad por ensayo pueden verse en la tabla IV.12 del Anexo IV. 


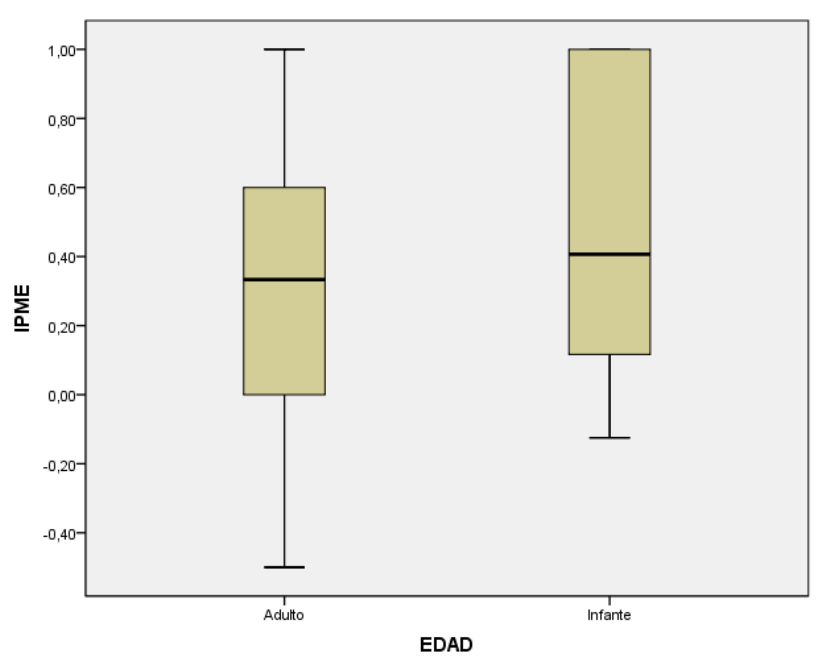

Gráfico 3.21: IPME promedio por categorías de edad para INV. Adultos $=0,33 \pm 0,44 \mathrm{DS}, \mathrm{IC}$ 95\%: 0,17 -0,5, N=30; infantes =0,46 $\pm 0,41 \mathrm{DS}$, IC 95\%: 0,27 -0,66, $\mathrm{N}=20$.

\section{Modelo generalizado lineal de efectos mixtos (MGLM) para el grupo Isla:}

El modelo con mejor fit fue aquel en el que se incluyeron los efectos fijos "ensayo" y "sexo" controlando para el efecto "período experimental" y "edad". Se encontraron diferencias en la performance (diferencias en el índice IPME) entre los ensayos dentro de cada período del experimento (MLGM, Chiq $=4.6087, \mathrm{p}=0.03181, \mathrm{gl}=1$ ), $\mathrm{y}$ también diferencias entre los sexos (MLGM, Chiq $=16.053, p=6.158 \mathrm{e}-05, \mathrm{gl}=1)$. No se encontraron diferencias entre los diferentes períodos MCP1, MCP2 e INVERSIÓN de los contenedores (MLGM, Chiq $=2.3498, \mathrm{p}=0.3089, \mathrm{gl}=2)$ ni entre las categorías de edad (MGLM, Chiq = 1.1242, $\mathrm{p}=0.57, \mathrm{gl}=2$ ).

La varianza asociada al efecto aleatorio "individuos" fue de 0,00 representando el $0 \%$ de la varianza total del modelo. Dado que la varianza del efecto aleatorio fue baja, puede concluirse que otros efectos no considerados en el modelo en relación a las diferencias entre individuos no fueron importantes.

En cuanto a los valores de IPME en cada período experimental (promedio de los valores individuales), la performance no aumentó con los ensayos ni se registró un aumento de la performance para $\mathrm{MCP} 2$, pero si se registraron valores elevados del índice promedio hacia el final del período experimental INV (Tabla 3.10). 


\begin{tabular}{|c|c|c|c|}
\hline $\begin{array}{l}\text { Período } \\
\text { experim. } \\
\text { Ensayo }\end{array}$ & MCP1 & MCP2 & INV \\
\hline 1 & $0,53 \pm 0,28$ IC: $0,23-0,83$ & $0,25 \pm 0,52$ IC: $-0,39-0,9$ & $-0,18 \pm 0,35$ IC: $-0,62-0,25$ \\
\hline 2 & $0,017 \pm 0,59$ IC: $-0,6-0,63$ & $0,12 \pm 0,24$ IC: $-0,18-0,42$ & $0,29 \pm 0,53$ IC: $-0,36-0,95$ \\
\hline 3 & $0,46 \pm 0,35$ IC: $0,09-0,84$ & $0,28 \pm 0,28$ IC: $-0,07-0,64$ & $0,19 \pm 0,26$ IC: $-0,12-0,51$ \\
\hline 4 & $0,45 \pm 0,31$ IC: $0,12-0,79$ & $0,32 \pm 0,28$ IC: $-0,02-0,67$ & $0,31 \pm 0,19 I C: 0,08-0,5$ \\
\hline 5 & $0,35 \pm 0,47$ IC: $-0,14-0,84$ & $0,28 \pm 0,59$ IC: $-0,45-1,01$ & $0,47 \pm 0,38$ IC: $-0,003-0,94$ \\
\hline 6 & $0,01 \pm 0,5$ IC: $-0,56-0,59$ & $0,1 \pm 0,39$ IC: $-0,39-0,59$ & $0,49 \pm 0,35$ IC: $0,05-0,92$ \\
\hline 7 & $0,48 \pm 0,53$ IC: $-0,17-1,14$ & $0,2 \pm 0,24$ IC: $-0,08-0,53$ & $0,49 \pm 0,31$ IC: $0,1-0,8$ \\
\hline 8 & $0,46 \pm 0,52$ IC: $-0,08-1,00$ & $0,52 \pm 0,37$ IC: $0,05-0,98$ & $0,74 \pm 0,35$ IC: $0,3-1,12$ \\
\hline 9 & $0,001 \pm 0,63$ IC: $-0,66-0,66$ & $0,24 \pm 0,49$ IC: $-0,37-0,86$ & $0,78 \pm 0,49$ IC: $0,16-1,3$ \\
\hline 10 & $0,4 \pm 0,54$ IC: $-0,16-0,97$ & & $0,3 \pm 0,41$ IC: $-0,2-0,81$ \\
\hline 11 & $0,47 \pm 0,3$ IC: $0,15-0,8$ & & \\
\hline 12 & $0,36 \pm 0,34$ IC: $-0,003-0,73$ & & \\
\hline
\end{tabular}

Tabla 3.10: IPME promedios \pm desvíos estándar (DS) e intervalos de confianza al 95\% (IC $95 \%$ ) por ensayo para cada período experimental del grupo Isla.

No se encontraron diferencias significativas en los valores de IPME del primero y último ensayos de MCP1 ( $\mathrm{E} 1-\mathrm{E} 12=1.050, \mathrm{p}=0,342$, IC 95\% para la diferencia de medias: $-0,25-0,59$; media $\mathrm{E} 1=0.53 \pm 0.28 \mathrm{DS}$, media $\mathrm{E} 12=0.36 \pm 0.34 \mathrm{DS})$. El tamaño del efecto fue bajo y negativo ( $d$ de Cohen $=-0,5 ; N=12$ ). Para MCP2 tampoco se encontraron diferencias significativas entre los valores promedio de IPME del primero y último ensayos ( $\mathrm{E} 1-\mathrm{E} 9=-0.52, p=0,961, \mathrm{IC} 95 \%$ para la diferencia de medias: $-0,72-0,75$; media $\mathrm{E} 1=0.25 \pm 52 \mathrm{DS}$, media $\mathrm{E9}=0.24 \pm 0.49 \mathrm{DS})$. El tamaño del efecto fue muy bajo y negativo ( $d$ de Cohen $=-0,02 ; \mathrm{N}=10$ ). El valor promedio de IPME del primer ensayo de INV fue negativo, encontrándose diferencias significativas entre el ensayo 1 y el 10 (t E1-E10 $=-3.865, p=0,018$, IC 95\% para la diferencia de medias: $-0,84--0,13$; media E1 $=-0.18 \pm 0.35 \mathrm{DS}$, media $\mathrm{E} 10=0.3 \pm$ $0.41 \mathrm{DS})$. El tamaño del efecto fue elevado ( $d$ de Cohen $=1,17 ; \mathrm{N}=10)$.

Períodos de memoria de largo plazo 1 y 2: al igual que en el grupo Jaula se realizaron dos ensayos únicos de memoria de largo plazo, uno a los 76 días del último ensayo MCP1 y previo al inicio de los ensayos del período MCP2 (llamado ensayo de memoria de largo plazo 1 o MLP1), y un ensayo de memoria de largo plazo 2 (MLP2) 
al haber transcurrido 4 meses del último ensayo MCP2, previo al inicio del período experimental INV.

Memoria de largo plazo 1 (MLP1): se registraron 43 visitas correctas y 33 incorrectas (en la tabla III.8 del Anexo III se observan los valores individuales) registrándose para algunos individuos valores negativos de IPME. No se encontraron diferencias significativas entre los IPME promedio del ensayo 12 de MCP1 y el ensayo único MLP1 $(t=1.266, p=0,274$, IC 95\% para la diferencia de medias: $-0,21-0,58$; media $\mathrm{E} 12=0.36 \pm 0.34 \mathrm{DS} ;$ media $\mathrm{E}$ MLP1 $=0,22 \pm 0,37 \mathrm{DS})$, pero es importante notar que a pesar de que ambos ensayos tuvieron valores medios de IPME por encima de cero, los desvíos estándar indicaron que existió elevada variación individual. El tamaño del efecto fue bajo y negativo ( $d$ de Cohen $=-0,3 ; N=10$ ), dado que la media de MLP1 fue menor que la del E12 de MCP1.

Memoria de largo plazo 2 (MLP2): se registraron 43 visitas correctas y 56 incorrectas (en la tabla III.8 del Anexo III se observan los valores individuales).No se encontraron diferencias significativas en los valores promedio de IPME entre el ensayo 9 de MCP2 $y$ el segundo ensayo MLP ( $\mathrm{E}$-E MLP2 $=0.444, p=0,687$, IC 95\% para la diferencia de medias: $-1,12-1,49$; media E9 $=0,24 \pm 0,49 \mathrm{DS}$, media $\mathrm{E}$ MLP2 $=-0,05 \pm 0.46 \mathrm{DS}$ ). Los adultos ÑO y ALE presentaron valores de IPME mayores a cero mientras que la adulta MAMI y los dos infantes presentaron valores de visitas incorrectas superiores a los de visitas correctas, ocasionando índices negativos. El tamaño del efecto fue moderado y negativo ( $d$ de Cohen $=-0,5 ; N=10$ ), pudiendo concluirse que existió una diferencia aunque no muy elevada.

\subsubsection{Descripción y análisis de las secuencias de forrajeo}

Se obtuvieron 19 mapas correspondientes a los 15 ensayos de memoria de corto plazo 1 y 2. Los ensayos del período de inversión fueron excluidos del análisis, dado que la modificación de las posiciones del diseño alteró por completo las secuencias. Se muestra un mapa a modo de ejemplo (Figura 3.7). En el Anexo V pueden verse los mapas más representativos del análisis. 


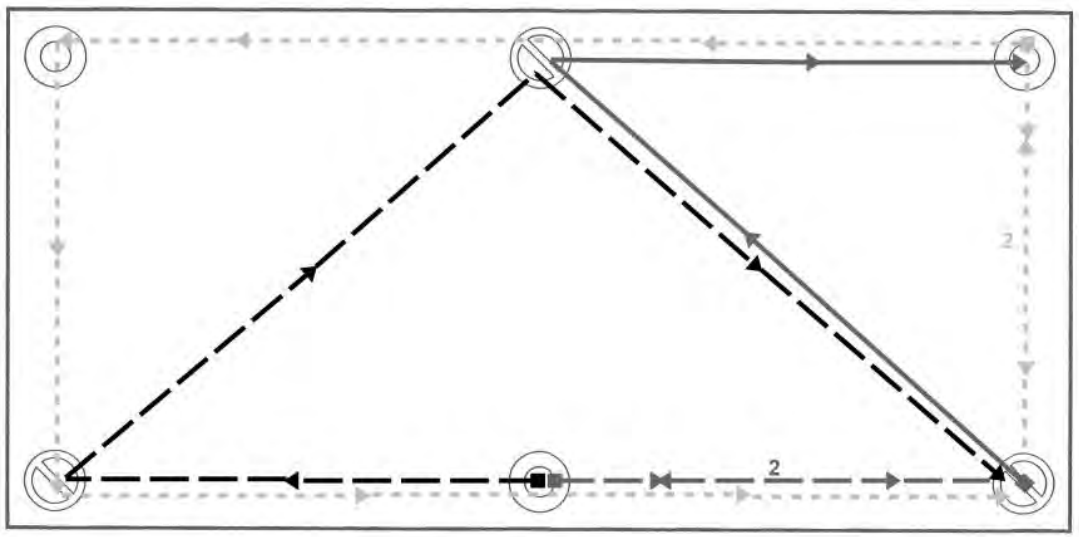

Figura 3.7: Ejemplo de mapa de secuencias (ensayo 1, Memoria de Corto Plazo 1). Los números muestran cuántas veces fue ejecutada la secuencia. Cada secuencia representa un individuo diferente.

Como resultado del análisis gráfico se identificaron secuencias de visita a los contenedores que se codificaron de la siguiente manera: 6 visitas a un único contenedor accesible o inaccesible, 10 secuencias de visita de 2 contenedores (Tabla 3.11 ) y 25 secuencias de 3 contenedores (tabla 3.12 ).

Tabla 3.11: Descripción de las secuencias de dos contenedores.

Secuencias de dos contenedores

\begin{tabular}{cc}
\hline Tipo de contenedor & Contenedores involucrados \\
\hline 2 CCA & $1-1$ \\
$3-3$ & $5-5$ \\
$1-5$ \\
$3-1$ or $1-3$ \\
$3-5$ or $5-3$ \\
2 CCA+CCI \\
$1-4$ \\
$3-2$ \\
$4-5$ or $5-4$ \\
$5-6$ or $6-5$
\end{tabular}

Referencias: 2 CCA: secuencias de 2 contenedores accesibles; $2 \mathrm{CCA}+\mathrm{CCl}$ : secuencias que incluyen 1 contenedor accesible más 1 inaccesible. 
Tabla 3.12: Descripción de las secuencias de tres contenedores

Secuencias de tres contenedores

Tipo de contenedor

Simple CCA o CCl

(3S CCA o $\mathrm{CCl})$

Simple $\mathrm{CCA}+\mathrm{CCl}$

(3S CCA+CCI)

$(3 S C C A+C C)$

Complejo $\mathrm{CCA}$ o $\mathrm{CCl}$

(3C CCA o $\mathrm{CCl})$

Complejo $\mathrm{CCA}+\mathrm{CCl}$

$(3 \mathrm{C} C \mathrm{CA}+\mathrm{CCl})$
Contenedores involucrados

1-3-1 or 3-1-3

$1-5-1$ or $5-1-5$

$3-5-3$ or $5-3-5$

3-2-3

4-1-4

1-6-1 or 6-1-6

3-6-3 or 6-3-6

4-5-4 or 5-4-5

$5-6-5$ or $6-5-6$

4-2-6

$1-5-3$ or $5-1-3$ or $1-3-5$ or $3-1-5$ or $5-3-1$

3-2-4

1-4-6 or 6-1-4

2-1-5 or $5-1-2$

$3-1-4$ or $1-3-4$ or $4-1-3$

$5-4-3$ or $4-5-3$ or $3-4-5$

6-2-1 or 2-1-6 or 6-1-2

$6-2-3$ or $2-6-3$ or $3-2-6$

$1-6-5$ or $1-5-6$ or $6-1-5$ or $5-6-1$

$3-1-6$ or $1-6-3$ or $6-3-1$ or 3-6-1

$3-2-1$ or $1-3-2$ or $2-3-1$ or $1-2-3$

$5-4-1$ or $5-1-4$ or $1-4-5$ or $4-5-1$

$6-5-4$ or $5-6-4$ or $4-6-5$ or $4-5-6$

$3-6-5$ or $5-3-6$ or $3-5-6$ or $5-6-3$ or $6-5-3$

$3-2-5$ or $5-3-2$ or $2-3-5$ or $2-5-3$ or $5-2-3$

Referencias: Simple CCA o $\mathrm{CCl}$ (3S CCA $\circ \mathrm{CCl}$ ): secuencia simple de 3 contenedores que incluye contenedores accesibles $\mathrm{o}$ inaccesible solamente y 2 de los 3 contendores son el mismo que es visitado 2 veces; Simple $C C A+C C l(3 S \mathrm{CCA}+\mathrm{CCl}$ ): secuencia simple de 3 contenedores que incluye contenedores accesibles más inaccesibles y 2 de los 3 contendores son el mismo que es visitado 2 veces; Compleja CCA o $\mathrm{CCl}$ (3C CCA o $\mathrm{CCl}$ ): secuencia compleja de 3 contenedores que incluye 3 contenedores diferentes accesibles o inaccesibles; Compleja $\mathrm{CCA}+\mathrm{CCl}(3 \mathrm{C} C \mathrm{CA}+\mathrm{CCl})$ : secuencia compleja de 3 contenedores que incluye contenedores accesibles más inaccesibles en la misma secuencia. 
Después de identificar y codificar las secuencias se analizaron las frecuencias de ejecución de las mismas en cada período de memoria para cada individuo. Las secuencias de 1 contenedor accesible (CCA) tuvieron los valores más altos de ejecución en los dos períodos para todos los individuos (Gráficos 3.22 y 3.23), con un $38,9 \%$ en MCP1 y un 59,2 \% en MCP2, mientras que la ejecución de secuencias de 1 contenedor inaccesible (CCl) cayó de 9,2 \% en MCP1 a 1,2 \% en MCP2.

La ejecución de las secuencias de dos contenedores fue mayor en MCP1 que en MCP2 para todos los individuos (Gráficos 3.22 y 3.23 ): las secuencias 2 CCA cayeron de $4,6 \%$ a $2,4 \%$ y las secuencias $2 \mathrm{CCA}+\mathrm{CCl}$ de $4,6 \%$ a $1,0 \%$.

Se registró una disminución en los niveles de ejecución de las secuencias simples y complejas de 3 contenedores accesibles e inaccesibles (3S $\mathrm{CCA}+\mathrm{CCl}$ y $3 \mathrm{C}$ $\mathrm{CCA}+\mathrm{CCl}$ ). Sus ocurrencias fueron $13.7 \%$ y $26 \%$ en MCP1 y disminuyeron a $3.7 \%$ y $15.4 \%$ respectivamente (Gráficos 3.24 y 3.25 ). Por otra parte, se obtuvo lo opuesto para las secuencias simples y complejas de 3 contenedores accesibles o inaccesibles (3S CCA ० $\mathrm{CCl}$ y $3 \mathrm{C} \mathrm{CCA} \mathrm{\circ} \mathrm{CCl}$ ), que mostraron un aumento en su ocurrencia desde $0.7 \%$ a $8.8 \%$ para $3 \mathrm{~S} \mathrm{CCA} \mathrm{o} \mathrm{CCl}$, y $0.8 \%$ a $8.3 \%$ para $3 \mathrm{C} \mathrm{CCA} \mathrm{o} \mathrm{CCl.}$

El número de ejecuciones de las secuencias de 1 y 2 contenedores mostró el siguiente patrón de diferencias entre sujetos: durante MCP1 (Gráfico 3.22), las secuencias de 1 contenedor CCA mostraron un valor promedio similar para adultos ( $\mathrm{M}=6 \pm 2$ ) y juveniles ( $M=5 \pm 1,5$ ) mientras que durante MCP2 (Gráfico 3.23) los juveniles mostraron valores más altos ( $M=58,2 \pm 6,46$, excepto el sujeto TO que ejecutó el doble de secuencias que el resto de los individuos) que los adultos ( $M=37,7 \pm 6,8)$. La ejecución de secuencias de 1 contenedor $\mathrm{CCl}$ tuvo valores menores para adultos en comparación con juveniles en los dos períodos ( 0 a 3 ejecuciones por sujeto, excepto el sujeto TO que ejecutó 5 secuencias en MCP2).

La ejecución de secuencias de 2 contenedores CCA durante MCP1 y MCP2 (Gráficos 3.22 y 3.23) tuvo valores bajos para adultos y juveniles, yendo desde 0 a 3 secuencias ejecutadas, exceptuando TO con 10 ejecuciones en MCP2. La ejecución de 2 $\mathrm{CCA}+\mathrm{CCl}$ no mostró diferencias entre períodos y en ambos casos los valores fueron bajos ( 0 a 2 ejecuciones exceptuando al sujeto PU quien ejecutó 5 en MCP2).

Para las secuencias de 3 contenedores, simples o complejas, accesibles o inaccesibles (Gráfico 3.24), no se registraron ejecuciones de estas secuencias en MCP1 (excepto el sujeto RO con 1 ejecución de una secuencia 3S CCA o CCl y el sujeto $\mathrm{CH}$ con 1 ejecución de una secuencia $3 \mathrm{C} \mathrm{CCA} \mathrm{o} \mathrm{CCl).} \mathrm{Sin} \mathrm{embargo,} \mathrm{la} \mathrm{cantidad}$ de ejecuciones en MCP2 aumentó (Gráfico 3.25), mostrando un valor promedio de 9,3 $\pm 3,7$ en juveniles y de $6 \pm 3,6$ en adultos para las secuencias 3S CCA o $\mathrm{CCl}$, y $\mathrm{M}=$ $9,3 \pm 2,7$ en juveniles y $M=6,5 \pm 2,1$ en machos adultos para $3 \mathrm{C} \mathrm{CCA} \mathrm{o} \mathrm{CCl.} \mathrm{La} \mathrm{única}$ 
hembra adulta CE no ejecutó ninguna de estas secuencias de 3 contenedores accesibles o inaccesibles.

Por último, las secuencias de 3 contenedores, simples y complejas $\mathrm{CCA}+\mathrm{CCl}$ no fueron ejecutadas por adultos en MCP1 mientras que los juveniles mostraron una ejecución de 17 secuencias simples y 32 complejas (Gráfico 3.24). Durante MCP2 todos los adultos ejecutaron secuencias de este tipo, con un total de 31 y 129 secuencias simples y complejas respectivamente, y con las siguientes diferencias entre adultos y juveniles: $M=2,7 \pm 1,5$ para adultos y $M=3,8 \pm 2.4$ para juveniles (3S $\mathrm{CCA}+\mathrm{CCl})$, y $\mathrm{M}=13,3 \pm 3,05$ y $\mathrm{M}=14,8 \pm 8,7$ para $3 \mathrm{C} \mathrm{CCA}+\mathrm{CCl}$ respectivamente (Gráfico 3.25).

\section{MCP1}

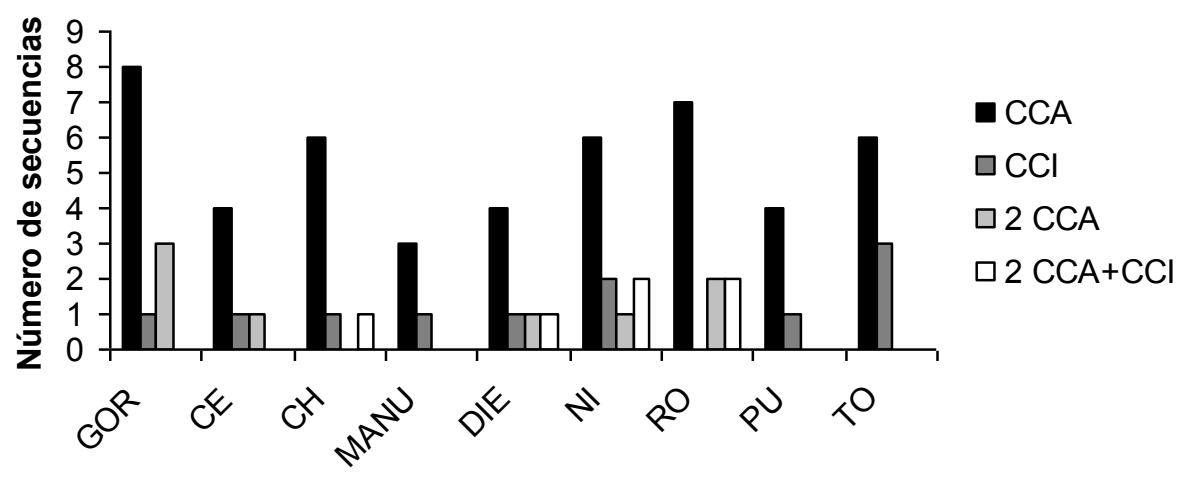

Individuos

Gráfico 3.22: Secuencias de 1 y 2 contenedores durante el período experimental MCP1 para cada individuo.

\section{MCP2}

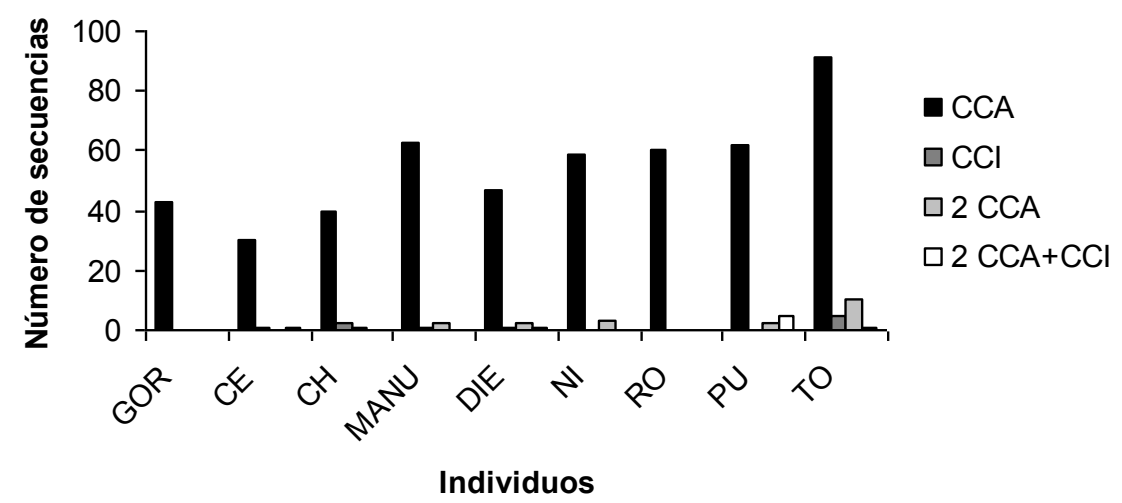

Gráfico 3.23: Secuencias de 1 y 2 contenedores durante el período experimental MCP2 para cada individuo. 


\section{MCP1}

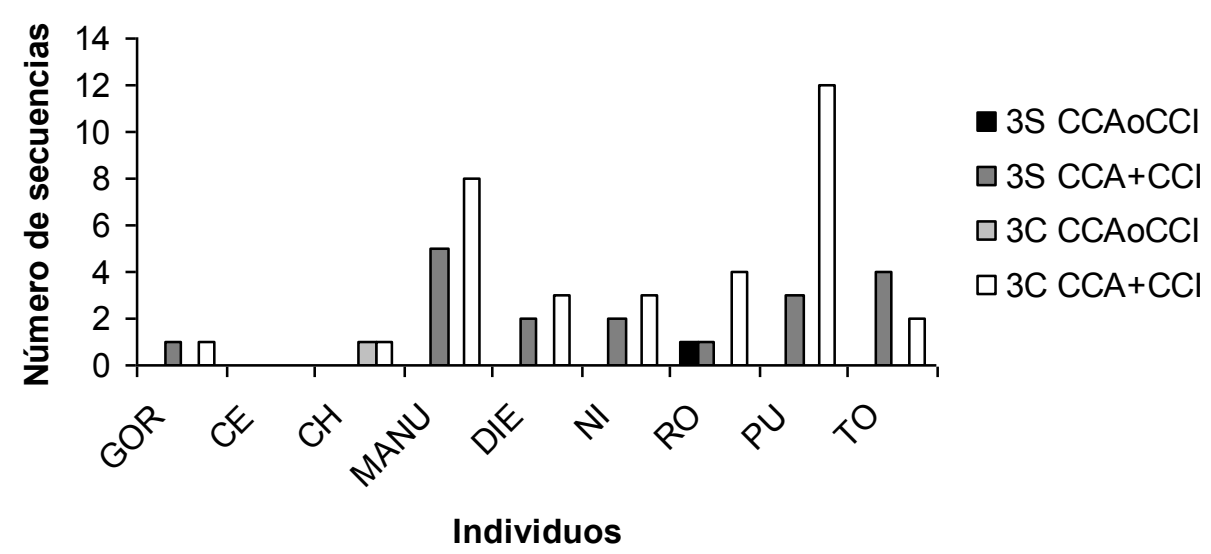

Gráfico 3.24: Secuencias de 3 contenedores durante el período experimental MCP1 para cada individuo.

\section{MCP2}

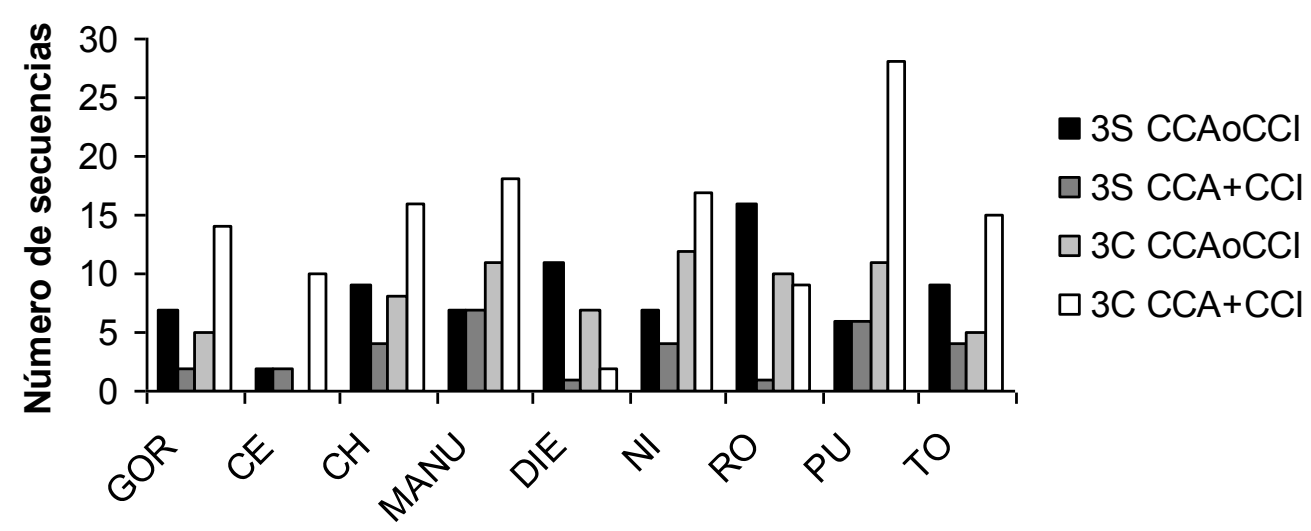

Individuos

Gráfico 3.25: Secuencias de 3 contenedores durante el período experimental MCP2 para cada individuo.

\subsection{Discusión}

\subsubsection{Duración de los ensayos}

Durante el período experimental de memoria de corto plazo 1 los individuos de ambos grupos tardaron más tiempo en vaciar los contenedores (ya sea por haber realizado una mayor cantidad de visitas o por una ausencia de registro de los lugares correctos donde obtener el alimento). 
La duración de las etapas experimentales en general fue mayor en la jaula que en la isla. Esta diferencia entre los grupos pudo relacionarse con el hecho de que en la isla fue frecuente observar a los individuos retirar alimento del interior de los contenedores accesibles y arrojarlo al suelo, sin consumirlo (esto fue observado sólo de manera esporádica en la jaula), vaciando así los contenedores en menor tiempo. Una posible causa de este comportamiento podría vincularse con el hecho de que, si bien ambos grupos estaban en ayunas del alimento suministrado en el zoológico y se insertó el diseño en ambos ambientes en los mismos momentos del día (durante las mismas horas de la mañana), la isla ofrecía a los individuos la posibilidad de forrajear insectos, brotes y eventualmente romper nueces o atrapar un pequeño vertebrado. Esta fuente extra de alimento imposible de controlar pudo contribuir a disminuir el interés de los individuos por consumir los copos de maíz.

\subsubsection{Aprendizaje y performance de memoria espacial}

Para el caso del grupo Jaula, los individuos estudiados aprendieron a buscar el alimento en todos los períodos experimentales, evidenciando la capacidad de recordar la ubicación de los contenedores accesibles CCA y de los contenedores inaccesibles $\mathrm{CCl}$. En los períodos MCP2 e INV ocurrió una consolidación de la memoria (los valores del índice aumentaron y se volvieron estables en promedio para cada ensayo al tiempo que disminuyeron las variaciones entre individuos) que superó a la del período MCP1. Para el grupo Isla los individuos lograron una consolidación de la memoria recién al final del período INV, indicando que posiblemente la frustración (entendida como un "no reforzamiento") ocasionada por la inversión de las posiciones del diseño funcionó como "detonante" para exteriorizar el aprendizaje logrado, el cual no había sido identificado en las etapas previas del experimento. Los mecanismos de reforzamiento explican que es más fácil advertir la ausencia de un reforzador (en este caso, la comida en los contenedores accesibles) luego de un programa de reforzamiento continuo (siempre recibir la recompensa de manera constante en el mismo sitio) (Domjan, 1998).

Frente a la situación invertida, los individuos de ambos grupos evidenciaron un registro de la situación aprendida disminuyendo su performance de manera abrupta en el primer ensayo de esta etapa. Los valores superiores para el período INV en comparación con MCP1 indicarían la posible existencia de sets de aprendizaje. La teoría de los sets de aprendizaje o aprendizaje de conjuntos (Harlow, 1949) fue diseñada para demostrar que no existe una discrepancia real entre el aprendizaje por ensayo y error, y la teoría de la Gestalt: cuando un animal aprende un nuevo tipo de problema, lo resuelve al principio de manera lenta por ensayo y error, pero a medida que su experiencia aumenta frente al mismo problema, el ensayo y error es 
reemplazado por un eventual insight de la situación, que le permite reorientar su comportamiento frente a una situación novedosa en la que puede detectarse un patrón ya aprendido.

En cuanto a la memoria de largo plazo, los individuos retuvieron el registro de las posiciones de los contenedores por períodos de 76 días hasta 4 meses, evidenciándose un registro consolidado a mayor tiempo transcurrido. Esto es muy interesante desde el punto de vista adaptativo: los monos caí tienen vidas largas (hasta 50 años en cautiverio y alrededor de 30 años en vida silvestre) y se desplazan en el mismo ambiente a lo largo de casi toda su vida. Estos registros permanentes de larga duración serán muy útiles para recordar fuentes de recurso estables, y a la vez podrían transformarse en un problema en zonas donde los capuchinos se consideran animales "conflictivos", por ejemplo, en la interacción con el turismo dentro de los parques nacionales (Tujague, obs. Pers.).

Las diferencias existentes entre los individuos no generaron un disturbio en el modelo, a pesar de que algunas características como el rango social que tienen importancia en los grupos de caí en relación al acceso a la comida (Di Bitetti \& Janson, 2001, Garber \& Brown, 2005) no fueron medidas en este estudio. Aun así es importante tener presente que un simple estadístico no nos permite descartar con total seguridad que no existieron diferencias, y esto pudo observarse en los análisis descriptivos por etapa experimental, sobre todo para el grupo Isla. La diferencia de performance entre sexos para este grupo no parece tener una causa evidente. Un detalle a considerar es que el macho alfa de la isla (Ñ) registró desde los comienzos de las observaciones una elevada frecuencia de comportamientos locomotores estereotipados (secuencias repetitivas y uniformes, sin función aparente), que en general se asocian a aspectos sub-óptimos del ambiente y su función es aliviar el stress (Mason, 1991). Su bajo rendimiento (que habría contribuido a esas diferencias encontradas) pudo deberse a esta situación de estrés crónico.

El aprendizaje social es una instancia en la que la adquisición de un comportamiento por parte de un individuo es influenciada por las interacciones sociales con otros (Heyes, 1994; Rapaport \& Brown, 2008). Clayton (1978) define al aprendizaje por facilitación social como un incremento en la frecuencia de un patrón de comportamiento en la presencia de otros individuos realizando el mismo comportamiento al mismo tiempo. Un compañero social puede mejorar la eficiencia de forrajeo de un individuo (Andrews \& Rosenblum, 1995 en Gibeault \& MacDonald 2000). La presencia de un conespecífico afecta la motivación y el comportamiento de otro individuo, aumentando la exploración y el descubrimiento en relación a una tarea específica. En su trabajo sobre facilitación social en el forrajeo exploratorio, Dindo et 
al. (2009) estudiaron 24 individuos de Cebus apella frente a un aparato diseñado para que los monos aprendieran a extraer alimento. Se evaluó a los individuos en dos situaciones: aislados o junto a un compañero de grupo. El éxito en el experimento se alcanzó 3 veces más rápido en la condición social. En este capítulo el hecho de que juveniles e infantes registraran mayores frecuencias totales de visitas ( $N$ total de visitas correctas e incorrectas) podría relacionarse con su tendencia a observar e imitar, como también con una mayor frecuencia de comportamientos de exploración (Gibeault \& MacDonald, 2000). Aun así, esta diferencia de frecuencias no se tradujo en una diferencia en las performances en este experimento.

\subsubsection{Diferencias entre los grupos estudiados}

Las posibles causas de las diferencias entre los grupos de estudio son difíciles de determinar. El registro de comportamientos exploratorios dirigidos al diseño fue menor en la isla, donde la situación de semi-cautiverio pudo propiciar un menor interés por parte de los individuos de forrajear en los contenedores, dada la existencia de un ambiente enriquecido que cubriría de mejor manera sus necesidades cognitivas (Duncan \& Petherick, 1991). Scheumann \& Call (2006) sostienen que al realizar un experimento, la existencia de un ambiente de tamaño excesivo podría entorpecer el uso eficiente del diseño. Es difícil determinar que sería un tamaño excesivo pero puede asegurarse que la isla tiene un mayor tamaño que la jaula, y que a su vez el número de individuos en el ambiente de mayor tamaño era menor. A su vez, la isla no presentaba ningún individuo subadulto y el único juvenil existente escapó del ambiente al pasar la primera etapa experimental, y fue encontrado muerto a posteriori. Si, como se mencionó con anterioridad, el contexto de grupo es importante para el aprendizaje de juveniles e infantes, es muy posible que los infantes de la isla no aprendieran con la misma rapidez que los de la jaula debido a un ambiente social empobrecido.

\subsubsection{Análisis de secuencias para el grupo Jaula}

El análisis por repetición y redundancia de las secuencias codificadas por el observador para el grupo Jaula permitió obtener patrones de movimiento compartidos que los sujetos aprendieron en contexto de grupo. El análisis de las secuencias de utilización de los contenedores para este grupo mostró la existencia de estrategias a nivel individual y por categorías de edad. Estos análisis de secuencias no interfirieron con la evaluación de los índices de performance dado que dos individuos pueden presentar diferentes secuencias (órdenes de visita a los contenedores) pero su IPME puede ser el mismo.

De los resultados obtenidos, se observa que los individuos presentan un comportamiento diferencial al momento de buscar y obtener el alimento de localizaciones concretas. El resultado más llamativo fue el incremento de las 
ejecuciones de las secuencias de 3 contenedores (que incluían visitas a un contendor inaccesible) en MCP2, con valores semejantes para adultos y juveniles. Podría pensarse que esta inclusión de un contenedor inaccesible en la secuencia de debió a una ausencia de insigth, pero también pudo deberse simplemente a la tendencia exploratoria de los caí que los llevaba a revisar el contenedor cada vez que pasan cerca, en su camino hacia el próximo contenedor inaccesible. A pesar del aumento de estas secuencias la etapa MCP2 fue la que presentó la mejor performance en este grupo, con valores cercanos a 1, concluyendo que la presencia de estas visitas incorrectas no genero disturbios en el proceso de aprendizaje. Como Aparicio \& Huidobro (1990) han notado, muchos mamíferos en situación experimental (laboratorio o cautiverio) necesitan alternar entre localizaciones de comida una vez que han aprendido donde se ubica la comida accesible. Infiero que en el experimento la inercia de la actividad de forrajeo per se llevaba a los monos a incluir contenedores inaccesibles en las secuencias, a pesar de que nunca extrajeron alimento de uno de estos contenedor (posibilidad nula). En palabras de Visalberghi and Tomasello (1998) en Bicca-Marques and Garber (2005, p. 1341): "Much of the adaptive behaviour of primates depends on individual learning about recurrent sequences of events in their physical and social environments, and then exploiting the regularities in formulating their own behavioural strategies."

\subsection{Conclusión}

En su ambiente natural, un primate debe integrar conocimiento espacial obtenido del movimiento repetitivo a través de su territorio, como también información sobre la cantidad, calidad y condición del alimento (Cunningham \& Janson, 2007). Los experimentos en cautiverio pueden subestimar las habilidades de sus congéneres para desplazarse buscando alimento en su ambiente natural: lo ideal es la combinación de ambos enfoques (Janson \& Byrne, 2007). Estudiar a los individuos en cautiverio en contexto de grupo (y no aislado de sus conespecíficos) permite analizar la dimensión espacio-individual y espacio-grupal, que es sin dudas muy importante al momento de evaluar capacidades cognitivas de organismos sociales.

Las diferencias en los valores de visitas correctas e incorrectas en cada ensayo sugieren que los individuos realizan un registro espacial (mapa) de la situación (contexto o ámbito de la experiencia), y lo utilizan para la búsqueda y localización del alimento. Esto les permitirá optimizar la misma en un contexto de grupo, donde otros individuos estarán en simultáneo operando sobre el mismo ambiente. La eficiencia de forrajeo depende de la capacidad de los individuos de discernir señales precisas del alimento, y de su ubicación en tiempo y espacio (Dominy, 2004). Las variables visual y 
olfativa fueron controladas durante el experimento: los contenedores accesibles e inaccesibles eran idénticos externamente, y todos contenían alimento por lo cual si los monos pudieron guiarse por el olor de la comida, éste estuvo presente tanto en los contenedores de los cuales podían obtener alimento como de aquellos en los que no. Además, los individuos se encontraron en ayunas para asegurarse que los mismos tuvieron hambre, y los ensayos se realizaron en los mismos horarios del día durante todo el tiempo que duraron los experimentos. Teniendo en cuenta todo lo anterior, puede asegurarse que el aumento progresivo de los valores del índice de performance de memoria espacial no pudo relacionarse a otro proceso que no sea la generación de memoria para localizaciones en el espacio (Ludvig et al. 2003).

La conclusión más importante que podemos extraer es que los sujetos aprendieron las posiciones espaciales y los patrones de forrajeo que los llevaron al desarrollo de memoria espacial para CCA y $\mathrm{CCl}$, ayudándolos a optimizar su eficiencia de forrajeo por períodos de 48 horas, 76 días y 4 meses, logrando utilizar aprendizaje de conjuntos (o sets de aprendizaje) para solucionar en un menor tiempo un problema de modificación espacial de los recursos.

\subsection{Referencias}

Altmann, J. 1974. Observational study of behaviour: sampling methods. Behaviour, 49, 227265.

Anderson, D. R., Burnham, K. P. \& W. L. Thompson. 2000. Null Hypothesis Testing: problems, prevalence, and an alternative. The Journal of Wildlife Management, 64 (4): 912-923.

Aparicio, J. J. \& Huidobro, A. 1990. Las estrategias de repaso en la memoria espacial. Revista De Psicología General y Aplicada, 43 (1), 59-69.

Armstrong, J. S. 2007. Significance Tests Harm Progress in Forecasting. International Journal of Forecasting, 23: 321-327.

Basualdo, J. A., Grenóvero, M. S. \& M. C. Minvielle. 2005. Nociones básicas de metodología de la investigación en ciencias de la salud (Tomo 2). Ed. Gráfica Alemana, Buenos Aires.

Bicca-Marques, J. C. \& Garber, P. A. 2005. Use of social and ecological information in tamarin foraging decisions. International Journal of Primatology, 26 (6), 1321-1344.

Boyer, D., Miramontes, O., Ramos-Fernández, G., Mateos, J. L. \& G. Cocho. 2003. Modeling the searching behavior of social monkeys. Disordered Systems and Neural Networks, arXiv:cond-mat/0311252 v1.

Bolker, B. M., Brooks, M. E., Clark, C. J., Geange, S. W., Poulsen, J. R., Stevens, M. H. H. \& J. S. White. 2009. Generalized linear mixed models: a practical guide for ecology and evolution. Trends in Ecology and Evolution, 24 (3): 127-135. 
Cabrera, F. 2009. Evaluando memoria de trabajo y de referencia en hámsters dorados (Mesocricetus auratus): una tarea de memoria espacial. Revista Mexicana de Análisis de la Conducta, 35, 117-132.

Clayton, D. A. 1978. Socially facilitated behavior. Quarterly Review of Biology. 53: 373-392.

Coe, R. \& C. Merino. 2003. Magnitud del efecto: una guía para investigadores y usuarios. Revista de Psicología - PUCP, 21(1): 147-177.

Cunningham, E. \& C. H. Janson. 2007. Integrating information about location and value of resources in white-faced saki monkeys (Phitecia phitecia). Animal Cognition, $10: 293-$ 304.

De Lillo, C., Visalberghi, E. \& M. Aversano. 1997. The organization of exhaustive searches in a patchy space by capuchin monkeys (Cebus apella). Journal of Comparative Psychology, 111 (1), 82-90.

Di Bitetti, M. S. \& C. H. Janson. 2001. Social foraging and the finder"s share in capuchin monkeys, Cebus apella. Animal Behaviour, 62: 47-56.

Dindo, M., Whiten, A. \& F. B. M. de Waal. 2009. Social facilitation of exploratory foraging behavior in capuchin monkeys (Cebus apella). Am. J. of Primatol., 71: 419-426.

Dominy, N.2004. Fruits, fingers and fermentation: the sensory cues available to foraging primates. Integr. Comp. Biol. 44: 295-303.

Domjan, M. 1998. Principios de aprendizaje y conducta ( $4^{\circ}$ ed.). International Thompson Editores, Méjico.

Duncan, I. J. H. \& J. C. Petherick. 1991. The implication of cognitive processes for animal welfare. J. Anim. Sci., 69: 5017-5022.

Garber, P. A. \& E. Brown. 2005. Chapter 12. Use of landmark cues to locate feeding sites in wild Capuchin Monkeys (Cebus capucinus): an experimental field study. En: A. Estrada, P. A. Garber, M. S. M. Pavelka \& L. Luecke. New Perspectives in the Study of Mesoamerican Primates: Distribution, Ecology, Behavior, and Conservation, (pp.311332) Springer, New York,

Gibeault, S. \& S. E. MacDonald. 2000. Spatial Memory and Foraging Competition in Captive Western Lowland Gorillas (Gorilla gorilla gorilla). Primates, 41 (2): 147-160,

Gouteux, S., Vauclar, J. \& C. Thinus-Blanc. 1999. Reaction to spatial novelty and exploratory strategies in baboons. Animal Learning \& Behaviour. 27 (3): 323-332.

Greenwald, A. G. 1975. Consequences of prejudice against the Null Hypothesis. Psychological Bulletin, 82 (1): 1-20.

Groves, C.P. 2001. Primate Taxonomy, USA \& England: Smithsonian Institution Press.

Gunst, N., Boinski, S. \& D. Fragaszy. 2008. Acquisition of foraging competence in wild brown capuchins (Cebus apella), with special reference to conspecifics" foraging artefacts as an indirect social influence. Behaviour, 145: 195-229.

Harlow H F. 1949. The formation of learning sets. Psychol. Rev. 56:51-65.

Heyes, C. M. 1993. Imitation, culture and cognition. Anim. Behav.,46, 999-1010. 
Janson, C. H. 2012. Reconciling rigor and range: observations, experiments, and quasiexperiments in field primatology. Int J Primatol, 33: 520-541.

Janson, C.H. \& R. Byrne. 2007. What Wild primates know about resources: opening up the black box. Animal Cognition, 10: 357-367.

Lezak, M. 1995. Neuropsycological Assessment. 3rd edition. USA: Oxford.

Likken, D. T. 1968. Statistical significance in psychological research. Psychological Bulletin, 70 (3): 151-159.

Lindsay,P.H. \& D.A.Norman. 1983. Introducción a la Psicología Cognitiva. Editorial Tecnos.

Ludvig, N., Tang, H. M., Eichenbaum, H. \& Gohil, B. C. 2003. Spatial memory performance of freely-moving squirrel monkeys. Behavioural Brain Research, 140, 175-183.

MacKinnon, K. C. 2013. Chapter 17: Ontogeny of social behavior in the genus Cebus and the application of an integrative framework for examining plasticity and complexity in evolution. En: K.B.H. Clancy et al. (eds.), Building babies: primate development in proximate and ultimate perspective. Developments in primatology: progress and prospects 37, Springer Science+Business Media: New York (pp. 387-408).

Mason, G. J. 1991. Stereotypies: a critical review. Animal Behav. 41: 1015-1037.

Melfi, V. A. 2005. The appliance of science to zoo-housed primates. Applied Animal Behaviour Science, 90: 97-106.

Melfi, V. A. 2007. Diversity of Zoo Primate Research: A Sampler. Int J Primatol., 28:1413-1415.

Morales Vallejo, P. 2012. El tamaño del efecto (effect size): análisis complementarios al contraste de medias. Disponible en: http://www.upcomillas.es/personal/peter/investigacion/Tama\%F1oDelEfecto.pdf

Nakagawa, S. \& I. C. Cuthill. 2007. Effect size, confidence interval and statistical significance: a practical guide for biologists. Biol. Rev., 82: 591-605.

Rapaport, L. G. \& G. R. Brown. 2008. Social influences on foraging behavior in young nonhuman primates: learning what, where, and how to eat. Evolutionary Anthropology 17:189-201.

Rifa Burrull, H. 1999. Técnicas de registro de conducta espacial. En: Anguera, M. T. Observación en etología (animal y humana): aplicaciones. Ediciones Universidad de Barcelona, Barcelona.

Rylands, A.B., 2000. An assessment of the diversity of New World Primates. Neotropical Primates, 8 (2), 61-93.

Salkind, N. J. 1999. Métodos de investigación ( $3^{\circ}$ ed). Ed. Prentice Hall, Méjico.

Scheumann, M. \& J. Call. 2006. Sumatran Orangutans and a Yellow-Cheeked Crested Gibbon know what is where. International Journal of Primatology, 27 (2): 575-602.

Tarou, L. R \& T. L. Maple. 2000. The use of spatial memory in foraging by a group of captive golden lion tamarins (Leontopithecus rosalia). Am. Journal of Primatology. 51 (1): 1-20.

Yoerg, S. I. \& Kamil, A. C. 1982. Response estrategies in the radial arm maze: running around in circles. Animal Learning \& Behavior, 10 (4), 530-534. 


\section{Capítulo 4: Capacidad de memoria sobre la ubicación de árboles de fruta y sus estados de fructificación en el Parque Nacional Iguazú, Argentina}

\subsection{Resumen}

La memoria espacial es considerada un factor clave en la evolución de la inteligencia. La diversidad extrema de árboles frutales y su distribución espacio-temporal en las selvas han sido señaladas como importantes fuerzas selectivas en el desarrollo de la memoria en primates. Se llevaron a cabo seguimientos de tres grupos de monos caí, Cebus apella nigritus (Rita N=1219 , Gundolf $\mathrm{N}=20-23$, Macuco $\mathrm{N}=27-32$ ) en sus desplazamientos diarios durante octubrediciembre y marzo-abril de 2008 a 2011 ( $\mathrm{N=204}$ días). Se utilizó un diseño observacional cualitativo evaluando las cantidades de fruta madura e inmadura presentes en árboles de fruta que consumen los monos, y registrando las visitas a los mismos. Los grupos se desplazaron a mayor velocidad hacia árboles con fruta que sin fruta y sus intervalos de revisita a los mismos estuvieron asociados a la cantidad de fruta madura e inmadura presente, indicando que los monos retienen información particular de la ubicación y condición de cada árbol. Los resultados obtenidos sugieren que los grupos estudiados utilizan la memoria espacial de ubicaciones, estado de fructificación y cantidades de alimento para mejorar la eficiencia de forrajeo.

\subsection{Introducción}

La memoria espacial se considera un factor selectivo en la evolución de la inteligencia humana. En el caso de los primates sudamericanos, la diversidad de plantas que son fuente de alimento, y la forma en que éstas se distribuyen en tiempo y espacio, ha sido señalada como la mayor fuerza selectiva en el desarrollo de complejidades cerebrales avanzadas (Milton, 1981). Esa mayor diversidad de plantas leñosas ofrece un ambiente complejo para los frugívoros (Suarez, 2003), ya que el número posible de árboles con fruta que pueden encontrar es elevado y el movimiento en línea recta hacia cualquier dirección al azar llevará eventualmente a una fuente de recurso (Janson, 1998). Pero numerosas investigaciones han determinado que los primates realizan movimientos directos hacia parches de alimento de una forma que sugiere un propósito y la utilización de un mapa espacial del ambiente (Janson, 1998, Pochron, 2001, Cunningham \& Janson, 2007, Janson \& Byrne, 2007, Noser \& Byrne 2007). De la misma manera, si se asume que el hecho de minimizar las distancias hacia fuentes de recurso es un objetivo de la estrategia de forrajeo de primates, observar que se mueven al recurso disponible más cercano es consistente con la idea de que conocen dónde se ubican los recursos alternativos (Janson \& Byrne, 2007). A su vez, los 
patrones de maduración de cada especie, que se corresponden con fluctuaciones predecibles de lluvia, temperatura y luz, ofrecen una ventaja a aprovechar por los frugívoros si fueran capaces de memorizar estos esquemas (Janmaat et al., 2006; Anzelc, 2009).

Como Milton (1981) señaló, en las selvas tropicales existe un mayor número de especies de árboles frutales, pero en menor densidad y ubicadas en agregados. Las hojas se encontrarán menos concentradas en tiempo y espacio que los frutos: en su estudio en 1980, Milton estimó que las hojas están presentes 11,75 meses del año mientras que los frutos solo 3,67 meses, lo que reforzaría la necesidad de habilidades cognitivas para encontrarlos. El beneficio de recordar la ubicación de ítems de alimento previamente hallados depende de cuál fácil sea detectar ese ítem sin usar la memoria (Janson \& Di Bitetti, 1997). Numerosos investigadores han estudiado la capacidad de los primates frugívoros para utilizar información ecológica al buscar el alimento (Garber, 1989; Garber \& Paciulli, 1997; Janson, 1998; Janson \& Di Bitetti, 1997; Menzel, 1973; Menzel, 1991; Milton, 1981), incluyendo información sobre la localización del sitio de alimentación (Garber \& Paciulli, 1997; Garber and Dolins, 1996; Gibeault and MacDonald, 2000; Janson, 1998; MacDonald and Wilkie, 1990; MacDonald, 1994; MacDonald et al., 1994; MacDonald and Agnes,1999; Platt et al., 1996; Roberts et al.,1993), qué tipo de alimento se ubicaba en determinado lugar (Scheumann \& Call, 2006; Menzel, 1973; Menzel, 1991), el valor del sitio en cuanto a cantidades (Garber \& Paciulli, 1997, Janson, 1998) y la tasa de renovación de la fruta madura (Janson, 1998). Pero aunque los modelos de movimientos al azar imitan algunos aspectos de los patrones de movimiento de los primates, un análisis detallado de los comportamientos de forrajeo y elección de recursos revela preferencias difíciles de interpretar, a menos que los monos puedan conocer los estados de maduración y productividad de los recursos que visitan (Janson \& Byrne, 2007). Janson et al. (1986), en su estudio sobre Cebus apella, plantearon que la frecuencia de revisita del grupo de estudio a determinados árboles estaría asociada al período de disponibilidad de fruta y la tasa de maduración de los mismos, dos variables no medidas en su estudio. Hasta la actualidad son pocos los estudios en los que se ha encontrado evidencia de que los primates son exitosos diferenciando entre determinados árboles en su estado de maduración además de en cantidad (Cunningham \& Janson, 2007, Janmaat et al. 2006a, Janmaat et al., 2012), así como tampoco se tiene mucho conocimientos sobre su capacidad de considerar las condiciones climáticas pasadas para buscar comida (Janmaat et al. 2006b). En este capítulo serán evaluados los intervalos de revisita a árboles de fruta según sus estados de fructificación y las velocidades con las que los 
monos se desplazan hacia esos recursos con diferentes cantidades de fruta presente madura e inmadura.

A pesar de que estas estrategias de forrajeo son consistentes con una memoria espacial, existen otra razones por las cuales estos recursos podrían estar siendo escogidos (por ejemplo ser más grandes y por ende ser visualizados a mayores distancias: Janson \& Di Bitetti, 1997). A su vez, los animales podrían tener varias razones para viajar en línea recta, aun sin conocer la localización de recursos discretos:

- Monitoreo de su área de acción.

- Utilización de rasgos topográficos o de límites del territorio para viajar y orientarse.

- Como una forma de evitar revisitar sitios recientemente utilizados.

Para este capítulo es importante tener presente una premisa de base: la memoria de corto y largo plazo en los caí debe ser razonable como para recordar aunque sea lo que visitaron recientemente. Aunque no a igual escala, los datos obtenidos en el capítulo 3 de la presente tesis permiten aseverar que los monos caí son capaces de retener posiciones de sitios de comida hasta por un período de 4 meses. La utilización de memoria de largo plazo es de suma importancia para los primates en sus movimientos diarios, y esto se hace evidente al momento de explorar nuevas áreas: se ha encontrado que la eficiencia para encontrar frutos en estas situaciones novedosas disminuye, lo cual puede tomarse como evidencia de que no pueden usar el conocimiento adquirido de su área de acción habitual a través de la memoria espacial de largo plazo (Janmaat \& Chancellor, 2010).

\subsection{Métodos}

Con la finalidad de cumplir con los objetivos específicos 1 a 3 detallados en el capítulo 1 , se realizaron observaciones de grupos en vida silvestre que permitieron evaluar la capacidad de los individuos de recordar la ubicación y el estado de maduración de frutos de diferentes especies.

\subsubsection{Sitio de estudio}

Las observaciones se desarrollaron en el Parque Nacional Iguazú, ubicado en la Provincia de Misiones, Argentina $\left(54^{\circ} \mathrm{O}, 26^{\circ} \mathrm{S}\right)$. El área comprende una porción de selva subtropical semidecidua caracterizada por clima subtropical húmedo, carente de estación seca predecible (Brown \& Zunino, 1990). La producción de frutos es estacional, con el pico de baja producción entre junio y agosto y el de máxima entre octubre y noviembre (Janson \& Di Bitetti, 1997). La mayoría de especies muestran 
periodos de maduración de frutos bastante cortos, de un mes o menos, por lo cual las especies más productivas varían de un mes al otro (Placci et al. 1994). Además, los sitios críticos de alimentación, entendidos como árboles de fruta o concentraciones de alimento, están distribuidos de forma heterogénea (Di Bitetti, 2001). Según un estudio realizado por Placci et al. (1994), existen dos tipos de bosques dentro del Parque Nacional Iguazú, los cuales presentan diferentes patrones de fructificación y caída de frutos carnosos y secos. El bosque Yacaratiá (B. Y.), dominado por un estrato de árboles de gran porte (alta representatividad de individuos mayores a $40 \mathrm{~cm}$ de diámetro a la altura del pecho o DAP), y el bosque Macuco (B. M.), con un estrato arbóreo de individuos de mediano porte (entre 5 y $40 \mathrm{~cm}$ de DAP). El B. Y. presenta menor abundancia de especies de árboles productoras de frutos secos (115 Ind/ha) en relación al B. M. (215 Ind/ha), lo que se refleja en las diferencias en la caída anual de frutos secos ( $5 \mathrm{~g} / \mathrm{m}^{2}$ en B. Y. y $15 \mathrm{~g} / \mathrm{m}^{2}$ en B. M.). Sin embargo, en cuanto a los frutos carnosos, la caída anual es muy semejante entre ambos tipos de bosques $\left(9,9 \mathrm{~g} / \mathrm{m}^{2}\right.$ en B. Y. y $10 \mathrm{~g} / \mathrm{m}^{2}$ en B. M.), concordando con valores muy semejantes en su densidad (258 Ind/ha en B. Y. y 219 en B. M.). Los tres grupos de estudio seleccionados para el presente estudio tienen áreas de acción que incluyen ambos tipos de bosques.

El Parque Nacional Iguazú cuenta con una estación biológica, el Centro de Investigaciones Ecológicas Subtropicales (CIES), ubicado dentro de la zona de estudio de los grupos de caí. La misma tiene capacidad para alojar a los investigadores durante el tiempo en que realicen el trabajo de campo, y cuenta con habitaciones, cocina equipada y un laboratorio donde instalar equipos de trabajo.

\subsubsection{Sujetos}

A lo largo de los muestreos, se llevó a cabo el seguimiento de 3 grupos de monos caí, Cebus apella nigritus = Cebus nigritus $=$ Sapajus nigritus (Macuco, Gundolf y Rita, Tabla 4.1) a través de un sistema de sendas abiertas a machete (ver Gráfico 2.6, Capítulo 2) que permiten el desplazamiento por la selva y la correcta observación de los individuos. Desde 1991 se realizan estudios experimentales y de observación sobre comportamiento y ecología de los caí en el sitio. De cada grupo de monos en este estudio se conoce la identidad de los individuos, su ascendencia por vía materna y su edad, desde esa fecha a la actualidad (Janson et al. 2012).

Esta especie se distribuye en el Bosque Atlántico de Brasil y Argentina, desde Rio Doce, en el estado de Minas Gerais y Espírito Santo, hasta el noreste de la Provincia argentina de Misiones, al este del Río Paraná (Fragaszy et al., 2004). 


\begin{tabular}{|c|c|c|c|c|c|}
\hline Año & Mes Inicio & $\begin{array}{l}\text { Mes } \\
\text { finalización }\end{array}$ & $\begin{array}{l}\text { Total días de } \\
\text { seguimiento }\end{array}$ & Grupo & Tamaño del grupo \\
\hline 2008 & Noviembre & Diciembre & 26 & Macuco & $27(10 \hat{-}-17+)$ \\
\hline 2009 & Noviembre & Diciembre & 40 & Macuco & $32(14 \hat{\jmath}-18+)$ \\
\hline 2009 & Septiembre & Octubre & 37 & Gundolf & $20(7 \precsim-13+)$ \\
\hline 2010 & Noviembre & Diciembre & 31 & Gundolf & $23(9 \bigcirc-14+)$ \\
\hline 2010 & Marzo & Abril & 35 & Rita & $12(5 \hat{\circ}-7$ 우 \\
\hline 2011 & Marzo & Abril & 34 & Rita & $19(12 \hat{\jmath}-7+)$ \\
\hline
\end{tabular}

Tabla 4.1: Períodos de estudio en meses y años de cada grupo, total de días de seguimiento y tamaños de los grupos con sus composiciones por sexo.

\subsubsection{Diseño observacional}

La metodología aplicada consistió en comparar datos de observación con las predicciones de un modelo cualitativo en el que el observador selecciona previamente árboles de determinadas especies consumidas por los monos, y evalúa los mismos en función de la ausencia/presencia de fruta y su correspondiente estado madurativo.

Se realizaron seguimientos diarios de los grupos de monos en turnos de medio día, trabajando 2 observadores por turno. Todos los observadores fueron entrenados en la identificación de los individuos, la identificación de vocalizaciones y la correcta toma de datos en función de los comportamientos a registrar y las técnicas a utilizar. Los observadores llegaban antes del amanecer al sitio dormidero donde el grupo había quedado durmiendo la noche anterior, para poder seguir a los individuos sin perderlos apenas iniciaban sus desplazamientos diarios. Estos dos investigadores se encargaban de colectar datos hasta el mediodía, momento en el cual otros dos observadores se dirigían al campo para relevar a los primeros y seguir al grupo de estudio hasta el anochecer, cuando el grupo llegaba a un nuevo sitio dormidero para pasar la noche.

Los investigadores se comunicaban entre ellos y con el CIES utilizando equipos de radio VHF (Very High Frequency) en una frecuencia de uso propio asignada por el cuerpo de guardaparques.

Durante el seguimiento de los grupos de monos se utilizaron las siguientes metodologías:

Registro de las áreas de acción de los grupos: Se tomó la ubicación del centro del grupo cada 10 minutos en coordenadas UTM utilizando un GPS de mano Garmin modelo $60 \mathrm{Cx}$ y con la ayuda del sistema de sendas y, además, se registró la actividad general y la dirección de desplazamiento con brújula. Con los puntos de GPS de cada día, y utilizando el método de polígonos mínimos convexos, se calcularon las áreas de 
acción de cada grupo (áreas por las cuales se desplazaron) en cada período de trabajo utilizando el programa gv_SIG 1.00 (software libre, Asociación gvSIG, 2011).

Muestreos de árboles focales (AF): se utilizó una modificación del método de árboles focales utilizado por Janmaat et al. (2006a) para analizar la capacidad de los grupos de estudio de visitar y re-visitar sitios de alimentación importantes dentro de su territorio, en función de su ubicación espacial y cantidad de alimento disponible.

1. Selección de los AF: Previo al inicio de las observaciones de comportamiento se seleccionaron árboles de diferentes especies, cuyos frutos son consumidos por los monos y no presentan señales de larga distancia visuales ni olfativas evidentes acerca de estado de maduración: Maclura tinctoria (Mora amarilla), frutos verdosos con fructificación estimativa en diciembre-enero, Ficus sp. (Higuerón o higuera brava), frutos verde amarillentos y fructificación aleatoria a lo largo del año, Campomanesia xanthocarpa (Guavira o guabiroba), frutos amarillo-anaranjados, con fructificación estimada para noviembre-diciembre, Eugenia piryformis (Ubajai), con frutos amarilloanaranjados, Matayba eleagnoides (Camboatá), con frutos amarillo-rosados, Miconia sp. (Miconia) con frutos verde oscuros a negros, e Plinia rivularis (Yvaporoití) con frutos verde oscuros a morados (Eibl et al., 1995; Lorenzi, 2002; Ortega Torres et al., 1989). Además se registraron también todas las visitas a todas las especies de otros árboles de fruta que los monos estuvieran consumiendo durante el período de muestreo y se los identificó como árboles no focales (No-AF) para diferenciarlos de los AF. Los mismos no fueron incluidos en los análisis de velocidades y cantidades de fruta debido al tamaño notorio de sus frutos (por ejemplo el caso del Araticú, Rollinia $s p$., o los cítricos), coloración notoria (por ejemplo el Cocú, Allophyllus edulis, o los cítricos) y/o olor llamativo (por ejemplo el caso de la Hovenia dulcis).

La ubicación de los AF y No-AF (tomada en coordenadas UTM con un GPS de mano Garmin modelo 60Cx) fue volcada en un mapa de recursos que cada observador llevaba al campo durante la toma de datos (Janmaat et al., 2006a).

De cada AF se tomaron los siguientes datos botánicos siguiendo a Dallmeier (1992): 1) DAP - diámetro a la altura del pecho - en $\mathrm{cm}$., 2) altura en metros y 3) diámetro y altura de la copa en metros, los que se utilizaron para calcular el volumen de la misma. Siguiendo a Janmaat et al. (2006a) se incluyeron como AF aquellos árboles con DAP y diámetro de copa mayor que el más pequeño observado con frutas durante el período de muestreo. Se excluyeron del muestreo los árboles que llevaron lianas u otro tipo de fruto que no perteneciera al árbol focal. 
Cuando los monos se encontraban en las cercanías de un árbol, focal un observador se adelantaba al mismo y registraba la presencia de frutos en el árbol, según las siguientes categorías: 0 (0\%), 1 (1-25\%), 2 (26-50\%), 3 (51-75\%), 4 (76-100\%) (Janmaat et al., 2006a). Esto se realizó dividiendo visualmente la copa en 4 cuadrantes, siguiendo como ejes a los puntos cardinales, y realizando una estimación visual promedio del porcentaje de ramas que contenían fruta por cuadrante, desde la base al final de las mismas. Un árbol categoría 4 tendría entonces todas las ramas de todos los cuadrantes con fruta. Cuando un árbol no presentaba ramas en alguno de los cuatro cuadrantes se contaba a ese cuadrante como con $0 \%$ de fruta. A su vez, siempre que fue posible distinguir la presencia de fruta madura de la inmadura, se contaron las ramas por separado y se asignó un porcentaje promedio a las categorías finales. Las categorías de fructificación para frutas maduras e inmaduras pueden sumarse a más de 4 ya que el muestreo cuantifica solo la cobertura de la fruta pero no su densidad. Dado que los árboles pueden presentar diferencias en los estados de maduración y cantidades de fruta dentro de un mismo individuo como causa de la diferente influencia del sol y la temperatura (Houle et al. 2007), esta metodología de estimación permite controlar esta variación. Para el caso de frutas cuya coloración cambiaba del estado inmaduro a maduro, se utilizó este parámetro para la estimación. Para el caso de la mora amarilla (Figura 4.1), se consideró madura a la fruta una vez que hubiera perdido los tricomas y comenzaran a visualizarse las circunvoluciones típicas de la misma cuando ha aumentado de tamaño (De Oliveira Oyama \& De Souza, 2011). Dado que el tamaño de los frutos maduros de ficus varía ampliamente de un árbol a otro (Tujague, observaciones personales), fue necesario analizar cada árbol en particular procediendo a observar y evaluar al tacto los frutos maduros en el suelo, tomando como parámetro el tamaño de los mismos, para estimar visualmente la presencia de frutos de ese tamaño en el árbol. Se ha observado que los monos inspeccionan con la vista y el tacto la fruta antes de consumirla (Tujague, Obs. Pers.). 


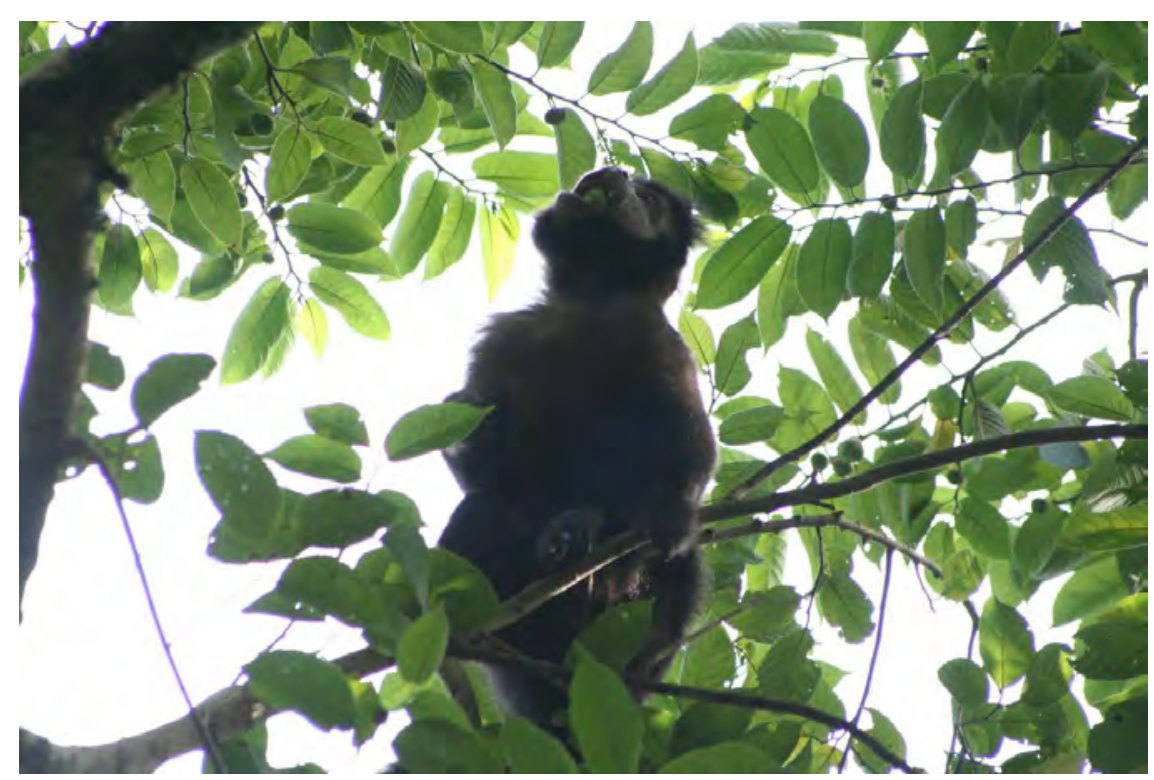

Figura 4.1: Macho adulto del grupo Macuco consumiendo frutos de Maclura tinctoria (B. Wheeler).

Se consideró una distancia mínima de separación entre árboles focales, estimada en función de la dispersión promedio de cada grupo de monos. Esta distancia se calculó como el doble de la dispersión longitudinal del grupo durante el forrajeo lento. La dispersión se estimó en función del número de individuos de cada grupo a partir de estudios previos que determinaron una dispersión típica de 57 × 42 metros para un grupo de 15 individuos en este sitio de estudio (Janson \& Di Bitetti, 1997; Janson, 1998). Se definió un radio crítico (RC) alrededor de cada árbol, como la mitad de la distancia mínima entre árboles focales o la medida de la dispersión longitudinal del grupo durante el forrajeo lento. A esta distancia se consideró que el grupo era incapaz de detectar el árbol. En Iguazú la distancia mínima de detección durante el forrajeo lento fue estimada en 36,2 metros y definida como la distancia a la que el animal focal, generalmente en el borde del grupo, detecta un recurso (Janson \& Di Bitetti, 1997). Hay que señalar que los recursos utilizados en el estudio de Janson \& Di Bitetti (1997) fueron plataformas aprovisionadas con mandarinas que, por su forma distintiva y color de fruta llamativo, probablemente eran más fáciles de ubicar que árboles silvestres con frutas pequeñas y/o verdosos/amarillentas.

En cada árbol se realizó un muestreo de árbol focal (Vogel \& Janson, 2007). Este método consiste en que un observador se adelante al frente del grupo y se ubique debajo del árbol de frutos que los monos están por visitar. Previo a la llegada del grupo, el observador registra la presencia/ausencia de frugívoros y la cantidad de fruta madura e inmadura según la escala 0-4 antes citada. Al llegar el grupo, ambos observadores registran: hora e identificación del primer individuo en el sitio, hora e 
identificación de los individuos que entran al árbol luego del primero y hora e identificación de cada individuo que abandona el árbol. A intervalos de 2 minutos se tomaron datos del número, identidad, actividad y posición relativa de todos los monos en el árbol. Para analizar si los monos eran capaces de recordar lo ocurrido en visitas previas a un sitio, se realizó una estimación indirecta de la "calidad" del árbol calculando el índice "Grupo-Minuto" (Janson, 1988):

Grupo-Min $=\underline{\mathrm{N} \text { individuos promedio durante la visita } \mathrm{x} \text { tiempo que duró la visita }}$

$\mathrm{N}$ total individuos del grupo

2. Datos de comportamiento: Durante el seguimiento de los grupos de monos en sus visitas a los AF se registraron la hora y ubicación del grupo (en coordenadas UTM y en el sistema de sendas) y la dirección del desplazamiento con brújula, antes de que los monos entraran a un radio crítico alrededor de un $A F$, en el momento en que ingresaban al mismo y en los casos en los que fue posible a la mitad entre el radio crítico y el árbol focal.

Los datos de ubicación y dirección permitieron estimar la velocidad y la aceleración de movimiento del grupo en los acercamientos a los árboles focales, como distancia recorrida en función del tiempo utilizado en recorrerla (Noser \& Byrne, 2007). La velocidad es una buena medida de la expectativa acerca del recurso que será encontrado (Pochron, 2001). Janson y Di Bitetti (1997), en su trabajo sobre la capacidad de detección de recursos en los capuchinos del mismo sitio de estudio encontraron que una velocidad mayor se relacionaba al acercamiento a un objetivo predefinido (en este caso, plataformas experimentales). Los monos se movían más rápido (10 $\mathrm{m} / \mathrm{min}$ ) entre plataformas previamente conocidas, que en el forrajeo lento de insectos $(2 \mathrm{~m} / \mathrm{min})$. A su vez una mayor velocidad de desplazamiento disminuía la posibilidad de detectar fuentes de recurso desconocidas (disminuía el campo de detección), sugiriendo que una mayor velocidad sólo tendría sentido si se conoce el objetivo hacia el cual se dirigen. La "expectativa" será en tendida entonces como la capacidad de los individuos de modificar su velocidad de desplazamiento en función de existencia de un recurso conocido al cual llegar.

Para que los cambios en la velocidad puedan ser usados para inferir que los monos conocen la dirección hacia un recurso determinado, estos deben ocurrir a una distancia a la que la fuente de alimento no haya podido ser percibida por los sentidos y, a la vez, se debe tener una evaluación independiente del "valor" del recurso, que no se base en el comportamiento del animal (Janson \& Byrne, 2007). 
A partir de estos datos se estimaron las siguientes velocidades y aceleraciones medidas en metros por minuto $(\mathrm{m} / \mathrm{min})$ :

- Velocidad Pre Radio Crítico (V Pre RC): velocidad con la que el grupo se movía antes de entrar al radio crítico del árbol.

- Velocidad Post Radio Crítico (V Post RC): velocidad con la que el grupo se movía inmediatamente luego de entrar al radio crítico del árbol.

- Velocidad Medio Radio Crítico (V Med RC): velocidad con la que el grupo se acercaba al árbol focal, estimada a la distancia media entre el árbol focal y el límite del radio crítico (distancia a la cual los monos aun no son capaces de visualizar el árbol).

- Aceleración 1: aceleración al entrar al radio crítico, medida como la diferencia de velocidades post y pre radio crítico (V Post $R C-V$ Pre $R C$ ).

- Aceleración 2: aceleración a la mitad del radio crítico, medida como la diferencia de velocidades medio y post radio crítico ( $V$ Medio $R C-V$ Post $R C$ ).

Se definieron las siguientes categorías de comportamiento (Tabla 4.2) durante los recorridos diarios de los grupos de monos:

\begin{tabular}{|c|c|}
\hline Visita (V) & Ingreso a un $\mathrm{AF}$, con o sin consumo de fruta \\
\hline $\begin{array}{l}\text { Entrada a radio } \\
\text { crítico }(\mathrm{RC}) \quad 0 \\
\text { acercamiento }\end{array}$ & $\begin{array}{l}\text { El grupo entra a la distancia alrededor de un AF dentro de la cual no } \\
\text { es posible aún visualizar el árbol. Luego del ingreso a un RC, el } \\
\text { grupo puede visitar (Visita) o no visitar (No Visita) el árbol. }\end{array}$ \\
\hline
\end{tabular}

Tabla 4.2: Categorías de comportamientos relacionados a los árboles focales.

Se realizó una estimación del promedio de árboles y/o parches de árboles de fruta visitados diariamente por los grupos de estudio. Este promedio se refirió a aquellas visitas a árboles y parches en los que al menos $1 / 3$ del grupo hubiera comido al menos por una vez en el sitio. No incluyó visitas de individuos aislados a árboles o parches aislados, entendiendo como parche a la presencia de más de un árbol de la misma especie separados entre sí por una distancia de hasta 10 metros.

\section{Análisis de datos}

Para el análisis de los patrones de visitas a árboles con y sin fruta se utilizaron test de Chi cuadrado con corrección de continuidad de Yates (Yates, 1934) y Phi (medida de asociación entre dos variables que se basa en el estadístico de Chi cuadrado) como 
método para estimar el tamaño del efecto (Trusty et al., 2004). El valor de Phi varía entre 0 (ausencia de asociación) y 1 (asociación fuerte).

Para evaluar las diferencias entre las velocidades de acercamientos y visitas a los árboles se utilizaron test de Student para muestras pareadas, test de Student para muestras independientes y test de probabilidad combinada de Fisher para muestras independientes con $\mathrm{N}$ bajo (Fisher, 1932). Para todos los test de Student se calculó el tamaño del efecto (effect size) mediante el método de Cohen ( $d$ de Cohen: Morales Vallejo, 2012; Nakawaga \& Cuthill, 2007) como análisis complementario al análisis de diferencias entre promedios. Cohen (1988 en Nakawaga \& Cuthiil, 2007) ha propuesto valores convencionales como puntos de referencia para interpretar el valor de d: bajos $(d=0,2$ o menores) medios o moderados $(d=0,5)$ y altos ( $d=0,8$ o mayores). Si bien estos valores son un tanto arbitrarios, pueden considerarse orientadores al momento de evaluar el tamaño del efecto encontrado (Coe \& Merino, 2003, Morales Vallejo, 2012), aunque siempre deben ser analizados en el contexto de los datos que se están evaluando. Los datos de velocidad no se ajustaron a una distribución normal por lo que se les aplicó transformación logarítmica para poder aplicar test paramétricos.

Se compararon las velocidades Post RC y Medio RC de visita según los porcentajes de fruta separados en las siguientes categorías: 1) árboles con el $50 \%$ o más de fruta (madura e inmadura) presente y aquellos con menos del $50 \%, 2$ ) árboles con el $25 \%$ o más de fruta (madura e inmadura) presente y aquellos con menos del $25 \%, 3$ ) árboles con el $50 \%$ o más de fruta madura presente y aquellos con menos del $50 \%$, y 4 ) árboles con el $25 \%$ o más de fruta madura presente y aquellos con menos del $25 \%$.

Se evaluó la asociación entre las aceleraciones 1 y 2 , y variables relacionadas al "valor del árbol" (categorías de fruta, grupo-minuto, volumen de la copa, DAP) utilizando correlación de Spearmann. Se descartaron del análisis las correlaciones con un $\mathrm{N}$ menor a 20 (Packard \& Boardman, 2008).

Se utilizó un Modelo Generalizado Lineal Mixto en R (MGLM - R Development Core Team 2010) para evaluar si los intervalos de revisita a los árboles fueron menores a mayor cantidad de fruta presente y en un estado de maduración avanzada. Los MGLM permiten el análisis de los datos cuando existe un efecto al azar en ellos (Bolker et al. 2009) ofreciendo una mejor evaluación de los efectos de las variables no controladas (Janson, 2012) como son en este caso, la presencia de varios grupos de estudio, diferentes árboles y diferentes años de muestreo. Se utilizó como efectos al azar (random effect) la identidad del grupo, la identidad del árbol, la especie y el año de muestreo, y como efectos fijos (fixed effects) las categorías de fruta madura e inmadura presentes. Se evaluaron todos los modelos posibles controlando para cada efecto fijo, y se los comparó con el modelo global general (que incluyó todos los 
efectos fijos a la vez). Se escogió como modelo con mejor fit al de menor CIA (Criterio de información de Akaike) que estima la distancia relativa esperada entre el modelo estimado y cada modelo generado con los datos observados (Bolker et al. 2009).

\subsection{Resultados}

\subsubsection{Tamaño de las áreas de acción}

Utilizando el programa gv_SIG 1.10 (software libre, Asociación gvSIG, 2011) se calculó el tamaño del área de acción de cada grupo para cada período de muestreo (Tabla 4.3) entendida como el área total utilizada por el grupo durante cada período de estudio (Anzelc, 2009). La exactitud de las estimaciones de las áreas de acción mejoran con datos tomados a intervalos menores, a pesar del posible aumento de la autocorrelación entre las observaciones (de Solla et al., 1999).

Se elaboraron mapas cartográficos de las mismas (Figuras 4.2 a 4.4), en los que puede visualizarse la ubicación de los grupos en el área de muestreo. Se observa que el grupo Macuco presenta el mayor tamaño del área de acción.

\begin{tabular}{|c|c|c|c|c|c|}
\hline Año & Grupo & Área (ha) & $\begin{array}{l}\text { Días } \\
\text { completos de } \\
\text { seguimiento }\end{array}$ & $\begin{array}{l}\text { Puntos } \\
\text { promedio por día }\end{array}$ & $\begin{array}{l}\text { Puntos } \\
\text { totales }\end{array}$ \\
\hline 2008 & Macuco & 125 & 19 & $23 \pm 8,2$ DS & 453 \\
\hline 2009 & Macuco & 100 & 38 & $27 \pm 10,8$ DS & 1011 \\
\hline 2009 & Gundolf & 89 & 21 & $28 \pm 12,9$ DS & 620 \\
\hline 2010 & Gundolf & 61 & 24 & $32 \pm 10,5$ DS & 807 \\
\hline 2010 & Rita & 75 & 30 & $30 \pm 10,3$ DS & 883 \\
\hline 2011 & Rita & 78 & 32 & $33 \pm 12$ DS & 1054 \\
\hline
\end{tabular}

Tabla 4.3: Tamaño del área de acción de cada grupo en hectáreas, cantidad de días completos de seguimiento, promedio y desvío estándar de los puntos georreferenciados colectados por día y el total de puntos colectados por grupo. 


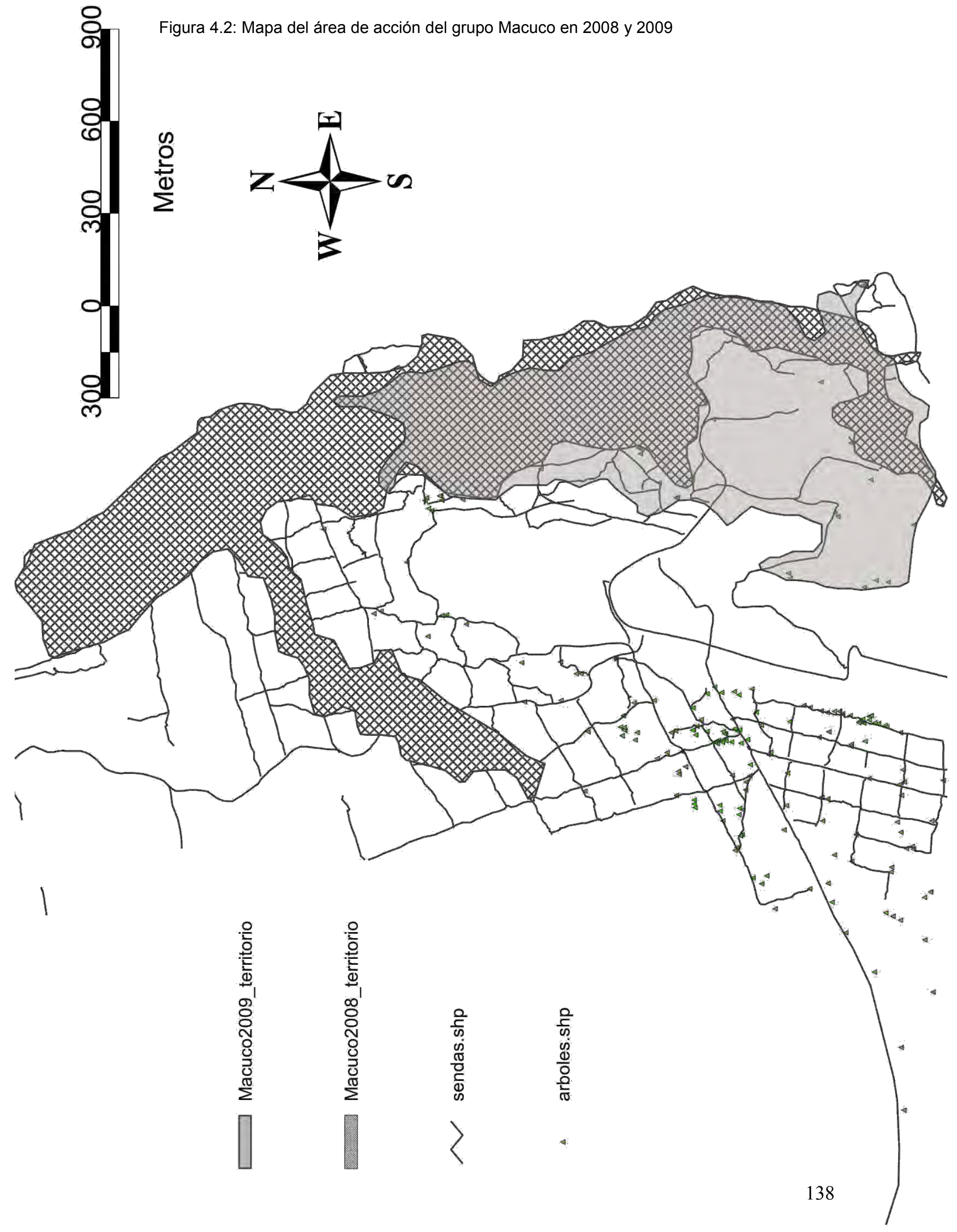


Figura 4.3: Mapa del área de acción del grupo Gundolf en 2009 y 2010

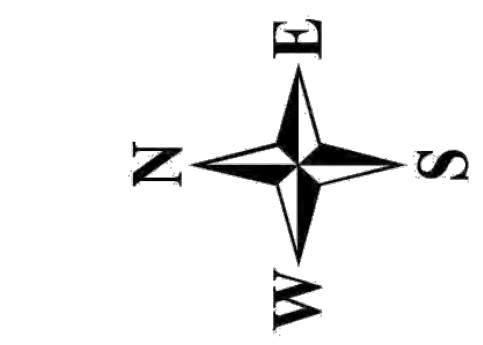


Figura 4.4: Mapa del área de acción del grupo Rita en 2010 y 2011.

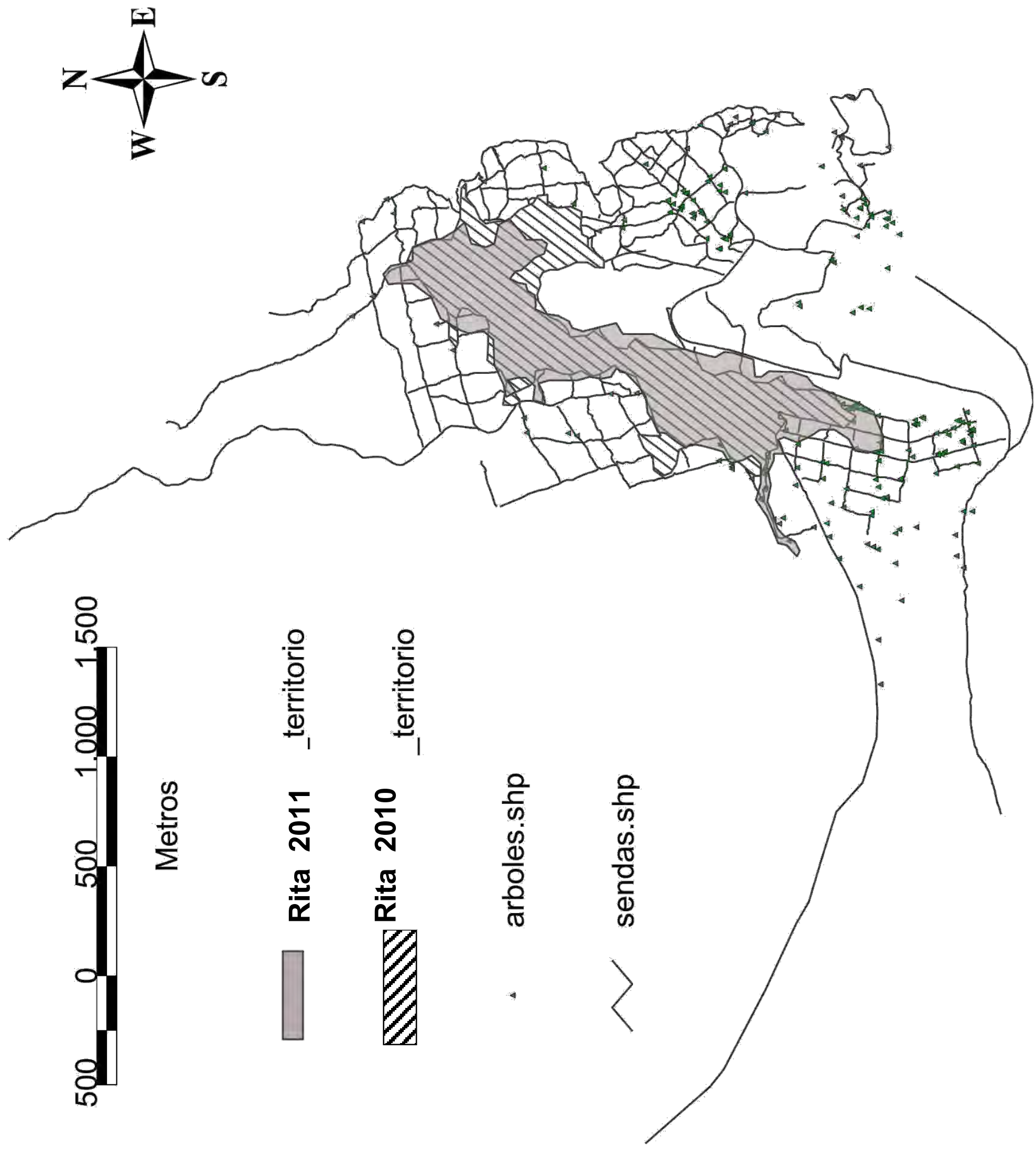


Para el cálculo del promedio de árboles visitados diariamente por los grupos se incluyeron los árboles infestados con homóptera dado que fueron sitios de alimentación importantes para el grupo Macuco en 2008 - 2009 y Gundolf en 2009. Los mismos fueron modelados como árboles frutales aunque no para los análisis que incluyeran cantidades de fruta (Tabla 4.4). Estos promedios se presentan junto con los tamaños de radios críticos de cada grupo y distancias entre los árboles focales.

\begin{tabular}{|l|l|l|l|l|l|}
\hline Grupo & Año & $\begin{array}{l}\text { Promedio de árboles } \\
\text { visitados por día }\end{array}$ & $\begin{array}{l}\text { Radio } \\
\text { crítico } \\
\text { (metros) }\end{array}$ & $\begin{array}{l}\text { Distancia } \\
\text { entre AF } \\
\text { (metros) }\end{array}$ & $\begin{array}{l}\mathbf{N}^{\circ} \\
\text { consumidas }\end{array}$ \\
\hline Macuco & 2008 & $\mathrm{M}=3,92 ; \mathrm{DS} \pm 2,23$ & 100 & 200 & 10 \\
\hline Macuco & 2009 & $\mathrm{M}=6,41 ; \mathrm{DS} \pm 2,77$ & 120 & 240 & 10 \\
\hline Gundolf & 2009 & $\mathrm{M}=2,77 ; \mathrm{DS} \pm 2,4$ & 75 & 150 & 11 \\
\hline Gundolf & 2010 & $\mathrm{M}=5,84 ; \mathrm{DS} \pm 2,96$ & 88 & 175 & 12 \\
\hline Rita & 2010 & $\mathrm{M}=3,53 ; \mathrm{DS} \pm 1,9$ & 50 & 100 & 12 \\
\hline Rita & 2011 & $\mathrm{M}=5,96 ; \mathrm{DS} \pm 3,01$ & 75 & 150 & 12 \\
\hline
\end{tabular}

Tabla 4.4: promedio de árboles / parches de fruta visitados por día, radio crítico, distancia mínima entre árboles focales y número de especies consumidas para cada grupo en cada período de muestreo. Es importante tener en cuenta que estos números son probablemente subestimaciones de los números reales de parches que forman destinos recordados por los monos en sus circuitos diarios, ya que existen fuentes de comida que son revisitados pero por menos de $1 / 3$ del grupo.

A lo largo de todos los muestreos los individuos se alimentaron de 25 especies de árboles de fruta y 2 especies de enredaderas (Tabla 4.5). El análisis de cada muestra evidenció una gran diferencia entre los años y los grupos de estudio tanto en el número y tipo de especies consumidas como en la cantidad de árboles/parches visitados en total. Se graficaron las especies consumidas por cada grupo en cada período de muestreo y sus porcentajes relativos de consumo. Para un mismo grupo, y entre grupos, se mantuvieron los mismos colores para identificar cada especie con el fin de poder observar a simple vista las diferencias entre grupos $y$, dentro de un mismo grupo, las diferencias entre años (Gráficos 4.1 a 4.6). 


\begin{tabular}{|l|l|l|}
\hline Nombre vulgar & Nombre científico & Abreviatura \\
\hline Ambay & Cecropia pachystachya & AM \\
\hline Azota caballo & Luehea divaricata & LU \\
\hline Aguaí & Chrysophyllum gonocarpum & AG \\
\hline Araticú & Rollinia sp. & AR \\
\hline Banana & Musa sp. & BAN \\
\hline Camboatá blanco & Matayba eleagnoides & CA \\
\hline Cancharana & Cabralea canjerana & CAN \\
\hline Carayá bola & Guarea pohlii & CB \\
\hline Guazatumba / Burro Caá & Cassearia decandra / sylvestris & CAS \\
\hline Cocú & Allophyllus edulis & CO \\
\hline Dicella nucífera, parches \\
enredadera & Dicella nucifera & DN \\
\hline Ficus o Higuerón & & \\
\hline Guabira & Ficus sp. & FI \\
\hline Hobenia & Campomanesia xanthocarpa & GB \\
\hline Yvaporoití & Hovenia dulcis & HOB \\
\hline Laurel & Plinia rivularis & IV \\
\hline Mboreví caá & Nectandra sp / Ocotea sp. & LA \\
\hline Mora amarilla & Coussarea contracta & COU \\
\hline Miconia & Maclura tinctoria & MA \\
\hline Mandarina & Miconia concolor & MI \\
\hline Naranja & Citrus reticulata & MAN \\
\hline Ñandipá & Citrus aurantium & NAR \\
\hline Pindó & Sorocea bonplandii & PI \\
\hline Tala trepador & Syagrus romanzoffiana & TA \\
\hline Tricostigma, parches de enredadera & Celtis iguanaea & Trichostigma octandrum \\
\hline Ubajai & Cugenia piryformis & TAsophyllum marginatum \\
\hline Vasurinia o comida de paloma & & \\
\hline
\end{tabular}

Tabla 4.5: Listado total de especies frutales (árboles y enredaderas) consumidas por los grupos de estudio. Nombre vulgar, nombre científico y codificación utilizada para gráficos posteriores. $\mathrm{N}$ total de especies $=27$. 


\section{Macuco 2008}

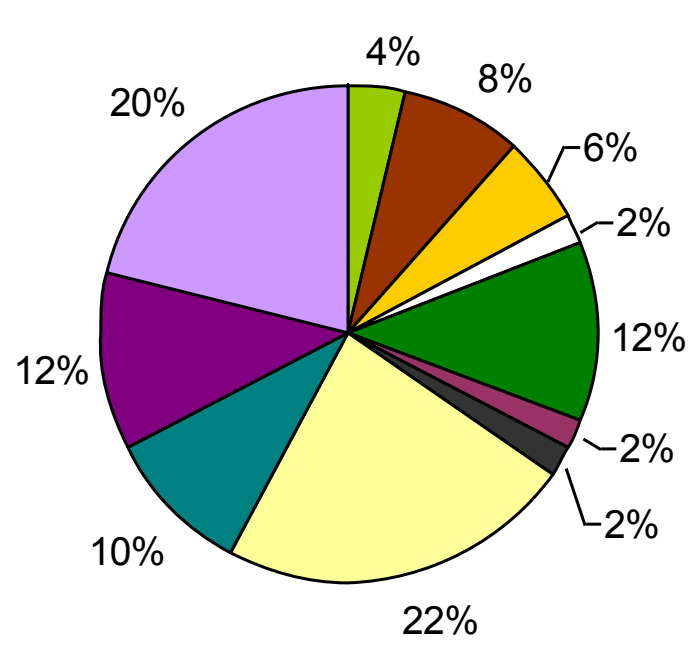

$\square \mathrm{AM}$

$\square \mathrm{CA}$

$\square \mathrm{CAN}$

$\square \mathrm{CB}$

$\square \mathrm{FI}$

$\square \mathrm{IV}$

$\square \mathrm{LA}$

$\square \mathrm{MA}$

$\square \mathrm{MI}$

$\square S A$

$\square T$

Gráfico 4.1: Especies frutales consumidas por el grupo Macuco en 2008. $\mathrm{N}{ }^{\circ}$ total: 52 parches/árboles de fruta. Referencias de las siglas en tabla 4.5. SA: árboles (cedros misioneros - Cedrela fissilis, marmeleros - Ruprechtia laxiflora y cancharanas - Cabralea canjerana) infestados con estados larvales de homópteros.



Gráfico 4.2: Especies frutales consumidas por el grupo Macuco en 2009. $\mathrm{N}^{\circ}$ total: 83 parches/árboles de fruta. Referencias de las siglas en tabla 4.5. 


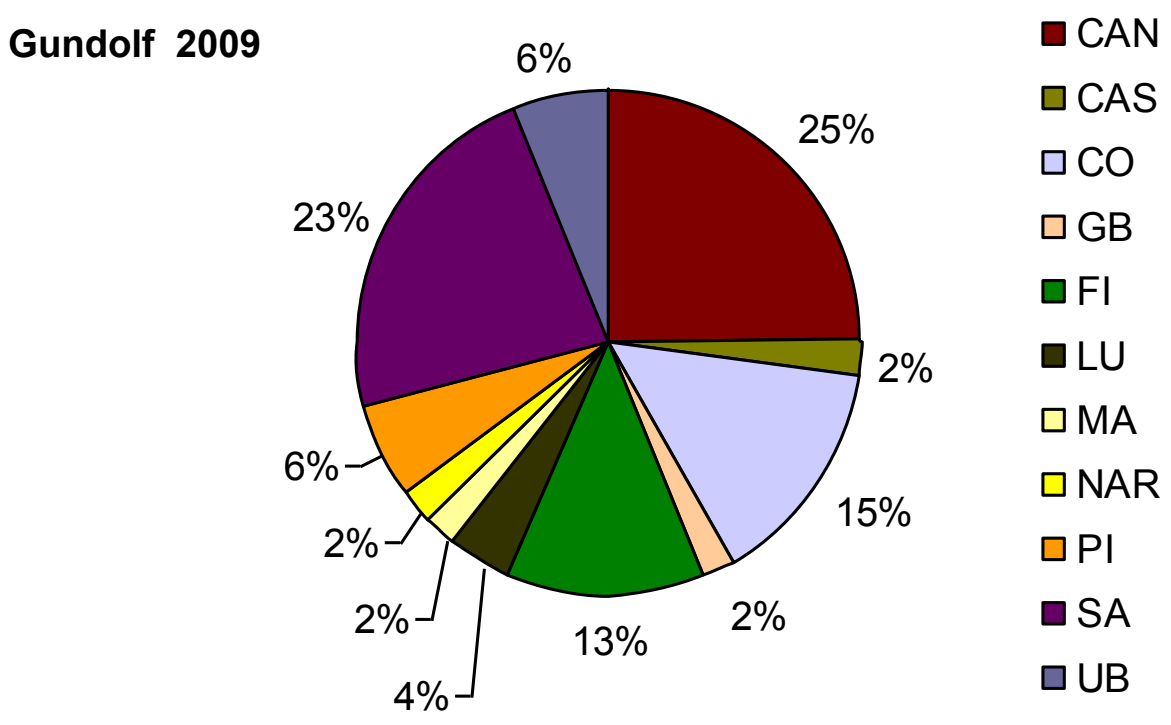

Gráfico 4.3: Especies frutales consumidas por el grupo Gundolf en 2009. $N{ }^{\circ}$ total: 48 parches/árboles de fruta. Referencias de las siglas en tabla 4.5. SA: árboles (cedros misioneros, marmeleros y cancharanas) infestados con estados larvales de homópteros.

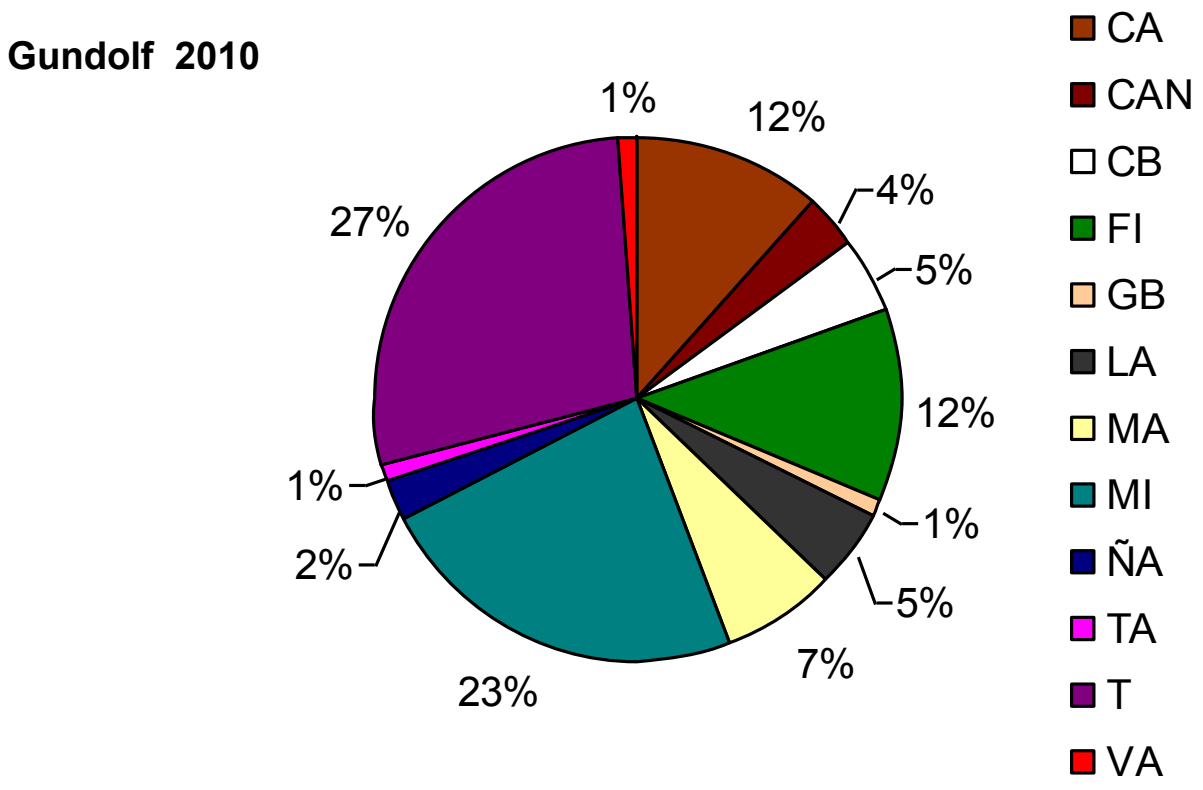

Gráfico 4.4: Especies frutales consumidas por el grupo Gundolf en 2010. $N{ }^{\circ}$ total: 86 parches/árboles de fruta. Referencias de las siglas en tabla 4.5. 
Rita 2010

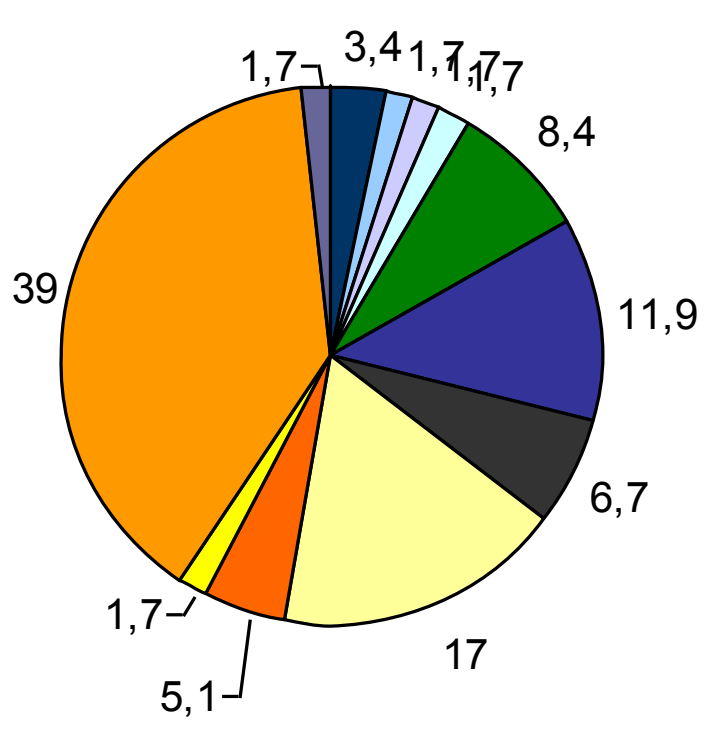

$\square A G$

$\square A R$

$\square \mathrm{CO}$

$\square \mathrm{DN}$

$\square \mathrm{FI}$

$\square \mathrm{HOB}$

$\square$ LA

$\square M A$

$\square$ MAN

口NAR

$\square \mathrm{PI}$

$\square$ UB

Gráfico 4.5: Especies frutales consumidas por el grupo Rita en 2010. N ${ }^{\circ}$ total: 59 parches/árboles de fruta. Referencias de las siglas en tabla 4.5.

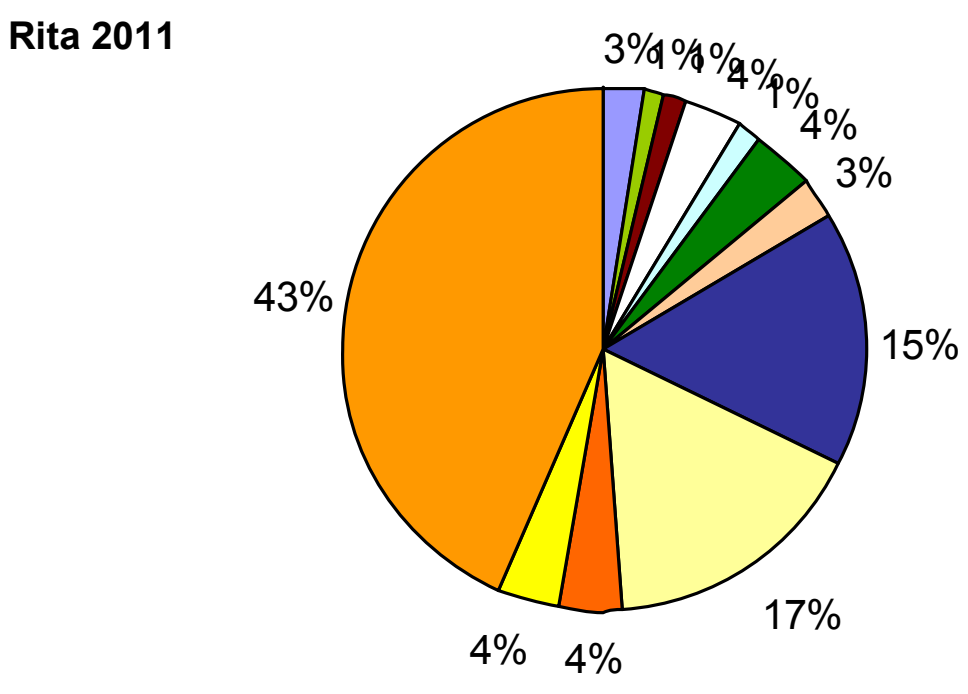

$\square A R$

$\square B A N$

$\square$ CAN

$\square \mathrm{CB}$

$\square D N$

$\square \mathrm{FI}$

$\square \mathrm{GB}$

$\square \mathrm{HOB}$

$\square \mathrm{MA}$

$\square$ MAN

$\square$ NAR

$\square \mathrm{PI}$

Gráfico 4.6: Especies frutales consumidas por el grupo Rita en 2011. $N{ }^{\circ}$ total: 78 parches/árboles de fruta. Referencias de las siglas en tabla 4.5. 


\subsubsection{Memoria de los estados de fructificación}

Aquellas visitas en las que se registró la presencia de otros frugívoros (pájaros y/o coatíes) en el árbol antes de la llegada del grupo fueron excluidas del análisis. Esta exclusión tuvo como fin controlar la posibilidad de que el grupo se acercara al árbol atraído por la audición de otros individuos alimentándose y no por el registro de la presencia de fruta (Macuco $2008 \mathrm{~N}=2$ / $2009 \mathrm{~N}=6$, Gundolf $2009 \mathrm{~N}=0 / 2010 \mathrm{~N}=2$, Rita $2010=0 / 2011=9$ ).

\subsubsection{Visitas a árboles focales en función de la probabilidad de los mismos de tener o no tener fruta.}

Se evaluó si los monos, una vez entrado el radio crítico de un árbol, seguían desplazándose hacia el mismo si este contenía fruta pero no lo hacían si estaba vacío. Para 4 de las muestras (Macuco 2008, Gundolf 2009 - 2010 y Rita 2010), se encontró una mayor probabilidad de visitar un árbol cuando tenía frutos versus cuando no tenía frutos una vez que hubieran entrado al radio crítico de los mismos (Gráficos 4.7 a 4.10 , test de Chi cuadrado con corrección de Yates y valor de Phi para tamaño del efecto, Macuco 2009: $X^{2}=1846.76, p=0.000$, Phi = 0,126, $p=0,037$; Gundolf 2009: $X^{2}=$ 10.55, $p=0.001$, Phi $=0,328, p=0,001$; Gundolf 2010: $X^{2}=26.408, p=0,000$, Phi $=$ 0,385, $p=0,000$; Rita 2010: $X^{2}=59.721, p=0,000$, Phi $=0,588, p=0,000$ ). Los tamaños de los efectos fueron débiles pero no nulos y en el caso de Rita 2010, el tamaño del efecto demostró que esta asociación fue elevada aunque no perfecta.

Para el caso de Macuco 2008 la asociación no fue significativa pero el valor de Phi reveló una asociación fuerte entre las variables (Macuco 2008: $X^{2}=2.135, p=0,1439$; Phi = 0,686, $p=0,000$; Gráfico 4.11). El grupo Rita 2011 no fui incluido en el análisis dado que, de un total de 204 entradas a radios críticos, solo 3 fueron a árboles sin fruta (Gráfico 4.12).

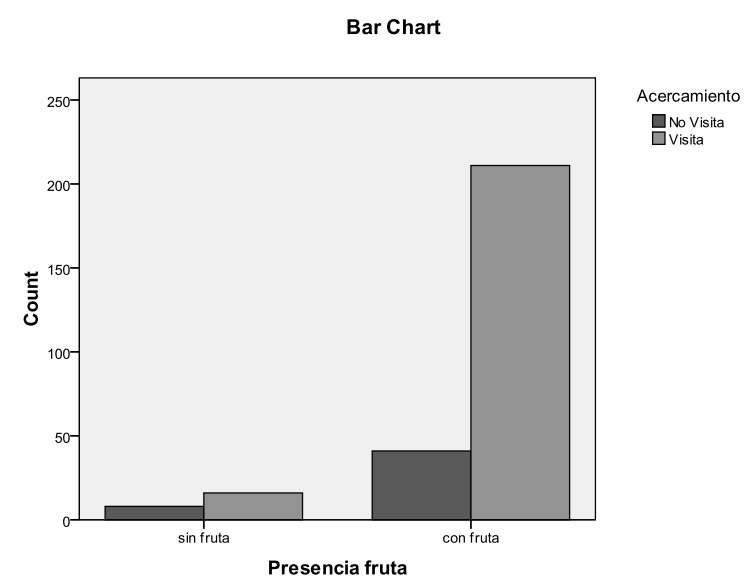

Gráfico 4.7: Entradas a radios críticos del grupo Macuco en 2009. Sin fruta $\mathrm{N}=24$ ( $\mathrm{N}$ no visitas = $8, \mathrm{~N}$ visitas $=16)$, Con fruta $\mathrm{N}=252(\mathrm{~N}$ no visitas $=41, \mathrm{~N}$ visitas $=211)$. 


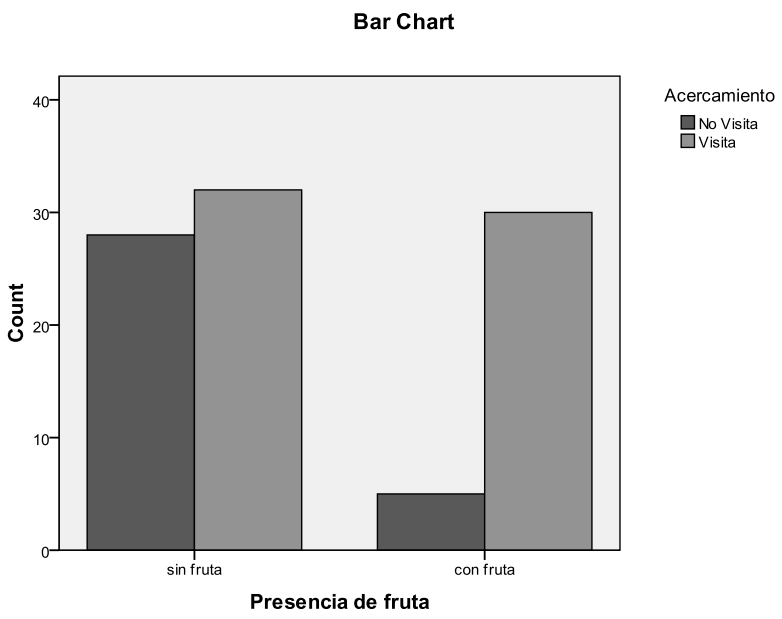

Gráfico 4.8: Entradas a radios críticos del grupo Gundolf en 2009. $\operatorname{Sin}$ fruta $\mathrm{N}=60$ ( $\mathrm{N}$ no visitas = $28, \mathrm{~N}$ visitas $=32)$; $y$ Con fruta $\mathrm{N}=35(\mathrm{~N}$ no visitas $=5, \mathrm{~N}$ visitas $=30)$.

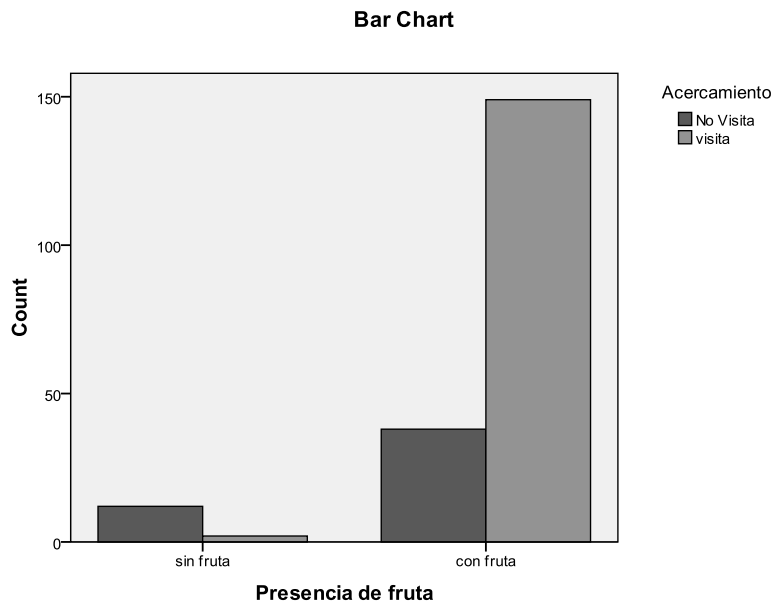

Gráfico 4.9: Entradas a radios críticos de grupo Gundolf en 2010. Sin fruta N=14 (N no visitas = $12, \mathrm{~N}$ visitas $=2)$, Con fruta $\mathrm{N}=187(\mathrm{~N}$ no visitas $=38, \mathrm{~N}$ visitas $=149)$.

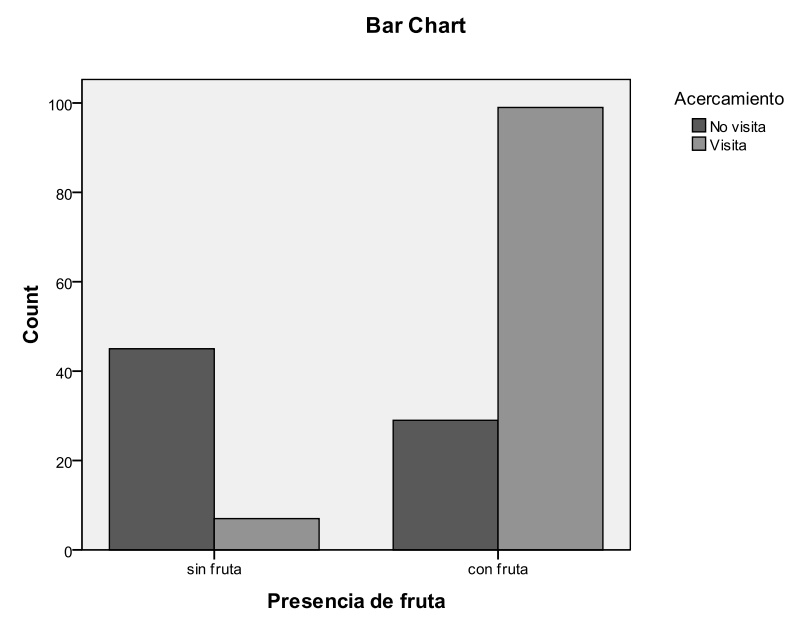

Gráfico 4.10: Entradas a radios críticos del grupo Rita en 2010. Sin fruta $N=52$ ( $N$ no visitas $=$ $45, \mathrm{~N}$ visitas $=7)$, Con fruta $\mathrm{N}=128(\mathrm{~N}$ no visitas $=29, \mathrm{~N}$ visitas $=99)$. 




Gráfico 4.11: Entradas a radios críticos del grupo Macuco en 2008. Sin fruta $N=18$ ( $N$ no visitas $=17, \mathrm{~N}$ visitas $=1)$, Con fruta $\mathrm{N}=58(\mathrm{~N}$ no visitas $=10, \mathrm{~N}$ visitas $=48)$.

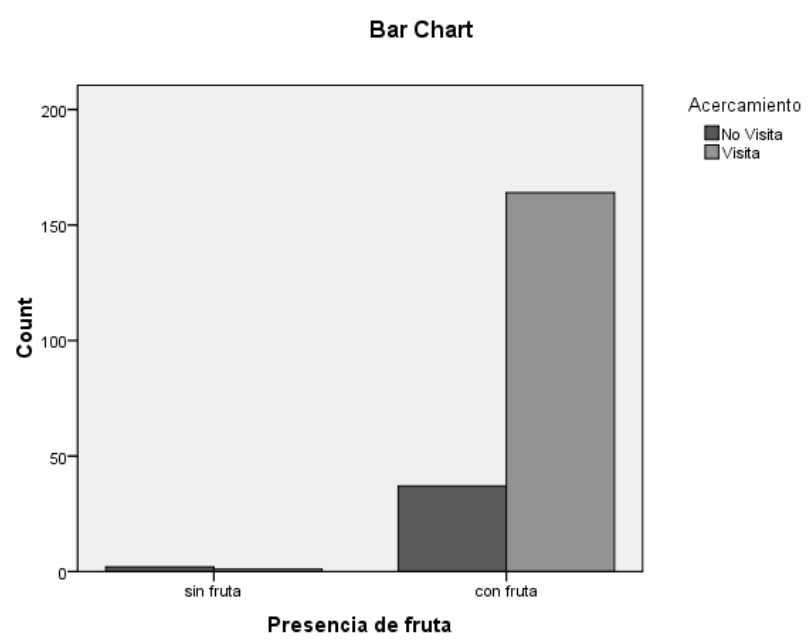

Gráfico 4.12: Entradas a radios críticos del grupo Rita en 2011. Sin fruta $N=3$ ( $N$ no visitas $=2$, $\mathrm{N}$ visitas $=1)$, Con fruta $\mathrm{N}=201(\mathrm{~N}$ no visitas $=37, \mathrm{~N}$ visitas $=164)$.

En el caso de Gundolf 2009, donde existió una mayor cantidad de entradas a radios críticos de árboles sin fruta que con fruta y la misma cantidad de visitas en ambas categorías ( $\mathrm{N}$ visitas $\sin$ fruta $=32 ; \mathrm{N}$ visitas con fruta $=33$ ), existe la posibilidad de que los monos estuvieran evaluando árboles vacíos con el fin de monitorear la presencia de larvas de homóptera dado que, como se explicó con anterioridad, ese año se registró una elevada cantidad de árboles infestados.

Para evaluar si, una vez entrado el radio crítico (y aun sin poder visualizar el árbol), los monos tenían una expectativa de lo que iban a encontrar más adelante se compararon los promedios de las velocidades Post RC sin visita y con visita a los árboles focales. 
Este análisis reveló diferencias significativas (test de probabilidad combinada de Fisher para muestras independientes, $X^{2}{ }_{F}=21.4222, p=0.045, g l=12$ ), evidenciando que los monos, una vez entrado el radio crítico de un árbol, lo hacían a mayor velocidad cuando esa entrada terminaba finalmente en una visita. De los test de Student para muestras independientes sobre los que se basó el análisis combinado solo uno registró diferencias estadísticamente significativas entre los promedios, y los cálculos de tamaño del efecto revelaron la existencia de diferencias bajas a moderadas considerando el $\mathrm{N}$ bajo de todos los análisis (tabla 4.6). Los promedios de las velocidades se presentan sin transformar y log transformadas. Es importante observar que los promedios de las visitas fueron siempre superiores a los de las no visitas excepto para Gundolf 2010 donde los promedios fueron casi iguales.

\begin{tabular}{|c|c|c|c|c|c|c|c|}
\hline $\begin{array}{l}\text { Velocidades } \\
\text { post radio } \\
\text { crítico }\end{array}$ & $\begin{array}{l}\text { Entradas a } \\
\text { radios } \\
\text { críticos }\end{array}$ & $\mathrm{N}$ & $\begin{array}{l}\text { Promedio } \pm \\
\text { desvío sin } \\
\text { transformar }\end{array}$ & $\begin{array}{l}\text { Promedio } \pm \\
\text { desvío } \\
\text { transformadas }\end{array}$ & Valor de $\mathrm{t}$ & p-valor & $\begin{array}{l}d \text { de } \\
\text { Cohen }\end{array}$ \\
\hline \multirow[t]{2}{*}{ Rita 2011} & No visita & 10 & $6,8 \pm 6,2$ & $1,62 \pm 0,77$ & \multirow[t]{2}{*}{$-1,223$} & \multirow[t]{2}{*}{0,225} & \multirow[t]{2}{*}{0,41} \\
\hline & Visita & 68 & $7,7 \pm 5,3$ & $1,87 \pm 0,57$ & & & \\
\hline \multirow[t]{2}{*}{ Macuco 2008} & No visita & 27 & $3,9 \pm 1,3$ & $1,69 \pm 0,57$ & \multirow[t]{2}{*}{$-1,872$} & \multirow[t]{2}{*}{0,065} & \multirow[t]{2}{*}{0,4} \\
\hline & Visita & 48 & $9,9 \pm 10,4$ & $1,96 \pm 0,62$ & & & \\
\hline \multirow[t]{2}{*}{ Macuco 2009} & No visita & 20 & $7,3 \pm 5,4$ & $1,84 \pm 0,49$ & \multirow[t]{2}{*}{0,349} & \multirow[t]{2}{*}{0,727} & \multirow[t]{2}{*}{0,07} \\
\hline & Visita & 92 & $7,4 \pm 5,5$ & $1,79 \pm 0,69$ & & & \\
\hline \multirow[t]{2}{*}{ Gundolf 2009} & No visita & 19 & $4,9 \pm 3,4$ & $1,44 \pm 0,5$ & \multirow[t]{2}{*}{$-0,719$} & \multirow[t]{2}{*}{0,475} & \multirow[t]{2}{*}{0,21} \\
\hline & Visita & 37 & $5,8 \pm 4,8$ & $1,56 \pm 0,6$ & & & \\
\hline \multirow[t]{2}{*}{ Gundolf 2010} & No visita & 31 & $5,4 \pm 3,1$ & $1,55 \pm 0,53$ & \multirow[t]{2}{*}{0,459} & \multirow[t]{2}{*}{0,647} & \multirow[t]{2}{*}{0,09} \\
\hline & Visita & 96 & $5,2 \pm 3,4$ & $1,50 \pm 0,51$ & & & \\
\hline \multirow[t]{2}{*}{ Rita 2010} & No visita & 72 & $4,4 \pm 2,8$ & $1,34 \pm 0,5$ & \multirow[t]{2}{*}{$-2,757$} & \multirow[t]{2}{*}{0,007} & \multirow[t]{2}{*}{0,54} \\
\hline & Visita & 43 & $5,8 \pm 3,9$ & $1,61 \pm 0,5$ & & & \\
\hline
\end{tabular}

Tabla 4.6: Promedios de las velocidades Post RC con y sin visitas de cada grupo a árboles focales, análisis de comparación de medias (test de Student para muestras independientes utilizando la variable log transformada) y cálculo del tamaño del efecto para cada comparación de medias.

\subsubsection{Velocidades Pre RC, Post RC y Medio RC de visita a árboles focales}

Para analizar si los grupos incrementaban su velocidad en dirección hacia el árbol focal cuando éste aún se encontraba fuera de la vista, se compararon las velocidades pre, post y medio RC entre sí. El promedio de las velocidades Pre RC fue menor que las Post RC, y a su vez el promedio de la velocidad Post RC fue menor que el promedio de las velocidades Medio RC en todos los casos (Gráficos 4.13 a 4.18). 


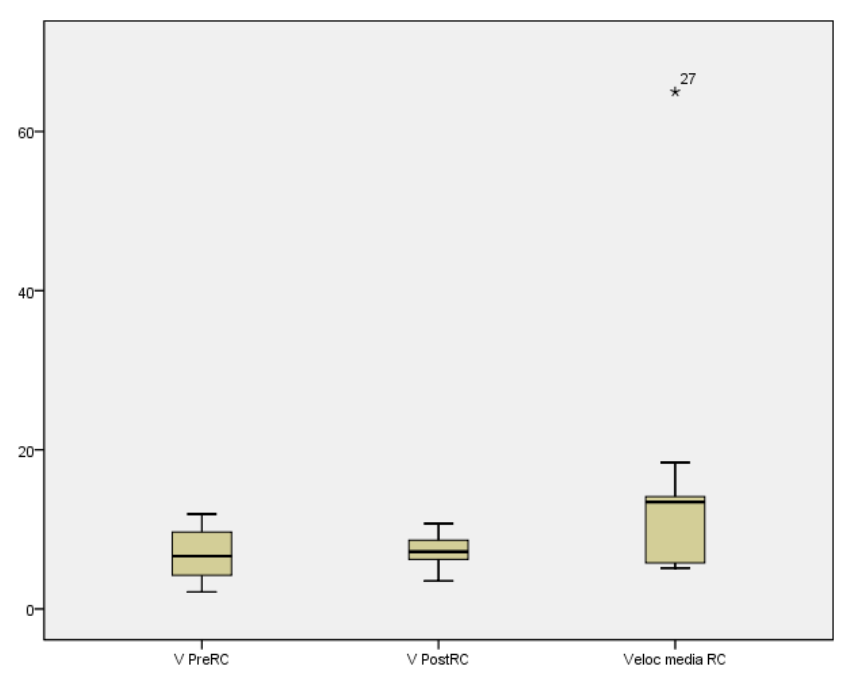

Gráfico 4.13: Promedio de las velocidades de visitas Pre-RC (6,7 $\pm 3,4$ DS, IC 95\%: 4,2-9,6, N = 9), Post-RC (7,3 $\pm 2,3$ DS, IC 95\%: 5,5-9,1, N = 9) y Medio-RC (16,47 $\pm 18,8$ DS, IC 95\%: 2$30,9, N=9)$ del grupo Macuco en 2008.

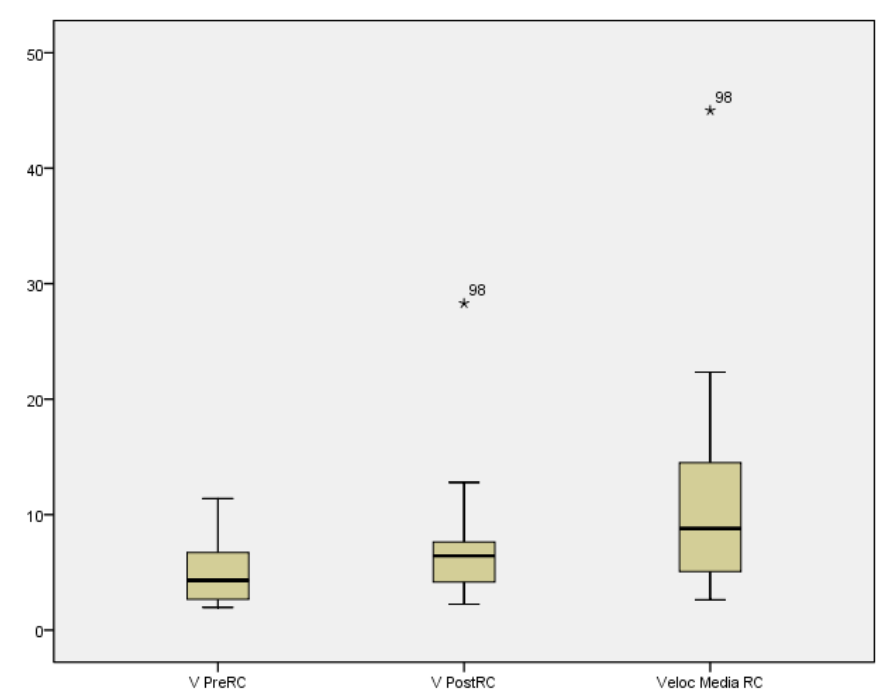

Gráfico 4.14: Promedio de las velocidades en $\mathrm{m} / \mathrm{min}$ de visitas Pre-RC $(4,9 \pm 2,5 \mathrm{DS}$, IC $95 \%$ : 3,7-6, $\mathrm{N}=21)$, Post-RC (7,2 $\pm 5,5 \mathrm{DS}$, IC $95 \%: 4,7-9,7, \mathrm{~N}=21)$ y Medio-RC $(11,2 \pm 9,4 \mathrm{DS}, \mathrm{IC}$ 95\%: 6,8-15,5, $\mathrm{N}=21$ ) del grupo Macuco en 2009. 




Gráfico 4.15: Promedio de las velocidades en $\mathrm{m} / \mathrm{min}$ de visitas Pre-RC (4,2 \pm 2 DS, IC $95 \%$ : $3,2-5,3, N=17)$, Post-RC (5,09 $\pm 2,1 \mathrm{DS}, \mathrm{IC} 95 \%: 4-6,2, \mathrm{~N}=17)$ y Medio-RC $(5,05 \pm 2,3 \mathrm{DS}$, IC 95\%: 3,8-6,2, $N=17$ ) del grupo Gundolf en 2009.

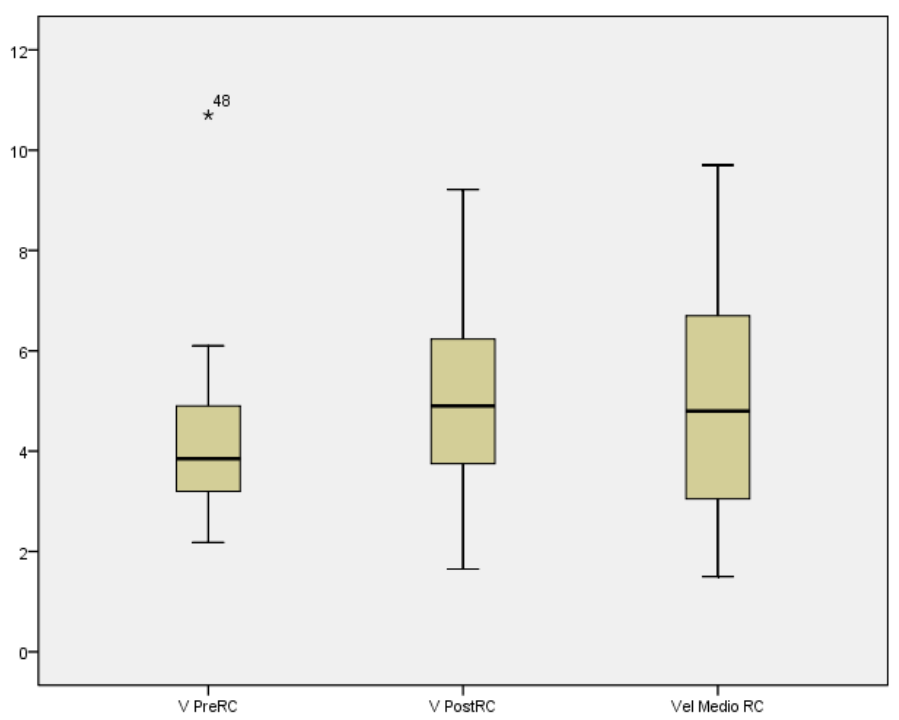

Gráfico 4.16: Promedio de las velocidades en $\mathrm{m} / \mathrm{min}$ de visitas Pre-RC (3,8 $\pm 1,9 \mathrm{DS}$, IC $95 \%$ : $3,2-4,5, N=35)$, Post-RC (4,8 $\pm 1,8 \mathrm{DS}$, IC $95 \%: 4,1-5,4, \mathrm{~N}=35)$ y Medio-RC $(6,3 \pm 4 \mathrm{DS}$, IC 95\%: 5-7,7, N = 35) del grupo Gundolf en 2010.

En el caso Rita 2010 y 2011 se registraron varios valores atípicos (Gráfico 4.17 y 4.18). 


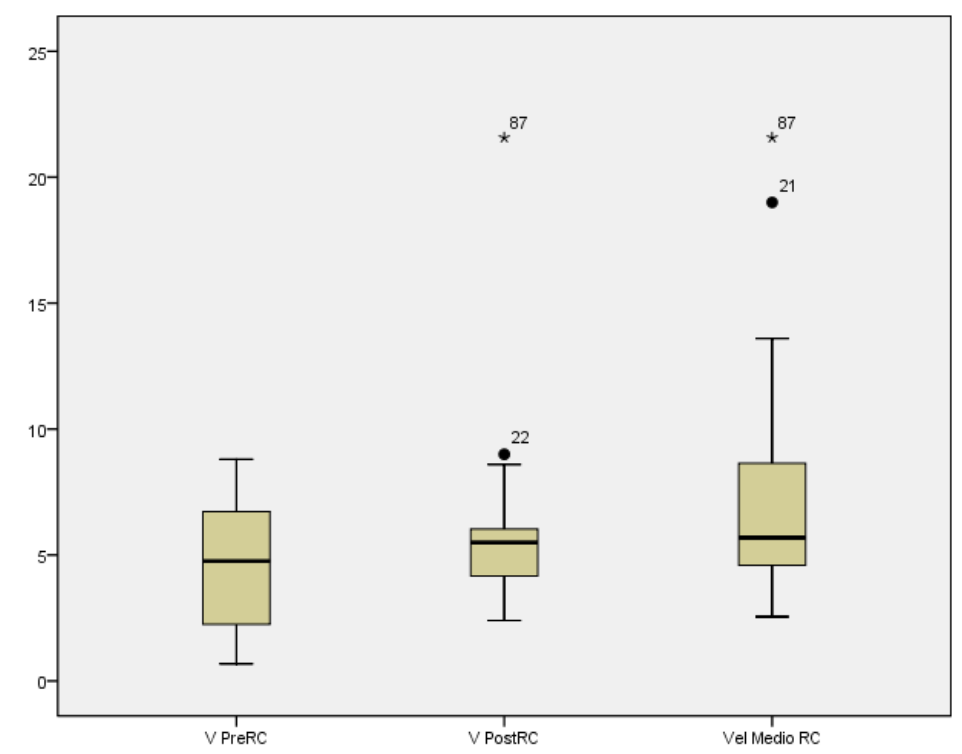

Gráfico 4.17: Promedio de las velocidades en $\mathrm{m} / \mathrm{min}$ de visitas Pre-RC (4,6 $\pm 2,5 \mathrm{DS}, \mathrm{IC} 95 \%$ : $3,5-5,7, \mathrm{~N}=24)$, Post-RC (5,8 $\pm 3,7 \mathrm{DS}$, IC $95 \%: 4,2-7,3, \mathrm{~N}=24)$ y Medio-RC (7,5 $\pm 4,7 \mathrm{DS}$, IC 95\%: 5,5-9,5, $\mathrm{N}=24$ ) del grupo Rita en 2010.

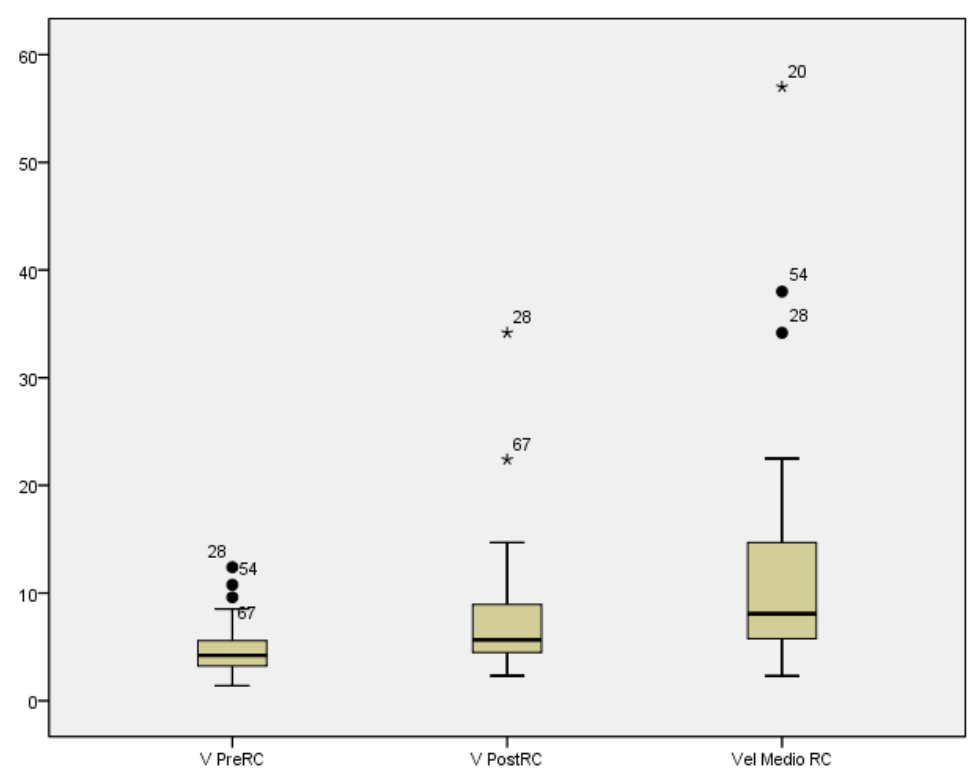

Gráfico 4.18: Promedio de las velocidades en $\mathrm{m} / \mathrm{min}$ de visitas Pre-RC (4,8 $\pm 2,4 \mathrm{DS}$, IC $95 \%$ : 3,9-5,6, $N=37)$, Post-RC (7,8 \pm 6 DS, IC 95\%: 5,8-9,8, $N=37)$ y Medio-RC (12,3 $\pm 11,1$ DS, IC 95\%: 8,6-16, $N=37$ ) del grupo Rita en 2011.

Se encontraron diferencias entre las velocidades Pre RC y Post RC de las visitas (test de probabilidad combinada de Fisher para muestras independientes: $X^{2}{ }_{F}=85.95, p=$ $0,000, \mathrm{gl}=12$ ). El único grupo dentro de este análisis que presentó un valor no significativo en el test de Student independiente fue el grupo Gundolf 2009 (Tabla 4.7) pero, a pesar de esto, se encontró un tamaño del efecto moderado en todos los casos 
indicando una diferencia entre los promedios de las muestras. Nuevamente el muestreo del año 2009 coincidió con el mayor consumo de larvas de homóptera por parte del grupo Gundolf. También se encontró una diferencia entre las velocidades Post RC y Medio RC (test de probabilidad combinada de Fisher para muestras independientes: $X^{2}=78.61, p=0.000$ ). Dos grupos (Gundolf 2009 y Macuco 2008) presentaron un valor no significativo en el test de Student independiente (Tabla 4.8) aunque nuevamente los tamaños de los efectos fueron moderados para todos los casos.

\begin{tabular}{|c|c|c|c|c|c|}
\hline & \multicolumn{5}{|c|}{ Velocidades Pre y Post Visitas $(\mathrm{m} / \mathrm{min})$} \\
\hline & $\mathrm{N}$ & Promedio \pm desvío & Valor $\mathrm{t}$ & $P$ - valor & $d$ de Cohen \\
\hline \multirow[b]{2}{*}{ Mac2008 } & Pre 31 & $1,78 \pm 0,48$ & \multirow[b]{2}{*}{$-2,943$} & \multirow[b]{2}{*}{0,006} & \multirow[b]{2}{*}{0,58} \\
\hline & Post 31 & $2,1 \pm 0,6$ & & & \\
\hline \multirow[b]{2}{*}{ Mac2009 } & Pre 53 & $1,5 \pm 0,54$ & \multirow[b]{2}{*}{$-3,46$} & \multirow[b]{2}{*}{0,001} & \multirow[b]{2}{*}{0,64} \\
\hline & Post 53 & $1,9 \pm 0,69$ & & & \\
\hline \multirow[b]{2}{*}{ Gund2009 } & Pre 22 & $1,4 \pm 0,4$ & \multirow[b]{2}{*}{$-1,42$} & \multirow[b]{2}{*}{0,17} & \multirow[b]{2}{*}{0,39} \\
\hline & Post 22 & $1,6 \pm 0,6$ & & & \\
\hline \multirow[b]{2}{*}{ Gund2010 } & Pre 42 & $1,2 \pm 0,43$ & \multirow[b]{2}{*}{$-3,411$} & \multirow[b]{2}{*}{0,001} & \multirow[b]{2}{*}{0,67} \\
\hline & Post 42 & $1,5 \pm 0,46$ & & & \\
\hline \multirow[b]{2}{*}{ Rita2010 } & Pre 38 & $1,3 \pm 0,65$ & \multirow[b]{2}{*}{$-2,05$} & \multirow[b]{2}{*}{0,047} & \multirow[b]{2}{*}{0,49} \\
\hline & Post 38 & $1,58 \pm 0,47$ & & & \\
\hline \multirow[b]{2}{*}{ Rita2011 } & Pre 51 & $1,4 \pm 0,48$ & \multirow[b]{2}{*}{$-5,362$} & \multirow[b]{2}{*}{0,000} & \multirow[b]{2}{*}{0,57} \\
\hline & Post 51 & $1,7 \pm 0,56$ & & & \\
\hline
\end{tabular}

Tabla 4.7: test de Student individuales para muestras independientes de las velocidades Pre RC y Post RC log transformadas de Visitas a árboles focales para cada grupo en cada período de muestreo, promedios \pm desvío estándar y tamaño del efecto para cada comparación de medias.

\begin{tabular}{|c|c|c|c|c|c|}
\hline & \multicolumn{5}{|c|}{ Velocidades Post y Medio Visitas ( $\mathrm{m} / \mathrm{min}$ ) } \\
\hline & $\mathrm{N}$ & Promedio \pm desvío & Valor t & P -valor & $d$ de Cohen \\
\hline \multirow[t]{2}{*}{ Mac2008 } & Post 16 & $1,7 \pm 0,46$ & & & \\
\hline & Medio 16 & $2,1 \pm 0,8$ & $-1,915$ & 0,075 & 0,61 \\
\hline \multirow[t]{2}{*}{ Mac2009 } & Post 46 & $1,7 \pm 0,65$ & & & \\
\hline & Medio 46 & $2,04 \pm 0,7$ & $-3,102$ & 0,03 & 0,5 \\
\hline \multirow[t]{2}{*}{ Gund2009 } & Post 27 & $1,4 \pm 0,4$ & & & \\
\hline & Medio 27 & $1,48 \pm 0,5$ & $-0,467$ & 0,645 & 0,17 \\
\hline \multirow[t]{2}{*}{ Gund2010 } & Post 78 & $1,5 \pm 0,5$ & & & \\
\hline & Medio 78 & $1,68 \pm 0,6$ & $-3,411$ & 0,001 & 0,32 \\
\hline \multirow[t]{2}{*}{ Rita2010 } & Post 28 & $1,69 \pm 0,49$ & & & \\
\hline & Medio 28 & $1,8 \pm 0,54$ & $-2,232$ & 0,034 & 0,21 \\
\hline \multirow[t]{2}{*}{ Rita2011 } & Post 60 & $1,9 \pm 0,58$ & & & \\
\hline & Medio 60 & $2,3 \pm 0,7$ & $-5,519$ & 0,000 & 0,62 \\
\hline
\end{tabular}

Tabla 4.8: test de Student individuales para muestras independientes de las velocidades Post RC y Medio RC log transformadas de Visitas a árboles focales para cada grupo en cada período de muestreo, promedios \pm desvío estándar y tamaño del efecto para cada comparación de medias. 


\subsubsection{Velocidades de visita a árboles según porcentajes de fruta (madura e inmadura) y madura}

Dadas las diferencias encontradas en las velocidades Post RC y Medio RC se procedió a evaluar si los monos poseían algún tipo de registro sobre la cantidad y estado de maduración de la fruta del árbol por visitar. Para esto se compararon las velocidades de visita a los árboles según diferentes porcentajes de fruta presente (madura e inmadura) y de fruta madura presente. Todos los análisis se realizaron a una cola dado el supuesto de base de que el grupo debería desplazarse más rápido cuánto más fruta hubiera en el árbol (y sabiendo que las velocidades se incrementan en dirección al árbol focal como se vió en los análisis anteriores).

No se encontraron diferencias entre las velocidades Post RC para árboles con menos o más del $50 \%$ de fruta (madura e inmadura) presente (test de probabilidad combinada de Fisher para muestras independientes, $X^{2}{ }_{F}=5,581 p=0,84, g l=10$ ). Tampoco se encontraron diferencias al comparar las velocidades Medio RC de esta categoría (test de probabilidad combinada de Fisher para muestras independientes, $X^{2}{ }_{F}=7,075, p=$ $0,71, \mathrm{gl}=10$ ). Ninguno de los grupos presentó diferencias significativas en los test de Student independientes sobre los que se basó el análisis, y los cálculos de tamaño del efecto demostraron que no existió una diferencia considerable, excepto en las velocidades Medio RC de Macuco 2008 y Rita 2010, donde el tamaño del efecto fue moderado pero los promedios mayores correspondieron a los árboles con $50 \%$ o menos de fruta presente (Tabla 4.9). Se observa que en los promedios de las velocidades Post RC sin transformar prácticamente no existen diferencias entre las categorías. En cambio en los promedios de las velocidades Medio RC si aunque en la mayoría de los casos las velocidades a árboles con 50\% o menos de fruta fueron mayores. 


\begin{tabular}{|c|c|c|c|c|c|c|c|}
\hline \multicolumn{8}{|c|}{ V Post RC más o menos $50 \%$ de fruta presente } \\
\hline & $\%$ & $\mathrm{~N}$ & $\begin{array}{l}\text { Promedio } \pm \text { desvío sin } \\
\text { transformar }\end{array}$ & $\begin{array}{l}\text { Promedio } \pm \text { desvío } \\
\text { transformada }\end{array}$ & Valor de $\mathrm{t}$ & p-valor & $\begin{array}{l}d \text { de } \\
\text { Cohen }\end{array}$ \\
\hline \multirow[b]{2}{*}{ Mac2008 } & $50 \% 0-$ & 13 & $8,1 \pm 3,3$ & $2,02 \pm 0,4$ & \multirow[t]{2}{*}{0,09} & \multirow[t]{2}{*}{0,92} & \multirow[t]{2}{*}{0,04} \\
\hline & $+50 \%$ & 22 & $8,6 \pm 5,5$ & $2 \pm 0,5$ & & & \\
\hline \multirow[b]{2}{*}{ Mac2009 } & $50 \% 0-$ & 21 & $8,6 \pm 6$ & $1,9 \pm 0,58$ & \multirow[t]{2}{*}{0,975} & \multirow[t]{2}{*}{0,3} & \multirow[t]{2}{*}{0,16} \\
\hline & $+50 \%$ & 51 & $7,6 \pm 5,9$ & $1,8 \pm 0,6$ & & & \\
\hline \multirow[b]{2}{*}{ Gun2010 } & $50 \%$ o- & 8 & $4,9 \pm 2,7$ & $1,46 \pm 0,5$ & \multirow[t]{2}{*}{$-0,725$} & \multirow[t]{2}{*}{0,474} & \multirow[t]{2}{*}{$-0,28$} \\
\hline & $+50 \%$ & 28 & $5,8 \pm 4,1$ & $1,6 \pm 0,5$ & & & \\
\hline \multirow[b]{2}{*}{ Rit2010 } & $50 \%$ o- & 19 & $5,8 \pm 5,1$ & $1,5 \pm 0,58$ & \multirow[t]{2}{*}{$-0,54$} & \multirow[t]{2}{*}{0,593} & \multirow[t]{2}{*}{$-0,28$} \\
\hline & $+50 \%$ & 19 & $5,7 \pm 2,8$ & $1,65 \pm 0,45$ & & & \\
\hline \multirow[b]{2}{*}{ Rit2011 } & $50 \% \circ-$ & 32 & $8,1 \pm 4,4$ & $1,9 \pm 0,5$ & \multirow[t]{2}{*}{0,379} & \multirow[t]{2}{*}{0,7} & \multirow[t]{2}{*}{0} \\
\hline & $+50 \%$ & 34 & $8,2 \pm 6,3$ & $1,9 \pm 0,6$ & & & \\
\hline \multicolumn{8}{|c|}{ V Medio RC más o menos $50 \%$ de fruta presente } \\
\hline & $\%$ & $\mathrm{~N}$ & $\begin{array}{l}\text { Promedio } \pm \text { desvío sin } \\
\text { transformar }\end{array}$ & $\begin{array}{l}\text { Promedio } \pm \text { desvío } \\
\text { transformada }\end{array}$ & Valor de $\mathrm{t}$ & p-valor & $\begin{array}{l}d \text { de } \\
\text { Cohen }\end{array}$ \\
\hline \multirow[b]{2}{*}{ Mac2008 } & $50 \%$ o- & 5 & $19,7 \pm 25,5$ & $2,4 \pm 1$ & \multirow[t]{2}{*}{1,029} & \multirow[t]{2}{*}{0,32} & \multirow[t]{2}{*}{0,62} \\
\hline & $+50 \%$ & 11 & $9,1 \pm 5,5$ & $1,9 \pm 0,7$ & & & \\
\hline \multirow[b]{2}{*}{ Mac2009 } & $50 \%$ o- & 7 & $14,5 \pm 15,2$ & $2,3 \pm 0,87$ & \multirow[t]{2}{*}{0,584} & \multirow[t]{2}{*}{0,563} & \multirow[t]{2}{*}{0,27} \\
\hline & $+50 \%$ & 30 & $10,3 \pm 7,5$ & $2,1 \pm 0,68$ & & & \\
\hline \multirow[b]{2}{*}{ Gun2010 } & $50 \%$ o - & 7 & $7,1 \pm 3,2$ & $1,84 \pm 0,57$ & \multirow[t]{2}{*}{0,375} & \multirow[t]{2}{*}{0,71} & 0,16 \\
\hline & $+50 \%$ & 28 & $7,1 \pm 5,4$ & $1,74 \pm 0,6$ & & & \\
\hline & $50 \%$ o - & 12 & $9,1 \pm 6,5$ & $2 \pm 0,6$ & 1,215 & 0,237 & 0,54 \\
\hline Rit2010 & $+50 \%$ & 13 & $6,4 \pm 3,2$ & $1,7 \pm 0,5$ & & & \\
\hline & $50 \%$ o - & 24 & $14,1 \pm 10,7$ & $2,3 \pm 0,8$ & $-0,056$ & 0,956 & 0 \\
\hline Rit2011 & $+50 \%$ & 30 & $12,7 \pm 9,1$ & $2,3 \pm 0,6$ & & & \\
\hline
\end{tabular}

Tabla 4.9: test de Student para muestras independientes para las velocidades Post RC y Medio $\mathrm{RC}$ sin transformar y log transformadas $(\mathrm{m} / \mathrm{min}$ ) de Visitas árboles focales con más o menos del $50 \%$ de fruta presente, promedios \pm desvíos estándar, y valor de $d$ de Cohen. El grupo Gundolf 2009 fue excluido del análisis por datos insuficientes.

No se encontraron diferencias entre las velocidades Post RC para árboles con más o menos del $25 \%$ de fruta (madura e inmadura) presente (test de probabilidad combinada de Fisher para muestras independientes, $X^{2}{ }_{F}=8.639, p=0,37, g l=8$ ), ni entre las velocidades Medio RC para árboles con más o menos del $25 \%$ de fruta (test de probabilidad combinada de Fisher para muestras independientes, $X^{2}{ }_{F}=11.393, p=$ $0,18, g l=8)$. Ninguno de los grupos presentó diferencias significativas en los test de Student independientes sobre los que se basó el análisis. Los cálculos de tamaño del efecto demostraron que existió una diferencia baja a moderada (Rita 2010 y 2011) y alta en el caso de Macuco 2008 pero el $\mathrm{N}$ del análisis fue bajo (Tabla 4.10). Puede observarse que en algunos casos el valor del $d$ de Cohen fue negativo indicando que el valor del promedio dos (en este caso árboles con más del $25 \%$ de fruta presente) fue mayor, lo que puede observarse en los promedios de las velocidades sin transformar. Nuevamente los promedios de las velocidades Post RC fueron semejantes mientras que las mayores diferencias se encontraron en los promedios de 
las velocidades Medio RC, registrándose en algunos casos velocidades mayores para los árboles con $25 \%$ o menos de fruta presente. Es importante notar que algunas de estas muestras tuvieron $\mathrm{N}$ bajos.

\begin{tabular}{|c|c|c|c|c|c|c|c|}
\hline \multicolumn{8}{|c|}{ V Post más o menos $25 \%$ de fruta presente } \\
\hline & $\%$ & $\mathrm{~N}$ & $\begin{array}{l}\text { Promedio } \pm \text { desvío sin } \\
\text { transformar }\end{array}$ & $\begin{array}{l}\text { Promedio } \pm \text { desvío } \\
\text { transformada }\end{array}$ & $\begin{array}{l}\text { Valor de } \\
t\end{array}$ & $\mathrm{p}$-valor & $\begin{array}{l}d \text { de } \\
\text { Cohen }\end{array}$ \\
\hline \multirow[b]{2}{*}{ Mac2008 } & $25 \% 0-$ & 6 & $8,7 \pm 4,4$ & $2,08 \pm 0,4$ & \multirow[b]{2}{*}{0,388} & \multirow[b]{2}{*}{0,7} & \multirow{2}{*}{0,37} \\
\hline & $+25 \%$ & 29 & $8,3 \pm 4,9$ & $1,9 \pm 0,5$ & & & \\
\hline \multirow[b]{2}{*}{ Mac2009 } & $25 \% \circ-$ & 15 & $7,8 \pm 4,6$ & $1,9 \pm 0,58$ & \multirow[b]{2}{*}{0,242} & \multirow[b]{2}{*}{0,8} & \multirow{2}{*}{0,16} \\
\hline & $+25 \%$ & 57 & $7,9 \pm 6,2$ & $1,8 \pm 0,6$ & & & \\
\hline \multirow[b]{2}{*}{ Rit2010 } & $25 \% \circ-$ & 8 & $3,9 \pm 1$ & $1,3 \pm 0,26$ & \multirow[b]{2}{*}{$-1,614$} & \multirow[b]{2}{*}{0,115} & \multirow{2}{*}{$-0,64$} \\
\hline & $+25 \%$ & 30 & $6,3 \pm 4,5$ & $1,6 \pm 0,5$ & & & \\
\hline \multirow[b]{2}{*}{ Rit2011 } & $25 \% \circ-$ & 18 & $9,1 \pm 5$ & $2,08 \pm 0,5$ & \multirow[b]{2}{*}{1,283} & \multirow[b]{2}{*}{0,204} & \multirow[b]{2}{*}{0,36} \\
\hline & $+25 \%$ & 48 & $7,8 \pm 5,6$ & $1,9 \pm 0,5$ & & & \\
\hline \multicolumn{8}{|c|}{ V Medio más o menos $25 \%$ de fruta presente } \\
\hline & $\%$ & $\mathrm{~N}$ & $\begin{array}{l}\text { Promedio } \pm \text { desvío sin } \\
\text { transformar }\end{array}$ & $\begin{array}{l}\text { Promedio } \pm \text { desvío } \\
\text { transformada }\end{array}$ & $\begin{array}{l}\text { Valor de } \\
\text { t }\end{array}$ & p-valor & $\begin{array}{l}d \text { de } \\
\text { Cohen }\end{array}$ \\
\hline \multirow[b]{2}{*}{ Mac2008 } & $25 \% \circ-$ & 3 & $27,7 \pm 32,4$ & $2,8 \pm 1,2$ & \multirow[b]{2}{*}{1,558} & \multirow[b]{2}{*}{0,141} & \multirow{2}{*}{1,13} \\
\hline & $+25 \%$ & 13 & $8,9 \pm 5,2$ & $1,9 \pm 0,7$ & & & \\
\hline \multirow[b]{2}{*}{ Mac2009 } & $25 \% \circ-$ & 6 & $9,4 \pm 7,9$ & $2,04 \pm 0,6$ & \multirow[b]{2}{*}{$-0,404$} & \multirow[b]{2}{*}{0,688} & \multirow{2}{*}{$-0,08$} \\
\hline & $+25 \%$ & 31 & $11,5 \pm 9,7$ & $2,1 \pm 0,7$ & & & \\
\hline \multirow[b]{2}{*}{ Rit2010 } & $25 \% \circ-$ & 3 & $5,3 \pm 2$ & $1,62 \pm 0,36$ & \multirow[b]{2}{*}{$-0,826$} & \multirow[b]{2}{*}{0,417} & \multirow{2}{*}{$-0,49$} \\
\hline & $+25 \%$ & 22 & $8 \pm 5,3$ & $1,9 \pm 0,58$ & & & \\
\hline \multirow[b]{2}{*}{ Rit2011 } & $25 \% \circ-$ & 13 & $17,3 \pm 10,6$ & $2,6 \pm 0,7$ & \multirow[b]{2}{*}{1,768} & \multirow[b]{2}{*}{0,083} & \multirow[b]{2}{*}{0,64} \\
\hline & $+25 \%$ & 41 & $12,09 \pm 9,3$ & $2,2 \pm 0,6$ & & & \\
\hline
\end{tabular}

Tabla 4.10: test de Student para muestras independientes para las velocidades Post RC y Medio RC sin transformar y log transformadas $(\mathrm{m} / \mathrm{min})$ de Visitas árboles focales con más o menos del $25 \%$ de fruta presente, promedios \pm desvíos estándar, y valor de $d$ de Cohen. El grupo Gundolf 2009 y 2010 fueron excluidos del análisis por datos insuficientes.

No se encontraron diferencias entre las velocidades Post RC para árboles con más o menos del $50 \%$ de fruta madura presente (test de probabilidad combinada de Fisher para muestras independientes, $X^{2}{ }_{F}=5.426, p=0,71, \mathrm{gl}=8$ ) $\mathrm{ni}$ al comparar las velocidades Medio RC para árboles con más o menos del $50 \%$ de fruta madura presente (test de probabilidad combinada de Fisher para muestras independientes, $X^{2}$ $\mathrm{F}=4.794, \mathrm{p}=0,57, \mathrm{gl}=6$ ). Ninguno de los grupos presentó diferencias significativas en los test de Student independientes sobre los que se basó el análisis y los cálculos de tamaño del efecto demostraron que existió una diferencia baja a moderada (Macuco 2008, Rita 2010 para velocidad post RC y Rita 2011 para velocidad medio $\mathrm{RC}$, Tabla 4.11). Puede observarse que en algunos casos el valor del $d$ de Cohen es negativo, indicando que el promedio dos (en este caso árboles con más del $50 \%$ de fruta madura presente) fue mayor, lo que puede observarse en los promedios de las 
velocidades. En los dos casos en los que se observó una magnitud del efecto elevada (velocidades Post RC Rita 2010 y Medio RC Rita 2011) el mayor promedio correspondió a las visitas a árboles con $50 \%$ o menos de fruta madura presente, aunque es importante notar que el $\mathrm{N}$ de las visitas a árboles con más del $50 \%$ de fruta fue muy bajo en ambos casos.

\begin{tabular}{|c|c|c|c|c|c|c|c|}
\hline \multicolumn{8}{|c|}{ V Post más o menos $50 \%$ de fruta madura presente } \\
\hline & $\%$ & $\mathrm{~N}$ & $\begin{array}{l}\text { Promedio } \pm \text { desvío } \\
\text { sin transformar }\end{array}$ & $\begin{array}{l}\text { Promedio } \pm \text { desvío } \\
\text { transformada }\end{array}$ & Valor de $\mathrm{t}$ & p-valor & $\begin{array}{l}d \text { de } \\
\text { Cohen }\end{array}$ \\
\hline \multirow[b]{2}{*}{ Mac2008 } & $50 \%$ o- & 23 & $8,17 \pm 3,6$ & $1,9 \pm 0,5$ & \multirow[t]{2}{*}{$-0,897$} & \multirow[t]{2}{*}{0,377} & \multirow[t]{2}{*}{$-0,57$} \\
\hline & $+50 \%$ & 7 & $1,07 \pm 8,4$ & $2,2 \pm 0,6$ & & & \\
\hline \multirow[b]{2}{*}{ Mac2009 } & $50 \%$ o- & 51 & $8,3 \pm 6,6$ & $1,89 \pm 0,6$ & \multirow[t]{2}{*}{0,248} & \multirow[t]{2}{*}{0,8} & \multirow[t]{2}{*}{0,08} \\
\hline & $+50 \%$ & 13 & $6,8 \pm 3,1$ & $1,84 \pm 0,4$ & & & \\
\hline \multirow[b]{2}{*}{ Rit2010 } & $50 \%$ o - & 24 & $6 \pm 4,7$ & $1,6 \pm 0,5$ & \multirow[t]{2}{*}{1,051} & \multirow[t]{2}{*}{0,304} & \multirow[t]{2}{*}{0,81} \\
\hline & $+50 \%$ & 3 & $3,7 \pm 1,6$ & $1,2 \pm 0,4$ & & & \\
\hline \multirow[b]{2}{*}{ Rit2011 } & $50 \%$ o - & 55 & $8,1 \pm 4,6$ & $1,95 \pm 0,56$ & \multirow[t]{2}{*}{0,361} & \multirow[t]{2}{*}{0,719} & \multirow[t]{2}{*}{0,13} \\
\hline & $+50 \%$ & 8 & $9 \pm 10,3$ & $1,87 \pm 0,75$ & & & \\
\hline \multicolumn{8}{|c|}{ V Medio mas o menos $50 \%$ de fruta madura presente } \\
\hline & $\%$ & $\mathrm{~N}$ & $\begin{array}{l}\text { Promedio } \pm \text { desvío } \\
\text { sin transformar }\end{array}$ & $\begin{array}{l}\text { Promedio } \pm \text { desvío } \\
\text { transformada }\end{array}$ & Valor de $\mathrm{t}$ & p-valor & $\begin{array}{l}d \text { de } \\
\text { Cohen }\end{array}$ \\
\hline \multirow[b]{2}{*}{ Mac2008 } & $50 \%$ o- & 11 & $8,4 \pm 4,6$ & $1,9 \pm 0,7$ & \multirow[t]{2}{*}{$-0,355$} & \multirow[t]{2}{*}{0,729} & \multirow[t]{2}{*}{$-0,29$} \\
\hline & $+50 \%$ & 2 & $9,2 \pm 4,9$ & $2,1 \pm 0,5$ & & & \\
\hline \multirow[b]{2}{*}{ Mac2009 } & $50 \%$ o- & 25 & $12 \pm 10,8$ & $2,17 \pm 0,78$ & \multirow[t]{2}{*}{0,262} & \multirow[t]{2}{*}{0,795} & \multirow[t]{2}{*}{0,1} \\
\hline & $+50 \%$ & 5 & $9 \pm 4,6$ & $2,08 \pm 0,54$ & & & \\
\hline \multirow[b]{2}{*}{ Rit2011 } & $50 \% \circ-$ & 45 & $14 \pm 9,8$ & $2,4 \pm 0,69$ & \multirow[t]{2}{*}{1,438} & \multirow[t]{2}{*}{0,157} & \multirow[t]{2}{*}{0,71} \\
\hline & $+50 \%$ & 6 & $10,2 \pm 11,8$ & $1,9 \pm 0,8$ & & & \\
\hline
\end{tabular}

Tabla 4.11: test de Student para muestras independientes para las velocidades Post RC y Medio RC sin transformar y log transformadas $(\mathrm{m} / \mathrm{min})$ de Visitas árboles focales con más 0 menos del $50 \%$ de fruta madura presente, promedios \pm desvíos estándar, y valor de $d$ de Cohen. El grupo Gundolf 2009 y 2010, y Rita 2010 para velocidades medio RC fueron excluidos del análisis por datos insuficientes.

Por último, tampoco se encontraron diferencias entre las velocidades Post RC para árboles con más o menos del $25 \%$ de fruta madura presente (test de probabilidad combinada de Fisher para muestras independientes, $\left.X^{2}{ }_{F}=8.24, p=0,6, g l=10\right)$ ni al comparar las velocidades Medio RC para árboles con más o menos del $25 \%$ de fruta madura presente (test de probabilidad combinada de Fisher para muestras independientes, $X^{2}{ }_{F}=12.747, p=0,23, g l=10$ ). Ninguno de los grupos presentó diferencias significativas en los test de Student independientes sobre los que se basó el análisis y los cálculos de tamaño del efecto demostraron que existió una diferencia baja a moderada (Tabla 4.12), excepto en el caso de las velocidades medio RC de Macuco 2008 donde el tamaño del efecto fue elevado siendo mayores las velocidades 
a árboles con más del $25 \%$ de fruta (aunque nuevamente el $\mathrm{N}$ de esta comparación fue bajo).

A diferencia de los análisis anteriores en este caso los promedios de velocidades post $\mathrm{RC}$ y Medio RC fueron mayores a árboles con más del $25 \%$ de fruta madura presente en casi todos los casos (excepto velocidades Medio RC de Rita 2010 y 2011).

\begin{tabular}{|c|c|c|c|c|c|c|c|}
\hline \multicolumn{8}{|c|}{ Post más o menos $25 \%$ de fruta madura presente } \\
\hline & $\%$ & $\mathrm{~N}$ & $\begin{array}{l}\text { Promedio } \pm \text { desvío } \\
\text { sin transformar }\end{array}$ & $\begin{array}{l}\text { Promedio } \pm \text { desvío } \\
\text { transformada }\end{array}$ & \begin{tabular}{|l|} 
Valor de \\
$\mathrm{t}$
\end{tabular} & p-valor & $d$ de Cohen \\
\hline \multirow[b]{2}{*}{ Mac2008 } & $25 \% \circ-$ & 8 & $7,7 \pm 4,5$ & $1,8 \pm 0,63$ & \multirow[t]{2}{*}{$-0,969$} & \multirow[t]{2}{*}{0,341} & \multirow[t]{2}{*}{$-0,5$} \\
\hline & $+25 \%$ & 22 & $9,1 \pm 5,3$ & $2,09 \pm 0,48$ & & & \\
\hline \multirow[b]{2}{*}{ Mac2009 } & $25 \% \circ-$ & 41 & $7,9 \pm 5,4$ & $1,8 \pm 0,6$ & \multirow[t]{2}{*}{$-0,184$} & \multirow[t]{2}{*}{0,854} & \multirow[t]{2}{*}{$-0,16$} \\
\hline & $+25 \%$ & 23 & $8,1 \pm 7,2$ & $1,9 \pm 0,58$ & & & \\
\hline \multirow[b]{2}{*}{ Gun2010 } & $25 \% \circ-$ & 20 & $5,4 \pm 2,6$ & $1,54 \pm 0,47$ & \multirow[t]{2}{*}{$-0,454$} & \multirow[t]{2}{*}{0,653} & \multirow[t]{2}{*}{$-0,17$} \\
\hline & $+25 \%$ & 11 & $6,3 \pm 5,9$ & $1,63 \pm 0,6$ & & & \\
\hline \multirow[b]{2}{*}{ Rit2010 } & $25 \% \circ-$ & 20 & $5,5 \pm 4,3$ & $1,5 \pm 0,54$ & \multirow[t]{2}{*}{$-0,24$} & \multirow[t]{2}{*}{0,812} & \multirow[t]{2}{*}{$-0,17$} \\
\hline & $+25 \%$ & 7 & $6,2 \pm 5,5$ & $1,6 \pm 0,65$ & & & \\
\hline \multirow[b]{2}{*}{ Rit2011 } & $25 \% 0-$ & 39 & $7,8 \pm 4,3$ & $1,93 \pm 0,51$ & \multirow[t]{2}{*}{$-0,149$} & \multirow[t]{2}{*}{0,882} & \multirow[t]{2}{*}{$-0,03$} \\
\hline & $+25 \%$ & 24 & $8,9 \pm 7,2$ & $1,95 \pm 0,69$ & & & \\
\hline \multicolumn{8}{|c|}{ Medio más o menos $25 \%$ de fruta madura presente } \\
\hline & $\%$ & $\mathrm{~N}$ & $\begin{array}{l}\text { Promedio } \pm \text { desvío } \\
\text { sin transformar }\end{array}$ & $\begin{array}{l}\text { Promedio } \pm \text { desvío } \\
\text { transformada }\end{array}$ & \begin{tabular}{|l|}
$\begin{array}{l}\text { Valor de } \\
\mathrm{t}\end{array}$ \\
\end{tabular} & $p$-valor & $d$ de Cohen \\
\hline \multirow[b]{2}{*}{ Mac2008 } & $25 \% 0-$ & 5 & $6,3 \pm 4$ & $1,6 \pm 0,8$ & \multirow[t]{2}{*}{$-1,648$} & \multirow[t]{2}{*}{0,128} & \multirow[t]{2}{*}{$-0,95$} \\
\hline & $+25 \%$ & 8 & $10,1 \pm 4,2$ & $2,2 \pm 0,5$ & & & \\
\hline \multirow[b]{2}{*}{ Mac2009 } & $25 \% \circ-$ & 18 & $10,7 \pm 10,4$ & $2,05 \pm 0,7$ & \multirow[t]{2}{*}{$-0,932$} & \multirow[t]{2}{*}{0,359} & \multirow[t]{2}{*}{$-0,35$} \\
\hline & $+25 \%$ & 12 & $12,7 \pm 9,8$ & $2,3 \pm 0,69$ & & & \\
\hline \multirow[b]{2}{*}{ Gun2010 } & $25 \%$ o - & 20 & $6,5 \pm 3,4$ & $1,7 \pm 0,56$ & \multirow[t]{2}{*}{$-0,426$} & \multirow[t]{2}{*}{0,674} & $-0,15$ \\
\hline & $+25 \%$ & 10 & $8,6 \pm 7,8$ & $1,8 \pm 0,79$ & & & \\
\hline & $25 \% \circ-$ & 11 & $7,5 \pm 5$ & $1,8 \pm 0,48$ & 0,918 & 0,373 & 0,35 \\
\hline Rit2010 & $+25 \%$ & 6 & $6,5 \pm 6$ & $1,6 \pm 0,7$ & & & \\
\hline & $25 \% \circ-$ & 31 & $14,1 \pm 10,7$ & $2,37 \pm 0,78$ & 0,11 & 0,913 & 0,02 \\
\hline Rit2011 & $+25 \%$ & 20 & $12,7 \pm 9,1$ & $2,35 \pm 0,62$ & & & \\
\hline
\end{tabular}

Tabla 4.12: test de Student para muestras independientes para las velocidades Post RC y Medio RC sin transformar y log transformadas $(\mathrm{m} / \mathrm{min})$ de Visitas árboles focales con más 0 menos del $25 \%$ de fruta madura presente, promedios \pm desvíos estándar, y valor de $d$ de Cohen. El grupo Gundolf 2009 fue excluido del análisis por datos insuficientes.

\subsubsection{Aceleraciones y medidas de los árboles focales}

Para evaluar si los monos tomaban en consideración otras medidas del árbol a parte de las categorías de fruta se realizaron correlaciones de Spearmann entre las variables aceleración 1, aceleración 2, categoría total de fruta (Cat total F), categoría de fruta inmadura (CatFINM), categoría de fruta madura (CatFMAD) de los árboles, el valor de grupo-minuto de la visita (Grupo-min), el volumen de la copa (Vol Copa) y el diámetro a la altura del pecho (DAP) de los árboles focales. La razón por la cual se 
utilizó la aceleración en lugar de la velocidad fue que la misma permitía simplificar el análisis al incluir la diferencia entre dos variables en una sola simplificando así el número de variables a correlacionar.

A continuación se detallan las asociaciones significativas que se encontraron (Tabla 4.13). La aceleración 1 presentó una asociación positiva con la categoría de fruta madura y el volumen de la copa solo para una muestra (Macuco 2008), mientras que la aceleración 2 presentó una asociación negativa con la cantidad de fruta total y la cantidad de fruta inmadura y madura (Rita 2011). El total de fruta presente se correlacionó de manera positiva con la cantidad de fruta inmadura y madura para prácticamente todos los grupos excepto en dos casos donde la correlación fue negativa (Macuco 2009 y Rita 2010). También se correlacionó positivamente con el volumen de copa y DAP (Macuco 2008), indicando que durante algunos de los períodos muestreados el tamaño del árbol pudo estar brindando información sobre la cantidad de fruta a encontrar. A su vez, el total de fruta se correlacionó de forma positiva con la variable grupo-minuto para 3 de las 6 muestras (Macuco 2009, y Rita 2010-2011). También se encontró una asociación positiva entre la variable fruta madura y el grupo-minuto en 3 casos. Las cantidades de fruta madura e inmadura presentaron una asociación positiva en una muestra (Macuco 2009), y negativa en dos (Gundolf 2010 y Rita 2010). La variable fruta madura presentó una correlación positiva con el DAP en un caso, mientras que se encontró una asociación negativa con el volumen de copa (dos casos) y el DAP (un caso). La variable grupo-minuto solo tuvo una asociación positiva con el volumen de copa en dos muestras (Macuco 2008 y 2009), mientras que el DAP y el volumen de copa se correlacionaron de manera positiva en todas las muestras con excepción de Rita 2011.

Resumiendo, no existió una asociación homogénea entre las variables que caracterizan al árbol (DAP, volumen copa) en relación a las cantidades de fruta, aunque en algunos grupos en los que esta asociación fue positiva, los monos podrían haber tomado en consideración otras características además de la cantidad y estado de maduración del recurso al momento de registrar el árbol. La asociación positiva entre la cantidad total de fruta y la cantidad de fruta madura con el grupo-minuto estaría indicando que el tiempo que los monos pasaban en los árboles estaba asociado a la cantidad de fruta total y madura presente. 


\begin{tabular}{|c|c|c|c|c|c|c|c|}
\hline & Acel.2 & Total Fruta & Fruta Inmad & Fruta Mad & Grupo-min & Vol Copa & DAP \\
\hline Acel.1 & & & & $\begin{array}{l}\text { Mac08 } r=0,398 \\
p=0,049 N=25\end{array}$ & & $\begin{array}{l}\text { Mac08 } r=0,46 \\
p=0,02 N=25\end{array}$ & \\
\hline Acel.2 & & $\begin{array}{l}\text { Rita11 } r=-0,39 \\
p=0,025 N=33\end{array}$ & $\begin{array}{l}\text { Rita11 } r=-0,369 \\
p=0,035 N=33\end{array}$ & & & & \\
\hline $\begin{array}{l}\text { Total } \\
\text { Fruta }\end{array}$ & & & $\begin{array}{l}\text { Mac08 } r=0,7 p=0,000 N=52 \\
\text { Mac09 } r=0,709 p=0,000 N=119 \\
\text { Gun09 } r=0,567 p=0,034 N=14 \\
\text { Gun10 } r=0,573 p=0,000 N=53 \\
\text { Rita10 } r=-\mathbf{0}, 787 p=0,000 ~ N=61 \\
\text { Rita11 } r=0,819 p=0,000 N=84\end{array}$ & $\begin{array}{l}\text { Mac09 } r=-\mathbf{0 , 4 3 1} \\
p=0,000 \quad N=119 \\
\text { Gun10 } r=0,304 \\
p=0,027 N=53 \\
\text { Rita10 } r=0,31 \\
p=0,015 N=61 \\
\text { Rita11 } r=0,541 \\
p=0,000 N=84\end{array}$ & $\begin{array}{l}\text { Mac09 } r=0,221 \\
p=0,032 N=94 \\
\text { Rita10 } r=0,379 \\
p=0,007 \quad N=49 \\
\text { Rita11 } r=0,261 \\
p=0,022 N=77\end{array}$ & $\begin{array}{l}\text { Mac08 } r=0,551 \\
p=0,000 N=46\end{array}$ & $\begin{array}{l}\text { Mac08 } r=0,33 \\
p=0,022 N=48\end{array}$ \\
\hline $\begin{array}{l}\text { Fruta } \\
\text { Inmad }\end{array}$ & & & & $\begin{array}{l}\text { Mac09 } r=0,709 \\
p=0,000 N=119 \\
\text { Gun10 } r=\mathbf{- 0 , 4 7} \\
p=\mathbf{0 , 0 0 0 ~} \mathbf{=}=\mathbf{5 3} \\
\text { Rita10 } r=\mathbf{- 0 , 2 7 2} \\
p=\mathbf{0 , 0 3 4 ~} \mathbf{N}=\mathbf{6 1}\end{array}$ & & $\begin{array}{l}\text { Mac08 } r=0,3 \\
p=0,043 N=46\end{array}$ & \\
\hline $\begin{array}{l}\text { Fruta } \\
\text { Mad }\end{array}$ & & & & & $\begin{array}{l}\text { Mac09 } r=0,391 \\
p=0,000 N=94 \\
\text { Rita10 } r=0,379 \\
p=0,007 \quad N=49 \\
\text { Rita11 } r=0,36 \\
p=0,001 \quad N=77\end{array}$ & $\begin{array}{l}\text { Gun10 } r=-0,594 \\
p=0,000 N=40 \\
\text { Rita11 } r=-0,325 \\
p=0,008 N=65\end{array}$ & $\begin{array}{lll}\text { Mac09 } & r=0,419 & p=0,000 \\
N=106 & & \\
\text { Gun10 } r=-\mathbf{0 , 4 9 9} & p=\mathbf{0 , 0 0 1} \\
\mathbf{N}=\mathbf{4 0} & \end{array}$ \\
\hline $\begin{array}{l}\text { Grupo- } \\
\min \end{array}$ & & & & & & $\begin{array}{l}\text { Mac08 } r=0,461 \\
p=0,005 N=36 \\
\text { Mac09 } r=0,291 \\
p=0,005 N=90\end{array}$ & \\
\hline $\begin{array}{l}\text { Vol } \\
\text { Copa }\end{array}$ & & & & & & & $\begin{array}{llll}\text { Mac08 } & r=0,567 & p=0,000 \\
N=51 & & \\
\text { Mac09 } & r=0,499 & p=0,000 \\
N=122 & & \\
\text { Gund09 } & r=0,906 & p=0,000 \\
N=26 & & \\
\text { Gund10 } & r=0,53 & p=0,000 \\
N=61 & & \\
\text { Rita10 } & r=0,668 & p=0,000 \\
N=55 & & \end{array}$ \\
\hline
\end{tabular}

Tabla 4.13: Resumen de las correlaciones positivas y negativas significativas para todos los grupos entre las variables aceleración 1 y 2 , total de fruta madura, fruta inmadura, fruta madura, grupo-minuto, volumen de copa (Vol Copa) y diámetro a la altura del pecho (DAP). En negrita las asociaciones negativas significativas. 


\subsubsection{Cantidades de fruta e intervalos de revisita}

Se analizaron los intervalos de revisita (en horas) en relación a las cantidades de fruta madura e inmadura presentes en los árboles para evaluar si los monos poseían un registro de la visita previa a cada árbol, ajustando sus tiempos de revisita a los mismos en función de ese registro. Los datos correspondientes al grupo Gundolf en 2009 no fueron incluidos en este análisis debido a la baja cantidad de visitas en las que pudo estimarse la cantidad de fruta presente.

El modelo con mejor fit (menor CIA) fue aquel en el que se incluyeron los efectos fijos "categoría de fruta madura" y "categoría de fruta inmadura" juntos. Se encontraron diferencias en la duración del intervalo de revisita tanto para la categoría de fruta madura (MGLM, Chiq $=15.309, \mathrm{p}=0.000, \mathrm{gl}=1$ ) como inmadura (MGLM, Chiq = 15.534, $p=0.000, g l=1$ ), indicando que los monos ajustan sus tiempos de revisita en función de la cantidad de fruta madura e inmadura presente. A su vez el modelo demostró una elevada variación no relacionada a las cantidades de fruta que pudo deberse a la diferencia entre años en la cantidad de árboles visitados y también a las diferencias entre los tamaños de los grupos.

Los intervalos de revisita fueron menores cuánto más era la cantidad de fruta (madura o inmadura) presente en el árbol (Gráfico 4.19). Puede observarse además que para el caso de la fruta madura los intervalos de revisita fueron mayores que para la fruta inmadura en los árboles con baja cantidad de fruta, mientras que en los árboles con mayor cantidad de fruta los intervalos fueron menores para la presencia de fruta madura y mayores para la presencia de fruta inmadura, indicando que los monos utilizaban información no sólo sobre cantidad sino también sobre el estado de maduración de sus visitas previas para ajustar sus tiempos de retorno. 


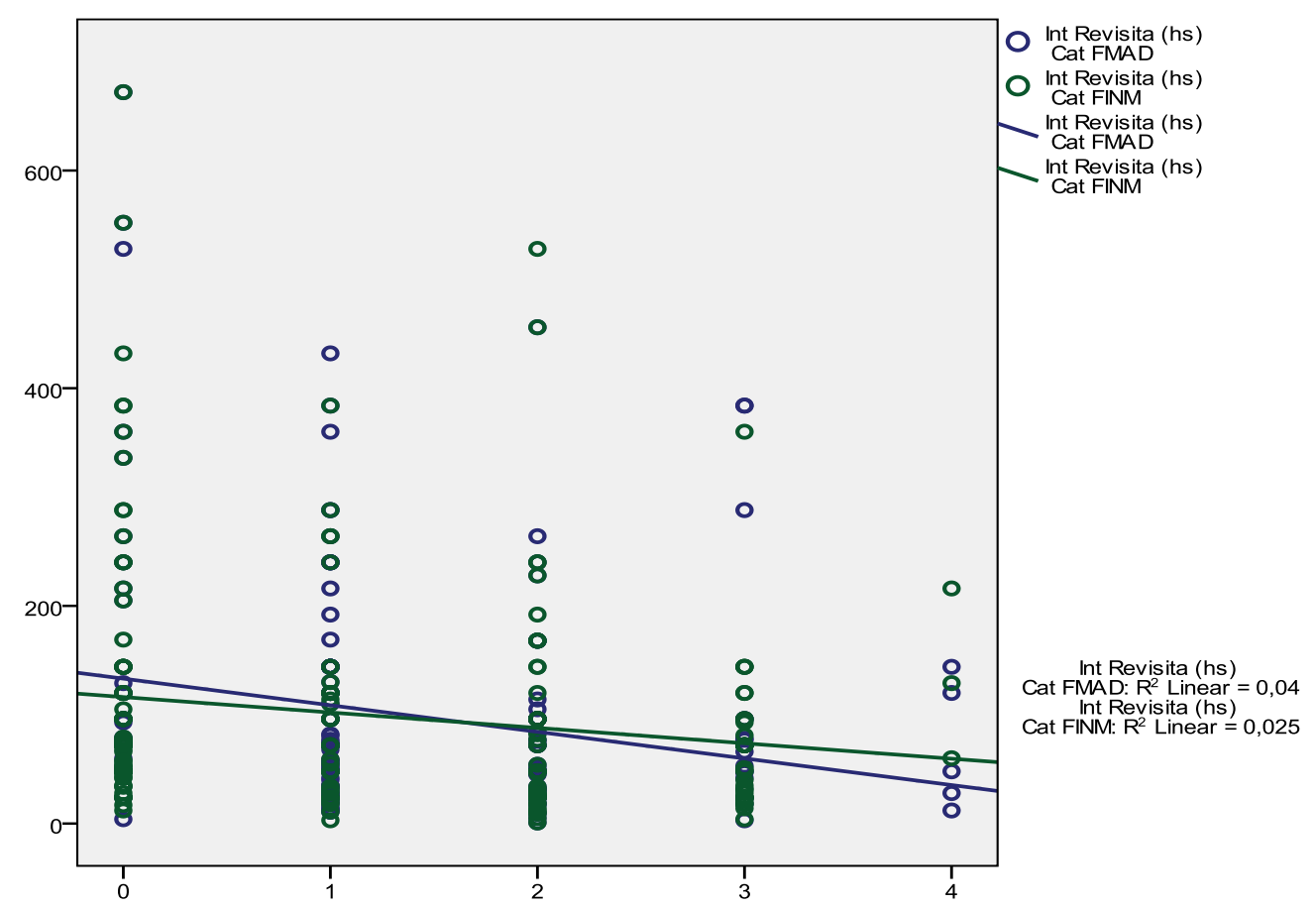

Gráfico 4.19: Intervalos de revisita (en horas) a los árboles según sus categorías de fruta madura e inmadura ( 0 a 4 ).

\subsection{Discusión}

\subsubsection{Variaciones en el consumo de frutos}

Placci, Arditi \& Ciotek (1994) determinaron que los diferentes tipos de bosques dentro del Parque Nacional Iguazú presentan diferentes patrones de fructificación y caída de frutos carnosos y secos. Los autores registraron fluctuaciones estacionales importantes en la disponibilidad de frutos carnosos las cuales parecerían compensarse por la heterogeneidad ambiental de ambos bosques, disminuyendo así los períodos de escasez del recurso "frutos" para la comunidad de frugívoros de estos ambientes. Dado que ambos grupos de estudio incursionan en ambos tipos de bosque durante su forrajeo diario y que, con excepción del grupo Gundolf, los muestreos se realizaron en los mismos meses pero diferentes años, puede considerarse que existe en la zona de estudio una variación inter-anual en las especies que fructifican. Esta situación parece explicar la variabilidad en el consumo de frutos de cada período de muestreo, pero manteniendo un número constante de especies consumidas (entre 10 y 12 especies diferentes durante cada año de muestreo).

Para el grupo Macuco, además de algunas especies que fructificaron en ambos años (mora amarilla, ficus, miconia y camboatá), en 2008 los monos consumieron frutos de cancharana, carayá bola, laurel, y visitaron también numerosos árboles infestados con 
homópteros mientras que en 2009 consumieron frutos de casearia, cocú, guabira y ubajai que no estuvieron presentes en el año anterior y viceversa. Para el grupo Rita, además de algunas especies que fructificaron en ambos años (mora amarilla, ficus, araticú, Disella nucífera, hobenia, naranjas, mandarinas y pindó), en 2010 los monos consumieron aguaí, cocú, Coussarea contracta y ubajai, mientras que en 2011 estas especies no fructificaron y en cambio consumieron cancharanas, carayá bola, laureles, bananas y guabiras. Los muestreos de cada año para el grupo Gundolf no fueron en los mismos meses.

\subsubsection{Memoria de los árboles focales y su estado de fructificación}

Los grupos estudiados demostraron un registro de la condición de los árboles, continuando hacia los mismos cuando estos tenían fruta una vez entrado el radio crítico. Dados los recaudos tomados en cuanto a distancias de detección puede asegurarse que los monos no utilizaron señales visuales ni olfativas durante este proceso, teniendo en cuenta que los primates no-humanos y humanos se encuentran dentro del mismo rango de performance olfatoria que les impide detectar el olor de la fruta a más de $20 \mathrm{~cm}$ (Janmaat et al., 2006). La presencia de velocidades mayores cuando la entrada a un radio crítico terminaba en una visita reafirma las conclusiones anteriores.

Los monos incrementaron su velocidad de desplazamiento a medida que se acercaban al árbol indicando que existió una expectativa del recurso a encontrar y por lo tanto un registro previo. Los monos aceleraban de manera progresiva a medida que se acercaban al recurso (pero mientras este aún continuaba fuera del alcance visual del grupo). Puede reafirmarse entonces que la velocidad es una buena medida de la expectativa del grupo como se había notado en estudios previos en esta especie (Janson \& Di Bitetti, 1997) y en otras (Papio urcinus: Noser \& Byrne, 2007; Papio hamadryas cynocephalus: Pochron, 2001).

La predicción de que los monos viajaban más rápido a árboles con una mayor cantidad de fruta madura presente no tiene una base teórica conocida por lo cual la falta de encontrarse ese patrón no necesariamente indica que los monos no conocen el estado de fruta del árbol. Podría haber ocurrido que, una vez dentro del radio crítico y al no percibir señales auditivas de otros frugívoros en el sitio (coatíes, pájaros), correr hacia el recurso que tenga más fruta madura no sería necesario (a pesar del ya mencionado incremento en la velocidad que de por si existía a medida que se acercaban al árbol). A pesar de esto el análisis de los intervalos de revisita evidenció que los grupos volvían con mayor frecuencia (en menor tiempo) a árboles con mayor cantidad de fruta madura presente, indicando que poseían un registro de la cantidad y estado de maduración de la fruta encontrada en la visita anterior y corroborando los 
resultados de Janson (1998) sobre la capacidad de los caí de recordar las cantidades de recompensa. Entonces, o bien la velocidad (o la aceleración) no es un buen indicador de que los monos recuerdan el estado de maduración del árbol, o los grupos se desplazan de manera rápida a cualquier recurso que pueda alojar a 1/3 del grupo en la visita (como fueron los árboles seleccionados en este estudio) independientemente del estado del mismo. A su vez, ciertas características de los árboles como el tamaño de la copa y su volumen (además del estado de la fruta y su cantidad) podrían ser recordadas por los monos influyendo así en los patrones de visita de los grupos.

Otra posibilidad a considerar es que el ambiente ofreciera a los individuos suficientes nutrientes como para no necesitar visitar los árboles de manera más rápida teniendo en cuenta que los objetivos nutricionales son determinantes de la selección de la dieta por parte de los primates (para una revisión sobre ecología nutricional ver Felton et al. 2009). Las diferencias nutricionales entre las frutas no fue una variable considerada en este trabajo, pero podría ser muy interesante para estudios futuros.

Al igual que durante el trabajo de Janmaat y colaboradores (2006a) ocurrieron dos eventos anecdóticos durante los seguimientos de uno de los grupos (Macuco 2008) que apoyan la hipótesis de que los monos utilizan la memoria para encontrar fruta y para no regresar una vez que ésta se ha agotado: 1) en 3 ocasiones el grupo se desplazó a través de un cañaveral recorriendo aproximadamente 1,5 km para terminar su recorrido en un parche compuesto por dos árboles de mora amarilla de gran porte ubicados por fuera del territorio habitual del grupo, llegando incluso a utilizar el sitio como dormidero; y 2) los monos realizaron visitas a un árbol de Yvaporoití ubicado en la barranca del río Iguazú (desplazándose de manera directa al árbol al llegar a la barranca) pero una vez que el árbol se quedó sin fruta (categoría 0) nunca más volvieron hacia la barranca ni se aproximaron a los alrededores del mismo.

\subsection{Conclusión}

A pesar del carácter puramente observacional del diseño, las implicancias de considerar las variables "cantidad" y "estado de maduración" de los recursos es importante dado que permite analizar como la variación espacio-temporal del comportamiento de los primates se asocia al registro de fruta disponible para ser consumida en los árboles mediante la regulación de los tiempos entre visitas. Cuánto conseguirán comer dependerá de su propio comportamiento pasado (Janson, 2000). Esa información espacio-temporal aprendida en determinado momento tendrá valor en un tiempo posterior e incrementará la probabilidad de retorno al mismo sitio. El tiempo óptimo para regresar a un recurso conocido debe ser un equilibrio entre la ventaja de 
utilizar la información aprendida y recordada sobre el estado del mismo y el tiempo de renovación de ese recurso. La valoración elevada de un recurso al inicio (por ejemplo, mucha cantidad de fruta apta de ser consumida por su estado de maduración) favoreceran los bajos tiempos de retorno al mismo (Spencer, 2012).

Los resultados de este capítulo permiten concluir que los capuchinos en Iguazú poseen un registro de la ubicación de los árboles de fruta (registro espacial) y de las cantidades y estados de maduración de la fruta en cada uno (registro temporal) utilizando esta información para optimizar las visitas a los mismos.

\subsection{Referencias}

Anzelc, A. 2009. The foraging and travel patterns of whited-faced sakis in Brownsberg Nature Park, Suriname: preliminary evidence for goal-directed foraging behavior. Master of Arts Thesis, Kent State University.

Boesch, C. \& H. Boesch. 1984. Mental map in wild chimpanzees: an analysis of hammer transports for nut cracking. Primates, 25: 160-170

Bolker, B. M., Brooks, M. E., Clark, C. J., Geange, S. W., Poulsen, J. R., Stevens, M. H. H. \& J. S. White. 2009. Generalized linear mixed models: a practical guide for ecology and evolution. Trends in Ecology and Evolution, 24 (3): 127-135.

Brown, A. D. \& Zunino, G. E. 1990. Dietary variability in Cebus apella in extreme habitats: evidence of adaptability. Folia Primatol. 54: 187-195.

Coe, R. \& C. Merino. 2003. Magnitud del efecto: una guía para investigadores y usuarios. Revista de Psicología - PUCP, 21(1): 147-177.

Cunningham, E. \& C. H. Janson. 2007. Integrating information about location and value of resources in white-faced saki monkeys (Phitecia phitecia). Animal Cognition, 10: 293304.

Dallmeier, F. 1992. Long-term monitoring of biological diversity in tropical forest areas: methods for establishment and inventory of permanent plots. MAB Digest II. UNESCO, Paris.

De Oliveira Oyama, S. \& L. A. de Souza. 2011. Morphology and anatomy of the developing fruit of Maclura tinctoria, Moraceae. Revista Brasil. Bot. 34 (2): 187-195.

De Solla, S. R., Bonduriansky, R. \& R. J. Brooks. 1999. Eliminating autocorrelation reduces biological relevance of home range estimates. Journal of Animal Ecology, 68: 221-234.

Di Bitetti, M. 2001. Home-range use by tufted capuchin monkeys (Cebus apella nigritus) in a subtropical rainforest of Argentina. J. Zool. 253: 33-45.

Di Fiore, A. \& S. A. Suarez. 2007. Route-based travel and shared routes in sympatric spider and woolly monkeys: cognitive and evolutionary implications. Animal Cognition, 10:317-329.

Eibl, B.; Silva, F.; Bobadilla, A. \& G. Ottenweller. 1995. Fenología de especies forestales nativas de la selva misionera. Revista Yvyrareta 8 (8): 78-87.

Felton, A. M., Felton, A., Lindenmayer, D. B. \& W. J. Foley. 2009. Nutritional ecology: Nutritional goals of wild primates. Functional Ecology, 23: 70-78. 
Fragaszy, D.M., Visalberghi, E., \& Fedigan, L. 2004. The Complete Capuchin. The biology of genus Cebus. Cambridge University Press: United Kingdom.

Fisher, R. A. 1932. Statistical Methods for Research Workers (4 Edition). Edinburgh: Oliver \& Boyd.

Garber, P. A. 1989. Role of spatial memory in primate foraging patterns: Saguinus mystax and Saguinus fuscicollis. Am. J. Primatol. 19: 203-216.

Garber, P. A. \& F. L. Dolins. 1996. Testing learning paradigms in the field: Evidence for use of spatial and perceptual information and rule-based foraging in wild moustached tamarins. En: Norconk, M. A., Rosenberger, A. L., and Garber, P. A. (eds.), Adaptive Radiations of Neotropical Primates, Plenum Press, New York, pp. 201-216.

Garber, P. \& L. M. Pacuilli. 1997. Experimental field study of spatial memory and learning in wild capuchin monkeys (Cebus capuchinus). Folia Primatológica. 68: 236-253.

Garber, P. \& P. E. Jelinek. 2005. Chapter 11: Travel patterns and spatial mapping in Nicaraguan Mantled Howler Monkeys (Alouatta palliata). En: Alejandro Estrada, Paul A. Garber, Mary S. M. Pavelka, and LeAndra Luecke (Eds), New Perspectives in the Study of Mesoamerican Primates: Distribution, Ecology, Behavior, and Conservation (pp. 287309). Springer, New York.

Gibeault, S. \& S. E. MacDonald. 2000. Spatial memory and foraging competition in captive western lowland gorillas (Gorilla gorilla gorilla). Primates 41: 147-160.

Houle, A., C. A. Chapman \& W. L. Vickery. 2007. Intratree variation in fruit production and implications for primate foraging. Int J Primatol, 28:1197-1217

Janmaat, KRL; Byrne, RW \& Zuberbühler, K. 2006a. Evidence for a spatial memory of fruiting states of rainforest trees in wild mangabeys. Animal Behaviour. 72: 797-807.

Janmaat, K. R. L., Byrne, R. W. \& K. Zuberbühler. 2006b. Primates take weather into account when searching for fruits. Current Biology, 16: 1232-1237.

Janmaat, K. R. L. \& R. L. Chancellor. 2010. Exploring new areas: how important is long-term spatial memory for Mangabey (Lophocebus albigena johnstonii) foraging efficiency? Int J Primatol, 31: 863-886.

Janmaat, K. R. L., Chapman, C. A., Meijer, R. \& K. Zuberbühler. (2012). The use of fruiting synchronyby foraging mangabey monkeys: a ,simple tool" to find fruit. Animal Cognition, 15: 83-96.

Janson, C. H. 1988. Food competition in brown capuchin monkeys (Cebus apella): quenatitative effects of group size and tree productivity. Behaviour, 105: 53-76.

Janson, C. H. 1998. Experimental evidence for spatial memory in foraging wild capuchin monkeys, Cebus apella. Animal Behaviour. 55: 1229-1243.

Janson, C. H. 2000. Chapter 7. Spatial movement strategies: theory, evidences and challenges. En: Boinski, S. \& P. A. Garber (eds.). On the move: how and why animals travel in groups (pp. 165-203). Chicago University Press. USA.

Janson, C. H. 2007. Experimental evidence for route integration and strategic planning in wild capuchin monkeys. Animal Cognition, 10: 341-356. 
Janson, C. H. 2012. Reconciling rigor and range: observations, experiments, and quasiexperiments in field primatology. Int J Primatol, 33: 520-541.

Janson, C.H. \& M. Di Bitetti. 1997. Experimental analysis of food detection in capuchin monkeys : effects of distance, travel speed and resource size. Behav. Ecol. Sociobiol. 41:17-24.

Janson, C. H.; Stiles, E. W. \& D. W. White.1986. Chapter 7. Selection on plant fruiting traits by brown capuchin monkeys: a multivariate approach. En: Estrada, A. \& Fleming, T. H. (eds.). Frugivores and seed dispersal (pp: 85-92). Dr W. Junk Publishers, Dordrecht.

Janson, C.H. \& R. Byrne. 2007. What Wild primates know about resources: opening up the black box. Animal Cognition, 10: 357-367.

Lorenzi, Harri. 2002. Brazilian Trees - A Guide to identification and cultivation of Brazilian Native Trees ( $\left.4^{\circ} \mathrm{Edic}\right)$. Vol.01. Harri Lorenzi Eds. USA.

MacDonald, S. E. 1994. Gorillas" (Gorilla gorilla gorilla) spatial memory in a foraging task. J. Comp. Psychol. 108: 107-113.

MacDonald, S. E. \& D. M. Wilkie. 1990. Yellow-nosed monkey"s (Cercopithecus ascanius whitesidei) spatial memory in a simulated foraging environment. J. Comp. Psychol. 104: 382-387.

MacDonald, S. E., Pang, J. C. \& S. Gibeault. 1994. Marmoset (Callithrix jacchus jacchus) spatial memory in a foraging task: Win-stay versus win-shift strategies. J. Comp. Psychol. 108: 328-334.

MacDonald, S. E. \& M. M. Agnes. 1999. Oranutan (Pongo pygmaeus abelii) spatial memory and behavior in a foraging task. J. Comp. Psychol. 113: 213-217.

Menzel, E. W. 1973. Chimpanzee spatial memory organization. Science. 182: 943-945.

Menzel, C. R. 1991. Cognitive aspects of foraging in Japanese monkeys. Animal Behaviour, 41: 397-402.

Milton, K. 1981. Distribution patterns of tropical plant foods as an evolutionary stimulus to primate mental development. American Anthropologist, New Series, 83: 534-548.

Morales Vallejo, P. 2012. El tamaño del efecto (effect size): análisis complementarios al contraste de medias. Disponible en: http://www.upcomillas.es/personal/peter/investigacion/Tama\%F1oDelEfecto.pdf

Nakagawa, S. \& I. C. Cuthill. 2007. Effect size, confidence interval and statistical significance: a practical guide for biologists. Biol. Rev., 82: 591-605.

Noser, R. \& R. Byrne. 2007. Travel routes and planning of visits to out-of-sight resources in wild chacma baboons, Papio urcinus. Animal Behav. 73: 257-266.

Noser, R. \& R. Byrne. 2010. How do wild baboons (Papio ursinus) plan their routes? Travel among multiple high-quality food sources with inter-group competition. Anim Cogn, 13: 145-155.

Norman, E. \& C. Boesch. 2009. Sophisticated euclidean maps in forest chimpancés. Animal Behaviour, 77: 1195-1201. 
Normand, E., Ban, S. D. \& C. Boesch. 2009. Forest chimpanzees (Pan troglodytes verus) remember the location of numerous fruit trees. Anim Cogn, 12: 797-807.

Ortega Torres, E.; Stutz de Ortega, L. \& R. Spichiger. 1989. Flora del Paraguay. Editions des Conservatoire et Jardin Botaniques de la Ville de Genève \& Missouri Botanical Garden. Ginebra.

Packard, G. C. \& T. J. Boardman. 2008. 1. Model selection and logarithmic transformation in allometric analysis. Physiological and Biochemical Zoology, 81 (4): 496-507.

Placci, L. G., Arditi, S. I. \& L. E. Ciotek. 1994. Productividad de hojas, flores y frutos en el Parque Nacional Iguazú. Yvyrareta, 5: 49-56.

Platt, M. L., Brannon, E. M., Briese, T. L. \& J. A. French, J. A. 1996. Differences in feeding ecology predict differences in performance between golden lion tamarins (Leontopithecus rosalia) and Wied's marmosets (Callithrix kuhli) on spatial and visualmemory tasks. Anim. Learn. Behav. 24: 384-393.

Pochron, S. T. 2001. Can concurrent speed and directness of travel indicate purposeful encounter in the yellow baboons (Papio hamadryas cynocephalus) of Ruaha National Park, Tanzania? International Journal of Primatology, 22 (5): 773-785.

Roberts, W. A., Mitchell, S. \& M. T. Phelps. 1993. Foraging in laboratory trees: Spatial memory in squirrel monkeys. En: Zentall, T. R. (ed.), Animal Cognition. A Tribute to Donald A. Riley, Lawrence Erlbaum, Mahwah, NJ, pp. 131-151.

Scheumann, M. \& J. Call. 2006. Sumatran orangutans and a yellow-cheeked crested gibbon know what is where. International Journal of Primatology, 27 (2): 575-602.

Spencer, W. D. 2012. Home ranges and the value of spatial information. Journal of Mammalogy, 93 (4): 929-947.

Suarez, S. A. 2003. Spatio-temporal foraging skills of white-bellied spider monkeys (Ateles belzebuth belzebuth) in the Yasuni National Park, Ecuador. PhD. Dissertation, State University of New York at Stony Brook.

Trusty, J., Thompson, B. \& J. V. Petrocelli. 2004. Practical guide for reporting effect size in quantitative research. Journal of Counseling \& Development, 82 (1): 107-110.

Vogel, E. R. \& C. Janson. 2007. Predicting the frequency of food-related agonism in white-faced capuchin monkeys (Cebus capucinus), using a novel focal-tree method. American Journal of Primatology. 69: 1-18.

Yates, F. 1934. Contingency tables involving small numbers and the $X^{2}$ Test. Journal of the Royal Statistical Society, Ser. B, Supp., 1: 217-235.

Zuberbühler, K. \& K. Janmaat. 2010. Chapter 4: Foraging cognition in nonhuman primates. En: M. Platt and A. Ghazanfar (Eds): Primate Neuroethology (pp. 64-83). Oxford University Press: United Kingdom. 


\section{Capítulo 5: Conclusiones finales y planteos futuros}

"Había topado con el mismo orgullo herido con el que se toparon Copérnico y Darwin: a los seres humanos no les gusta que les priven de ser el centro del universo (Ridley, 2004: 275)".

\subsection{Introducción}

El comportamiento humano tiene dos características esencialmente distintas del resto de los primates: es racional (o "lógico", en otras palabras) y está íntimamente relacionado a la capacidad de lenguaje hablado. La palabra lógico tiene un doble significado, dado que describe una manera de pensar y también una de las más antiguas disciplinas: la ciencia de razonar (Watanabe \& Huber, 2006). Los humanos desarrollan habilidades en contexto social, donde la identidad y la experiencia individual tienen importancia, y exhiben una marca única en sus actividades, esto es, el potencial para el pensamiento recursivo entendido como la capacidad de análisis lógico de una gran cantidad de información en poco tiempo (Keller, 2004).

Se estima que los primeros primates no fueron cognitivamente diferentes del resto de los mamíferos, pero en algún momento alrededor de 30 millones de años atrás, una rama de sus descendientes se especializó en un aprendizaje más rápido, lo que implicó la necesidad de una neocorteza cerebral mayor, involucrada en procesar una mayor cantidad de información social como resultado de vivir en grupos semipermanentes y/o de expandir su dieta, conllevando la necesidad de localizar y procesar nuevos alimentos. Esta antigua población primaria habría dado origen a todos los primates modernos (incluyendo al ser humano). Luego (aproximadamente hace unos 12 millones de años atrás), una rama de este linaje habría desarrollado la habilidad de entender relaciones causales entre objetos, acciones y eventos, los estados mentales de otros individuos y la organización jerárquica del comportamiento. El fenómeno de lograr entender los estados mentales de otros fue crucial para el desarrollo del lenguaje en algún punto de la evolución de los homínidos (Byrne, 2000). Como explica Wallace (1989), el mapa cognitivo humano es único, porque está íntimamente relacionado con el lenguaje: los humanos somos capaces de representar la ubicación de un objeto (place) y también decir dónde estaba antes (misplace) aunque ya no esté presente. Como se mencionó en el capítulo 1, el proceso de formación del mapa cognitivo ocurre predominantemente en el hipocampo. En todos los mamíferos, excepto el humano, los dos hemisferios del hipocampo se utilizan para 
el mapeo cognitivo. En cambio, en humanos el hemisferio derecho está especializado en el mapeo espacial mientras que el izquierdo lo está en la producción de material verbal (las lesiones de este lado del hemisferio generan la pérdida de memoria verbal), indicando que el lenguaje y la cognición espacial están íntimamente relacionados. El lenguaje humano propicia la rápida y flexible solución de problemas vinculados al uso del espacio (Hermer-Vazquez et al., 2001). Nuevos resultados han puesto de manifiesto que existe una importante influencia de uno sobre otro: se han registrado variaciones sobre la predominancia de los diferentes marcos de referencia espacial utilizados para recordar las posiciones de los objetos según las distintas lenguas. Dentro del inglés, el alemán y el holandés, por ejemplo, existe una predominancia del marco egocéntrico (ver capítulo 1), mientras que en otras lenguas es el marco exocéntrico el que prima. La aculturación determina las diferentes representaciones y procesos espaciales, y podría ser que la divergencia temprana de humanos y simios se relacionara con diferentes experiencias con objetos y su forma de afrontarlas (para mayores detalles ver Gentner, 2007).

Los primates no-humanos no son capaces de "lenguajear", pero esta ausencia de lenguaje hablado no los priva de compartir características comunes a nivel cognitivoespacial con los humanos. En el caso de los capuchinos (Cebus, Sapajus), su longevidad (41 años en promedio con un record de 54 años en cautiverio: Hakeem et al., 1996 en MacKinnon, 2013, y un promedio de 20 años en vida libre), sus grandes cerebros y sus comportamientos complejos, los hacen un excelente ejemplo de plasticidad (MacKinnon, 2013), como también de flexibilidad, dos características esenciales para el desarrollo de habilidades cognitivas. La plasticidad puede entenderse como la habilidad de un organismo para reaccionar por medio de un cambio en la forma, el estado o el movimiento de una actividad, a un input ambiental interno o externo, mientras que la flexibilidad será un conjunto de posibles respuestas que le permiten a un organismo adaptarse a un ambiente heterogéneo (WestHeberhard 2003 en MacKinnon, 2013).

\subsection{Relevancia de la presente tesis}

A lo largo de esta tesis se han puesto de manifiesto las características principales del comportamiento espacial y la memoria de los capuchinos estudiados. Los datos obtenidos durante las etapas experimentales en zoológico y de observación en vida silvestre fueron utilizados para crear un modelo descriptivo - explicativo de los comportamientos observados y registrados, para luego ser evaluados en función del concepto de asociación de intermodalidades (cambios de posición o forma) de los individuos, expresadas en comportamientos externalizados. El observador realiza un 
mapeo e infiere a partir de ello la estructura espacial interna o configuración del organismo en cuestión (Lahitte \& Tujague, 2007). Se analizaron las relaciones espaciales con las que los monos lograron recordar las localizaciones de comida $u$ otros organismos, en otras palabras, el modo en que por recurrencia y repetición se efectiviza un mapa cognoscitivo en función de un territorio recorrido.

La descripción detallada del etograma elaborado en el capítulo 2 ofreció la posibilidad de conocer el comportamiento de los individuos independientemente de los diseños utilizados a posteriori para medir las variables seleccionadas. A su vez, la existencia de este listado parcial de pautas de conducta ofrece un marco de referencia para futuros meta-análisis (Nakagawa \& Cuthill, 2007) disminuyendo así los errores de interpretación al momento de observar comportamientos en cautiverio o vida silvestre. Un etograma alimentario de los caí, aunque parcial, no había sido publicado ni era accesible a los investigadores hasta el momento. Así se ha cumplido con el objetivo específico 1.

A lo largo del capítulo 3 se abordaron los objetivos específicos 2, 3, 4 y 5, y las siguientes hipótesis y predicciones, encontrando sustento para ellas. Los individuos estudiados en el zoológico retuvieron la información espacial aprendida, incrementando su performance individual y grupal, y manteniendo ese aprendizaje por períodos de hasta 4 meses (Capacidad de memoria: $\mathrm{H} 1$ - predicciones 1, 2 y 3;). A su vez, disminuyeron su performance de manera abrupta frente a la alteración (por parte del investigador) de las posiciones aprendidas a lo largo del experimento (Capacidad de memoria: H3 - predicción 1). El resultado más importante dentro de este capítulo es que los individuos estudiados fueron capaces de aprender la nueva información de las posiciones invertidas en menor tiempo que el que tomaron para aprender las posiciones iniciales, por medio de la integración de sets de aprendizaje (capacidad de memoria: H4 - predicción 1). Este resultado es totalmente novedoso para Cebus. Asimismo se observó que el aprendizaje por facilitación social ocurrió de manera dirigida, encontrándose que existieron diferencias entre sexos y categorías de edad, como también, aunque en menor medida, entre individuos (Aprendizaje en contexto de grupo: $\mathrm{H} 1$ - predicciones 1 y 2 ).

Dentro del capítulo 4 (vida silvestre) se abordaron los objetivos específicos 2, 3 y 4 , y las siguientes hipótesis y predicciones, encontrando también sustento para ellas. Los grupos estudiados visitaron los árboles focales de manera reiterada mientras los mismos tuvieron fruta (Capacidad de memoria: H1 - predicción 3), ajustando sus intervalos de revisita en función de la cantidad de fruta madura en los mismos (intervalos menores a mayor cantidad de fruta madura; capacidad de memoria: $\mathrm{H} 2$ predicciones 1 y 2). Los grupos se dirigieron a mayor velocidad cuando su objetivo 
final era una visita a un árbol que cuando no lo era y aumentaron gradualmente la velocidad al acercarse a los mismos (Capacidad de memoria: $\mathrm{H} 2$ - predicciones 2 y 3 ). Este es el primer trabajo en el que se obtiene información sobre la capacidad de Cebus para diferenciar entre estados de maduración de la fruta, utilizando esta información para organizar sus revisitas a los árboles.

El modelo de aprendizaje observacional basado en la identificación y el vínculo con compañeros sociales (bonding-and-identification-based observational learning), pone su énfasis en la recompensa intrínseca de actuar de la misma forma que otros, especialmente si esos otros son individuos afiliativamente cercanos al actor (Matsuzawa et al., 2001 en Bonnie \& de Waal, 2007). Este modelo fue estudiado en Cebus apella en cautiverio por Bonnie y de Waal (2007) quienes concluyeron que los capuchinos no necesitan una recompensa de alimento (e incluso no necesitan ver una recompensa) para dejarse influenciar por el comportamiento alimentario de otros, aunque en la presencia de una recompensa el comportamiento se vuelve más robusto. En el caso del capítulo 3 es posible que los individuos estuvieran actuando como otros aun sin ver la recompensa de los contenedores de alimento.

Tanto en el capítulo 3 como en el 4 se encontró evidencia de los 4 tipos de aprendizaje asociativo explicitados en el capítulo 1 (aprendizaje exploratorio, espacial o de lugares, observacional y por formación de conjuntos o sets de aprendizaje), como también de los 3 tipos de aprendizaje planteados por Bateson (1974): tipos 0, I y II. Pudo comprobarse también la capacidad de los grupos estudiados de retener información por períodos de tiempo que abarcaban desde 1-2 días (memoria de corto plazo) hasta semanas a meses (memoria de largo plazo). Es probable que esta memoria de semanas a meses no sea útil para un frugívoro para el cual la memoria de los últimos sitios visitados (algunos días) será la más informativa, dado las características efímeras de los frutos (aproximadamente 1 a 6 semanas) y sus tasas de renovación (1-2 días) (Corlett, 2011). Podría pensarse que la memoria de largo plazo será útil para recordar los sitios donde siempre hubo fruta a lo largo del tiempo interactuando con el área de acción. La utilización ineficaz de memoria de largo plazo se hace evidente al momento de explorar nuevas áreas: se ha encontrado que la eficiencia para encontrar frutos en estas situaciones disminuye y esto puede tomarse como indicador de que los individuos no utilizan el conocimiento almacenado acerca de su área de acción habitual al enfrentarse con estas situaciones (Janmaat \& Chancellor, 2010).

En el registro de los intervalos de visita y en el registro de los contenedores de comida en el zoológico, los individuos estudiados estaban poniendo en funcionamiento la memoria de trabajo (Baddeley \& Hitch, 1974): un tipo de registro temporario que activa memorias permanentes en un momento específico. 
Resumiendo, se pusieron de relieve novedosas cuestiones del comportamiento espacial de los monos caí: elevados tiempos de retención de la memoria, capacidad de formar sets de aprendizaje y capacidad de recordar cuestiones vinculadas al estado de maduración del alimento distribuido en el ambiente. Estos aportes permiten conocer con mayor detalle las características de base de una especie ampliamente estudiada en trabajos de cognición comparada.

\subsection{Observaciones finales}

Muchas de las predicciones utilizadas para confirmar la existencia de información cognitiva sobre presencia y condición de comida, se basan en expectativas "teóricas" sobre los comportamientos que los observadores esperan del objeto de estudio (los monos). Por ejemplo, se espera que los monos aceleren el paso cuando se dirigen a sitios de comida previamente conocidos (en vida silvestre), o que prefieran buscar comida en sitios donde anteriormente la habían encontrado (cautiverio). Pero es importante reconocer que hay muchos factores adicionales que pueden impedir que se realicen estas expectativas. Por ejemplo, al evaluar los diagramas de secuencias de visita de los individuos del grupo Jaula resultó evidente que, por más que los individuos nunca lograron retirar comida en los contenedores inaccesibles, continuaban visitándolos aunque con una baja frecuencia (probablemente, porque en condiciones de competencia social no podrían haber estado seguros de que los mismos nunca tuvieron comida realmente, o que alguien de su grupo agotó el sitio previamente a la visita actual). Igualmente, en vida silvestre, la cobertura de frutos puede ser una de muchas variables que influyen en el "incentivo" del grupo para llegar a los árboles, pudiendo incluirse también el estado de saciedad o hambre, las variaciones en la distribución de la fruta madura e inmadura dentro de un mismo árbol, las variaciones en los tipos de nutrientes presentes en las frutas, etc. Por lo tanto, es importante recordar que, en ausencia de un conocimiento detallado de qué factores influyen de manera precisa en la cognición ecológica de la especie estudiada, los resultados negativos deben tomarse con cautela.

En la presente tesis se obtuvieron resultados cuali y cuantitativos que fueron analizados de manera complementaria. La evidencia convergente originada de los estudios cualitativos y cuantitativos es posiblemente más competente que aquella que se origina de un solo tipo de estudio por separado. Los resultados cualitativos son esenciales para capturar eventos raros y para generar hipótesis con significado adaptativo para determinados comportamientos. Los resultados cuantitativos son esenciales para testear esas y otras hipótesis derivadas (de Waal, 1991). 
Posiblemente el único tipo de memoria que aún se considera exclusivamente humana es la memoria episódica que puede definirse como un sistema de memoria de largo plazo que implica la recuperación de un evento que integra múltiples componentes y que forma parte del propio pasado personal. Debido a que es difícil indagar sobre la existencia de un sentido del pasado consciente en los animales no humanos, se hace referencia a una memoria de tipo episódica (episodic-like memory) (Clayton et al, 2003). Esta memoria de tipo episódica es clásicamente estudiada sobre 4 ejes: 1) el "qué" se recuerda (por ejemplo, un tipo de alimento), 2) el "dónde" ocurrió el evento (por ejemplo, dónde estaba localizada esa comida), 3) el "cuándo" del evento recordado (por ejemplo, el momento del día en que ocurrió) y 4) por último un criterio adicional, el "quién" intervino en el evento recordado (por ejemplo, quién suministró el alimento) (Clayton et al, 2003, Schwartz \& Evans, 2001). La memoria episódica no debe ser el resultado de la experiencia repetitiva sobre un evento, sino la capacidad de recordar un evento único (Gazzaniga, 2010). En la actualidad numerosos resultados ponen en duda la exclusividad humana en relación con este tipo de memoria (Basile et al., 2009, Bourjade et al, 2012; Clayton et al, 2003; González-Gómez et al, 2011; Flores-Abreu et al, 2012; Hampton et al, 2005). En esta tesis se ha encontrado evidencia para el dónde, el qué y el cuándo del evento recordado en la búsqueda y localización del alimentos de los monos caí. Coincidiendo con Gazzaniga, el ajuste de intervalos de revisita no es fruto de una experiencia repetitiva, dado que las condiciones de cada árbol cambian constantemente en función del tiempo. Estas observaciones abren la pregunta sobre la existencia de memoria de tipo episódica en los capuchinos, y plantean la posibilidad de estudios futuros sobre la capacidad de discernir de manera precisa entre diferentes frutas e incluso de recordar quién intervino en un evento de alimentación pasado.

Concluyendo, una reflexión final: en los últimos años ha existido una tendencia a explicar todas las semejanzas y diferencias entre especies mediante semejanzas y diferencias genéticas. Sin embargo, los genes están a merced de nuestro comportamiento, no al contrario. Lo que consigue que se establezcan las asociaciones de Pavlov está hecho de la misma materia que los cromosomas que transportan la herencia. El fenómeno de la memoria a nivel molecular parece ser totalmente hebbiano. Lo que Donald Hebb proponía en 1949 era que el aprendizaje consistía en fortalecer las conexiones neuronales que se utilizaban con mayor frecuencia. Imitar, manipular y hablar son tres cosas que los seres humanos hacen especialmente. No es que sean elementos centrales de la cultura: son la cultura. Pero, lo que es aún más importante, "esos tres elementos acercan entre sí los pensamientos de otras mentes: 
externalizan la memoria" (Ridley, 2004, p. 249). La sofisticación cognitiva de los primates puede ser producto de su elevada encefalización, que se origina en las adaptaciones especiales necesarias para afrontar las condiciones ecológicas de los hábitats que ocupan (Zuberbühler \& Janmaat, 2010).

En su libro, Ridley (2004) nos muestra que "cuanto más sabemos de los genes que influyen en la conducta, más encontramos que funcionan a través del ambiente, y cuanto más encontramos que aprenden los animales, más descubrimos que el aprendizaje se realiza a través de los genes" (pp. 312). Esto es lo que lleva a que numerosos investigadores en la actualidad tomen en consideración que los factores genéticos acompañan a los culturales en la producción de diversidad entre y dentro de las poblaciones humanas (Borgerhoff Mulder et al., 2006). En definitiva, en el estudio de otros primates, pueden encontrarse las características que nos asemejan más allá de nuestra diversidad genómica y cultural.

\section{4 Referencias}

Baddeley, A. D. \& G. Hitch. 1974. Working memory. University of Striling, Scotland.

Basile, B. M., Hampton, R. R., Suomi, S. J. \& E. A. Murray. 2009. An assessment of memory awareness in tufted capuchin monkeys (Cebus apella). Anim. Cogn., 12 (1): 169-180.

Bateson, G. 1974. Observations of a cetacean community (Pp. 146-167). En: J. Mclntyre, ed. Mind in the waters. Charles Scribner's Sons, New York, NY.

Bonnie, K. E. \& F. B. M. de Waal. 2007. Coping without rewards: socially influenced foraging decisions among brown capuchin monkeys. Animal Cognition. 10: 283-292.

Borgerhoff Mulder, M., Nunn, C. L. \& M. C. Towner. 2006. Cultural Macroevolution and the transmission of traits. Evolutionary Anthropology, 15 (2): 52-64.

Bourjade, M., Thierry, B. Call, J. \& V. Dufour. 2012. Are monkeys able to plan for future exchange? Animal Cognition. En prensa.

Byrne, R. W. 2000. Evolution of primate cognition. Cognitive Science, 24 (3): 543-570.

Clayton, N. S., Bussey, T. J. \& A. Dickinson. 2003. Can animals recall the past and plan for the future? Nature Reviews, 4: 685-691.

Corlett, R. T. 2011. How to be a frugivore (in a changing world). Acta Oecologica, 37: 674-681.

de Waal, F. 1991. Complementary methods and convergent evidence in the study of primate social cognition. Behaviour, 118: 297-320.

Flores-Abreu, I. N. Hurly, T. A. \& S. D. Healy. 2012. One-trial spatial learning: wild hummingbirds relocate a reward after a single visit. Animal Cognition. En prensa

Gazzaniga, M. S. 2010. ¿Qué nos hace humanos? La explicación científica de nuestra singularidad como especie. Ed. Paidós: Barcelona.

Gentner, D. 2007. Spatial cognition in apes and humans. Trends in Cognitive Sciences, 11 (5): 192-194. 
González-Gómez, P., Bozinovic, F. \& R. A. Vásquez. 2011. Elements of episodic-likem memory in free-living hummingbirds, energetic consequences. Animal Behaviour, 81: 12571262.

Hampton, R. R., Hampstead, B. M. \& E. A. Murray. 2005. Rhesus monkeys (Macaca mulatta) demostrate robust memory for what and where, but not when, in an opne-field test of memory. Learning and Motivation, 36: 245-259.

Hebb, D. O. 1949. Organization of behavior. New York: Wiley.

Hermer-Vazquez, L., Moffet, A. \& P. Munkholm. 2001. Language, space, and the development of cognitive flexibility in humans: the case of two spatial memory tasks. Cognition, 79 (3): 263-299.

Janmaat, K. R. L. \& R. L. Chancellor. 2010. Exploring new areas: how important is long-term spatial memory for Mangabey (Lophocebus albigena johnstonii) foraging efficiency? Int J Primatol, 31: 863-886.

Keller, J. D. 2004. Human Cognitive Ecology: An Instructive Framework for Comparative Primatology. Am. J. Primatol., 62: 229-241.

Lahitte, H. B. \& M. P. Tujague. 2007. El conocimiento Etológico como fantasma de la Biología y su importancia para los estudios comparados. Revista Antípoda, 5: 317-332.

MacKinnon, K. C. 2013. Chapter 17: Ontogeny of social behavior in the genus Cebus and the application of an integrative framework for examining plasticity and complexity in evolution. En: K.B.H. Clancy et al. (eds.), Building babies: primate development in proximate and ultimate perspective. Developments in primatology: progress and prospects 37, Springer Science+Business Media: New York (pp. 387-408).

Nakagawa, S. \& I. C. Cuthill. 2007. Effect size, confidence interval and statistical significance: a practical guide for biologists. Biol. Rev., 82: 591-605.

Ridley, Matt. 2004. Qué nos hace humanos. Editorial Taurus: Madrid.

Schwartz, B. L. \& S. Evans. 2001. Episodic memory in primates. Am. J. Primatol., 55:71-85.

Wallace, R. 1989. Cognitive mapping and the origin of language and mind. Current Anthropology, 30 (4): 518-526.

Watanabe, S. \& L. Huber. 2006. Animal logics: Decisions in the absence of human language. Anim Cogn, 9: 235-245.

Zuberbühler, K. \& K. Janmaat. 2010. Chapter 4: Foraging cognition in nonhuman primates. En: M. Platt and A. Ghazanfar (Eds): Primate Neuroethology (pp. 64-83). Oxford University Press. 


\section{ANEXO I}

Actos de conducta adicionales:

\section{Categoría 1 - Comportamientos dirigidos a conespecíficos}

\section{Eventos}

Juego (P - Play): difícil de definir. Puede ser juego solitario (dirigido a objetos u otros animales), o entre 2 o más individuos. Generalmente juveniles e infantes, pero puede darse entre un adulto e infantes. Implica desplazarse de un lado a otro de forma repetitiva, tocándose y agarrándose entre si, hasta mordiéndose unos a otros, colgando de ramas, ya sea por la cola o las extremidades. Se parece a una lucha (ver Anexo Videos).

Serbena \& Leite de Araujo Monteiro-Filho (2002) ofrecen una detallada definición de comportamientos incluidos en la categoría de juego social.

Acicalamiento (G - Grooming): con manos y/o boca, manipular el pelaje de otro individuo (cualquier parte del cuerpo), y retirar del mismo ectoparásitos (al menos ejecutar la acción). El individuo puede hacer o recibirlo (ver Anexo Videos).

Display de encuentro (DE): entre dos individuos, realizan movimientos del cuerpo hacia los laterales, tocándose el vientre del tronco, al tiempo que se emiten vocalizaciones de manera simultánea. Se van acercando hasta hacer contacto físico, llegando incluso a rodearse con los brazos el uno y el otro (ver Anexo Videos).

Vocalizar: Su descripción excede la finalidad de la presente tesis. Sin embargo, el aprendizaje y la identificación de las vocalizaciones más comunes dentro de los grupos de monos son de gran ayuda para el trabajo en el campo. Se definirán de manera general como la acción de emitir sonidos con la boca. Es por esto que se identificaron las siguientes: llamadas de comida (para una descripción detallada ver Di Bitetti 2003, Di Bitetti 2005; ver Anexo Videos), alarmas de depredadores (para una descripción detallada ver Wheeler 2010), llamadas de perdido, llamadas de encuentro con otros grupos, notas de contacto, trinos de infantes.

Fragaszy, Visalberghi \& Fedigan (2004) ofrecen un etograma de comportamientos sexuales de capuchinos (Pp. 222). Y en el capítulo 6 /Desarrollo), se encuentra una descripción de los comportamientos de crianza y relación madre-cría.

\section{Categoría 2 - comportamientos autodirigidos}

\section{Eventos}

Autoacicalamiento (SG - Selfgrooming): idem acicalamiento, pero el individuo que ejecuta lo hace sobre si mismo. 
Rascado (SC - Scratching): realizar movimientos continuos de ascenso y descenso con uno de los pies o manos mientras contacta con alguna parte del cuerpo.

1. Rascado 1: rasca con pie derecho o izquierdo la región anterior del cuerpo: dorsal o ventral. El miembro posterior del pie a utilizar está estirado en ángulo. La postura que antecede a esta pauta es en general la de "sentada de gato", "sentado a favor de la rama" o "sentado perpendicular a la rama" (ver Anexo Videos).

2. Rascado 2: rasca con el pie la axila o el miembro anterior del mismo lado del cuerpo.

3. Rascado 3: rasca con el pie la cabeza (ya sea la trompa y las orejas) o el cuello.

4. Rascado 4: rasca con miembro anterior la región dorsal o ventral del cuerpo (ver Anexo Videos, Figura I.1).

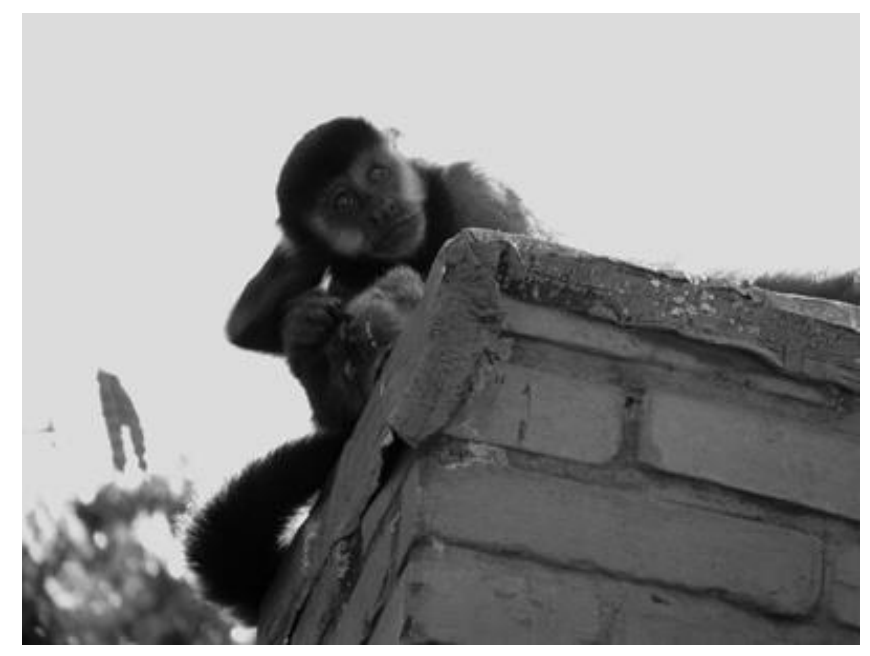

Figura I.1: Rascado (M. P. Tujague)

Orinar ( $\mathbf{U}$ - Urinate): parado en 4 patas en un tronco por encima del suelo, ubica la cola horizontal sin apoyo y en línea con el cuerpo, y elimina la orina sin alterar la posición de los miembros y la cola.

Baño de orina (UW - Urine-Washing): orinar sobre manos y/0 pies y pasar luego las mismas sobre el cuerpo (Campos et al., 2007 - ver Anexo Videos).

Fricción o roce de pelo (FR - Fur Rubbing): tomar un miriápodo con ambas manos y frotarlas una contra la otra manteniendo el miriápodo entre ellas, o bien frotarlos contra alguna superficie cercana (tronco o ramas de un árbol). Luego tomar el miriápodo con una de las manos y frotarlo contra los brazos, piernas o laterales del tronco. Algunos de los eventos de fur rubbing que observé en los grupos de estudio en vida libre finalizaron con la ingesta del miriápodo por parte del individuo que ejecutó la pauta. Este comportamiento ha sido descripto para C. capucinus (Baker, 1996; Leca et al., 2007; Verderane et al., 2007). Los autores consideran que su función es la de controlar ectoparásitos, dadas las propiedades urticantes de los fluidos corporales de los miriápodos utilizados. En cautiverio observé a los individuos realizar las mismas 
acciones utilizando un trozo de cebolla o pasarse agua con lavandina de la misma manera, con manos y pies por el cuerpo.

Defecar (DF - Defecate): parado en 4 patas en un tronco por encima del suelo, ubica la cola horizontal sin apoyo y la va elevando a medida que elimina las heces por el ano.

Estirarse: luego de descansar, el individuo se para en 4 patas y estira sus miembros anteriores al tiempo que desciende la parte anterior del tronco y la cabeza, mientras dirige la zona posterior del tronco hacia atrás y arriba. Cola colgando.

\section{Bibliografía}

Campos, F., Manson, J. H. \& S. Perry. Urine washing and sniffing in wild white-faced capuchins (Cebus capucinus): testing functional hypotheses. International Journal of Primatology, 28 (1): 55-72.

Baker, M. 1996. Fur rubbing: use of medicinal plants by capuchin monkeys (Cebus capuccinus). Amercan Journal of Primatology, 38: 263-270.

Di Bitetti, M. S. 2003. Food-associated calls of tufted capuchin monkeys (Cebus apella nigritus) are functionally referential signals. Behaviour 140 (5): 565-592.

Di Bitetti, M. S. 2005. Food-associated calls and audience effects in tufted capuchin monkeys, Cebus apella nigritus. Animal Behaviour 69: 911-919.

Fragaszy, D.M; Visalberghi, E. \& L.M. Fedigan. 2004. The complete capuchin: The Biology of the Genus Cebus. Cambridge University Press. United Kingdom.

Leca, J-B., Gunst, N. \& O. Petit. 2007. Social aspects of fur-rubbing in Cebus capucinus and C. Apella. Int J Primatol., 28:801-817.

Verderane, M. P., Falótico, T., Resende, B. D., Labruna, M. B., Izar, P. \& E. B. Ottoni. 2007. International Journal of Primatology, 28 (1): 47-53.

Wheeler, B. 2010. Production and perception of situationally variable alarm calls in wild tufted capuchin monkeys (Cebus apella nigritus). Behav Ecol Sociobiol 64:989-1000. 


\section{ANEXO II}

\section{Lista código comportamientos para el registro posterior de datos*}

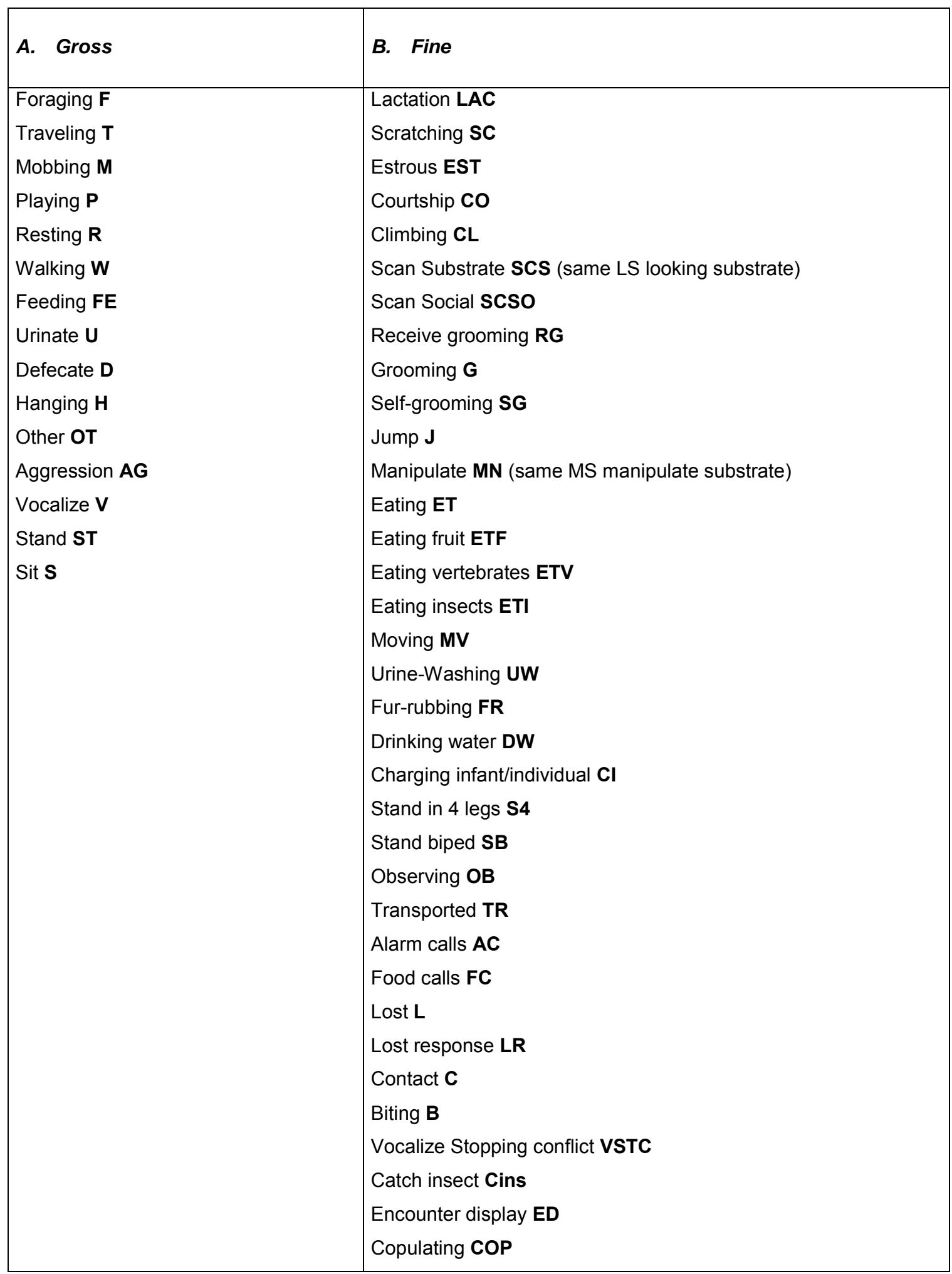

*El idioma escogido para el código fue el inglés debido a la presencia de asistentes extranjeros durante el trabajo de campo. Para facilitar el manejo del código por parte de todos los participantes procedí a utilizar el idioma mundial para publicaciones cientificas. 


\section{ANEXO III}

Valores del Índice de Performance de Memoria Espacial (IPME) y estadísticos promedio, desvío estándar e intervalo de confianza al 95\% de confiabilidad para cada individuo por ensayo dentro de los períodos experimentales de memoria de corto plazo 1 (MCP1), memoria de corto plazo 2 (MCP2) e inversión de los contenedores (INV).

\section{Grupo Jaula}

Tabla III.1: IPME Período experimental MCP1 Jaula

\begin{tabular}{|l|l|l|l|l|l|l|l|l|l|l|}
\hline Individuos & $\begin{array}{l}\text { GOR } \\
(1)\end{array}$ & $\begin{array}{l}\text { CE } \\
(2)\end{array}$ & $\begin{array}{l}\text { EU } \\
(3)\end{array}$ & $\begin{array}{l}\text { TO } \\
(4)\end{array}$ & $\begin{array}{l}\text { CH } \\
(5)\end{array}$ & $\begin{array}{l}\text { PU } \\
(6)\end{array}$ & $\begin{array}{l}\text { DIE } \\
(7)\end{array}$ & $\begin{array}{l}\text { NI } \\
(8)\end{array}$ & $\begin{array}{l}\text { MANU } \\
(9)\end{array}$ & $\begin{array}{l}\text { RO } \\
(10)\end{array}$ \\
\hline Ensayos & & & & & & & & & & \\
\hline 1 & 0 & S/D & 1 & 0,3 & 0 & 0,5 & 1 & 0,33 & $-0,27$ & 1 \\
\hline 2 & 0,6 & -1 & S/D & 0,25 & 0,3 & $-0,05$ & 0,33 & $-0,22$ & $-0,14$ & 1 \\
\hline 3 & 0,67 & 1 & 0 & 0,38 & 0,2 & 0,47 & 0,6 & 0,28 & 0 & 0,4 \\
\hline 4 & 1 & 0,6 & 0,4 & 0,6 & S/D & 0,64 & 0,42 & 0,75 & 1 & 0,71 \\
\hline 5 & 0 & 1 & S/D & 0,28 & 0,63 & 0,04 & 1 & $-0,17$ & 0,09 & 0,2 \\
\hline 6 & 1 & S/D & 1 & 0,14 & 1 & 0,22 & $-0,25$ & 0,06 & 0,33 & 0,56 \\
\hline 7 & $-0,3$ & S/D & 0,2 & 0,23 & 1 & 0,42 & 0,4 & 0,2 & 0,57 & 0,27 \\
\hline 8 & 1 & 0 & -1 & 1 & 0,6 & 1 & 0,6 & 1 & 0,5 & 1 \\
\hline 9 & 0,6 & 0,6 & 1 & 0,8 & 0,67 & 0,5 & 1 & 0,5 & 0,71 & 0,7 \\
\hline 10 & 0 & 0,5 & 1 & 0,27 & 1 & 0,25 & 0,67 & 0,07 & 1 & 0,46 \\
\hline 11 & 0,3 & 0 & 1 & 1 & 1 & 0,78 & 1 & 0,5 & $-0,2$ & 0,63 \\
\hline 12 & S/D & 1 & 1 & 0,6 & 1 & 0,6 & 0,5 & 1 & 0,2 & 0,6 \\
\hline 13 & 0,3 & 0,67 & S/D & 0,3 & 1 & 0,42 & 1 & 0 & 1 & 1 \\
\hline 14 & 0 & 1 & S/D & $-0,2$ & S/D & 0,27 & 1 & $-0,2$ & 0,16 & 0,42 \\
\hline 15 & 1 & S/D & S/D & 0,5 & -1 & 0,5 & 0 & 0,3 & $-0,14$ & 0,5 \\
\hline $\mathrm{N}$ & 14 & 11 & 10 & 15 & 13 & 15 & 15 & 15 & 15 & 15 \\
\hline
\end{tabular}

Referencias: $S / D=$ sin datos.

Tabla III.2: IPME Período experimental MCP2 Jaula

\begin{tabular}{|c|c|c|c|c|c|c|c|c|c|}
\hline $\begin{array}{l}\text { Individuos } \\
\text { Ensayos }\end{array}$ & $\begin{array}{l}\text { GOR } \\
\text { (1) }\end{array}$ & $\begin{array}{l}\mathrm{CE} \\
(2)\end{array}$ & $\begin{array}{l}\text { TO } \\
\text { (4) }\end{array}$ & $\begin{array}{l}\mathrm{CH} \\
(5)\end{array}$ & $\begin{array}{l}\mathrm{PU} \\
\text { (6) }\end{array}$ & $\begin{array}{l}\text { DIE } \\
\text { (7) }\end{array}$ & $\begin{array}{l}\mathrm{NI} \\
(8)\end{array}$ & $\begin{array}{l}\text { MANU } \\
\text { (9) }\end{array}$ & $\begin{array}{l}\mathrm{RO} \\
(10)\end{array}$ \\
\hline 1 & 0,78 & 0,6 & 0,3 & 0,41 & 0,47 & 0,78 & 0,71 & 0,45 & 0,62 \\
\hline 2 & 0,67 & 0,3 & 1 & 0,8 & 0,78 & 0,78 & 0,67 & 0,4 & 0,83 \\
\hline 3 & 0,6 & 0,3 & 0,68 & 0,3 & 0,71 & 0,56 & 0,4 & 0,78 & 0,85 \\
\hline 4 & 0,56 & 0,5 & 0,63 & 0,63 & 1 & 1 & 1 & 0,67 & 1 \\
\hline 5 & 0 & 0,5 & 0,83 & 0,2 & 1 & 0,78 & 0,3 & 0,6 & 0,87 \\
\hline 6 & 0,71 & 0 & 1 & 1 & 0,63 & 1 & 1 & 0,78 & 1 \\
\hline 7 & 0,42 & 0,3 & 1 & 0,6 & 0,71 & 1 & 1 & 0,71 & 1 \\
\hline 8 & 0,42 & 0,5 & 0,57 & 0,61 & 0,75 & 1 & 0,5 & $-0,05$ & 0,81 \\
\hline 9 & 0,6 & 0 & 0,5 & 0,2 & 0,75 & 1 & 0,5 & 0,53 & 1 \\
\hline 10 & 0,75 & 1 & 0,73 & 0,57 & 1 & 1 & 0,63 & 1 & 1 \\
\hline 11 & 0,6 & 0,3 & 0,69 & 1 & 1 & 0,6 & 1 & 0,69 & 1 \\
\hline 12 & 1 & 1 & 1 & 1 & 1 & 1 & 0,56 & 0,78 & 1 \\
\hline 13 & 1 & 0,5 & 0,78 & 1 & 0,81 & 1 & 0,67 & 0,6 & 1 \\
\hline 14 & 0,5 & $-0,2$ & 1 & 1 & 1 & 1 & 1 & 1 & 1 \\
\hline 15 & 1 & 1 & 1 & 0,76 & 1 & 1 & 1 & 0,87 & 1 \\
\hline$N$ & 15 & 15 & 15 & 15 & 15 & 15 & 15 & 15 & 15 \\
\hline
\end{tabular}


Tabla III.3: IPME Período experimental INV Jaula

\begin{tabular}{|c|c|c|c|c|c|c|c|c|c|}
\hline $\begin{array}{l}\text { Individuos } \\
\text { Ensavos }\end{array}$ & $\begin{array}{l}\text { GOR } \\
(1)\end{array}$ & $\begin{array}{l}\text { CE } \\
(2)\end{array}$ & $\begin{array}{l}\text { TO } \\
(4)\end{array}$ & $\begin{array}{l}\mathrm{CH} \\
(5)\end{array}$ & $\begin{array}{l}\text { PU } \\
\text { (6) }\end{array}$ & $\begin{array}{l}\text { DIE } \\
(7)\end{array}$ & $\begin{array}{l}\mathrm{NI} \\
\text { (8) }\end{array}$ & $\begin{array}{l}\text { MANU } \\
(9)\end{array}$ & $\begin{array}{l}\text { RO } \\
(10)\end{array}$ \\
\hline 1 & 0 & 0,14 & 0,06 & 0,09 & 0,2 & 0,5 & 0 & $-0,12$ & 0,1 \\
\hline 2 & 0,6 & $S / D$ & 0,42 & 0,71 & 0,14 & 0,3 & 0,71 & 0,6 & 0,06 \\
\hline 3 & 0,33 & $-0,25$ & 0,27 & 0,71 & 0,36 & 0 & 0,38 & 0 & 0,3 \\
\hline 4 & 1 & $-0,2$ & 0,17 & 0,5 & 0,27 & 0,1 & 0,64 & 0,47 & 0,4 \\
\hline 5 & 0,33 & 0,6 & 0,56 & 0,5 & 0,5 & 0,42 & 0,53 & 0,3 & $-0,09$ \\
\hline 6 & 1 & 0,2 & 0,28 & 0,56 & 0,1 & 0,6 & 0,4 & 0,29 & 0 \\
\hline 7 & 1 & $-0,14$ & 1 & 1 & 0,8 & 1 & 0,87 & 0,71 & 0,67 \\
\hline 8 & $-0,14$ & $-0,67$ & 0,17 & 0,4 & 0,37 & 0,2 & 0,8 & 0,5 & 0,42 \\
\hline 9 & 0,6 & 0 & 0,12 & 1 & 1 & 0,71 & 0,61 & 0,8 & 0,5 \\
\hline 10 & 0,6 & $-0,33$ & 0,63 & 1 & 0,2 & 0 & 0,5 & 0,14 & 0 \\
\hline 11 & 1 & 0,14 & 1 & 1 & 0,2 & 0,5 & 0,5 & 0,8 & 0,56 \\
\hline 12 & 0,71 & 0,5 & 1 & 1 & 0,89 & 0,71 & 0,8 & 0,83 & 0,73 \\
\hline 13 & 0 & 0,33 & 0,67 & * & 1 & 1 & 1 & 0,67 & 0,6 \\
\hline 14 & 1 & 1 & 0,75 & * & 0,4 & 0 & 0,47 & 0,56 & 0,71 \\
\hline 15 & 1 & 0,56 & 0,71 & * & 0,3 & 1 & 0,78 & 0,5 & 1 \\
\hline $\mathrm{N}$ & 15 & 14 & 15 & 12 & 15 & 15 & 15 & 15 & 15 \\
\hline
\end{tabular}

Referencias: * ya no estaba presente en el grupo.

Tabla III.4: IPME Períodos MLP1 y MLP2 Jaula

\begin{tabular}{|l|r|r|}
\hline Individuo & MLP1 & MLP2 \\
\hline GOR (1) & 0,78 & 1 \\
\hline CE (2) & 0,6 & 1 \\
\hline TO (4) & 0,3 & 0,2 \\
\hline CH (5) & 0,41 & 0,1 \\
\hline PU (6) & 0,47 & 1 \\
\hline DIE (7) & 0,78 & 1 \\
\hline NI (8) & 0,71 & 1 \\
\hline MANU (9) & 0,53 & 0,78 \\
\hline RO (10) & 0,62 & 0,67 \\
\hline N & 9 & 9 \\
\hline
\end{tabular}




\section{Grupo Isla}

Tabla III.5: IPME Período experimental MCP1 Isla

\begin{tabular}{|l|l|l|l|l|l|l|}
\hline \multirow{2}{*}{ Individuo } & $\begin{array}{l}\text { ÑO } \\
(1)\end{array}$ & $\begin{array}{l}\text { ALE } \\
(2)\end{array}$ & $\begin{array}{l}\text { MAMI } \\
(3)\end{array}$ & $\begin{array}{l}\text { MAT } \\
(4)\end{array}$ & $\begin{array}{l}\text { FER } \\
(5)\end{array}$ & $\begin{array}{l}\text { JU } \\
(6)\end{array}$ \\
\cline { 1 - 4 } Ensayo & 0,6 & 0,5 & 0,63 & 0,28 & 0,2 & 1 \\
\hline 1 & 0,25 & $-0,25$ & 0,63 & 0,46 & 0 & -1 \\
\hline 2 & 0,3 & 1 & 0,6 & $-0,06$ & 0,3 & 0,6 \\
\hline 3 & 0,14 & 0,4 & 0,56 & 0,15 & 0,5 & 1 \\
\hline 4 & $-0,2$ & 0,5 & 1 & 0,4 & $-0,2$ & 0,6 \\
\hline 5 & 0,14 & 0,6 & 0,3 & 0,14 & $-0,14$ & -1 \\
\hline 6 & 0 & 1 & 0,53 & $-0,1$ & 1 & S/D \\
\hline 7 & 0,67 & 0,2 & 1 & 0,25 & $-0,3$ & 1 \\
\hline 8 & $-0,09$ & 0 & 0 & 0,1 & -1 & 1 \\
\hline 9 & $-0,26$ & 1 & 0,52 & 0,3 & $-0,14$ & 1 \\
\hline 10 & 0,6 & 0,3 & 0,5 & 0,3 & 0,09 & 1 \\
\hline 11 & 0,09 & 1 & 0,5 & 0,17 & 0,09 & 0,3 \\
\hline 12 & 12 & 12 & 12 & 12 & 12 & 11 \\
\hline $\mathrm{N}$ & & & & & \\
\hline
\end{tabular}

Referencias: S/D sin datos.

Tabla III.6: IPME Período experimental MCP2 Isla

\begin{tabular}{|l|l|l|l|l|l|}
\cline { 1 - 4 } Individuo & $\begin{array}{l}\text { NO } \\
(1)\end{array}$ & $\begin{array}{l}\text { ALE } \\
(2)\end{array}$ & $\begin{array}{l}\text { MAMI } \\
(3)\end{array}$ & $\begin{array}{l}\text { FER } \\
(5)\end{array}$ & $\begin{array}{l}\text { JU } \\
(6)\end{array}$ \\
\cline { 1 - 5 } Ensayo & $-0,47$ & 1 & 0,3 & 0,29 & 0,12 \\
\hline 1 & $-0,14$ & $-0,14$ & 0,3 & 0,23 & 0,3 \\
\hline 2 & $-0,1$ & 0,2 & 0,6 & 0,2 & 0,52 \\
\hline 3 & $-0,02$ & 0,71 & 0,3 & 0,17 & 0,45 \\
\hline 4 & $-0,4$ & 1 & 0 & 0 & 0,8 \\
\hline 5 & 0,25 & 0,25 & 0,2 & $-0,6$ & 0,4 \\
\hline 6 & 0,1 & 0,3 & 0,5 & $-0,14$ & 0,3 \\
\hline 7 & 0 & 1 & 0,67 & 0,3 & 0,6 \\
\hline 8 & $-0,3$ & 0,2 & 0,71 & $-0,14$ & 0,78 \\
\hline 9 & 9 & 9 & 9 & 9 & 9 \\
\hline $\mathrm{N}$ & & & & \\
\hline
\end{tabular}

Tabla III.7: IPME Período experimental INV Isla

\begin{tabular}{|l|l|l|l|l|l|}
\hline Individuo & $\begin{array}{l}\text { NO } \\
(1)\end{array}$ & $\begin{array}{l}\text { ALE } \\
(2)\end{array}$ & $\begin{array}{l}\text { MAMI } \\
(3)\end{array}$ & $\begin{array}{l}\text { FER } \\
(5)\end{array}$ & $\begin{array}{l}\text { JU } \\
(6)\end{array}$ \\
\cline { 1 - 5 } Ensayo & $-0,3$ & $-0,4$ & $-0,5$ & 0,09 & 0,29 \\
\hline 1 & 0,14 & $-0,3$ & 1 & 0 & 0,67 \\
\hline 2 & $-0,2$ & 0,3 & 0,2 & 0,5 & 0,14 \\
\hline 3 & 0,3 & 0,3 & 0,5 & 0,42 & 0 \\
\hline 4 & 0,5 & 0,5 & 0,42 & $-0,07$ & 1 \\
\hline 5 & 0,75 & 0,6 & 0,6 & $-0,12$ & 0,63 \\
\hline 6 & 0,3 & 0,6 & 0,3 & 0,23 & 1 \\
\hline 7 & 0,3 & 1 & 1 & 0,38 & 1 \\
\hline 8 & $-0,1$ & 1 & 1 & 1 & 1 \\
\hline 9 & 0 & 0 & 0,3 & 0,2 & 1 \\
\hline 10 & 10 & 10 & 10 & 10 & 10 \\
\hline $\mathrm{N}$ & & & & \\
\hline
\end{tabular}


Tabla III.8: IPME Período MLP1 y MLP2 Isla

\begin{tabular}{|l|r|r|}
\hline Individuo & MLP1 & MLP2 \\
\hline$\tilde{N} O(1)$ & $-0,06$ & 0,09 \\
\hline ALE (2) & 0,5 & 0,5 \\
\hline MAMI (3) & 0,2 & S/D \\
\hline FER (5) & $-0,21$ & $-0,2$ \\
\hline JU (6) & 0,68 & $-0,6$ \\
\hline N & 5 & 5 \\
\hline
\end{tabular}




\section{ANEXO IV}

Promedios, desvío estándar, valores mínimo y máximo del intervalo de confianza al 95\% de confiabilidad, y rango para el Índice de Performance de Memoria Espacial (IPME) por sexo y categoría de edad para cada ensayo dentro de cada período experimental.

\section{Grupo Jaula}

Tabla IV.1: IPME por sexo para cada ensayo (Período MCP1 Jaula)

\begin{tabular}{|c|c|c|c|c|c|c|c|}
\hline ENS & SEXO & Promedio & $\mathrm{N}$ & Desvío & Mínimo & Máximo & Rango \\
\hline \multirow[t]{2}{*}{1} & Macho & 0,14 & 6 & 0,28 &,- 27 &, 50 & ,77 \\
\hline & Hembra & 1 & 3 & 0 & 1,00 & 1,00 &, 00 \\
\hline \multirow[t]{2}{*}{2} & Macho & 0,12 & 6 & 0,31 &,- 22 &, 60 & ,82 \\
\hline & Hembra & 0,1 & 3 & 1 & $-1,00$ & 1,00 & 2,00 \\
\hline \multirow[t]{2}{*}{3} & Macho & 0,3 & 6 & 0,23 & ,00 & ,67 & 67 \\
\hline & Hembra & 0,5 & 4 & 0,4 &, 00 & 1,00 & 1,00 \\
\hline \multirow[t]{2}{*}{4} & Macho & 0,79 & 5 & 0,19 & ,60 & 1,00 & ,40 \\
\hline & Hembra & 0,54 & 4 & 0,13 & ,43 & ,71 & ,29 \\
\hline \multirow[t]{2}{*}{5} & Macho & 0,14 & 6 & 0,28 &,- 18 & 64 & 81 \\
\hline & Hembra & 0,73 & 3 & 0,46 & ,20 & 1,00 &, 80 \\
\hline \multirow[t]{2}{*}{6} & Macho & 0,46 & 6 & 0,42 & ,07 & 1,00 & ,93 \\
\hline & Hembra & 0,43 & 3 & 0,63 &,- 25 & 1,00 & 1,25 \\
\hline \multirow[t]{2}{*}{7} & Macho & 0,34 & 6 & 0,44 &,- 33 & 1,00 & 1,33 \\
\hline & Hembra & 0,3 & 3 & 0,13 & ,20 & , 45 & ,25 \\
\hline \multirow[t]{2}{*}{8} & Macho & 0,85 & 6 & 0,23 &, 50 & 1,00 &, 50 \\
\hline & Hembra & 0,15 & 4 & 0,86 & $-1,00$ & 1,00 & 2,00 \\
\hline \multirow[t]{2}{*}{9} & Macho & 0,58 & 6 & 0,13 & ,43 & ,80 & ,37 \\
\hline & Hembra & 0,84 & 4 & 0,19 &, 60 & 1,00 &, 40 \\
\hline \multirow[t]{2}{*}{10} & Macho & 0,38 & 6 & 0,39 & ,00 & 1,00 & 1,00 \\
\hline & Hembra & 0,65 & 4 & 0,24 &, 47 & 1,00 &, 53 \\
\hline \multirow[t]{2}{*}{11} & Macho & 0,76 & 6 & 0,29 & ,33 & 1,00 & 67 \\
\hline & Hembra & 0,65 & 4 & 0,47 &, 00 & 1,00 & 1,00 \\
\hline \multirow[t]{2}{*}{12} & Macho & 0,6 & 5 & 0,48 &,- 20 & 1,00 & 1,20 \\
\hline & Hembra & 0,7 & 4 & 0,26 &, 50 & 1,00 &, 50 \\
\hline \multirow[t]{2}{*}{13} & Macho & 0,38 & 6 & 0,3 & ,00 & 1,00 & 1,00 \\
\hline & Hembra & 0,8 & 3 & 0,19 &, 67 & 1,00 & ,33 \\
\hline \multirow[t]{2}{*}{14} & Macho & 0,17 & 5 & 0,5 &,- 20 & 1,00 & 1,20 \\
\hline & Hembra & 0,8 & 3 & 0,32 &, 43 & 1,00 &, 57 \\
\hline \multirow[t]{2}{*}{15} & Macho & 0,19 & 6 & 0,69 & $-1,00$ & 1,00 & 2,00 \\
\hline & Hembra & 0,25 & 2 & 0,35 & ,00 &, 50 &, 50 \\
\hline
\end{tabular}


Memoria espacial monos caí - María Paula Tujague 2013

\begin{tabular}{|ll|r|r|r|r|r|r|}
\hline Total & Macho & 0,41 & 87 & 0,41 & $-1,00$ & 1,00 & 2,00 \\
& Hembra & 0,58 & 51 & 0,47 & $-1,00$ & 1,00 & 2,00 \\
& Total & 0,47 & 138 & 0,44 & $-1,00$ & 1,00 & 2,00 \\
\hline
\end{tabular}

Tabla IV.2: IPME por categoría de edad para cada ensayo (Período MCP1 Jaula)

\begin{tabular}{|c|c|c|c|c|c|c|c|}
\hline ENS & EDAD & Promedio & $\mathrm{N}$ & Desvío & Mínimo & Máximo & Rango \\
\hline \multirow[t]{4}{*}{1} & Adulto & 0,00 & 1 & . & , 00 & , 00 &, 00 \\
\hline & Subadulto & 0,5 & 2 & 0,7 & , 00 & 1,00 & 1,00 \\
\hline & Juvenil & 0,51 & 5 & 0,53 &,- 27 & 1,00 & 1,27 \\
\hline & Infante & 0,3 & 1 & &, 33 &, 33 &, 00 \\
\hline \multirow[t]{4}{*}{2} & Adulto & $-0,2$ & 2 & 1,13 & $-1,00$ & ,60 & 1,60 \\
\hline & Subadulto & 0,3 & 1 & . & ,33 & ,33 &, 00 \\
\hline & Juvenil & 0,18 & 5 & 0,5 &,- 22 & 1,00 & 1,22 \\
\hline & Infante & 0,25 & 1 & &, 25 & ,25 &, 00 \\
\hline \multirow[t]{4}{*}{3} & Adulto & 0,83 & 2 & 0,23 & ,67 & 1,00 & ,33 \\
\hline & Subadulto & 0,1 & 2 & 0,14 & , 00 & ,20 & ,20 \\
\hline & Juvenil & 0,35 & 5 & 0,2 & 00 & ,60 & ,60 \\
\hline & Infante & 0,38 & 1 & & ,38 & , 38 &, 00 \\
\hline \multirow[t]{4}{*}{4} & Adulto & 0,8 & 2 & 0,28 & ,60 & 1,00 & ,40 \\
\hline & Subadulto & 0,42 & 1 & . & ,43 & ,43 & ,00 \\
\hline & Juvenil & 0,7 & 5 & 0,2 & ,43 & 1,00 &, 57 \\
\hline & Infante & 0,6 & 1 & & ,60 & ,60 &, 00 \\
\hline \multirow[t]{4}{*}{5} & Adulto & 0,5 & 2 & 0,7 & , 00 & 1,00 & 1,00 \\
\hline & Subadulto & 0,63 & 1 & . & ,64 & ,64 & ,00 \\
\hline & Juvenil & 0,23 & 5 & 0,45 &,- 18 & 1,00 & 1,18 \\
\hline & Infante & 0,28 & 1 & &, 29 & ,29 &, 00 \\
\hline \multirow[t]{4}{*}{6} & Adulto & 1,00 & 1 & . & 1,00 & 1,00 &, 00 \\
\hline & Subadulto & 1,00 & 2 & 0,00 & 1,00 & 1,00 &, 00 \\
\hline & Juvenil & 0,18 & 5 & 0,3 &,- 25 &, 56 & ,81 \\
\hline & Infante & 0,14 & 1 & & , 14 & , 14 &, 00 \\
\hline \multirow[t]{4}{*}{7} & Adulto & $-0,3$ & 1 & . &,- 33 &,- 33 &, 00 \\
\hline & Subadulto & 0,6 & 2 & 0,56 & ,20 & 1,00 & ,80 \\
\hline & Juvenil & 0,38 & 5 & 0,14 & ,20 &, 57 & ,37 \\
\hline & Infante & 0,23 & 1 & &, 23 & ,23 &, 00 \\
\hline \multirow[t]{4}{*}{8} & Adulto & 0,5 & 2 & 0,7 & , 00 & 1,00 & 1,00 \\
\hline & Subadulto & $-0,2$ & 2 & 1,13 & $-1,00$ & ,60 & 1,60 \\
\hline & Juvenil & 0,82 & 5 & 0,24 &, 50 & 1,00 &, 50 \\
\hline & Infante & 1,00 & 1 & & 1,00 & 1,00 &, 00 \\
\hline
\end{tabular}




\begin{tabular}{|c|c|c|c|c|c|c|c|}
\hline \multirow[t]{4}{*}{9} & Adulto & 0,6 & 2 & 0,00 & ,60 &, 60 & ,00 \\
\hline & Subadulto & 0,83 & 2 & 0,23 & ,67 & 1,00 & ,33 \\
\hline & Juvenil & 0,64 & 5 & 0,24 & ,43 & 1,00 &, 57 \\
\hline & Infante & 0,8 & 1 & &, 80 &, 80 &, 00 \\
\hline \multirow[t]{4}{*}{10} & Adulto & 0,25 & 2 & 0,35 &, 00 &, 50 &, 50 \\
\hline & Subadulto & 1,00 & 2 & 0,00 & 1,00 & 1,00 & , 00 \\
\hline & Juvenil & 0,43 & 5 & 0,27 & ,08 & ,71 & ,64 \\
\hline & Infante & 0,27 & 1 & & ,27 &, 27 &, 00 \\
\hline \multirow[t]{4}{*}{11} & Adulto & 0,16 & 2 & 0,23 &, 00 &, 33 & ,33 \\
\hline & Subadulto & 1,00 & 2 & 0,00 & 1,00 & 1,00 & , 00 \\
\hline & Juvenil & 0,78 & 5 & 0,2 &, 50 & 1,00 &, 50 \\
\hline & Infante & 1,00 & 1 & & 1,00 & 1,00 &, 00 \\
\hline \multirow[t]{4}{*}{12} & Adulto & 1,00 & 1 & & 1,00 & 1,00 & , 00 \\
\hline & Subadulto & 1,00 & 2 & 0,00 & 1,00 & 1,00 & , 00 \\
\hline & Juvenil & 0,5 & 5 & 0,43 &,- 20 & 1,00 & 1,20 \\
\hline & Infante & 0,6 & 1 & & ,60 & ,60 &, 00 \\
\hline \multirow[t]{4}{*}{13} & Adulto & 0,5 & 2 & 0,23 & ,33 & ,67 & ,33 \\
\hline & Subadulto & 1,00 & 1 & & 1,00 & 1,00 & ,00 \\
\hline & Juvenil & 0,52 & 5 & 0,45 & , 00 & 1,00 & 1,00 \\
\hline & Infante & 0,3 & 1 & &, 33 &, 33 &, 00 \\
\hline \multirow[t]{3}{*}{14} & Adulto & 0,5 & 2 & 0,7 & , 00 & 1,00 & 1,00 \\
\hline & Juvenil & 0,5 & 5 & 0,51 &,- 20 & 1,00 & 1,20 \\
\hline & Infante & $-0,2$ & 1 & &,- 20 &,- 20 &, 00 \\
\hline \multirow[t]{4}{*}{15} & Adulto & 1,00 & 1 & & 1,00 & 1,00 & ,00 \\
\hline & Subadulto & $-1,00$ & 1 & & $-1,00$ & $-1,00$ & 00 \\
\hline & Juvenil & 0,23 & 5 & 0,29 &,- 14 &, 50 & ,64 \\
\hline & Infante & 0,5 & 1 & &, 50 &, 50 &, 00 \\
\hline \multirow[t]{5}{*}{ Total } & Adulto & 0,46 & 25 & 0,52 & $-1,00$ & 1,00 & 2,00 \\
\hline & Subadulto & 0,56 & 23 & 0,6 & $-1,00$ & 1,00 & 2,00 \\
\hline & Juvenil & 0,46 & 75 & 0,38 &,- 27 & 1,00 & 1,27 \\
\hline & Infante & 0,43 & 15 & 0,32 &,- 20 & 1,00 & 1,20 \\
\hline & Total & 0,47 & 138 & 0,4 & $-1,00$ & 1,00 & 2,00 \\
\hline
\end{tabular}

Tabla IV.3: IPME por sexo para cada ensayo (Período MCP2 Jaula)

\begin{tabular}{|ll|r|r|r|r|r|r|}
\hline ENS & SEXO & Promedio & \multicolumn{1}{|c|}{$\mathrm{N}$} & \multicolumn{1}{|c|}{ Desvío } & \multicolumn{1}{c|}{ Mínimo } & \multicolumn{1}{c|}{ Máximo } & \multicolumn{1}{c|}{ Rango } \\
\hline 1 & Macho & 0,52 & 6 & 0,18 &, 30 &, 78 &, 47 \\
& Hembra & 0,6 & 3 & 0,09 &, 60 &, 78 &, 18 \\
\hline 2 & Macho & 0,6 & 6 & 0,2 &, 40 & 1,00 &, 60 \\
& Hembra & 0,64 & 3 & 0,27 &, 33 &, 83 &, 50 \\
\hline
\end{tabular}




\begin{tabular}{|ll|r|r|r|r|r|r|}
\hline 3 & Macho & 0,58 & 6 & 0,17 &, 33 &, 78 &, 44 \\
& Hembra & 0,58 & 3 & 0,26 &, 33 &, 86 &, 52 \\
\hline 4 & Macho & 0,74 & 6 & 0,19 &, 56 & 1,00 &, 44 \\
& Hembra & 0,83 & 3 & 0,28 &, 50 & 1,00 &, 50 \\
\hline 5 & Macho & 0,49 & 6 & 0,38 &, 00 & 1,00 & 1,00 \\
& Hembra & 0,71 & 3 & 0,19 &, 50 &, 87 &, 37 \\
\hline 6 & Macho & 0,85 & 6 & 0,16 &, 64 & 1,00 &, 36 \\
& Hembra & 0,6 & 3 & 0,57 &, 00 & 1,00 & 1,00 \\
\hline 7 & Macho & 0,74 & 6 & 0,2 &, 43 & 1,00 &, 57 \\
& Hembra & 0,78 & 3 & 0,38 &, 33 & 1,00 &, 67 \\
\hline 8 & Macho & 0,46 & 6 & 0,27 &,- 05 &, 75 &, 80 \\
& Hembra & 0,7 & 3 & 0,25 &, 50 & 1,00 &, 50 \\
\hline 9 & Macho & 0,52 & 6 & 0,17 &, 22 &, 75 &, 53 \\
& Hembra & 0,67 & 3 & 0,57 &, 00 & 1,00 & 1,00 \\
\hline 10 & Macho & 0,78 & 6 & 0,18 &, 57 & 1,00 &, 43 \\
& Hembra & 1,00 & 3 & 0,00 & 1,00 & 1,00 &, 00 \\
\hline 11 & Macho & 0,83 & 6 & 0,18 &, 60 & 1,00 &, 40 \\
& Hembra & 0,64 & 3 & 0,3 &, 33 & 1,00 &, 67 \\
\hline 12 & Macho & 0,8 & 6 & 0,18 &, 56 & 1,00 &, 44 \\
& Hembra & 1,00 & 3 & 0,00 & 1,00 & 1,00 &, 00 \\
\hline 13 & Macho & 0,81 & 6 & 0,16 &, 60 & 1,00 &, 40 \\
& Hembra & 0,83 & 3 & 0,28 &, 50 & 1,00 &, 50 \\
\hline 14 & Macho & 0,91 & 6 & 0,2 &, 50 & 1,00 &, 50 \\
& Hembra & 0,6 & 3 & 0,69 &,- 20 & 1,00 & 1,20 \\
\hline 15 & Macho & 0,93 & 6 & 0,1 &, 76 & 1,00 &, 24 \\
& Hembra & 1,00 & 3 & 0,00 & 1,00 & 1,00 &, 00 \\
\hline \multirow{2}{*}{ Total } & Macho & 0,71 & 90 & 0,25 &,- 05 & 1,00 & 1,05 \\
& Hembra & 0,76 & 45 & 0,32 &,- 20 & 1,00 & 1,20 \\
& Total & 0,73 & 135 & 0,27 &,- 20 & 1,00 & 1,20 \\
\hline
\end{tabular}

Tabla IV.4: IPME por categoría de edad por ensayo (Período MCP2 Jaula)

\begin{tabular}{|ll|r|r|r|r|r|r|}
\hline ENS & EDAD & Promedio & \multicolumn{1}{|c|}{$\mathrm{N}$} & \multicolumn{1}{c|}{ Devsvío } & \multicolumn{1}{c|}{ Mínimo } & \multicolumn{1}{c|}{ Máximo } & \multicolumn{1}{c|}{ Rango } \\
\hline 1 & Adulto & 0,68 & 2 & 0,12 &, 60 &, 78 &, 18 \\
& Subadulto & 0,41 & 1 & &, 41 &, 41 &, 00 \\
& Juvenil & 0,6 & 5 & 0,14 &, 45 &, 78 &, 32 \\
& Infante & 0,3 & 1 & &, 30 &, 30 &, 00 \\
\hline
\end{tabular}




\begin{tabular}{|c|c|c|c|c|c|c|c|}
\hline \multirow[t]{4}{*}{2} & Adulto & 0,5 & 2 & 0,23 & ,33 & ,67 &, 33 \\
\hline & Subadulto & 0,8 & 1 & & ,80 & ,80 & ,00 \\
\hline & Juvenil & 0,62 & 5 & 0,19 &, 40 & ,83 & ,43 \\
\hline & Infante & 1,00 & 1 & & 1,00 & 1,00 &, 00 \\
\hline \multirow[t]{4}{*}{3} & Adulto & 0,46 & 2 & 0,18 & ,33 & ,60 & ,27 \\
\hline & Subadulto & 0,3 & 1 & &, 33 & ,33 &, 00 \\
\hline & Juvenil & 0,6 & 5 & 0,18 &, 40 &, 86 & ,46 \\
\hline & Infante & 0,68 & 1 & &, 68 &, 68 &, 00 \\
\hline \multirow[t]{4}{*}{4} & Adulto & 0,52 & 2 & 0,03 &, 50 &, 56 &, 06 \\
\hline & Subadulto & 0,63 & 1 & & ,64 &, 64 &, 00 \\
\hline & Juvenil & 0,93 & 5 & 0,14 & ,67 & 1,00 &, 33 \\
\hline & Infante & 0,63 & 1 & &, 64 &, 64 &, 00 \\
\hline \multirow[t]{4}{*}{5} & Adulto & 0,25 & 2 & 0,35 &, 00 &, 50 &, 50 \\
\hline & Subadulto & 0,2 & 1 & & ,20 &, 20 &, 00 \\
\hline & Juvenil & 0,71 & 5 & 0,25 &, 33 & 1,00 & ,67 \\
\hline & Infante & 0,83 & 1 & &, 83 & ,83 &, 00 \\
\hline \multirow[t]{4}{*}{6} & Adulto & 0,35 & 2 & 0,5 &, 00 &, 71 &, 71 \\
\hline & Subadulto & 1,00 & 1 & & 1,00 & 1,00 &, 00 \\
\hline & Juvenil & 0,8 & 5 & 0,16 &, 64 & 1,00 &, 36 \\
\hline & Infante & 1,00 & 1 & & 1,00 & 1,00 &, 00 \\
\hline \multirow[t]{4}{*}{7} & Adulto & 0,38 & 2 & 0,06 &, 33 &, 43 & , 10 \\
\hline & Subadulto & 0,6 & 1 & &, 60 &, 60 &, 00 \\
\hline & Juvenil & 0,8 & 5 & 0,15 &, 71 & 1,00 &, 29 \\
\hline & Infante & 1,00 & 1 & & 1,00 & 1,00 &, 00 \\
\hline \multirow[t]{4}{*}{8} & Adulto & 0,46 & 2 & 0,05 &, 43 &, 50 &, 07 \\
\hline & Subadulto & 0,61 & 1 & & ,62 & ,62 &, 00 \\
\hline & Juvenil & 0,6 & 5 & 0,4 &,- 05 & 1,00 & 1,05 \\
\hline & Infante & 0,57 & 1 & &, 57 &, 57 &, 00 \\
\hline \multirow[t]{4}{*}{9} & Adulto & 0,3 & 2 & 0,42 &, 00 &, 60 & 60 \\
\hline & Subadulto & 0,2 & 1 & & ,22 & ,22 &, 00 \\
\hline & Juvenil & 0,75 & 5 & 0,24 &, 50 & 1,00 &, 50 \\
\hline & Infante & 0,5 & 1 & &, 56 &, 56 &, 00 \\
\hline \multirow[t]{4}{*}{10} & Adulto & 0,87 & 2 & 0,17 &, 75 & 1,00 &, 25 \\
\hline & Subadulto & 0,57 & 1 & &, 57 &, 57 &, 00 \\
\hline & Juvenil & 0,92 & 5 & 0,16 & ,64 & 1,00 &, 36 \\
\hline & Infante & 0,73 & 1 & &, 73 &, 73 &, 00 \\
\hline \multirow[t]{4}{*}{11} & Adulto & 0,46 & 2 & 0,18 &, 33 &, 60 &, 27 \\
\hline & Subadulto & 1,00 & 1 & & 1,00 & 1,00 &, 00 \\
\hline & Juvenil & 0,85 & 5 & 0,19 & ,60 & 1,00 &, 40 \\
\hline & Infante & 0,69 & 1 & &, 69 & ,69 &, 00 \\
\hline 12 & Adulto & 1,00 & 2 & 0,00 & 1,00 & 1,00 &, 00 \\
\hline
\end{tabular}




\begin{tabular}{|c|c|c|c|c|c|c|c|}
\hline & Subadulto & 1,00 & 1 & & 1,00 & 1,00 &, 00 \\
\hline & Juvenil & 0,86 & 5 & 0,19 &, 56 & 1,00 & ,44 \\
\hline & Infante & 1,00 & 1 & & 1,00 & 1,00 &, 00 \\
\hline 13 & Adulto & 0,75 & 2 & 0,35 &, 50 & 1,00 &, 50 \\
\hline & Subadulto & 1,00 & 1 & & 1,00 & 1,00 &, 00 \\
\hline & Juvenil & 0,81 & 5 & 0,18 & ,60 & 1,00 & ,40 \\
\hline & Infante & 0,7 & 1 & &, 78 & ,78 &, 00 \\
\hline 14 & Adulto & 0,15 & 2 & 0,49 &,- 20 &, 50 & ,70 \\
\hline & Subadulto & 1,00 & 1 & & 1,00 & 1,00 &, 00 \\
\hline & Juvenil & 1,00 & 5 & 0,00 & 1,00 & 1,00 &, 00 \\
\hline & Infante & 1,00 & 1 & & 1,00 & 1,00 &, 00 \\
\hline 15 & Adulto & 1,00 & 2 & 0,00 & 1,00 & 1,00 &, 00 \\
\hline & Subadulto & 0,76 & 1 & &, 76 & ,76 &, 00 \\
\hline & Juvenil & 0,97 & 5 & 0,05 &, 87 & 1,00 & ,13 \\
\hline & Infante & 1,00 & 1 & & 1,00 & 1,00 &, 00 \\
\hline Total & Adulto & 0,54 & 30 & 0,32 &,- 20 & 1,00 & 1,20 \\
\hline & Subadulto & 0,67 & 15 & 0,29 & ,20 & 1,00 & ,80 \\
\hline & Juvenil & 0,8 & 75 & 0,2 &,- 05 & 1,00 & 1,05 \\
\hline & Infante & 0,78 & 15 & 0,21 &, 30 & 1,00 & ,70 \\
\hline & Total & 0,73 & 135 & 0,27 &,- 20 & 1,00 & 1,20 \\
\hline
\end{tabular}

Tabla IV.5: IPME por sexo para cada ensayo (Período INV Jaula)

\begin{tabular}{|ll|r|r|r|r|r|r|}
\hline ENS & SEXO & Promedio & N & \multicolumn{1}{|c|}{ Desvío } & Mínimo & Máximo & \multicolumn{1}{c|}{ Rango } \\
\hline 1 & Macho & 0,03 & 6 & 0,1 &,- 13 &, 20 &, 33 \\
& Hembra & 0,25 & 3 & 0,21 &, 11 &, 50 &, 39 \\
\hline 2 & Macho & 0,53 & 6 & 0,21 &, 14 &, 71 &, 57 \\
& Hembra & 0,2 & 2 & 0,18 &, 07 &, 33 &, 27 \\
\hline 3 & Macho & 0,34 & 6 & 0,2 &, 00 &, 71 &, 71 \\
& Hembra & 0,02 & 3 & 0,29 &,- 25 &, 33 &, 58 \\
\hline 4 & Macho & 0,51 & 6 & 0,29 &, 17 & 1,00 &, 83 \\
& Hembra & 0,1 & 3 & 0,3 &,- 20 &, 40 &, 60 \\
\hline 5 & Macho & 0,46 & 6 & 0,1 &, 33 &, 56 &, 22 \\
& Hembra & 0,31 & 3 & 0,35 &,- 09 &, 60 &, 69 \\
\hline \multirow{2}{*}{6} & Macho & 0,44 & 6 & 0,31 &, 10 & 1,00 &, 90 \\
& Hembra & 0,26 & 3 & 0,3 &, 00 &, 60 &, 60 \\
\hline 7 & Macho & 0,89 & 6 & 0,12 &, 71 & 1,00 &, 29 \\
& Hembra & 0,5 & 3 & 0,58 &,- 14 & 1,00 & 1,14 \\
\hline \multirow{2}{*}{8} & Macho & 0,34 & 6 & 0,31 &,- 14 &, 80 &, 94 \\
& Hembra & $-0,012$ & 3 & 0,57 &,- 67 &, 43 & 1,10
\end{tabular}




\begin{tabular}{|ll|r|r|r|r|r|r|}
\hline 9 & Macho & 0,69 & 6 & 0,32 &, 13 & 1,00 &, 88 \\
& Hembra & 0,4 & 3 & 0,36 &, 00 &, 71 &, 71 \\
\hline 10 & Macho & 0,51 & 6 & 0,31 &, 14 & 1,00 &, 86 \\
& Hembra & $-0,1$ & 3 & 0,19 &,- 33 &, 00 &, 33 \\
\hline 11 & Macho & 0,75 & 6 & 0,3 &, 20 & 1,00 &, 80 \\
& Hembra & 0,39 & 3 & 0,2 &, 14 &, 56 &, 41 \\
\hline 12 & Macho & 0,87 & 6 & 0,1 &, 71 & 1,00 &, 29 \\
& Hembra & 0,64 & 3 & 0,12 &, 50 &, 73 &, 23 \\
\hline 13 & Macho & 0,6 & 5 & 0,4 &, 00 & 1,00 & 1,00 \\
& Hembra & 0,64 & 3 & 0,3 &, 33 & 1,00 &, 67 \\
\hline 14 & Macho & 0,64 & 5 & 0,23 &, 44 & 1,00 &, 56 \\
& Hembra & 0,57 & 3 & 0,51 &, 00 & 1,00 & 1,00 \\
\hline 15 & Macho & 0,65 & 5 & 0,26 &, 30 & 1,00 &, 70 \\
& Hembra & 0,85 & 3 & 0,25 &, 56 & 1,00 &, 44 \\
\hline \multirow{2}{*}{ Total } & Macho & 0,5 & 87 & 0,32 &,- 14 & 1,00 & 1,14 \\
& Hembra & 0,34 & 44 & 0,39 &,- 67 & 1,00 & 1,67 \\
& Total & 0,48 & 131 & 0,36 &,- 67 & 1,00 & 1,67 \\
\hline
\end{tabular}

Tabla IV.6: IPME por categoría de edad (Período INV Jaula)

\begin{tabular}{|c|c|c|c|c|c|c|c|}
\hline ENS & EDAD & Promedio & $\mathrm{N}$ & Desvío & Mínimo & Máximo & Rango \\
\hline \multirow[t]{4}{*}{1} & Adulto & 0,07 & 2 & 0,1 & ,00 & ,14 & ,14 \\
\hline & Subadulto & 0,09 & 1 & . & ,09 & ,09 &, 00 \\
\hline & Juvenil & 0,13 & 5 & 0,23 &,- 13 &, 50 & ,63 \\
\hline & Infante & 0,06 & 1 & &, 07 &, 07 &, 00 \\
\hline \multirow[t]{4}{*}{2} & Adulto & 0,6 & 1 & . & ,60 & ,60 &, 00 \\
\hline & Subadulto & 0,71 & 1 & . & ,71 & ,71 &, 00 \\
\hline & Juvenil & 0,37 & 5 & 0,28 & ,07 & ,71 & ,65 \\
\hline & Infante & 0,42 & 1 & &, 43 &, 43 &, 00 \\
\hline \multirow[t]{4}{*}{3} & Adulto & 0,04 & 2 & 0,41 &,- 25 & ,33 &, 58 \\
\hline & Subadulto & 0,71 & 1 & . & ,71 &, 71 &, 00 \\
\hline & Juvenil & 0,21 & 5 & 0,19 & ,00 & ,38 & ,38 \\
\hline & Infante & 0,27 & 1 & & ,27 & ,27 & ,00 \\
\hline \multirow[t]{4}{*}{4} & Adulto & 0,4 & 2 & 0,84 &,- 20 & 1,00 & 1,20 \\
\hline & Subadulto & 0,5 & 1 & . &, 50 &, 50 &, 00 \\
\hline & Juvenil & 0,38 & 5 & 0,2 & ,11 & ,65 &, 54 \\
\hline & Infante & 0,16 & 1 & &, 17 &, 17 &, 00 \\
\hline \multirow[t]{3}{*}{5} & Adulto & 0,46 & 2 & 0,18 & ,33 & ,60 &, 27 \\
\hline & Subadulto & 0,5 & 1 & . &, 50 &, 50 &, 00 \\
\hline & Juvenil & 0,34 & 5 & 0,25 &,- 09 & ,54 & ,63 \\
\hline
\end{tabular}




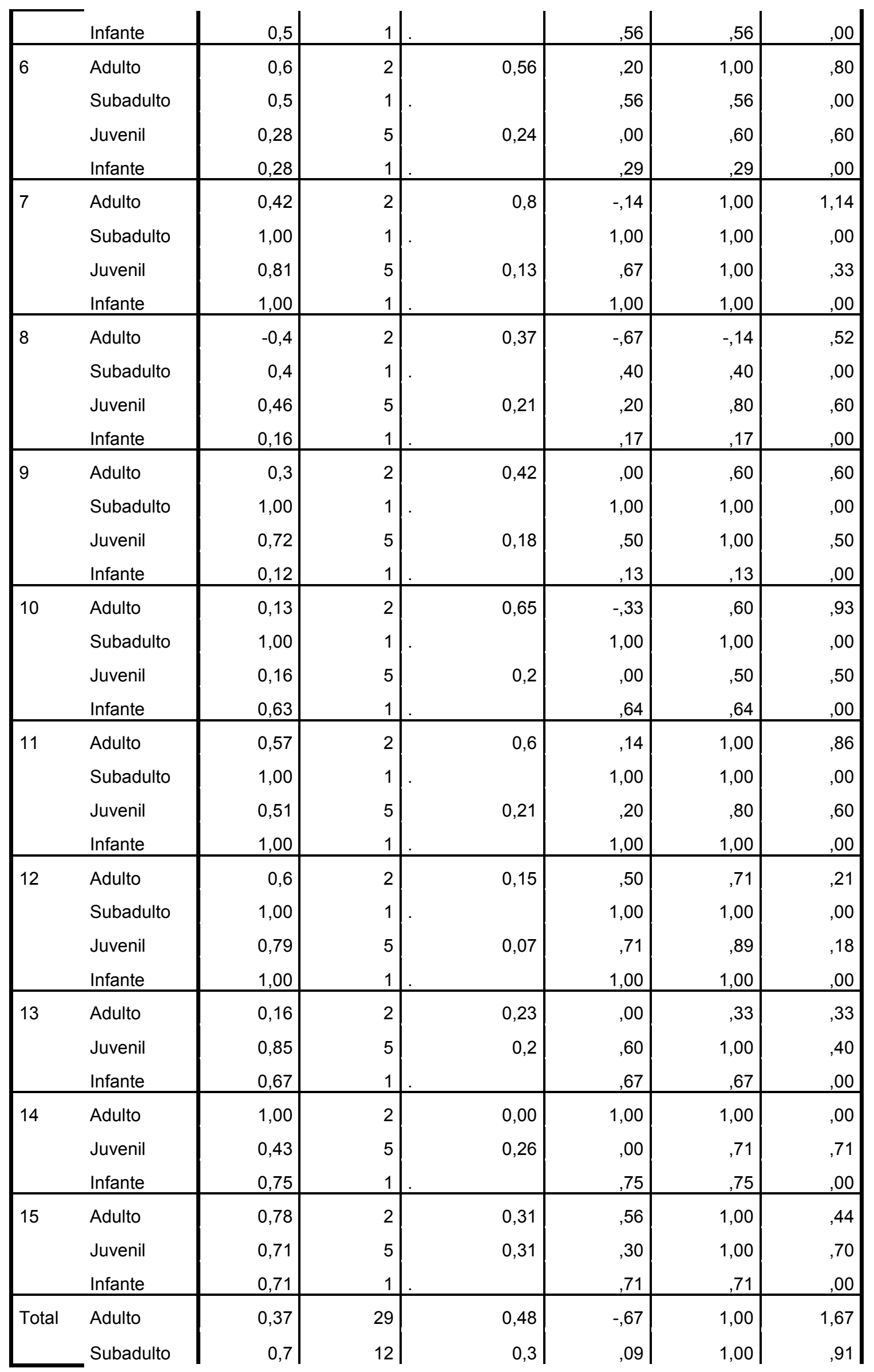




\begin{tabular}{|l|r|r|r|r|r|r|}
\hline Juvenil & 0,48 & 75 & 0,31 &,- 13 & 1,00 & 1,13 \\
Infante & 0,52 & 15 & 0,3 &, 07 & 1,00 &, 93 \\
Total & 0,48 & 131 & 0,36 &,- 67 & 1,00 & 1,67 \\
\hline
\end{tabular}

\section{Grupo Isla}

Tabla IV.7: IPME por sexo para cada ensayo (Período MCP1 Isla)

\begin{tabular}{|c|c|c|c|c|c|c|c|}
\hline ENS & SEXO & Promedio & $\mathrm{N}$ & Desvío & Mínimo & Máximo & Rango \\
\hline \multirow[t]{2}{*}{1} & Macho & 0,36 & 3 & 0,21 & ,20 & ,60 & ,40 \\
\hline & Hembra & 0,71 & 3 & 0,25 &, 50 & 1,00 &, 50 \\
\hline \multirow[t]{2}{*}{2} & Macho & 0,23 & 3 & 0,23 & ,00 & ,47 & ,47 \\
\hline & Hembra & $-0,2$ & 3 & 0,81 & $-1,00$ & ,64 & 1,64 \\
\hline \multirow[t]{2}{*}{3} & Macho & 0,2 & 3 & 0,23 &,- 07 & ,33 & ,40 \\
\hline & Hembra & 0,73 & 3 & 0,23 &, 60 & 1,00 &, 40 \\
\hline \multirow[t]{2}{*}{4} & Macho & 0,26 & 3 & 0,2 & ,14 &, 50 & ,36 \\
\hline & Hembra & 0,65 & 3 & 0,31 &, 40 & 1,00 & ,60 \\
\hline \multirow[t]{2}{*}{5} & Macho & 0,00 & 3 & 0,34 &,- 20 & ,40 & ,60 \\
\hline & Hembra & 0,7 & 3 & 0,26 &, 50 & 1,00 &, 50 \\
\hline \multirow[t]{2}{*}{6} & Macho & 0,05 & 3 & 0,17 &,- 14 & ,17 & ,31 \\
\hline & Hembra & $-0,02$ & 3 & 0,85 & $-1,00$ & ,60 & 1,60 \\
\hline \multirow[t]{2}{*}{7} & Macho & 0,29 & 3 & 0,61 &,- 11 & 1,00 & 1,11 \\
\hline & Hembra & 0,76 & 2 & 0,32 &, 54 & 1,00 & ,46 \\
\hline \multirow[t]{2}{*}{8} & Macho & 0,19 & 3 & 0,5 &,- 33 & ,67 & 1,00 \\
\hline & Hembra & 0,73 & 3 & 0,46 & ,20 & 1,00 & ,80 \\
\hline \multirow[t]{2}{*}{9} & Macho & $-0,3$ & 3 & 0,58 & $-1,00$ & , 10 & 1,10 \\
\hline & Hembra & 0,3 & 3 & 0,57 &, 00 & 1,00 & 1,00 \\
\hline \multirow[t]{2}{*}{10} & Macho & $-0,02$ & 3 & 0,31 &,- 26 & ,33 & ,60 \\
\hline & Hembra & 0,84 & 3 & 0,27 &, 53 & 1,00 & ,47 \\
\hline \multirow[t]{2}{*}{11} & Macho & 0,34 & 3 & 0,25 & ,09 & ,60 & ,51 \\
\hline & Hembra & 0,61 & 3 & 0,34 &, 33 & 1,00 & ,67 \\
\hline \multirow[t]{2}{*}{12} & Macho & 0,1 & 3 & 0,04 & ,09 & , 17 & ,08 \\
\hline & Hembra & 0,61 & 3 & 0,34 & ,33 & 1,00 & ,67 \\
\hline \multirow[t]{3}{*}{ Total } & Macho & 0,14 & 36 & 0,34 & $-1,00$ & 1,00 & 2,00 \\
\hline & Hembra & 0,53 & 35 & 0,5 & $-1,00$ & 1,00 & 2,00 \\
\hline & Total & 0,3 & 71 & 0,47 & $-1,00$ & 1,00 & 2,00 \\
\hline
\end{tabular}


Tabla IV.8: IPME por categoría de edad para cada ensayo (Período MCP1 Isla)

\begin{tabular}{|c|c|c|c|c|c|c|c|}
\hline ENS & EDAD & Promedio & $\mathrm{N}$ & Desvío & Mínimo & Máximo & Rango \\
\hline \multirow[t]{3}{*}{1} & Adulto & 0,57 & 3 & 0,07 &, 50 & ,64 & ,14 \\
\hline & Juvenil & 0,28 & 1 & & ,29 & ,29 &, 00 \\
\hline & Infante & 0,6 & 2 & 0,56 & ,20 & 1,00 &, 80 \\
\hline \multirow[t]{3}{*}{2} & Adulto & 0,21 & 3 & 0,4 &,- 25 & ,64 & ,89 \\
\hline & Juvenil & 0,46 & 1 & & ,47 & ,47 &, 00 \\
\hline & Infante & $-0,5$ & 2 & 0,7 & $-1,00$ &, 00 & 1,00 \\
\hline \multirow[t]{3}{*}{3} & Adulto & 0,64 & 3 & 0,3 &, 33 & 1,00 & ,67 \\
\hline & Juvenil & $-0,06$ & 1 & &,- 07 &,- 07 &, 00 \\
\hline & Infante & 0,46 & 2 & 0,18 &, 33 &, 60 &, 27 \\
\hline \multirow[t]{3}{*}{4} & Adulto & 0,36 & 3 & 0,2 & ,14 &, 56 & ,41 \\
\hline & Juvenil & 0,15 & 1 & & ,16 & ,16 &, 00 \\
\hline & Infante & 0,75 & 2 & 0,35 &, 50 & 1,00 &, 50 \\
\hline \multirow[t]{3}{*}{5} & Adulto & 0,43 & 3 & 0,6 &,- 20 & 1,00 & 1,20 \\
\hline & Juvenil & 0,4 & 1 & &, 40 &, 40 & ,00 \\
\hline & Infante & 0,2 & 2 & 0,56 &,- 20 & ,60 &, 80 \\
\hline \multirow[t]{3}{*}{6} & Adulto & 0,35 & 3 & 0,2 & ,14 &, 60 & ,46 \\
\hline & Juvenil & 0,16 & 1 & & ,17 &, 17 & ,00 \\
\hline & Infante & $-0,57$ & 2 & 0,6 & $-1,00$ &,- 14 &, 86 \\
\hline \multirow[t]{3}{*}{7} & Adulto & 0,51 & 3 & 0,5 &, 00 & 1,00 & 1,00 \\
\hline & Juvenil & $-0,1$ & 1 & &,- 11 &,- 11 & ,00 \\
\hline & Infante & 1,00 & 1 & & 1,00 & 1,00 &, 00 \\
\hline \multirow[t]{3}{*}{8} & Adulto & 0,62 & 3 & 0,4 & ,20 & 1,00 & ,80 \\
\hline & Juvenil & 0,25 & 1 & & ,25 & ,25 &, 00 \\
\hline & Infante & 0,3 & 2 & 0,94 &,- 33 & 1,00 & 1,33 \\
\hline \multirow[t]{3}{*}{9} & Adulto & $-0,03$ & 3 & 0,05 &,- 09 &, 00 & ,09 \\
\hline & Juvenil & 0,10 & 1 & & ,10 & ,10 &, 00 \\
\hline & Infante & 0,00 & 2 & 1,41 & $-1,00$ & 1,00 & 2,00 \\
\hline \multirow[t]{3}{*}{10} & Adulto & 0,42 & 3 & 0,63 &,- 26 & 1,00 & 1,26 \\
\hline & Juvenil & 0,3 & 1 & & ,33 & ,33 &, 00 \\
\hline & Infante & 0,42 & 2 & 0,8 &,- 14 & 1,00 & 1,14 \\
\hline \multirow[t]{3}{*}{11} & Adulto & 0,47 & 3 & 0,13 & ,33 &, 60 &, 27 \\
\hline & Juvenil & 0,3 & 1 & & ,33 & ,33 & ,00 \\
\hline & Infante & 0,54 & 2 & 0,64 & ,09 & 1,00 & ,91 \\
\hline \multirow[t]{3}{*}{12} & Adulto & 0,53 & 3 & 0,45 & ,09 & 1,00 & ,91 \\
\hline & Juvenil & 0,16 & 1 & &, 17 & 17 &, 00 \\
\hline & Infante & 0,21 & 2 & 0,17 &, 09 &, 33 &, 24 \\
\hline Total & Adulto & 0,42 & 36 & 0,37 &,- 26 & 1,00 & 1,26 \\
\hline
\end{tabular}




\begin{tabular}{|l|r|r|r|r|r|r|}
\hline Juvenil & 0,2 & 12 & 0,17 &,- 11 &, 47 &, 58 \\
Infante & 0,25 & 23 & 0,67 & $-1,00$ & 1,00 & 2,00 \\
Total & 0,3 & 71 & 0,47 & $-1,00$ & 1,00 & 2,00 \\
\hline
\end{tabular}

Tabla IV.9: IPME por sexo para cada ensayo (Período MCP2 Isla)

\begin{tabular}{|ll|r|r|r|r|r|r|}
\hline ENS & SEXO & Promedio & \multicolumn{1}{|c|}{$\mathrm{N}$} & \multicolumn{1}{|c|}{ Desvío } & \multicolumn{1}{c|}{ Mínimo } & \multicolumn{1}{|c|}{ Máximo } & \multicolumn{1}{c|}{ Rango } \\
\hline 1 & Macho & $-0,08$ & 2 & 0,53 &,- 47 &, 29 &, 76 \\
& Hembra & 0,48 & 3 & 0,45 &, 13 & 1,00 &, 88 \\
\hline 2 & Macho & 0,04 & 2 & 0,26 &,- 14 &, 23 &, 37 \\
& Hembra & 0,17 & 3 & 0,27 &,- 14 &, 33 &, 48 \\
\hline 3 & Macho & 0,04 & 2 & 0,21 &,- 11 &, 20 &, 31 \\
& Hembra & 0,4 & 3 & 0,21 &, 20 &, 60 &, 40 \\
\hline 4 & Macho & 0,06 & 2 & 0,13 &,- 03 &, 17 &, 20 \\
& Hembra & 0,5 & 3 & 0,19 &, 33 &, 71 &, 38 \\
\hline 5 & Macho & $-0,2$ & 2 & 0,28 &,- 40 &, 00 &, 40 \\
& Hembra & 0,6 & 3 & 0,52 &, 00 & 1,00 & 1,00 \\
\hline \multirow{2}{*}{6} & Macho & $-0,17$ & 2 & 0,6 &,- 60 &, 25 &, 85 \\
& Hembra & 0,28 & 3 & 0,1 &, 20 &, 40 &, 20 \\
\hline 7 & Macho & $-0,01$ & 2 & 0,17 &,- 14 &, 11 &, 25 \\
& Hembra & 0,38 & 3 & 0,09 &, 33 &, 50 &, 17 \\
\hline 8 & Macho & 0,16 & 2 & 0,23 &, 00 &, 33 &, 33 \\
& Hembra & 0,75 & 3 & 0,21 &, 60 & 1,00 &, 40 \\
\hline \multirow{2}{*}{9} & Macho & $-0,23$ & 2 & 0,13 &,- 33 &,- 14 &, 19 \\
& Hembra & 0,56 & 3 & 0,31 &, 20 &, 78 &, 58 \\
\hline \multirow{2}{*}{ Total } & Macho & $-0,04$ & 18 & 0,27 &,- 60 &, 33 &, 93 \\
& Hembra & 0,46 & 27 & 0,3 &,- 14 & 1,00 & 1,14 \\
& Total & 0,26 & 45 & 0,38 &,- 60 & 1,00 & 1,60 \\
\hline
\end{tabular}

Tabla IV.10: IPME por categoría de edad para cada ensayo (Período MCP2 Isla)

\begin{tabular}{|ll|r|r|r|r|r|r|}
\hline \multirow{2}{*}{ ENS } & EDAD & Promedio & \multicolumn{1}{|c|}{$\mathrm{N}$} & \multicolumn{1}{|c|}{ Desvío } & \multicolumn{1}{c|}{ Mínimo } & \multicolumn{1}{c|}{ Máximo } & \multicolumn{1}{c|}{ Rango } \\
\hline & Adulto & 0,28 & 3 & 0,73 &,- 47 & 1,00 & 1,47 \\
& Infante & 0,2 & 2 & 0,1 &, 13 &, 29 &, 17 \\
\hline 2 & Adulto & 0,01 & 3 & 0,27 &,- 14 &, 33 &, 48 \\
& Infante & 0,28 & 2 & 0,07 &, 23 &, 33 &, 10 \\
\hline 3 & Adulto & 0,2 & 3 & 0,35 &,- 11 &, 60 &, 71 \\
& Infante & 0,36 & 2 & 0,23 &, 20 &, 53 &, 33 \\
\hline \multirow{2}{*}{4} & Adulto & 0,3 & 3 & 0,37 &,- 03 &, 71 &, 74 \\
& Infante & 0,31 & 2 & 0,2 &, 17 &, 45 &, 29 \\
\hline
\end{tabular}




\begin{tabular}{|ll|r|r|r|r|r|r|}
\hline 5 & Adulto & 0,2 & 3 & 0,72 &,- 40 & 1,00 & 1,40 \\
& Infante & 0,4 & 2 & 0,56 &, 00 &, 80 &, 80 \\
\hline 6 & Adulto & 0,23 & 3 & 0,02 &, 20 &, 25 &, 05 \\
& Infante & $-0,1$ & 2 & 0,7 &,- 60 &, 40 & 1,00 \\
\hline 7 & Adulto & 0,31 & 3 & 0,19 &, 11 &, 50 &, 39 \\
& Infante & 0,09 & 2 & 0,3 &,- 14 &, 33 &, 48 \\
\hline 8 & Adulto & 0,5 & 3 & 0,5 &, 00 & 1,00 & 1,00 \\
& Infante & 0,46 & 2 & 0,18 &, 33 &, 60 &, 27 \\
\hline 9 & Adulto & 0,19 & 3 & 0,52 &,- 33 &, 71 & 1,05 \\
& Infante & 0,31 & 2 & 0,65 &,- 14 &, 78 &, 92 \\
\hline \multirow{2}{*}{ Total } & Adulto & 0,26 & 27 & 0,41 &,- 47 & 1,00 & 1,47 \\
& Infante & 0,26 & 18 & 0,34 &,- 60 &, 80 & 1,40 \\
& Total & 0,26 & 45 & 0,38 &,- 60 & 1,00 & 1,60 \\
\hline
\end{tabular}

Tabla IV.11: IPME por sexo para cada ensayo (Período INV Isla)

\begin{tabular}{|c|c|c|c|c|c|c|c|}
\hline ENS & SEXO & Promedio & $\mathrm{N}$ & Desvío & Mínimo & Máximo & Rango \\
\hline \multirow[t]{2}{*}{1} & Macho & $-0,14$ & 2 & 0,3 &,- 38 & ,09 & ,48 \\
\hline & Hembra & $-0,21$ & 3 & 0,43 &,- 50 & ,29 & ,79 \\
\hline \multirow[t]{2}{*}{2} & Macho & 0,07 & 2 & 0,1 & , 00 & ,14 & 14 \\
\hline & Hembra & 0,4 & 3 & 0,69 &,- 33 & 1,00 & 1,33 \\
\hline \multirow[t]{2}{*}{3} & Macho & 0,15 & 2 & 0,49 &,- 20 &, 50 & ,70 \\
\hline & Hembra & 0,2 & 3 & 0,09 & ,14 & ,33 & ,19 \\
\hline \multirow[t]{2}{*}{4} & Macho & 0,38 & 2 & 0,06 & 33 & ,43 & , 10 \\
\hline & Hembra & 0,27 & 3 & 0,25 &, 00 &, 50 &, 50 \\
\hline \multirow[t]{2}{*}{5} & Macho & 0,21 & 2 & 0,4 &,- 08 &, 50 & ,58 \\
\hline & Hembra & 0,64 & 3 & 0,31 &, 43 & 1,00 &, 57 \\
\hline \multirow[t]{2}{*}{6} & Macho & 0,31 & 2 & 0,61 &,- 13 & ,75 & 88 \\
\hline & Hembra & 0,61 & 3 & 0,02 & ,60 & ,64 & ,04 \\
\hline \multirow[t]{2}{*}{7} & Macho & 0,28 & 2 & 0,07 & ,23 & ,33 & 10 \\
\hline & Hembra & 0,64 & 3 & 0,3 & ,33 & 1,00 & ,67 \\
\hline \multirow[t]{2}{*}{8} & Macho & 0,35 & 2 & 0,03 & ,33 & ,38 & ,05 \\
\hline & Hembra & 1,00 & 3 & 0,00 & 1,00 & 1,00 & ,00 \\
\hline \multirow[t]{2}{*}{9} & Macho & 0,4 & 2 & 0,78 &,- 11 & 1,00 & 1,11 \\
\hline & Hembra & 1,00 & 3 & 0,00 & 1,00 & 1,00 & ,00 \\
\hline \multirow[t]{2}{*}{10} & Macho & 0,1 & 2 & 0,14 & ,00 & ,20 & ,20 \\
\hline & Hembra & 0,4 & 3 & 0,5 & 00 & 1,00 & 1,00 \\
\hline & Macho & 0,21 & 20 & 0,3 &,- 38 & 1,00 & 1,38 \\
\hline & Hembra & 0,5 & 30 & 0,45 &,- 50 & 1,00 & 1,50 \\
\hline
\end{tabular}






Tabla IV.12: IPME por categoría de edad para cada ensayo (Período INV Isla)

\begin{tabular}{|c|c|c|c|c|c|c|c|}
\hline ENS & EDAD & Promedio & $\mathrm{N}$ & Desvío & Mínimo & Máximo & Rango \\
\hline \multirow[t]{2}{*}{1} & Adulto & $-0,43$ & 3 & 0,05 &,- 50 &,- 38 & ,12 \\
\hline & Infante & 0,19 & 2 & 0,14 & ,09 & ,29 & ,20 \\
\hline \multirow[t]{2}{*}{2} & Adulto & 0,26 & 3 & 0,67 &,- 33 & 1,00 & 1,33 \\
\hline & Infante & 0,3 & 2 & 0,47 & ,00 & ,67 & ,67 \\
\hline \multirow[t]{2}{*}{3} & Adulto & 0,1 & 3 & 0,27 &,- 20 & ,33 &, 53 \\
\hline & Infante & 0,32 & 2 & 0,25 & ,14 &, 50 & ,36 \\
\hline \multirow[t]{2}{*}{4} & Adulto & 0,38 & 3 & 0,09 & ,33 &, 50 & ,17 \\
\hline & Infante & 0,21 & 2 & 0,3 &, 00 &, 43 &, 43 \\
\hline \multirow[t]{2}{*}{5} & Adulto & 0,47 & 3 & 0,04 & ,43 &, 50 & ,07 \\
\hline & Infante & 0,46 & 2 & 0,76 &,- 08 & 1,00 & 1,08 \\
\hline \multirow[t]{2}{*}{6} & Adulto & 0,65 & 3 & 0,08 &, 60 & ,75 & ,15 \\
\hline & Infante & 0,25 & 2 & 0,53 &,- 13 & ,64 &, 76 \\
\hline \multirow[t]{2}{*}{7} & Adulto & 0,42 & 3 & 0,15 & ,33 & ,60 & ,27 \\
\hline & Infante & 0,61 & 2 & 0,54 & ,23 & 1,00 & ,77 \\
\hline \multirow[t]{2}{*}{8} & Adulto & 0,78 & 3 & 0,38 & ,33 & 1,00 & ,67 \\
\hline & Infante & 0,69 & 2 & 0,43 &, 38 & 1,00 & ,62 \\
\hline \multirow[t]{2}{*}{9} & Adulto & 0,62 & 3 & 0,64 &,- 11 & 1,00 & 1,11 \\
\hline & Infante & 1,00 & 2 & 0,00 & 1,00 & 1,00 &, 00 \\
\hline \multirow[t]{2}{*}{10} & Adulto & 0,1 & 3 & 0,19 &, 00 & ,33 & ,33 \\
\hline & Infante & 0,6 & 2 & 0,56 &, 20 & 1,00 &, 80 \\
\hline \multirow[t]{3}{*}{ Total } & Adulto & 0,3 & 30 & 0,4 &,- 50 & 1,00 & 1,50 \\
\hline & Infante & 0,46 & 20 & 0,41 &,- 13 & 1,00 & 1,13 \\
\hline & Total & 0,39 & 50 & 0,43 &,- 50 & 1,00 & 1,50 \\
\hline
\end{tabular}




\section{ANEXO V}

Mapas representativos del análisis gráfico de las secuencias de desplazamiento:

Ejemplos de mapas (Figuras V.1 a V.6) para el grupo Jaula durantes los períodos de memoria de corto plazo 1 y 2 (MCP1 y MCP2).

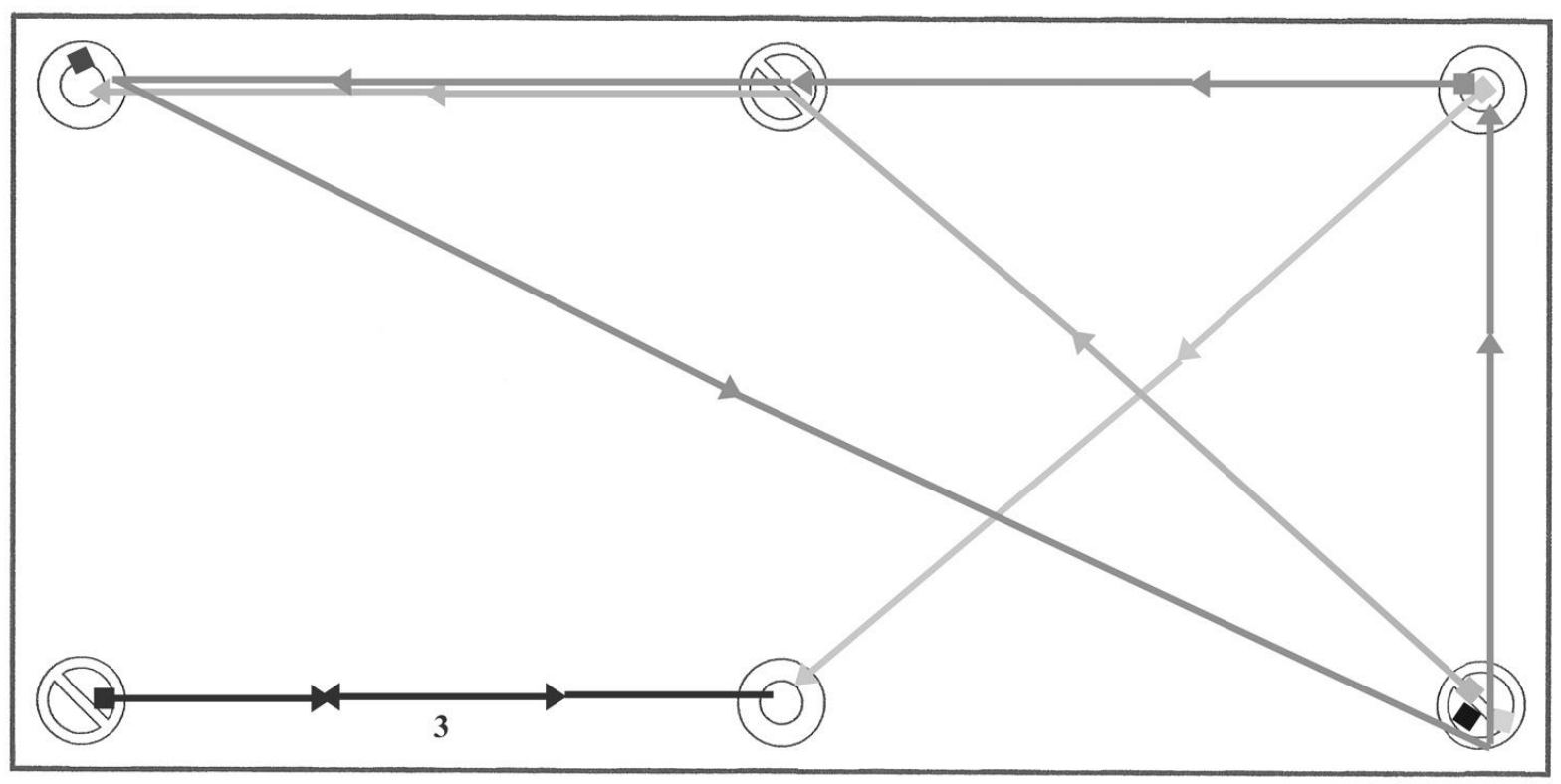

Figura V.1: Mapa del Ensayo 3, período MCP1

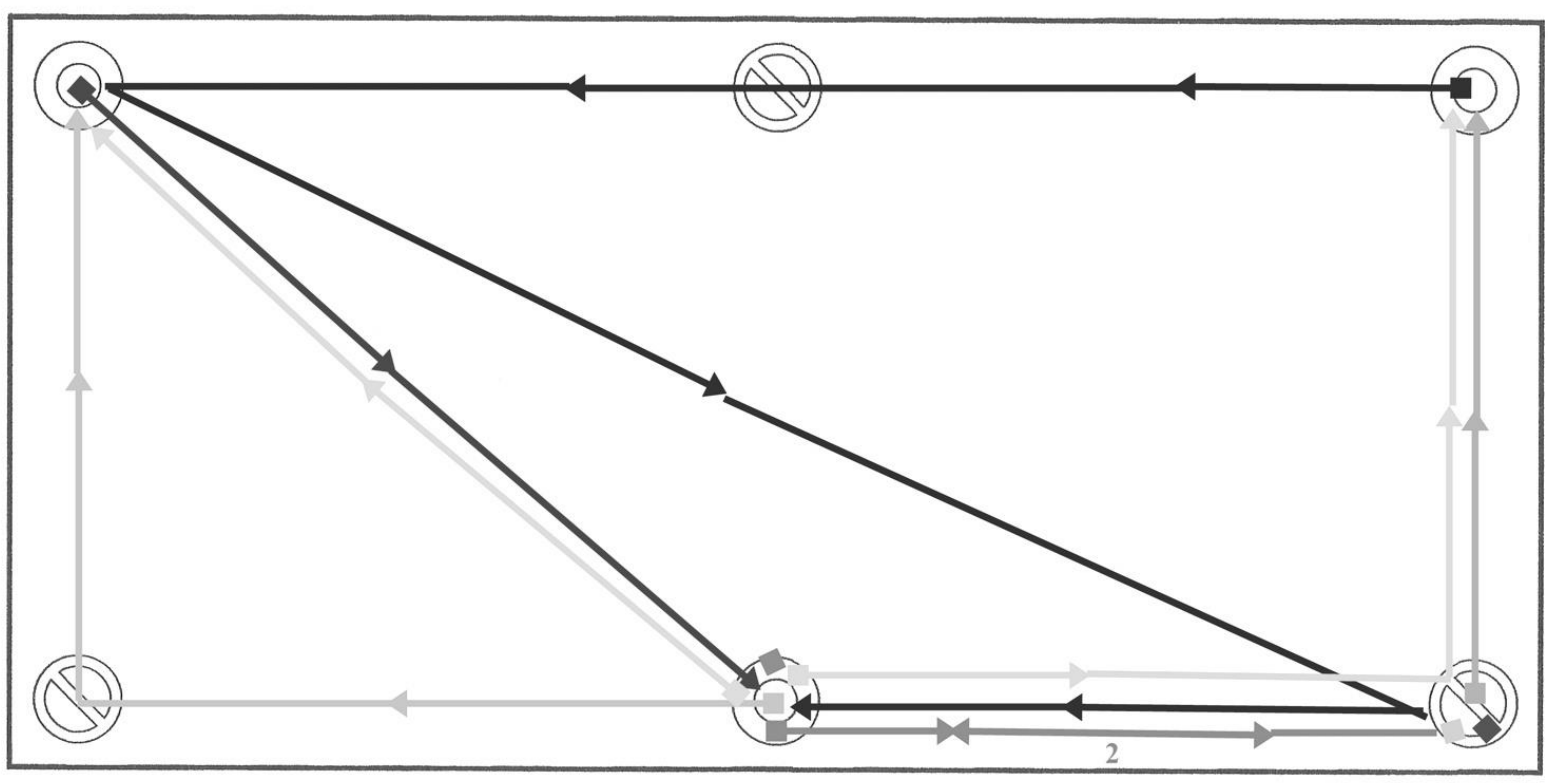

Figura V.2: Mapa del Ensayo 8, período MCP1 


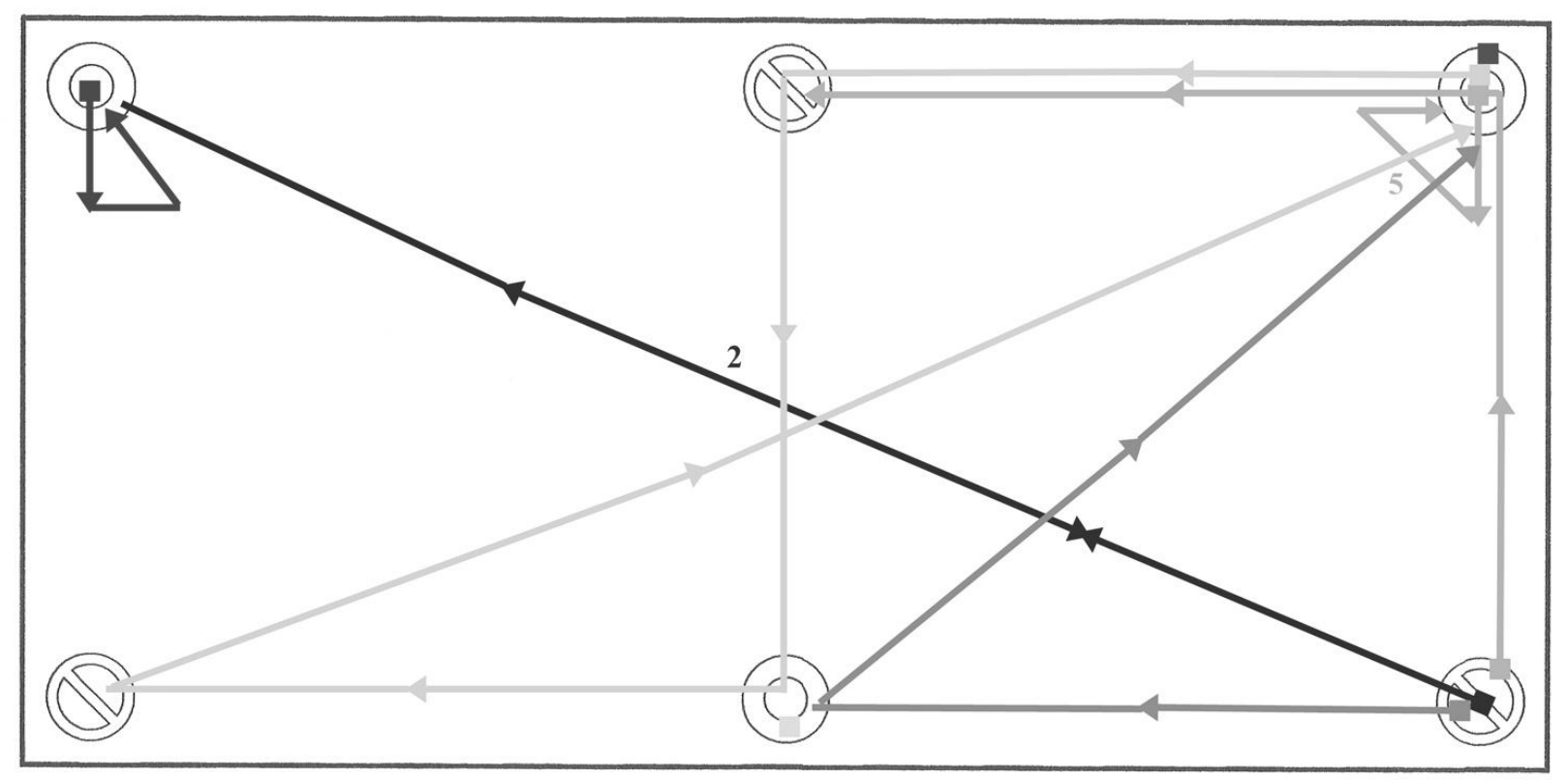

Figura V.3: Mapa del Ensayo 10, período MCP1

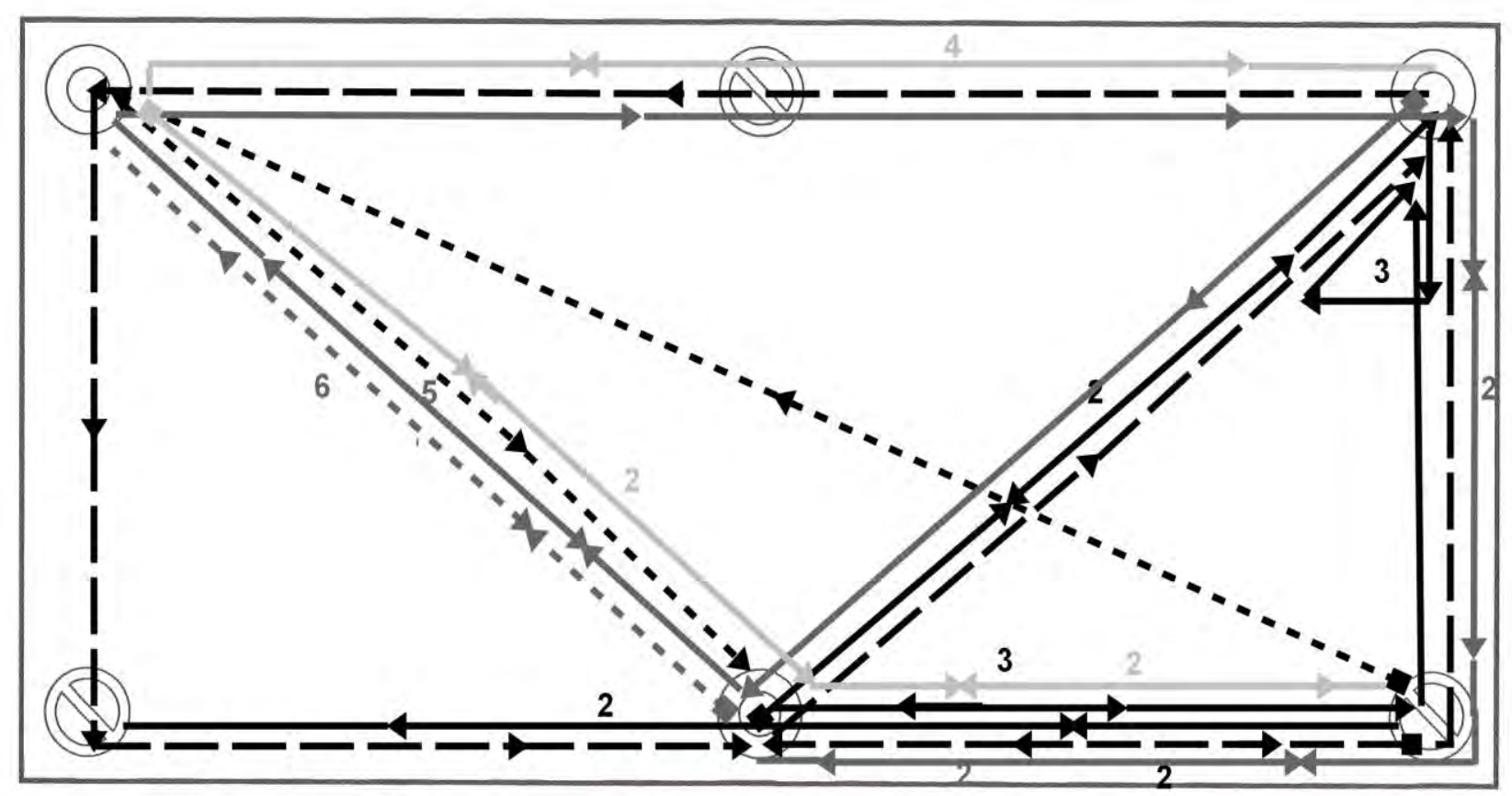

Figura V.4: Mapa del Ensayo 2, período MCP2 


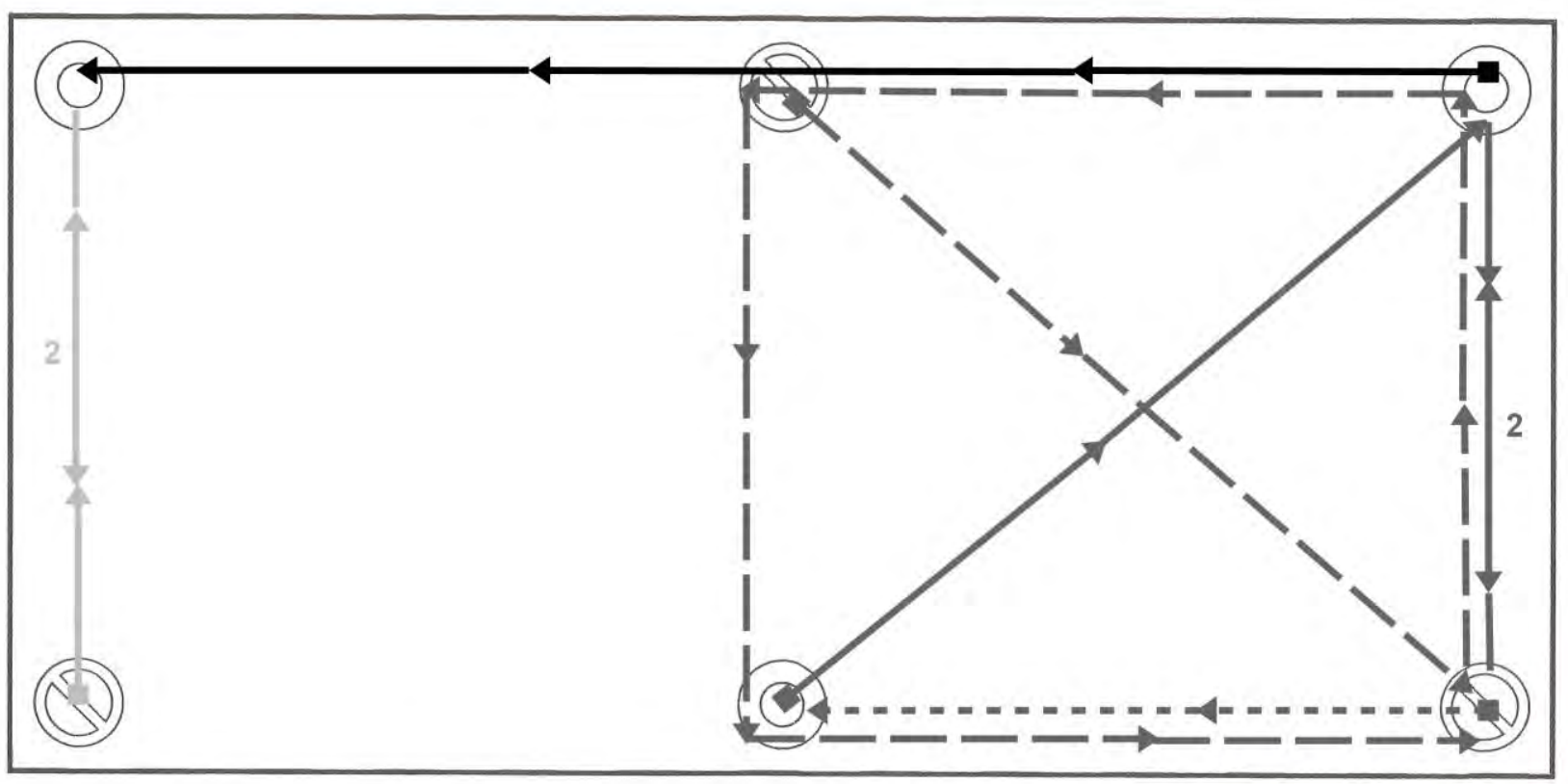

Figura V.5: Ensayo 5, período MCP2

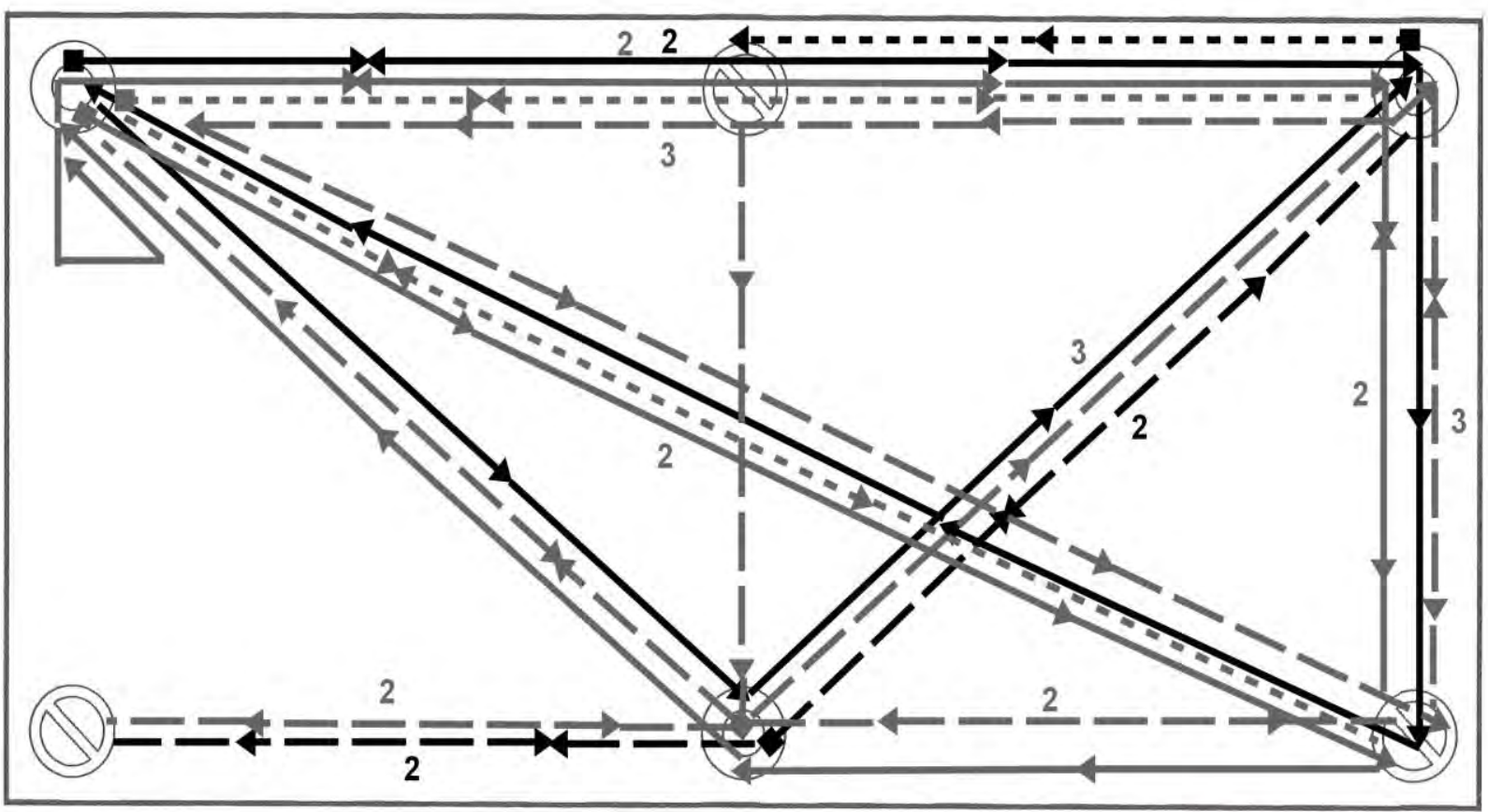

Figura V.6: Mapa del Ensayo 9, período MCP2 
Memoria espacial monos caí - María Paula Tujague 2013

ANEXO VIDEOS 